

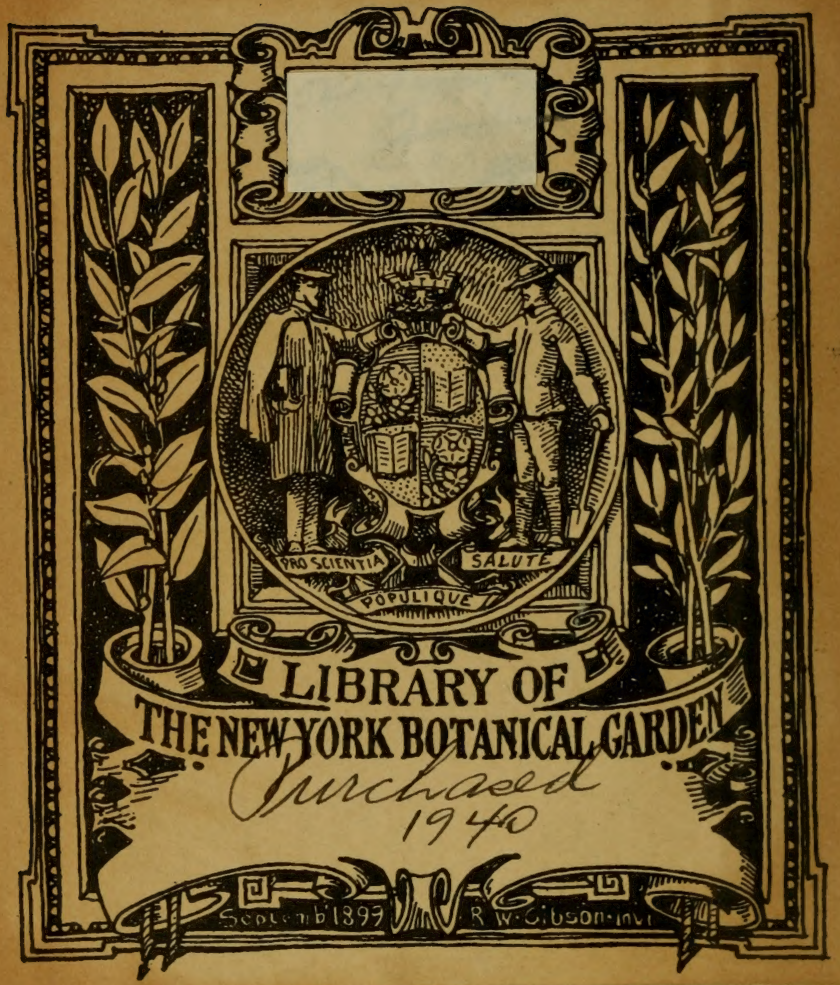




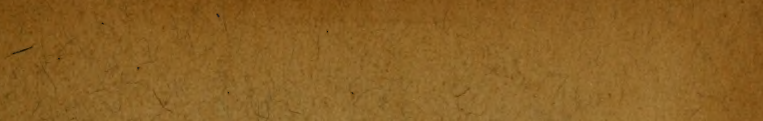

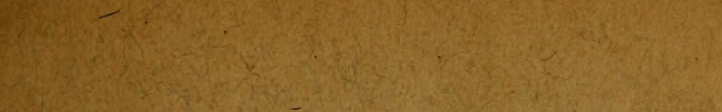

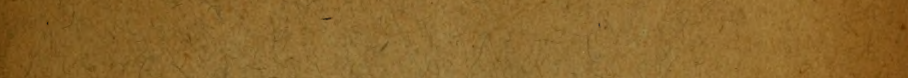

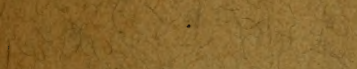

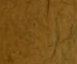
(x)
$x^{2}+x^{2}+x^{2}$

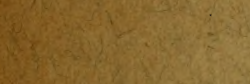

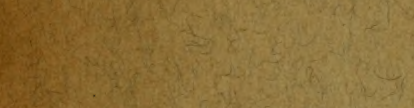

$6 x^{2}+2 x+2 x$

$(x+2)$

(4.

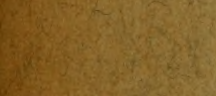

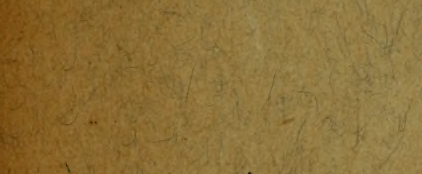

2. is +2

xin

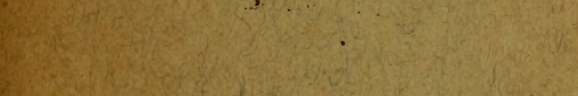

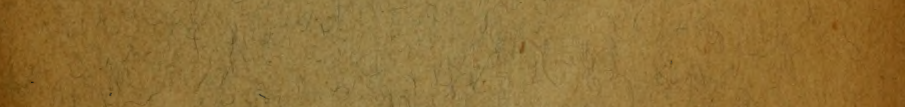

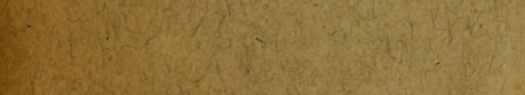

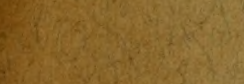

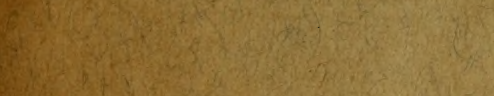

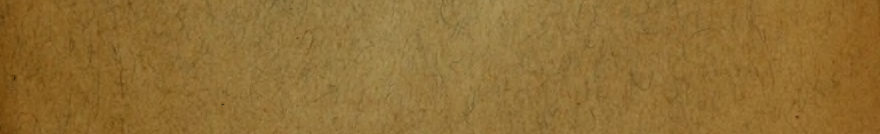




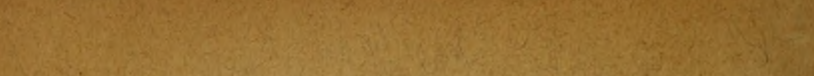

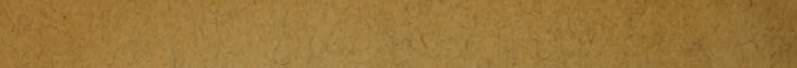
Whate

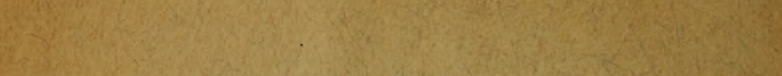

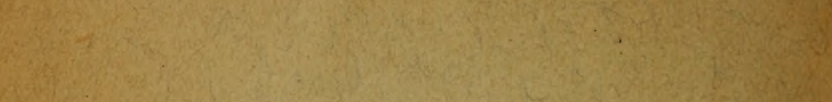

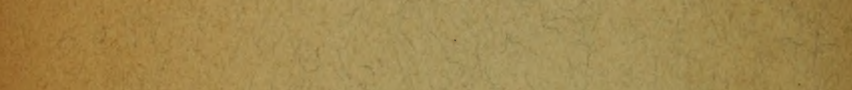

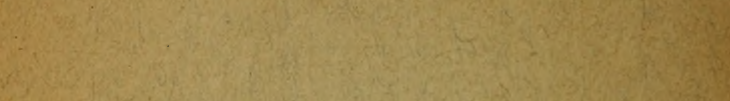

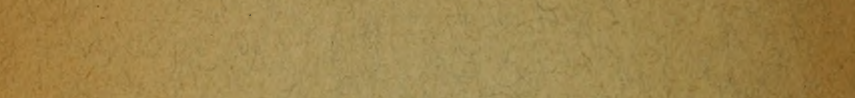
restion

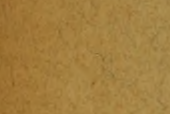
Ifos 20.

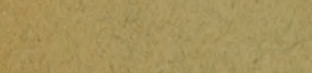

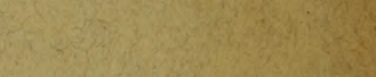

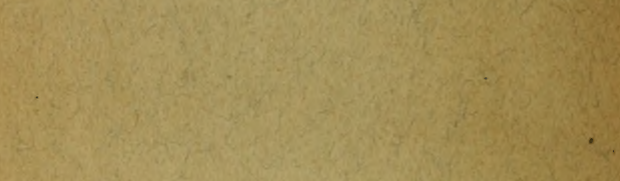
IE: Qf. We

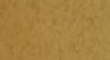
Hathes

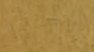
tis.

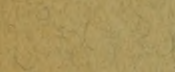

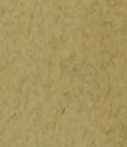

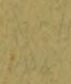

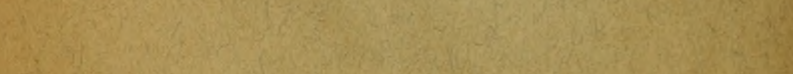

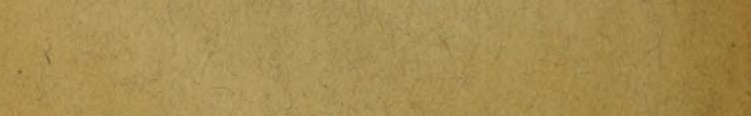


a'Plonsuis Soncain Honcmaye de licunters

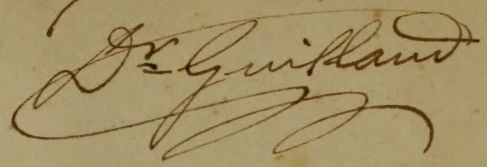

FLORE DE BORDEAUX ET DU SUD-OUEST 


\section{A VIS}

Cette Flone sera divisée en deux petits volumes. Celui-ci, qui est le premier, est consacré aux plantes supérieures et à fleurs, c'est-à-dire à celles qu'on nomme Phanérogames. Le second, qui paraîtra l'an prochain, comprendra les Fougères, les Mousses, les Algues el les Champignons, c'est-à-dire les plantes inférieures et sans fleurs, qui sont appelées CF.тPT0GAMES. 


\title{
FLORE
}

\section{DE BORDEAUX ET DU SUD-OUEST}

\section{ANALYSE ET DESCRIPTION SOMMAIRE}

\author{
DES PLANTES SAUVAGES
}

OU GÉNÉRALEMENT CULTIVÉES DANS LES PARTIES NON MONTAGNEUSES

\author{
DE B BSIIS
}

\section{DR LA GARONIR, DE LA CHARENTE ET DE L'ADOUR}

\section{comprenant :}

Les départements de la Gironde, de la Charente-Inférieure, de la Vendée, des Deux-Sèvres,

de la Vienne, de la Haute-Vienne, de la Charente, de la Dordogne, du Lot, de Tarn-et-Garonne, de Lot-et-Garonne, du Gers et des Landes; et en grande partie, ceux de la Corrèze,

de l'Aveyron, du Tarn, de la Haute-Garonne, de l'Ariège, des Hautes-Pyrénées et des Basses-Pyrénées,

\section{A L'USAGE}

DES ÉTUdIANTS, DES INSTITUTEuRS ET DES ÉLÈves DES ÉCOLES BOTAN

\section{Par le Dr J.-A. GUILLAUd}

Professeur de Botanique et d'Histoire naturelle 'médicale à la Faculté de Médecine et de Pharmacie de Bordeaux

\section{PREMIER VOLUME PHA NEROGA MES}

BORDEAUX

F E R E T E T FIL S Libraires

15, Cours de l'Intendance, 15
PARIS

G. M A S S O N

Libraire-Éditeur

120, Boulevard Saint-Germain, 120. 
$Q K 313$

- G835 


\section{A M. J. LLOYD}

Auteur de la Flore de l'Ouest de la France.

\section{Cifer Monsieur,}

Ce petit ouvrage élémentaire, embryon d'un meilleur, j'espère, est assez peu digne d'un botaniste aussi autorisé que vous. Permettez-moi néanmoins de vous offrir, si faible qu'il soit, ce témoignage de cordiale et respectueuse reconnaissance, écho d'un passé déjà loin de vingt ans. Je me souviens, en effet, toujours avec un vif plaisir des études botaniques de mon enfance, auprès de cet excellent M. Pinatel, instituteur de la Société évangélique de Genève à Saint-Jean d'Angély, études dont vous étiez le guide aussi bienveillant que sûr; je me souviens toujours que vous ne dédaigniez pas de venir chercher, jusque sur les bancs du collège de Saintes, un gamin amoureux de plantes, de soleil et de liberté, pour le mener herboriser. Vos encouragements de toutes sortes m'ont été précieux, et, si je dois à notre science favorite plus que je ne lui ai encore donné, je m'efforce du moins d'inspirer à mes élèves le goût et l'entraînement que m'ont donnés mes bons et chers premiers maîtres.

$$
\text { 'D J.-A. GUILLAUD. }
$$





\section{INTRODUGTION}

Le but de cette Flore, ou plutôt de ce Vademecum destiné aux herborisations, est de permettre aux étudiants de la Faculté de médecine et de pharmacie de Bordeaux, aux médecins, pharmaciens, instituteurs de la région, aux élèves de nos Ecoles normales et primaires, à tous ceux, enfin, qui s'occupent de botanique par utilité ou par goût, de reconnaître euxmêmes et de déterminer facilement les plantes sauvages qu'ils rencontrent autour d'eux.

Ce n'est jamais chose facile que de distinguer ou d'apprendre à distinguer les uns des autres un très grand nombre d'êtres, à quelque règne de la nature qu'ils appartiennent. Cela est encore plus vrai des plantes que de tout le reste, soit à cause de leur plus grande uniformité d'organisation, soit à cause des procédés employés.

Les ouvrages de description et de détermination que nous avons, ont surtout trois grands inconvénients. D'abord, ils s'adressent pour la plupart à la France entière, ce qui les rend forcément un peu confus et embrouillés, à cause 
du grand nombre de plantes qu'ils sont obligés de comprendre. Puis, leur's descriptions sont toujours beaucoup trop étendues et trop détaillées pour les besoins réels de ceux qui commencent à s'instruire. Ensuite, ils parlent tous une langue fort savante, inconnue du public ordinaire, voire des dictionnaires français. En limitant celui-ci à la régrion du Sud-Ouest, de façon à n'embrasser qu'un nombre relatirement restreint de plantes, trois mille au maximum; en réduisant la description des espèces aux traits vraiment caractéristiques; en n'employant pour cette description et pour la distinction des genres que des termes connus, compris de tout le monde, je crois rendre de réels services à bien des personnes. Car on se demande souvent, avec étonnement, comment on a pu faire de la botanique, la science la plus agréable et la plus populaire de toutes, un g'enre d'étude en quelque sorte chiffré, dans lequel on ne peut s'engager que si on en possède préalablement la clef. Quelques-uns ont été rebutés pour toujours par les difficultés qui ont hérissé leurs débuts; mais beaucoup d'autres n'attendent que le moment où on aura fait disparaître toutes ces épines superflues pour cueillir des fleurs.

Au point de vue des limitcs à admettre, je n'ai eu, pour les fixer, qu'à consulter les données de la physique du globe relatives à notre coin de terre et celles de la géographie botanique. 
Le Sud-Ouest de la France, jadis l'Aquitaine, compris, d'une part, entre les Pyrénées et les massifs granitiques de la Vendée, du Limousin et de l'Auvergne; de l'autre, entre les Cévennes, la Montagne-Noire, les Corbières et le golfe de Gascogne, constitue un véritable pays, une région tout à fait naturelle.

C'est une grande plaine, inclinée au nordouest, plate ou seulement creusée de vallées secondaires, qui semble n'être que le cul de sac émergé du golfe de Gascogne. Ouverte à l'ouest dans cette vaste échancrure de l'ossature européenne comprise entre l'Espagne et l'Irlande et placée en face de Terre-Neure et du Canada; séparée de l'Espag’ne et du Midi par de véritables murailles qui arrètent ou détournent les masses d'air sec et chaud qui planent sur les pays méditerranéens; en communication plus facile avec le nord et le nord-est du continent, cette plaine du Sud-Ouest appartient, malgré sa latitude moyenne qui est celle de la Provence, de la Haute-Italie et de la Crimée, aux climats geénéraux de l'Europe centrale. Mais, plus que tout autre pays voisin de l'Océan, le nôtre est soumis aux vents humides et tièdes que nous amènent les grands courants d'eau et d'air, connus sous le nom de Gulf-stream atlantiques. Ces vents, soit qu'ils viennent directement de l'ouest, soit qu'ils aient contourné le cap Finistère espagnol et longé les Cantabres, s'engouffrent dans notre région, qui n'offre, sur plus de 
300 kilomètres, de La Rochelle à Bayonne, que des rivages fort bas et des landes uniformes. Ils créent ainsi au loin, sur de très grandes surfaces et d'une façon à peu près constante, un régime météorologique essentiellement tempéré, humide et pluvieux, qui s'étend aussi en partie à la lisière nord des Cantabres, à notre Bretagne, à la presqu'île anglaise de Cornouailles et au sud de l'Irlande, c'est-à-dire à tout le pourtour du véritable golfe géographique hispano-irlandais dont nous venons de parler.

Cette nature particulière du climat, due ainsi au relief du sol et aux courants généraux d'eau et d'air à la surface du globe, domine absolument toute la végétation du Sud-Ouest et des bords de l'Océan, au voisinage du $45^{\circ}$ de latitude, et lui imprime le cachet septentrional de la zone moyenne et forestière de l'Europe.

Une autre cause contribue aussi puissamment que le climat à soumettre notre pays aux populations végétales du nord: c'est l'influence physique et chimique du sol, qui est presque partout sablonneux ou siliceux. Un épais manteau de terrains de transport descendus des Pyrénées et de l'Auvergne, s'étend du pied des massifs granitiques et montagneux jusqu'à la mer; ce manteau n'a été déchiré que cà et là par l'érosion fluviale, de manière à mettre à nu les argiles et les calcaires sous-jacents. Tant à cause du refroidissement nocturne plus considérable des sols siliceux, qu'à cause d'une 
meilleure adaptation première, les espèces granitiques, montagnardes ou pseudo-boréales, venues cles basses montug'nes avec les cailloux et la terre qui les nourrit, ont été avantagées dans la lutte pour l'existence. En compagnie de leurs congénères accourues du centre de l'Europe, elles sont restées en possession de nos plateaux et de nos vallons depuis l'époque glaciaire, qui a dû favoriser, du reste, leur première occupation. Aussi les chênes qui perdent leurs feuilles, le rourre et le tauzin (Quercus Robur L. et Quercus Toza DC.), constituent-ils le fond de nos bois; aussi le châtaignier, les bruyères, les genêts, les ajoncs et les fougères sont-ils partout aussi abondants qu'en Auvergne et dans le Limousin, partout aussi vigoureux que sur les flanes des Pyrénées. Des plantes alpines ou subalpines bien caractérisées, telles que Helleborus viridis, Anemone ranunculoïdes, Vicia Orobus, Saxifraya gramulata, Doronicum arnica, Erica Dabcecii, Daphne Cneorum, etc., se sont établies jusqu'aux portes de Bordeaux, tout au moins jusque dans le département de la Gironde, vers lequel toutes les pentes générales de la région viennent converger. Les plantes de cet ordre étaient certainement plus nombreuses encore, lorsque le pays était à l'état de végétation primitive, c'est-ì-dire avant l'introduction des cultures.

C'est seulement dans les environs de Bayonne, dans le Gers, le Lot, les Charentes et le Poitou, 
c'est seulement sur les pentes des grandes vallées, où les calcaires sont à nu, qu'on rencontre une végétation différente, plantes du Midi ou plantes des champs cultivés introduites indirectement. Ces colonies méridionales sont frappantes sur les flancs des coteaux de la rive droite de la Garonne, où croissent en abondance des arbres et arbustes toujours verts, tels que l'yeuse (Quercus Ilex), le Laurus nobilis parfaitement naturalisé, les Phillyrea, le Rhammus alaternus, l'Ilex aquifolium, le Rosa sempervirens, le Romarin et le Thymus vulgaris, et surtout des herbes, comme Psoralea bituminosa, Echinops Ritro,Carduus Galactites, etc., etc.; sur les coteaux rocailleux du Lot et sur les rives de la Dordogne, où se trourent le Coriaria myrtifolia, le Rhus Coriaria, le Pistacia Tercbinthus, le Cactus Opuntia naturalisé, etc., etc.; le long du Gers, où croît l'Aphyllanthes monspeliensis; dans les champs pierreux des Charentes, où se retrouvent Centaurea conifera et Stipa pennata; enfin à SaintJean-de-Luz et au pied des coteaux de Bourgsur-Gironde, où l'olivier peut vivre indéfiniment et mûrir ses fruits. Le chêne-liègre (Quercus Suber), la lavande, le Clematis flammula, le Smilax aspera, et autres plantes méridionales aussi typiques sont sauvages ou s'échappent partout des cultures de Bayonne à Poitiers.

Si donc la surface du sol était surtout calcaire au lieu d'être siliceuse, il est permis de penser que nous aurions un fond de végétation sensi- 
blement différent, tenant beaucoup plus de celui du Portugal et du nord de l'Espagne, qu'il n'en tient actuellement.

En résumé, si on considère la végétation par son côté arborescent qui donne le ton général, si on l'examine par grandes masses et par rapport au nombre des individus qui prennent part au banquet de la vie, le sud-ouest de la France appartient sans conteste, à ce point de vue comme au point de vue du relief du sol et du climat, à l'Europe centrale et moyenne, c'est-àdire au domaine forestier de notre continent, et se sépare très nettement des contrées espagnoles et méditerranéennes. Ceperdant, si on compte les espèces, abstraction faite de la quantité de leurs représentants, on voit que de nos jours, par suite des modifications de milieu dues à l'affouillement continu des rivières et à la mise en culture du sol, notre flore renferme une forte proportion de plantes méridionales, le dixième environ, soit 250 à 300 espèces, herbacées pour la plupart. Grâce à la douceur des hivers et à cette humidité constante qui favorise tant les végétaux, les plantes du Midi sont en train de regagner une partie du terrain perdu, et on dirait que le bassin de la Garonne est devenu un immense champ de bataille, où deux sortes de populations végétales d'origine opposée luttent ardemment pour la possession du sol.

Certes, ce sont des faits assez remarquables que de voir pousser côte à côte le Vicia Orobus 
et le Linaria cirrhosa, comme aux environs de Saint-Savin-de-Blaye; l'Helleborus viridis et l'Echinops Ritro, comme autour de La Réole; le chêne vert et le bouleau, comme dans les environs de Saintes et dans les Landes; le Daphne Cneorum des Pyrénées, le Lobclia Dortmanna de Sibérie et le Lychnis corsica, comme près d'Arcachon; le Térébinthe et l'Arabis alpina, comme dans la vallée de la Dordogne; le myrtille et la lavande, comme à Aire (Landes); le chênelièg'e ou l'olivier et le pommier à cidre de Normandie, comme autour de Bayonne, etc., pour ne citer que les principales de ces antithèses botaniques. Cela permet déjà d'assigner au Sud-Ouest un rang tout à fait à part dans la zone geénérale à laquelle il se rattache. C'est, en effet, ce qui a été reconnu depuis fort longtemps. Il suffit de jeter les yeux sur la carte botanique dressée par De Candolle $\left({ }^{1}\right)$ pour saisir tout de suite les limites des trois grandes régions botaniques de la France, abstraction faite des pays de montagnes : région de Montpellier ou de la Méditerranée, région de Paris ou de l'Europe centrale et région de Bordeaux ou des bords de l'Atlantique (²).

Iais il y a plus encore qu'un simple mélange d'espèces du Nord et du Midi, vivant en concur-

(') Flo:e froncaise de Lamarck et De Candolle, 3: éd., 1805.

(2) Toir aussi Raulin : Sur le champ d'étude d'une Société d'histoire saturelle séant à Bordean.x. (Mém. de la Suc. des eciences prhysiques et naturelles de Bordeauc, t. I, 185'.) 
rence dans le même pays. Notre Sud-Ouest possède, en commun avec le nord de l'Espag'ne, le Portugal et l'Irlande, un certain nombre de plantes qui semblent se rattacher à une flore atlantique disparue, comme Forbes l'a admis le premier. Telles seraient une quinzaine d'espèces ou variétés, parmi lesquelles nous citerons: Erica Dabccii, Erica arborea var. lusitanica, Erica carnea ou mediterranea var. occidentalis, Gentiana ou Erythrœa chloodes, Lithospermum suffruticosum var. prostratum, etc. Un nombre d'espèces à peu près égal lui appartiendrait même en propre, selon certains auteurs. Ce qui lui donnerait dix fois plus d'espèces locales qu'à tout le reste de la France, la région de Paris n'en ayant qu'une ou deux et la région de Montpellier, pas du tout $\left({ }^{1}\right)$. Mais ces prétendues espèces locales, croissant surtout sur le littoral, Quercus occidentalis, Libanotis Sibthorpii, Hieracium eriophorum, etc., ne sont au fond que des formes d'espèces plus continentales ou que des espèces venues peut-être du Portugal, pays encore mal exploré. Quoi qu'il en soit, que le Sud-Ouest de la France ait précieusement conservé les restes d'une végétation ensevelie sous les flots de l'Océan ou qu'il soit devenu depuis l'immersion de l'Atlantide un centre de nouvelles créations naturelles, il n'en constitue pas moins, d'après tous les faits observés jusqu'à présent, l'expres-

(1) Voir Grisebach : La végétation du globe, trad. française, t. I, p. 291 et suiv. 
sion la plus complète de la flore ecéanique du domaine végétal de l’Europe moyenne.

Il est encore un autre genre d'originalité que le Sud-Ouest peut réclamer hautement. C'est la facilité d'acclimatation qu'il présente pour les plantes étrangères, venues fortuitement du Brésil, du Mexique, des États-Unis et d'ailleurs. Il y a là, dans ce climat auquel les excès de chaleur comme de froid sont inconnus, des conditions extrêmement favorables pour elles, et Bordeaux et Bayonne, Bayonne surtout, sont en France des lieux de naturalisation par excellence pour les plantes américaines. D'un autre côté, les plantes d'Italie et même de la Perse nous arrivent également par Carcassonne et la vallée de la Garonne. On peut estimer à $\frac{1}{30}$ environ de la flore totale le nombre des plantes aujourd'hui naturalisées sur lesquelles on a quelques documents.

Cette aptitude du Sud-Ouest à accueillir ainsi des éléments étrangers a été signalée, il y a près de vingt ans, par mon maître de Montpellier, M. le professeur Ch. Martins, qui engageait à ce propos «quelque riche propriétaire des envi» rons de Bayonne ou de Saint-Jean-de-Luz à » tenter des naturalisations qui auraient les plus » grandes chances de réussir $\left({ }^{1}\right)$. » Cette tentative

(1) Le climat et la végétation des îles Borromées, sur le lac Majeur, comparés au climat et à la régétation des environs de Bayonne et de Saint-Jean-de-Lũ, Montpellier, 1866, et Amales de la Société d'horticulture et de botanique de l'Herault. 
a été faite depuis sur une grande échelle, à Pau, par le regretté M. Tourasse, et a pleinement justifié les prévisions et la perspicacité du savant naturaliste. Le fait ne fût-il pas aujourd'hui acquis au nom de l'expérience, qu'une étucle approfondie de la flore du pays en̂t entraîné à l'avance notre certitude à cet égard ( $\left.{ }^{1}\right)$.

A tous ces divers titres, on voit que nous sommes autorisés à parler d'une région ou d'un centre botanique du Sud-Ouest et à consacrer en quelque sorte son individualité, en ne dépassant pas ses limites naturelles. C'est même pour cette raison, c'est-ḋ-dire pour mettre plus en relief qu'on ne l'a fait jusqu'ici la valeur botarique de tout ce grand coin de la France, que je me suis plus étendu sur ce sujet que ne le comporte l'introduction ordinaire d'un livre de nature élémentaire.

Au point de vue du mode de rédaction é de description, je n'ai pas perdu de vue un seul instant que j'écrivais pour les commençants, que je faisais un livre destiné, non à être relégrué dans un coin de bibliothèque, mais à devenir le compagnon assidu et le guide de toute herborisation.

J'ai d'abord employé pour l'analyse des familles et des genres le système dichotomique inauguré par Lamarck et si souvent copié et

(1) Voir Dr Blanchet: Notice sur la naturalisation à Buyonine des plantes exotiques, 1882. 
recopié depuis. Parmi toutes les variantes introduites dans le texte primitif, parmi toutes les modifications et corrections qu'on a fait subir à ce système, il en est de fort savantes, bonnes pour le cabinet, mais qui ont le grand désavantage de n'être pas pratiques sur le terrain ou dans une salle d'élèves. C'est à l'usag'e qu'on reconnaît un bon instrument. Or, la clef analytique rédigée sur le cadre de Lamarck par Boreau, pour sa Flore du centre de la France, est celle qui m'a toujours paru la plus simple et la plus claire pour des étudiants et des débutants. Je l'ai donc adoptée et suivie presque phrases par phrases, en la mettant au courant des plantes du Sud-Ouest et en changeant les termes trop techniques. Sachant, en outre, qu'une clef quelconque, si bonne qu'elle soit, laisse toujours à désirer pour certaines plantes variables, qu'il suffit d'une simple erreur d'observation ou de chiffre pour dérouter les débutants, j'ai ajouté aussi l'analyse des g'enres et des familles par le système de Linné, système fondé sur l'examen détaillé des organes mâles et femelles de la fleur. Si l'on n'arrive pas à un nom satisfrisant avec la clef dichotomique de Lamarck, on prendra la clef sexuelle de Linné, et l'on aura les meilleures chances d'aboutir à bien arec l'une, si ce n'est pas avec l'autre. On pourra même contrôler soi-même sa première détermination, en employant successivement les deux méthodes. Ces clefs analytiques sont si 
simples, l'une et l'autre, qu'il est inutile d'indiquer en détail la façon de s'en servir. C'est une combinaison de paragraphes avec numéros de renvoi, où l'on a à choisir entre deux ou trois caractères simples, très visibles sur la plante, dans le premier cas; c'est une suite de caractères positifs tirés, d'abord des étamines et des parties de l'ovaire, puis des particularités saillantes de la fleur et du reste de la plante, dans le second cas. Il suffit d'y jeter les yeux pour saisir la marche à suivre.

Quant à la description des espèces, je me suis surtout inspiré de la rédaction courte et précise des anciens ouvrages, comme le Species de Linné, par exemple, ainsi que de l'excellente Flore de l'Ouest de la France, par M. James Lloyd, laquelle néglige tous les détails de peu de valeur. Ces descriptions, par leur brièveté, m'ont permis de leur intercaler une analyse dichotomique des espèces, analogue à celle adoptée pour les genres et dont le texte en italique tranche assez nettement sur l'ensemble de la page pour éviter la confusion. De telle sorte qu'en partant des grandes divisions du début, on peut arriver, par choix et éliminations successives de caractères frappants et visibles à l'œil le moins exercé, jusqu'au nom de l'espèce et même de la variété.

$\mathrm{Au}$ point de vue du langage botanique luimême, je lui ai fait subir ici de nombreuses modifications dans le sens de simplification déjà 
indiqué. Les sciences qui, comme la botanique, datent des commencements de la Renaissance, ont d'abord été traitées en latin. Plus tard, lorsque la langue mationale a pris le dessus, on a seulement francisé les termes, pour ne pas rompre avec la tradition, et aujourd'hui on les conserve, dit-on, pour la précision du langage. J'ai mis de côté, dans mon livre, comme je l'ai fait depuis longtemps dans mon enseignement à la Faculté, toute cette geênante livrée qui a fait croire, avec apparence de raison, que la botanique était une science de mots; j'ai proscrit impitoyablement tout terme néo-g'rec ou néo-latin qui n'était pas indispensable, et je l'ai remplacé par le mot français correspondant ou la tournure française la plus courte, ce qu'il m'a toujours été facile de trouver. J'ai appelé tout simplement queue ou pédicule le petit pied de la feuille ou de la fleur, qu’on a appelé pétiole et pédoncule; j’ai appelé feuille ronde, ce que d'autres appellent feuille orbiculaire; feuille en cour, ce qu'on nomme feuille corlée, et feuille sans queue, la fouille sessile de nos auteurs; j'ai appelé tête de fleurs ou tête tout court, ce qu'on qualifie de copitule, de calathide ou d'anthode; j'ai appelé tige souterraine, le rhizome; rameau aplati, le cladode classiques, etc., etc.; j'en passe et des meilleurs. On me jettera peut-être la pierre parmi les miens, l'habitude nous fait si souvent prendre pour une nécessité ce qui n’est qu’un inutile 
accessoire; mais mes lecteurs, qui n'auront plus la peine de recourir à chaque instant à un vocabulaire de termes botaniques, m'applaudiront, j'en suis sûr.

Quant au très petit nombre de termes techniques qu'il m'a fallu forcément conserver, je les ai expliqués par des exemples tirés de plantes communes et sous la main de tous, dans un petit Appendice organographique disposé par ordre alphabétique à la fin de chaque volume.

Que si, malgré la facilité que toutes ces précautions offrent pour la détermination des plantes à tous ceux qui sont munis de quelque instruction, même primaire, on avait parfois quelques déceptions, il ne faut point pour cela se décourager, s'accuser soi-même, accuser la science ou le livre. Il faut mettre de côté la plante en litige, afin de reprendre plus tard son analyse dans de meilleures conditions d'esprit ou, mieux encore, de la montrer ì quelque botaniste plus entendu. La nécessité d'un maître ou d'un guide à consulter se fait toujours sentir à un moment donné, ne serait-ce que pour se rendre compte de ses propres progrès.

Reste encore un point tout à fait important sur lequel il faut m'expliquer à l'avance. C'est au sujet de la classification adoptée et surtout des espèces acceptées dans ce livre.

On est généralement d'accord aujourd'hui, en 
France, pour suivre dans la rédaction des Flores la classification de Jussieu, telle qu'elle a été modifiée par De Candolle, ainsi que l'ordre des g’enres établi par Koch dans son Synopsis des plantes de l'Europe centrale, parce que c'est le premier traité général qui ait été publié et terminé selon cette dernière méthode de classer. Miais tout en acceptant ce cadre pour l'ensemble, les divers auteurs ont apporté une foule de modifications de détail, qui varient d'un ouvrage à l'autre. C'est surtout en ce qui concerne les espèces que les divergences sont grandes. Ici encore je n'ai point perdu de vue mon but principal, qui est de simplifier autant que possible l'ćtude de la botanique. Qu'on ne s'étonne done point de me roir réduire, non seulement des espèces plus ou moins admises depuis une trentaine d'années, au rang' de simples rariétés, mais encore des groupes génériques établis par De Candolle ou ses continuateurs, au rang de sous-genres, et de prétendus types de famille, au rang de simples g'enres. J'ai, pour agir ainsi, des raisons de plusieurs sortes, tontes meilleures les unes que les autres.

Ce sont d'abord des raisons de principe, tirées llu fond ct de l'expérience de la science botanique elle-même. Il est bien établi aujourd'hui que les plantes varient dans leur descendance et qu'il existe entre tous les végétaux une parenté d'origine aux degrés les plus variés. Ce ne sont que frères, cousins-germains, 
consanguins plus ou moins proches, collatéraux ou descendants éloignés de souches mères plus ou moins fécondes. En général comme en détail, la seule méthode de classification justifiée serait celle qui grouperait les êtres vivants suivant leur généalogie. Nais comme il n'existe pas d'états de naissance pour les plantes, nous avons bien été obligéés de les classer selon l'affinité de leurs caractères extérieurs, de mettre en jeu nos propres appréciations. Qu'avons-nous fait alors? Ce qu'on fait d'ordinaire, lorsqu'on se trouve en présence d'un très grand nombre d'objets à mettre en ordre. Nous avons créé un certain nombre de cadres bien gradués entre eux, l'embranchement, la classe, la famille et l'espèce, dans lesquels nous distribuons les individus. Nous avons répété et nous répétons ces cadres suivant les besoins, et nous les dénommons d'une façon uniforme par un simple artifice de langage.

Les moyens que nous avons ainsi pris, faute de meilleurs, nous rapprochent-ils autant que possible de la vérité généalogique? Pour ce qui est de nos cadres les plus généraux, les embranchements, les grandes classes, voire les principales familles, il est infiniment probable que nous les avons composés suivant l'ordre de la nature et des affinités originelles, parce que les caractères sur lesquels nous nous fondons, toujour's tirés de la fleur, sont saillants et importants. Mais il ne peut en être de même 
pour un grand nombre de familles, pour la majorité des g'enres, ni surtout pour la plupart des espèces. Ici les liens de parenté sont très étroits, les différences et les caractères peu sensibles, minimes, inconstants même, portant tantot sur un organe, tantôt sur un autre. Nous avons dû sûrement séparer bien des fois le père du fils, le frère de la sœur, rompre bien des chaînons et débiter en morceaux bien des séries légitimes.

Ainsi la réalité des choses, en histoire naturelle, ne justifie point partout et toujours les limites nettes et tranchées que nous sommes portés à y voir, eu prenant nos procédés intellectuels pour autre chose que ce qu'ils sont; elle ne permet point la cristallisation, pour ainsi dire, de nos genres ni de nos espèces. L'espèce surtout, à savoir le groupe qui derrait se reconnaître tout de suite à l'œil, d'après le sens étymologique du mot, n'est point dans la nature à titre d'unité première et irrédıctible; elle n'a point par elle-même, pas plus que le g’enre, de démarcations toujours nettes, et c'est nous qui, avec notre intelligence adaptée à une certaine modalité de phénomènes morphologiques, comme notre œil l'est à un certain champ visuel et notre oreille à une certaine quantité de ribrations sonores, étendons ou restreignons sa circonscription, c'est-ì-dire les catég’ories d'individus qu'elle doit embrasser sous un même nom. 
Alors à quoi bon se lancer sans cesse à la poursuite de mirag'es intellectuels qui se dérobent toujours au moment où on croit les tenir et les avoir réalisés? A quoi bon créer un nouveau genre pour une ou plusieurs espèces mieux séparées des autres qu'elles ne le sont entre elles, admettre une nouvelle espèce confondue jusque là avec une autre sa plus proche voisine, pour des caractères de très peu de valeur? C'est presque toujours superflu, souvent nuisible, quand ce n'est pas une affaire de sentiment ou même d'illusion personnelle. A force de remettre toujours sur le tapis les genres et les espèces légués par nos devanciers, à force de vouloir les polir et les perfectionner, on finit par les mettre en morceaux, comme un sculpteur trop méticuleux qui retoucherait constamment ses œuvres.

C'est ensuite la nature même de ce livre qui me porte à réduire au strict nécessaire le nombre des groupes, petits et grands. Des auteurs ayant à écrire des ouvrages geénéraux peuvent multiplier les genres et les espèces simplement pour la facilité de leur rédaction, quelles que soient du reste les idées qu'ils professent sur la nature vraie et la valeur de ces groupes. Et cela se comprend à la rigueur, parce que les g'enres renferment d'autant plus d'espèces que la Flore embrasse plus de pays divers, et parce qu'une espèce comprend d'autant plus de variétés, et de variétés plus 
accentuées, que son aire d'habitation est plus étendue. Mais il n'est pas logique d'introduire de pareilles distinctions dans des traités locaux et élémentaires, où les g'enres ne renferment qu'un petit nombre d'espèces et les espèces qu'un petit nombre de variétés, souvent légrères.

Ce sont, enfin, des raisons de pratique et d'enseignement qui militent d'une facon décisive en faveur de cette manière de voir, qui est celle de tous ceux qui jugrent les choses d'un peu plus haut que le terre à terre ordinaire. En pareille matière, la première règle à suivre, lorsqu'on n'a pas de mesure précise à sa disposition et qu'on est sûr de n'en pas trouver, c'est l'avantag’e de l'étude et la sûreté du travail intellectuel, c'est d'employer le moins de noms possible et de réduire même, dans une très larg'e mesure, ceux qui existent. Et quand cet avantage et cette réduction se trouvent surtout et fort heureusement d'accord avec les données de ceux qui ont engagé la science, il me paraît tout à fait bon et raisonnable de les suivre.

Ainsi donc la meilleure doctrine scientifique et la pratique courante unissent leurs exigences pour nous imposer le devoir, dans les livres élémentaires de botanique, de revenir autant que faire se peut, au point de vue des genres et des espèces, aux anciennes et larges coupures établies par des botanistes qui connaissaient en somme fort bien les plantes, qui les savaient 
variables, mais qui n'ont pas attaché à toutes leurs variations l'importance qu'on voudrait aujourd'hui leur donner. Plus tard, nos jeunes étudiants, devenus des savants distingués, seront libres de s'initier aux recherches détaillées des floristes de profession, s'ils le jugent à propos et s'ils en sentent le besoin, pour mieux résoudre une question particulière de culture, de géographie botanique ou autre.

En terminant, qu'il me soit permis d'émettre un vœu et d'exprimer un désir. Mon vœu est que ces deux petits volumes fassent surgir partout, de La Rochelle à Toulouse et de Bayonne à Poitiers, des botanistes qui herborisent. Dans les nouveaux programmes d'enseignement à tous les degrés, primaire comme secondaire, on a voulu que, sans disserter à perte de vue sur des sujets de botanique pure, la jeune fille pût connaître le no:n des fleurs qu'elle aime, le jeune homme le nom des plantes utiles ou nuisibles qui peuvent lui servir dans la vie. Le gout de la botanique et des herborisations ne peut donc que se développer dans nos écoles, à la campagne comme à la ville, et ce sera la source d'un grand bien physique et intellectuel. Mon désir serait que mes lecteurs voulussent bien m'adresser, sans crainte d'être indiscrets, toutes les plantes qu'ils n'auront pas pu déterminer eux-mêmes. Je les assure que je me ferai un scrupuleux devoir 
de les renseigner. De cette facon, nous arriverons facilement et rapidement à rassembler par nos communs efforts les éléments d'une Flore complète et réritablement géographique de nos départements du Sud-Ouest, dont le livre actuel peut être considéré comine le cadre et l'ébauche.

Bordeaux, le 1er août 1883.

\section{Dr J.-A. GUILLAUD,}

Professcur de Botanique ct d'Histoire naturelle mélicale

à la Faculté de Médecine et de Pharmacie.

\section{BIBIIOGRAPIIE}

et Ouvrages consultés pour la rédaction du premior volume.

OUVRAGES GÉNÉRAUX:

LINNÉ. - Genera plantarum, IIolmix, 175 亿. Species plantarum, Holmix, 1762.

Lamara et DE Cixdolde. - Flore francuise, Paris, an XIII (1805).

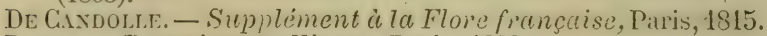
Duby. - Botanicon gallicum, Paris, 1828.

Loiselecr Desidoxicilamps. - Flora gallica, Paris, $18 \geq 3$.

Mutel. - Flore francaise, Paris, 183t.

Grenier et Godrox. - Flore firancaise, Paris, 18.7 i 1852.

LE MaOct et DeciIsne. - Flore élémentaire des jardins et des champs, Paris, 1855. 


\section{OUVRAGES LOCAUX.}

Prévost (Jean). - Catculogue des plantes qui croissent en Béarn, Navarie, Bigorne et ès coites de la mer des Basques depuis Bayonne iusqu'a Fontarabie et SaintSébastien, Pau, 1655, chez Burette.

Tournefort. - Toporjiphie botanique (partie insérée dans l'Histoire des plantes des Pyrénées de Lapeyrouse).

Fournault (Dom). - Liste des plantes d'Auvergne, dans le Dictionnaire de Buch'oz, Paris, 1771.

LE MÈ.M. - Liste des plantes de Souillac en Quercy et de Beaulieu en Bas-Limousin, dans le Dictionnaire de Buch'oz.

LE MÊME. - Liste des plantes qui se trouvent entre Souillac (Lot) et Saint-Jean-d'Angély (Gharente-Inférieure), dans le Dictionnaire de Buch'oz.

Gutereau. - Description des plantes qui croissent aux environs de Montauban, 1789.

X... - Catalogue des plantes du Jardin botanique de Rochefort, Rochefort, 1793.

Delarbre. - Flore d'A uvergne, Glermont-Ferrand, 1795.

Dr Gutllevienu. - Galendrier de Flore des environs de Niort, Niort, an IX (1801).

LApeyrouse. - Histoire abrégée des plantes des Pyrénées, Paris, 1803.

Trore. - Essai d'une Chloris du département des Landes, Dax, an XI (1803).

LE MẺMe. - Promenades sur les côtes du golfe de Gascogne, Bordeaux, 1810.

Bergeret. - Flore des Basses-Pyrénées, Pau, 1803.

Dr Tournon. - Flore de Toulouse, Toulouse, 1811.

Lesson. - Flore rochefortine, Rochefort, 1835.

Sarnt-Airans: - Flore agenaise, Agen, 1821.

Noulet. - Flore du bassin sous-piyrénéen, Toulouse, 1837. Supplément, 1846.

Delastre. - Flore du département de la Vienne, 1912.

Ghantelat. - Gatalogue des plantes des environs de La Teste de Buch, Bordeaux, 181'.

Laterrade. - Flore bordelaise et de la Gironde, Bordeaux, 1816. - Supplément, 1857.

LAGrìz-Fossat. - Flore de Tarn-ct-Garome, Nontauban, 1847.

Desmoulins. - Catalogue des Phanérogames de la Dordogne, Bordeaux, 1849. - Supplément, 1859.

LEGoQ et LAmothe. - Catalogue raisonné des plantes vasculaires du plateau central, Paris, 1818.

LAMothe. - Mème Catalogue, 1881.

Dr Puel. - Catalogue des plantes du Lot, Paris, 1852. 
Arrondeau. - Flore toulousaine, Toulouse, $185 \%$ '.

LAMY. - Flore de la Haute-Vienne, Limoges, 1856.

Boreat. - Flore du centre de la France, Paris, 1857.

Philippe. - Flore des Pyrénées, 1859.

Noulet. - Flore de Toulouse et environs, Toulouse, 1861.

Tré.jeau DE Rociebrixe et Savatier. - Catalogue des Phanérogames de la Charente, Paris, 1861.

Salzé et MaIlland. - Catalogue des plantes phanérogames des Deux-Sèvres, Niort, 1864.

Dulac (l'abbé). - Flore du département des Hautes-Pyrénées, Paris, Savy, 1867.

Porrault. - Catalogue des plantes vasculaires du départeiment de la Vienne, Poitiers, 1875.

Lloyd. - Flore de l'ouest de la France, Nantes et Paris, 1876. - Supplément,1876 et 1877. - Supplément, 1878 et 1879.

Foucaud. - Herborisations dans la Charente-Inférieure, 1876 et 1880 .

Dr Econchird. - Flore régionale des départements maritimes du nord-ouest et du sud-ouest de la France, Paris, 1878.

LÉoN. - Flore landaise, Pau, 1876.

LANDry et BeHr. - Tableau analytique de la Flore des Landes, Dax. (En cours de publication).

$\mathrm{D}^{\mathrm{r}}$ Blixcmet - Catalogue des plantes vasculaires du sudouest de la France, comprenant le département des Landes. (En cours de publication).

Licaxte. - Flore du département du Gers, Auch. (En cours de publication).

A. Claraud. - Flore de la Gironde, Bordeaux, 1882. (Thalamiflores; en cours de publication.)

E. Rupr. - Catalogue des plantes qui croissent dans le département de la Corrèze, Brive. (En cours de publication.)

Actes et comptes rendus de la Société Linnéenne de Bordeaux, 1828 à 1882.

Annales de la Société des sciences naturelles de La Rochelle, 1836 à 1882.

Bulletin de la Société botanique de France, 1854 à 1882.

Bulletin de la Société Ramond, Bagnères-de-Bigorre, 1865 a 1881 .

Bulletin de la Société de Borda, à Dax, 1875 à 1882.

Mémoires et comptes rendus de la Société des sciences physiques et naturelles de Bordeaux, t. I, 1854.

Mémoires et comptes rendus de l'Académie des sciences, inscriptions et belles-lettres de Toulouse. 


\section{ANALYSE}

\section{DES FAMILLES ET DES GENRES}

D'APRÈS LE SYSTĖME DICIOTOMIQUE DE LAIIARCK

Plantes à fleurs distinctes, c'est-à-dire dont les organes sexuels, étamines et ovaires, sont visibles à l'œil nu : Phanérogames.

Plantes sans fleur, c'est-di-dire sans étamines ni ovaires: Cryptogames $\left(^{(}\right)$.

\section{PLANTES PHANÉROGAMES.}

Fleurs groupées en tête munie d'une enveloppe commune, de telle sorte que l'ensemble parait ne constituer qu'une seule fleur. ........... 1 Fleurs non groupées en tête munie d'une enveloppe com-

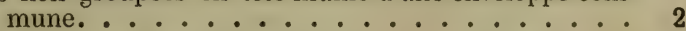

1 Etamines à anthères soudées entre elles: (Fam. des

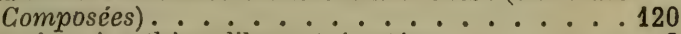

Etamines à anthères libres et écartées. . . . . . . 2

2 Enveloppe florale double; un calice et une corolle bien

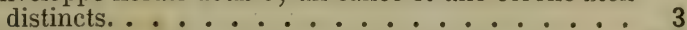

Enveloppe florale simple ou nulle : (APÉtALES). : 172

3 Corolle à pétales libres, c'est-à-dire composée de pièces distinctes : (Polypétales). . . . . . .

Corolle à pétales soudés, c'est-à-dire composée d'une seule pièce, divisée ou non : (Gàopétales). . . . 104

\section{POLYPÉTALES.}

4 Ovaire libre, placé dans la corolle ou an fond du calice. Ovaire soudé au calice ou placé sous la corolle, le façon a former un renflement visible au-dessous de la fleur.

(1) Voir le second rolume. 
5 Un seul ovaire dans chaque fleur.

Plusieurs oraires distincts ou un ovaire a plusieurs divisions profondes, dans chaque fleur. . . .

6 Etamines à filets libres ou non soudés en tube. . . .

Etamines à filets soudés entre eux, du moins à la base, en forme de tube.

7 Feuilles non charnues, simples, découpées, ou composées de folioles distinctes. . . . . . . . .

Feuilles épaisses et charnues, toujours simples et indivises. . . . . . . . . . .

Etamines insérées au fond de la fleur, très près de l'ovaire. ..............

Etamines insérées au-dessus du fond de la fleur et de l'oraire. .............

9 Pétales entiers ou seulement dentés et échancrés. . . Plusieurs pétales profondément découpés en petites lanières. G. Reseda L., p. 21.

Dix étamines seulement. G. Ailanthus Desf., p. 41.

\section{FAM. DEs ReNoNGulacéEs.}

11 Fenilles opposées sur des tiges ligneuses et sarmenteuses. G. Glematis L., p. 1.

Feuilles éparses ou toutes radicales; tiges herbacées.

10 Enveloppe de la fleur double, un calice et une corolle bien distincts. G. Ranunculus L., p. 3.

Enveloppe de la fleur simple, à pièces de couleur uniforme ou à peu près. . . . . . . . .

2 Enveloppe de la fleur munie à la base d'un ou plusieurs éperons ou prolongements. . . . . . . Enveloppe de la fleur sans éperon ni prolongement.

$3^{\circ}$ Un seul éperon. G. Delphinium L., p. 6.

Ginq éperons. . . . . . . . .

40 Petite plante naine, a fleurs rert jaunatre. G. Myjosurus L., p. 3.

Plante élevée, à fleurs bleues ou roses. G. Aquilegia L., p. 6.

כo Fleurs munies d'appendices glanduleux en dedans des pièces de l'enveloppe florale. . . . . . . . .

Fleurs sans appendices en dedans des pièces de l'enve. loppe florale. 
60 Fleurs blentitres; feuilles découpées en lobes fins. G. Nigella L., p. 6.

Fleurs rerdatres ou blanches. G. Ifelleborus DC., p. 3. Fleurs d'un beau jaune. G. Ranunculus L., p.3.

$7^{\circ}$ Feuilles larges, entières, arrondies; fleurs d'un beau jaune. G. Caltha L., p. 3.

Feuilles découpées en lobes nombreux. . . . . 80

So Fleurs accompagnées de petites feuilles disposées en collerette au-dessous d'elles. G. Anemone L., p. 2.

Fleurs sans collerette de feuilles. . . . . . 9?

90 Fleurs d'un rouge plus ou moins éclatant. G. Adlonis L., p. 2.

Fleurs blanchâtres ou jaunâtres. G. Thalictrum L., p. 1.

Fair. des CRassulacées.

12 Très petites plantes; fleurs à trois ou quatre élamines. G. Tilloea L., p. 71 .

Fleurs à cinq ou huit étamines et plus. . . . . . 10

10 Corolle tubuleuse, à pièces soudées. G. Umbilicus L., p. 72 .

Corolle étoilée, à pièces libres. . . . . . . $2^{\circ}$

20 Six à douze ovaires, et autant de pétales dans chaque fleur. G. Sempervirum L., p. 72.

Quatre à sept ovaires et autant de pétales. G. Sedum L., p. 71.

13 Corolle régulière, c'est-à-dire à divisions semblables et égales. • blables et inégales........... 75

14 Une à dix étamines. . . . . . . . . . 30 Douze étamines ou plus. . . . . . . . . . 15

15 Calice à deux pièces ou ì deux divisions profondes. . 16 Calice à plus de deux pièces ou divisions. . . . . 18

16 Cinq pétales; calice et corolle persistants. G. Porlılaca, p. 38.

Quatre pétales; calice très caduc, tombant au moment de l'épanouissement. . . . . . . . .

FaM. DEs Papavéracées.

17 Fleurs régulières. . . . . . . . . . . 10 Fleurs irregulieres. G. Funaria L, p. \&, 
10 Ovaire ou fruit court, plus ou moins globuleux. G. $\mathrm{Pa}-$ paver L., p. 7.

Ovaire ou fruit linéaire et allongé, à deux divisions au sommet. . . . . . . . . . .

2 . Etamines nombreuses; fruits uniformes. G. Ghelidonium L., p. 8.

Etamines 4 ; fruits articulés. G.Hypecoum T., p. 8.

18 Pétales insérés sur le calice, du moins en apparence.

Pétales insérés, comme les étamines, au fond de la fleur. . . . . . . . . . .

19 Ovaire pédiculé au milieu de la fleur; style à trois divisions au sommet; plantes à suc laiteux. G. Euphorbia L., p. 117.

Oraire non pédiculé; un ou plusieurs styles simples. . 20

20 Calice profondément divisé en cinq parties. . . . 103 Calice it six ou douze dents. G. Lythrum L. p. 70.

21 Feuilles alternes ou toutes radicales. . . . . . 22 Feuilles opposées, au moins les inférieures. . . . 28

22 Etamines soudées par les filets. . . . . . . 23 Etamines libres, à filets distincts de la base au sommet. 26

23 Etamines trés nombreuses, indéfinies. . . . . 24 Etamines en nombre fixe, cinq, dix, quinze au plus. . 25

\section{FAM. des Malvacées.}

24 Calice inférieur maissant de la base de l'autre, $\dot{a}$ trois pièces libres. G. Malva L., p. 24.

Calice inférieur naissant de la queue de la fleur. . . 10

10 Calice inférieur a trois divisions seulement. G. Lavater'a L., p. 25.

Calice inférieur à divisions nombreuses. . . . .

$2^{\circ}$ Styles filiformes; fruits très nombreux et petits. G. $A l$ thoea L., p. 25.

Styles terminés en bouton; un seul fruit assez gros. G. Hibiscus L., p. 25.

\section{Fan. des Géraniacées.}

25 Fenilles petites, très entières; fruit globuleux. G. Linum L., p. 28.

Feuilles plus ou moins découpées ou dentées; fruit plus long que large. .......... 10

1. Cinq étamines. G. Impatiens L., p. 28. Dix étamines. 
$2 \circ$ Fruit capsulaire; feuilles à trois folioles. G. Oxalis L., p. 29.

30 Fruit à cinq coques distinctes; feuilles jamais à trois folioles. G. Geranium L., p. 26.

26 Arbres. G. Tilia L., p. 38.

Herbes.

27 Plante aquatique, à grandes feuilles rondes. G. Nymphoea L., p. 7.

Plante terrestre, à feuilles composées. . . . . 11

28 Etamines libres et non soudées. . . . . . 29

Etamines soudées entre elles par les filets. G. Hypericum L., p. 39.

29 Arbres ou grands arbrisseaux; style à deux divisions au sommet. G. Acer L., p. 41.

Herbes ou plantes ligneuses basses et buissomnantes. G. Gistus L., p. 22.

30 Trois pétales. . . . . . . . . . . 31

Quatre pétales.............. 33

Ginq pétales. ............... 45

Six pétales. . . . . . . . . . . 73

31 Calice et corolle bien distincts de couleur. . . . . 32 Enveloppe florale toute entière de la même couleur' . 251

32 Petites plantes, à feuilles ovales et opposées. G. Elatine L., p. 37.

Plantes à feuilles linéaires, alternes et toutes radicales. 256

33 Deux étamines. G. Fraxinus L., p. 115.

Quatre étamines. ......... 34

Six étamines dont deux plus courtes. . . . . . . 44

Huit ou dix étamines. . . . . . . . . 38

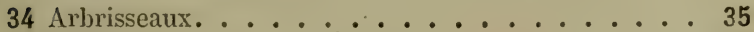

Herbes. . . . . . . . . 36

35 Feuilles alternes et épineuses. G. Ilex L., p. 43.

Feuilles opposées, non épineuses. G. Evonymus L., p. 42.

36 Feuilles opposées . . . . . . . . . 37

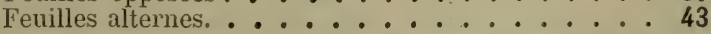

37 Fleurs blanchàtres, avec des feuilles orales et de petites tiges plusieurs fois fourchues. Linum Radiola L., p. 28.

Fleur's roses, ou jlanchitres, avec des feuilles linéaires et les tiges non fourchue... . . . . . . . 
38 Plante jaunàtre, munie d'écailles au lieu de feuilles. G. Monotropa L., p. 112.

Plante verte, d̀ feuilles ordinaires. . . . . . . 39

39 Feuilles composées; un seul style. G. Ruta L., p. 40. Feuilles simples; deux ou quatre styles......

40 Deux styles. (S. G. Mochringia). G. Arenaria L., p. 32.

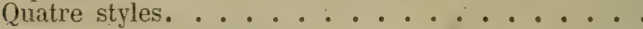

41 Tige à une seule fleur; feuilles ayant plus de 3 centimètres de large. G. Paris L., p. 166.

Tige à plusieurs fleurs; feuilles bien plus petites. . .

42 Herbes aqquatiques, a pétales sans pied. G. Elatine L., p. 37.

IIerbes terrestres, à pétales munis d'un pied. G. Linum L., p. 28.

43 Calice à rquatre pièces; 1 m style bifide ou pas de style. . . . . . . . . . . .

Calice à deux pièces; deux styles couts. G. IIypecoum L., p. 8.

\section{Fay. des Crucifìres.}

44 Ovaire on fruit grele, trois ou quatre fois plus long que large (silique des auteurs). . . . . . . .

Oraire ou fruit court, dont la longueur n'atteint pas trois fois la largeur (silicule). . . . . . . .

10 Fruit composé d'articles, imitant les grains d'un chapelet. G. Raphanus L., p. 10.

Fruits sans articles distincts. . . . . . . .

20 Style et fruit fendus en deux lames au sommet. . . . $3^{\circ}$

Stivle et fruit entiers all sommet, ou à peine bilobés. . $\mathbf{1}^{0}$

$3^{\circ}$ Fruits glabres, à graines anguleuses. G. Hesperis L., p. 14.

Fruits velus, a graines ovales et aplaties. G. Gheiranthus L., p. 14.

$4^{0}$ Oraire et fruits terminés en bee conique. Cr. Brassica L., p. 10.

Ovaire et fruits sans bec, ou à pointe très courte. . . $5^{0}$

$5^{\circ}$ Oratre et fruits crlindriques. (r. Sisymbrium L., 1) 12.

Oraire et fruits anguleux. G. Erysimum L., p. 13.

Ovaire et fruits comprimés et aplatis . . . . . $C^{n}$

$6^{\circ}$ Fruits a valres enroules, fruand elles sourent. . . . $7^{\text {n }}$

Fruits it villes nom élastiques. (r. Arabis L., \}). 1\%. 
$7^{\circ}$ Racine grèle; fruit sans pointe au sommet. G. Cardamine L., p. 15.

Racine charnue, cassante et garnie d'écailles; fruit allongé en corne. G. Dentaria L., p. 16.

80 Fruit à deux articles superposés. . . . . . . . co

Fruit ne s'ouvrant pas naturellement à la maturité. . 110

Fruit s'ouvrant en deux valves. . . . . . . 14 $14^{0}$

90Fleurs jaunes. (S. G. Rapistrum.) G. Myagmum L., p. 16.

Fleurs blanches. . . . . . . . . 10 $10^{\circ}$

$10^{\circ}$ Calice étalé, formé de sépales égaux à la base. G. Crambe L., p. 16.

Calice dressé, à deux sépales bossus à la base. G. Cakile L., p. 16.

$11^{\circ}$ Fleurs blanches.

Fleurs jaunes ou jaunatres. . . . . . . $13^{\circ}$

$12^{\circ}$ Fruit globuleux. (S. G. Galepina.) G. Myagrum L., p. 16.

Fruit à deux lobes et en forme de rein. G. Senebiera Pers., p. 20.

$13^{\circ}$ Fruit à quatre angles en crète. G. Bunias L., p. 16.

Fruit à deux lobes arrondis. G. Biscutella L., p. 20.

Fruit plat, bordé d'une aile. G. Isatis L., p. 17.

Fruit globuleux ou triangulaire, sans aile. G. Myagrum L., p. 16.

$14^{\circ}$ Fruit à faces convexes ou plates, comprimé parallèlement à la cloison qui est large. . . . . . . . .

Fruit plié en double carène, comprimé perpendiculairement à la cloison qui est très étroite. . . . . $26^{\circ}$

$15^{\circ}$ Fruit très large; fleurs violettes. G. Lunaria L., p. 18.

Fleurs blanches. ......... $16^{\circ}$

Fleurs jaunes. . . . . . . . . . . $18^{\circ}$

$16^{\circ}$ Fruit sans nervure sur le dos. G. Alyssum L., p. 18.

Fruit avec une nervure sur le dos. . . . . 17 $17^{\circ}$

$17^{\circ}$ Fruit ventru. G. Cochlearia L., p. 17.

Fruit presque plat. G. Draba L., p. 18.

$18^{\circ}$ Fruit sans nervure sur le dos. . . . . . . 190

Fruit avec une nervure sur le dos. (S. G. Cainelina.)

G. Myagrum L., p. 16.

$19^{\circ}$ Feuilles petites, grisàtres ou vertes, entières. G. Alyssuin L., p. 18.

Feuilles divisées ou munies d'oreillettes. (S. G, Nas-

turtium DC.) G. Sisymbrium L., p. 12. 
$20^{\circ}$ Pétales égaux entre eux. . . . . . . . 21\% Pétales inégaux, deux plus grands. G. Iberis L., p. 20.

$21^{\circ}$ Fruit à deux graines, ou à plusieurs graines, mais alors non échancrè au sommet. G. Lepidium L., p. 18.

Fruit à plus de deux graines, mais toujours échancré au sommet. G. Thlaspi L., p. 19.

45 Une à cinq étamines. . . . . . . . . 46 Plus de cinq étamines. ......... 63

46 Cinq styles. .................. 47

Moins de cinq styles. . . . . . . . . . 49

47 Feuilles petites, alternes le long de la tige. G. Linum L., p. 28.

Feuilles opposées le long de la tige.

72

Feuilles verticillées, renflées en vessie. G. Aldrovanda L., p. 24.

Feuilles toutes radicales. . . . . . . . .

48 Feuilles chargées de poils glanduleux et de gouttelettes brillantes. G. Djosera L., p. 23.

Feuilles sans poils glanduleux. G. Statice L., p. 139.

49 Arbres ou arbrisseaux. . . . . . . . . 50

Herbes. . . . . . . . . . 57

50 Feuilles très petites et menues, en forme d'écailles vertes. G. Tamarix L., p. 198.

Feuilles plus ou moins élargies. . . . . . . 51

$\mathbf{5 1}$ Feuilles alternes. .......... 52

Feuilles opposées ou verticillées par trois. . . . 55

52 Fleurs terminant les rameaux. ....... 53

Fleurs axillaires ou opposées aux feuilles. . . . . 54

53 Tige grimpante; un seul style. G. Hedera L., p. 74.

Tige non grimpante, dressée et buissonnante; style a trois divisions. G. Rhus L., p. 43.

54 Des vrilles opposées aux feuilles, G. Vitis L., p. 42.

Point de vrilles. G. Rhamnus L., p. 42.

55 Feuilles divisées ou même composées; style à deux divisions. G. Acer L., p. 41.

Feuilles indivises. . . . . . . . . .

56 Cinq styles. G. Coriaria L., p. 41.

Un seul style. G. Evonymus L., p. 42.

57 Feuilles alternes. . . . . . . . . 58

fieuilles opposées. . . . . . . . . . . 72 
58 Tige à une seule fleur, glanduleuse à l'intérieur des pétales. G. Parnassia L., p. 24.

Tige à plusieurs fleurs non glanduleuses. . . . . 59

59 Feuilles divisées ou fendues. . . . . . . . 60

Feuilles entières ou simplement dentées. . . . . . 62

60 Fleurs jaunes. G. Ruta L., p. 40.

Fleurs jamais jaunes. . . . . . . . . 61

61 Fleurs en têtes serrées. G. Telephium L., p. 37.

Fleurs jamais en têtes. G. Geranium L., p. 26.

62 Calice tubuleux, du moins en apparence; fleurs axillaires ou en épis. G. Lythrum L., p. 70.

Calice en cloche; fleurs en petits bouquets terminaux. G. Corrigiola L., p. 37.

63 Un seul style, simple au sommet. . . . . . . . 64 Plusieurs styles ou style divisé au sommet. . . . . 69

64 Herbes à feuilles alternes ou écailleuses. . . . . 66 Herbes à feuilles opposées. G. Tribulus L., p. $40^{\circ}$

Arbres ou arbrisseaux. . . . . . . . 65

65 Feuilles composées de folioles disposées comme les doigts de la main. G. AEsculus L., p. 41.

Feuilles seulement divisées. G. Acer L., p. 41.

66 Feuilles écailleuses, jaunâtres. G. Monotropa L. p. 112.

Feuilles vertes et ordinaires. . . . . . . 67

67 Fleurs jaunes. G. Ruta L., p. 40.

Fleurs blanches ou rougeâtres. . . . . . . 68

68 Calice tubuleux, du moins en apparence, à 5-12 dents. G. Lythrum L., p. 70.

Calice ouvert, à cinq divisions. . . . . . 145

69 Arbres ou arbrisseaux. G. Acer L., p. 41.

Tige herbacée ou à peine ligneuse à la base. . . . 70

70 Feuilles alternes sur la tige ou toutes radicales. . . 71

Feuilles opposées ou verticillées sur la tige. . . . 72

71 Deux styles. G. Saxifraga L., p. 73.

Quatre ou cinq styles......... 25

\section{Fam. des Caryophyllées.}

72 Feuilles ovales ou arrondies, avec de petites stipules. $1^{0}$ Feuilles sans stipules, ou filiformes quand elles en ont. $6^{\circ}$

10 Feuilles divisées ou incisées. . . . . . . . . 23

Feuilles entières. .......... . . . : $i_{20}$ 
$2^{\circ}$ Feuilles de la tige verticillées quatre par quatre. G. Polycarpon L., p. 37.

Feuilles opposées ou alternes. . ....... $3^{\circ}$

$3^{\circ}$ Stipules blanches, membraneuses. . . . . $4^{0}$

Stipules très petites, verdàtres. G. Herniaria T., p. 37.

$4^{0}$ Feuilles opposées. G. Illicebrum L., p. 37.

Feuilles alternes. . . . . . . . 5 50

$5^{\circ}$ Trois styles; fleurs en tètes. G. Telephium L., p. 37.

Ovaire à trois divisions au sommet; fleurs en grappes. G. Corrigiola L., p. 37.

60 Fruits s'ouvrant en travers. . . . . . . $7^{\circ}$

Fruits s'ouvrant au sommet, ou pas du tout. . . . $8^{\circ}$

70 Fleurs jaunes; plantes terrestres. G. Portulaca L., p. 38.

Fleurs blanches; plantes aquatiques ou du bord des eaux. G. Montia L., p. 38.

$8^{\circ}$ Calice divisé jusqu'à la base. . . . . . 14 ${ }^{\circ}$

Divisions du calice n'atteignant pas son milieu ou le dépassant peu. ................. $9^{\circ}$

90 Dix étamines. . . . . . . . . . $10^{\circ}$

Ioins de dix étamines. G. Lythrum L., p. 70.

$10^{\circ}$ Deux styles. . . . . . . . . . . 110

Trois styles. G. Silene L., p. 30.

Cinq styles. G. Lychnis L., p. 32.

$11^{\circ}$ Calice en cloche, à cinq divisions. . . . . . . 120

Calice en tube, à cinq dents. . . . . . . . 130

$12^{\circ}$ Pétales nuls ou rudimentaires; calice resserré à la gorge. G. Scleranthus L., p. 37.

Pétales bien dévelóppés; calice ouvert. G. Gypsophylla L., p. 29.

$13^{\circ}$ Calice entouré d'écailles ou de bractées adhérentes. G. Dianthus L.,p. 29.

Calice sans écailles ni bractées adhérentes. G. Saponaria L., p. 30.

$11^{\circ}$ Un seul style, a trois divisions au sommet; fleurs roses. G. Franlienia L., p. 29.

Deux styles; quatre étamines seulement ou quelquefois huit dans certaines fleurs. ........ $15^{\circ}$

Trois styles. .................. $17^{0}$

Quatre styles. G. Elatine L., p. 37.

Cinq styles. . . . . . . . . . . . 16"

$15^{\circ}$ Fruit à deux ou quatre valves. G. Arimaria L., p. 32.

Fruit à huit dents au sommet. G. Cerastium L., p. 3'. 
$16^{\circ}$ Pétales entiers; feuilles linéaires et étroites. G. Spergula L., p. 35.

Pétales échancrés; feuilles ovales ou élargies.G. Cerastium L., p. 34 .

$17^{\circ}$ Pétales entiers ou à peine échancrés. . . . . $18^{\circ}$

Pétales profondément divisés en deux parties. G. Stellaria L., p. 36.

Pétales dentés au sommet. G. Holosteum L., p. 34 .

$18^{\circ}$ Plante des eaux ou venant au bord des eaux. G. Elatine L., p. 37.

Plantes des sables et des lieux toujours secs. G. Arenaria L., p. 32

73 Arbuste épineux; fleurs jaunes. G. Berberis L., p. 7. Herbes non épineuses, à fleurs rouges ou blanchâtres.

74 Calice à tube cylindrique, du moins en apparence; feuilles allongées. G. Lythrum L., p. 70.

Calice en cloche; feuilles rondes. G. Peplis L., p. 70.

75 Un ou deux styles ou style à deux divisions. . . . 78

Plus de deux styles ou divisions du style. . . . . . 76

76 Pétales découpés en lanières. G. Reseda L., p. 21.

Pétales non découpés en lanières. . . . . 77

77 Très petite plante aquatique, à fleurs blanches. G. Montia L., p. 38.

Plantes terrestres, à fleurs non blanches. . . . . 25

78 Calice entier ou dont les divisions ne vont pas jusqu'a la base. .............. 79 Calice divisé jusqu'à la base en pièces distinctes. . . 80

79 Arbre élevé, à feuilles digitées. G. AEsculus L., p. 41. Plantes herbacées, ou ḋ feuilles non digitées quand elles sont ligneuses. .......... 86

80 Un éperon ou une bosse à la base de la fleur. . . . 83 Fleur sans éperon ni bosse saillante à la base. . ... 81

81 Tige herbacée, non épineuse. . . . . . . 82 Tige ligneuse et épineuse. . . . . . . . . . . 86

82 Quatre à six étamines libres; quatre pétales opposés deux à deux en croix. . . . . . . . . . . Huit étamines à filets soudés; pétales non en croix. G. Polygala L., p. 38.

83 Calice à cinq sépales verts, prolongés à la base et persistants. G. Viola L., p. 23

Calice n'ayant pas cinq sépales verts ni persistants. . 
84 Feuilles simples. G. Impätiens L., p. 28. Feuilles composées et très découpées. . . . .

85 Eperon allongé et très aigu. G. Delphinium L., p. 6. Eperon très court et obtus. G. Fumaria L., p. 8.

FAM. DES LĖGumineuses.

86 Calice à deux pièces distinctes. G. Ule.x L., p. 43.

Calice n'étant pas à deux pièces distinctes jusqu'à la base de la fleur. . . . . . . . . .

10 Feuilles munies au sommet d'un filet délié ou d'une vrille enroulée. . . . . . . . . 280 Feuilles terminées ni par un filet ni par une ville. . $2^{\circ}$

$2^{\circ}$ Feuilles simples ou composées de trois folioles. . . . $4^{\circ}$ Feuilles à folioles plus nombreuses. . . . . . $3^{\circ}$

$3^{\circ}$ Feuilles à cinq folioles, dont deux en contact avec la tige. G. Lotus L., p. 52.

Feuilles à folioles très nombreuses. . . . . . . $16^{\circ}$

$4^{\circ}$ Calice à deux lèrres, l’une supérieure ou postérienre, l'autre inférieure ou antérieure. . . . . . . . .

Calice à cinq dents ou lanières, ne formant pas deux lèvres distinctes. . . . . . . . . . .

50 Tige souvent ligneuse, non enroule; carène de la corolle non tordue en spirale. . . . . . . .

Tige herbacée et enroulée; carène torlue en spirale. G. Phaseolus L., p. 60.

$6^{0}$ Toutes les feuilles i trois folioles. G. Cytisus L., p. 4t. Feuilles simples ou a trois folioles dans le bas de la tige seulement. G. Genista L., p. 43.

7o Feuilles simples et très entières ou a trois folioles avec la terminale plus grande. . . . . . . . Feuilles simples et dentées ou a trois folioles a peu près égales....................... $11^{\circ}$

80 Fleurs en grappes fournies ou en tètes serrées. . . 90 Une à quatre fleurs sur une longue queue. . . . . 10

90 Fleurs en grappes, sovuent assez longues; feuilles très simples. G. Genista L., p. 43.

Fleurs en tètes serrées. G. Anthyllis L., p. 46.

$10^{\circ}$ Feuilles très simples; une seule fleur sur chaque queue. G. Lathyrus L., p. 58.

Feuilles tres simples; deux à quatre fleurs sur chaque queue. G. Scorpiurus L., p. כ̌́.

Feuilles composées. G. Coronilla L., p. 5\%. 
$11^{\circ}$ Carène très petite; corolle paraissant n'aroir que trois pièces. G. Trigonella L., p. 48.

Carène très visible, presque aussi grande que les ailes. $12^{\circ}$

$12^{\circ}$ Fleurs axillaires ou en épis feuillés. G. Ononis L., p. 45.

Fleurs solitaires, ou en têtes, ou en épis non feuillés. . $13^{\circ}$

$13^{\circ}$ Fruit droit et allongé. G. Lotus L., p. 52.

Fruit court ou contourné en spirale. . . . . 14 $14^{\circ}$

$14^{\circ}$ Fruit très court, caché et contenu au fond du calice. G. Trifolium L., p. 48 .

Fruit comprimé, velu, muni d'épines et d'un bec. G. Psoralea L., p. 53.

Fruit saillant au-dessus du calice, droit ou contourné. $15^{\circ}$

$15^{\circ}$ Fruit presque droit ou arrondi dans son pourtour. G. Melilotus L., p. 48.

Fruit courbé en faucille ou contourné en spirale. G. Medicago L., p. 46.

$16^{\circ}$ Feuilles en éventail. G. Lupinus L., p. 60.

Feuilles ailées..................... 170

$17^{\circ}$ Fleurs en têtes serrées; fruit renfermé dans le calice persistant. G. Anthyllis L., p. 46.

Fleurs non en têtes serrẻes; fruit non renfermé dans le calice. . . . . . . . . $18^{\circ}$

$18^{\circ}$ Arbres ou arbrisseaux . . . . . . . . 190

Plantes herbacées ou à peine ligneuses à la base. . . 210

$19^{\circ}$ Pied des pétales dépassant le calice; fruit grêle et cylindrique. G. Coronilla L., p. 54.

Pied des pétales ne dépassant pas le calice; fruit renflé ou comprimé..............20

$20^{\circ}$ Etendard à.deux renflements à la base; fruit très enflé. G. Colutea L., p. 53.

Etendard non renflé à la base; fruit plat et allongé. G. Robinia L., p. 53.

$21^{\circ}$ Fleurs d'un beau jaune. . . . . . . . . 220

Fleurs n'étant pas d'un jaune pur ni prononcé. . . . $23^{\circ}$

22 Fruit comprimé, à échancrures en forme de fer à cheval. G. Hippocrepis L., p. 55.

Fruit à quatre angles, non échancré, mais seulement articulé. G. Coronilla L., p. 54 .

$23^{\circ}$ Fleurs nombreuses, en ombelle et en couronne. G. Coronilla L., p. 54 .

Fleurs ne formant pas des ombelles ni des couronnes. $24^{\circ}$ 
$24^{\circ}$ Carène très petite; fruit comprimé, se partageant en articles. G. Ornithopus L., p. 54.

Carène presque égale aux ailes; fruit ne se partageant pas en articles............ $25^{\circ}$

25. Fruit divisé en deux loges par une cloison longitudinale. G. Astragalus L., p. 53.

Fruit à une seule loge.

$26^{\circ}$ Ailes de la corolle très courtes; fruit à une graine. G. Onobrychis L., p. 55.

Ailes au moins égales à la carène; fruit à deux ou plusieurs graines.

270 Point de stipules à la base des feuilles; carène divisée en deux pièces. G. Glycyrrhiza L., p. 53.

Des stipules à la base des feuilles; carène non partagée en deux. G. Galega L., p. 53.

28. Style creusé en canal ou élargi en palette au sommet; feuilles à peu de folioles. .

Style filiforme à son sommet, sans canal ni palette. G. Vicia L., p. 55.

290 Stipules larges et arrondies à la base; style aplati au sommet. G. Pisum L., p. 58.

Stipules prolongées en pointe à la base; style creusé en canal en dessous du sommet. G. Lathyrus L., p. 58.

87 Deux à dix étamines. . . . . . . . 88 Onze étamines ou plus. ......... 99

88 Deux étamines. G. Circcea L., p. 69.

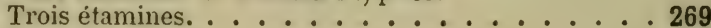

Quatre étamines. . . . . . . . . . 89

Cinq étamines. . . . . . . . . . . 91

Six étamines. G. Tamus L., p. 169.

Huit étamines. . . . . . 93

Neuf étamines. G. Hydrocharis L., p. 159.

Dix étamines. . . . . . 95

89 Arbrisseau à fleurs en petits bouquets au sommet des rameaux. G. Cornus L., p. 74.

Herbes aquatiques, à fleurs axillaires. . . . . 90 90

90 Feuilles flottantes triangulaires et dentées sur les bords. G. Trapa L., p. 69.

Feuilles ovales et entières. G. Isnardia L., p. 69.

91 Tige ligneuse. ................ 92

Tige herbacée ou à peu près. . . . .... 96 
92 Plante grimpante, à feuilles toujours vertes. G. Hedera L., p. 74.

Plante épineuse, à pétales roulées en dedans. G. Paliurus L., p. 42.

Plante non grimpante, buissonnante, à pétales dressés. G. Ribes L., p. 73.

93 Feuilles découpées en pièces nombreuses et très étroites. G. Myriophyllum L., p. 70.

Feuilles entières ou seulement dentées. . . . . . .

94 Graines à poils soyeux. G. Epilobium L., p. 68.

Graines nues, sans poils. G. Enothera L., p. 67.

95 Feuilles opposées le long de la tige. - • - · · · • • base. G. Saxifraga L., p. 73.

96 Fleurs assez grandes, jamais en ombelle ni en tête. • Fleurs petites, en ombelle ou en tête. . ......98

97 Plantes aquatiques; fruit sec. G. Jussicea L., p. 69.

Plantes terrestres; fruit charnu. ....... 107

\section{FAM. DES OMbellifères.}

98 Fruit sec; feuilles épineuses; fleurs en têtes serrées. G. Eryngium L., p. 74.

Fruit sec; feuilles non épineuses; fleurs n'étant jamais en têtes serrées. .................. $2^{\circ}$ Fruit charnu; plantes ligneuses. . . . . . . . 10

$1^{\circ}$ Arbrisseau grimpant. G. Hedera L., p. 74.

Arbrisseau non grimpant. G. Cornus L., p. 74.

20 Feuilles simples ou divisées en éventail, jaınais ailées ni découpées sur les côtés. . . . . . . 30

Feuilles composées, plusieurs fois ailées ou profondément découpées. ............ $5^{\circ}$

$3^{\circ}$ Feuilles découpées en éventail. G. Sanicula T., p. 74.

Feuilles entières, dentées ou crénelées. . . . . $4^{\circ}$

$4^{\circ}$ Fleurs jaunes; feuilles très entières, un peu épaisses et dures. G. Buplevrum L., p. 77.

Fleurs blanches, rougeàtres ou rosées; feuilles crénelées. G. Hydrocotyle T., p. 74.

$5^{\circ}$ Fruit velu, ou hérissé de pointes et de poils raides . . $50^{\circ}$

Fruit glabre, sans pointes ni poils....... $6^{\circ}$

$6^{\circ}$ Fleurs jaunes ou jaunâtres. . . . . . . . $7^{\circ}$

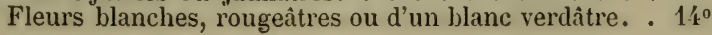


70 Folloles des feuilles ovales élargies, dentées ou incisées. $\quad 80$ Folioles des feuilles étroites et linéaires. . . . $13^{\circ}$

80 Feuilles supérieures opposées. ....... . . . . .

Feuilles supérieures alternes. . . . . . . 10 $10^{\circ}$

90 Ombelle sans collerette; fruit noir à la maturité. G. Smyrnium L., p. 82.

Ombelle munie d'une collerette à sa base; fruit jamais noir à la maturité. .......... 10 $10^{\circ}$

$10^{\circ}$ Fruit comprimé, entouré d'un bord simple ou de deux ailes saillantes. . . . . . . . . 110

Fruit dépourvu de rebord saillant. (S. G. Petroselinum.) G. Apium L., p. 75.

$11^{\circ}$ Fruit entouré de deux ailes un peu saillantes. G. Levisticum L., p. 79.

Fruit entouré d'un bord simple, peu saillant. . . . .

$12^{\circ}$ Point de collerette a l'ombelle; fleurs d'un beau jaune. G. Pastinaca L., p. 80.

Une collerette à l'ombelle; fleurs jaunâtres. G. Peucedanum L., p. 79.

$13^{\circ}$ Découpures des feuilles étroites, mais planes et non comme des cheveux. G. Peucedanum L., p. 79.

Découpures des feuilles très menues, fines et rondes comme des chereux. G. Anethum L., p. 78.

$14^{\circ}$ Dents du calice allongées, persistantes et dressées sur le fruit. G. Enanthe L., p. 77.

Dents du calice nulles ou courtes, et non dressées sur le fruit. ...................... $15^{0}$

$15^{\circ}$ Fruit au moins trois fois aussi long que large. . . . $48^{\circ}$

Fruit n'étant pas trois fois aussi long que large. . . . $16^{\circ}$

$16^{\circ}$ Fruit ayant huit ailes membraneuses et très saillantes. G. Laserpitium L., p. 81 .

Fruit n'étant pas ainsi.

$17^{\circ}$ Fruit sensiblement aplati et entouré d'un rebord ou d'ailes saillantes. .............. $18^{\circ}$

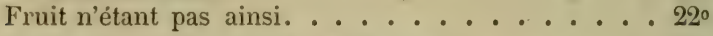

180 Fruit entouré d'un bord ou aile simple. . . . . 19\% Fruit entouré de deux ou plusieurs ailes distinctes. . $20^{\circ}$

19॰ Feuilles et tiges rudes, hérissées. G. Heracleum, p. 81. Feuilles et tiges lisses, glabres ou à peu près. G. Peucedanum L., p. 79.

$20^{\circ}$ Tige à angles aigus; feuilles à folioles étroites. G. Selinum L., p. 79 .

Tige sans angles aigus; feuilles à folioles élargies. . $21^{\circ}$ 
$21^{\circ}$ Feuilles toutes alternes; ombelles finement relues. G. Angelica L., p. 79.

Feuilles supérieures opposées; ombelles glabres. . . 90

$22^{\circ}$ Pétales entiers . . . . . . . . . . $23^{\circ}$

Pétales échancrés. . . . . . . . . $30^{\circ}$

$23^{\circ}$ Calice à cinq dents. . . . . . . . . $24^{\circ}$

Calice sans dents . . . . . . . . . . $25^{\circ}$

$24^{\circ}$ Plante aquatique; pétales ovales. (S. G. Helosciadum.) G. Sium L., p. 75.

Plante des lieux secs; pétales en ovale renversé. G. Seseli L., p. 78.

$25^{\circ}$ Collerettes supérieures nulles. . . . . . $26^{\circ}$

Collerettes supérieures à plus ou moins de pièces. . . $27^{\circ}$

$26^{\circ}$ Plante élevée; feuilles élargies; fleurs d'un blanc verdâtre. G. Apium L., p. 75.

Plante basse; feuilles étroites; fleurs blanches. G. Trinia Hoff., p. 75.

$27^{\circ}$ Feuilles charnues, cassantes. G. Girthmum L., p. 79.

Feuilles non charnues, souples. ...... $28^{\circ}$

$28^{\circ}$ Racine tuberculeuse; feuilles supérieures à divisions très menues. G. Conopodium K., p. 76.

Racine non tuberculeuse; feuilles à lobes non sétacés. $29^{\circ}$

$29^{\circ}$ Plante aquatique ou du bord des eaux. (S. G. Helosciadum.) G. Sium L., p. 75.

Plante venant dans les lieux secs. (S. G. Petroselinum.) G. Apium L., p. 75.

$30^{\circ}$ Calice à cinq dents distinctes. . . . . . $31^{\circ}$

Calice sans dents. . . . . . . . . $35^{\circ}$

$31^{\circ}$ Fruit globuleux ou arrondi. . . . . . . $32^{\circ}$

Fruit comprimé, ovale ou allongé. . . . . . $33^{\circ}$

$32^{\circ}$ Plante aquatique; feuilles à lobes dentés, lancéolés. G. Cicuta L., p. 74.

Plante des lieux secs; feuilles supérieures à lobes linéaires, très étroits. G. Coriandrum L., p. 83.

$33^{\circ}$ Ombelles pourvues de collerettes inférieures et supérieures. ..................... $3 \mathrm{i}^{0}$

Ombelles à peu près dépourvues de collerettes inférieures, mais munies de collerettes supérieures. G. Seseli L., p. 78.

$34^{\circ}$ Feuilles à nombreuses folioles linéaires et très étroites. G. Carum L., p. 76.

Feuilles à folioles ovales et élargies ou bien lancéolées. G. Sium L., p. 75. 
$35^{\circ}$ Fruit formé de deux carpelles globuleux et très distinets. (S. G. Bifora.) G. Coriandrum L., p. 83.

Fruit n'étant pas ainsi. . . . . . . . 36

$36^{\circ}$ Collerettes inférieures et supérieures nulles ou à une seule pièce. . . . . . . . . 370

Ombelles pourvues d'une collerette inférieure ou de collerettes supérieures. ...........

$37^{\circ}$ Toutes les feuilles à divisions linéaires étroites.

Feuilles ovales, élargies, au moins les radicales. $40^{\circ}$ $38^{\circ}$ $39^{\circ}$

$38^{\circ}$ Fruit ovoïle; collet de la racine garni de fibrilles grisâtres. G. Trinia Hoff., p. 75.

Fruit allongé; collet de la racine dépourvu de fibrilles. G. Carum L., p. 76.

$39^{\circ}$ Feuilles larges, une ou deux fois ailées et trifurquées. G. EEgopodium L., p. 76.

Feuilles simplement ailées. G. Pimpinella L., p. 77.

$40^{\circ}$ Ombelle sans collerette, mais ombellules munies de collerettes. .............. 410

Ombelle et ombellules ayant chacune une collerette. $42^{\circ}$

$41^{\circ}$ Pétales extérieurs plus grands; folioles des feuilles élargies; collerettes des ombellules pendantes et rabattues. G. Ethusa L., p. 78.

Pétales égaux entre eux; folioles linéaires très étroites; collerettes des ombellules droites ou étalées. G. Conopodium K., p. 76.

$42^{\circ}$ Pièces de la collerette de l'ombelle principale découpées en lobes allongés et fins. G. Ammi L., p. 76.

Pièces de la collerette de l'ombelle principale entières ou a lobes courts et non fins comme les chereux. .

$43^{\circ}$ Fruit doublement globuleux et à côtes crénelées. G. Conium L., p. 82.

Fruit à côtes non crénelées. . . . . . . . 440

$44^{\circ} \mathrm{Ombelle}$ à trois ou quatre rayons ....... . . $45^{\circ}$

Ombelle à plus de cinq rayons. . . . . . . $46^{\circ}$

$45^{\circ}$ Fenilles infériemres à neuf folioles tout au plus. G. Sison L., p. 76.

Fenilles infuirienres a plus de dix folioles. (S. G. Petroselinum Hoffm., p. 75.)

$46^{\circ}$ Fleurs verdatres on jaunâtres. (S. G. Silaus.) G. Peucedanum L., p. 79.

Fleurs blanches. 
$47^{\circ}$ Feuilles à divisions nombreuses, linéaires et étroites. G. Garum L., p. 76.

Feuilles à divisions lancéolées, élargies ou ovales. G. Sium L., p. 75.

$48^{\circ}$ Fruit à còtes aiguës, séparées par des sillons profonds. G. Myrrhis Scop., p. 82.

Fruit à côtes et sillons peu prononcés ou nuls. . . .

$49^{\circ}$ Fruit lisse ou strié, terminé en pointe ou bec plus ou moins long. G. Scandix L., p. 81.

Fruit strié, atténué au sommet, mais sans pointe ni bec. G. Ghorophyllum L., p. 82.

$50^{\circ}$ Pièces de la collerette de l'ombelle principale découpées

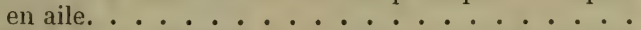

Pièces de la collerette de l'ombelle principale simples

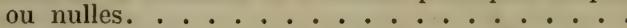

$51^{\circ}$ Fruit légèrement velu vers la base et en outre très allongé. G. Scandix L., p. 81.

Fruit court, hérissé de poils ou de pointes raides. G. Daucus L., p. 81 .

$52^{\circ}$ Fruit terminé par une pointe trois ou quatre fois plus longue que lui. G. Scandix L., p. 81 .

Pointe terminale nulle ou plus courte que le fruit. . $53^{\circ}$

$53^{\circ}$ Fruit à huit ailes membraneuses très saillantes. G. Laserpitium L., p. 81.

Fruit n'étant pas ainsi. . . . . . . . $54^{\circ}$

$5 \mathbf{t}^{0}$ Fruit aplati et à rebord élargi . . . . . . . . $55^{\circ}$

Fruit non comprimé ni entouré d'un rebord. . . . 56 $56^{\circ}$

$55^{\circ}$ Fruit très velu, à rebord épaissi en bourrelet. G. Tordylium L., p. 81.

Fruit i peine velu, muni d'un rebord aminci. G. Heracl:s:m L., p. 81 .

$56^{\circ}$ Fı uit hérissé, mais atténué en bec glabre au sommet. (S. G. Anthriscus.) G. Scandix L., p. 81.

Fruit non atténué en bec glabre, tout couvert de poils ou pointes................ 570

$57^{\circ}$ Fruit hérissé de pointes ou poils raides. G. Caucalis L., p. 82.

Fruit seulement velu, ou à poils courts et mous. G. Seseli L., p. 78.

99 Calice à deux divisions ou feuillets accolés dans le bouton. G. Portulaca T., p. 38.

Calice à plus de deux divisions. 
100 Fleurs naissant sur des tiges charnues et aplaties. G. Cactus L., p. 71.

Fleurs ne naissant pas ainsi. . . . . . . . 101

101 Feuilles opposées ou verticillées sur la tige. . . . . 102

Feuilles alternes, ou n'étant pas poussées quand la plante fleurit. . . . . . . . . . 103

102 Arbres ou arbrisseaux à grosses fleurs rouges. G. Punica T., p. 67.

Arbre ou arbrisseau à feuilles luisantes, à fleurs blanches. G. Myrtus T., p. 67.

Herbes. G. Lythrum L., p. 70.

FAM. DES ROSAGÉEs.

103 Un seul ovaire. . . . . . . . . . 10

Deux ou plusieurs ovaires. . . . . . . . $15^{\circ}$

10 Tige herbacée. . . . . . . . . . . $44^{\circ}$

20 Une à quatre étamines. . . . . . . . $3^{\circ}$

Douze étamines au moins. . . . . . . . . . . . $15^{\circ}$

$3^{\circ}$ Feuilles composées, ailées; fleurs en tètes serrées. . . $15^{\circ}$

Feuilles simples, à lobes en éventail; fleurs axillaires ou en corymbe. G. Alchemilla T., p. 6ł.

$4^{\circ}$ Ovaire libre, caché dans le calice et i un style. . . $13^{\circ}$

Ovaire adhérent, visible sous le calice et ordinairement à plusieurs styles. . . . . . . . . $5^{\circ}$

$5^{\circ}$ Calice à cinq divisions ou lanières. . . . . . . . C $C^{0}$

Calice seulement à cinq petites dents; fenilles très enticres, non dentées (S. G. Cotoneaster.) G. Cra!agus T., p. 66.

$6^{\circ}$ Feuilles ailées. ............. $7^{\circ}$

Feuilles simples, entières ou seulement incisées. . . . 80

$7^{\circ}$ Arbrisseau à tiges chargées d'aiguillons ou de piquants. G. Rosa L., p. 65.

Arbres ou arbustes sans aiguillons. (S. G. Sorbus.) G. Pyrus L., p. 65.

$8^{\circ}$ Divisions du calice dentées, allongées et foliacées. . . 9०

Divisions du calice courtes et non foliacées. . . . . 10 $10^{\circ}$

9० Divisions du calice dentées; feuilles ovales. G. Cydonia T., p. 66.

Divisions du calice entiẻres; feuilles lancéolées. (S. G. Mespilus.) G. Cratcegus T., p. 66. 
$10^{3}$ Pétales lancéolés, très allongés; très petit arbuste à feuilles simples. (S. G. Amelanchier.) G. Cratoegus T., p. 66.

Pétales plus ou moins arrondis; arbres ou arbrisseaux très ramifiés. . . . . . . . 110

$11^{\circ}$ Queues des fleurs ramifiées en corymbe. . . . . 120 Queues des fleurs simples, solitaires, ou en bouquet non rameux. G. Pyrus L., p. 65.

$12^{\circ}$ Arbrisseau épineux. G. Cratcegus T., p. 66.

Arbre ou arbrisseau non épineux. (S. G. Sorbus.) G. Pyrus L., p. 65.

$13^{\circ}$ Feuilles poussant avant ou avec les feuilles. G. Prunus T., p. 60.

Fleurs poussant après les feuilles. . . . . . $14^{\circ}$

$14^{\circ}$ Feuilles simples, dentelées. G. Prunus T., p. 60.

Feuilles ailées. G. Rosa L., p. 65.

$15^{\circ}$ Fleurs unisexuées. G. Sanguisorba L., p. 64 .

Fleurs munies tout à la fois d'étamines et de carpelles. $16^{\delta}$

$16^{\circ}$ Fleurs en têtes serrées; quatre étamines. G. Sanguisorba L., p. 64.

Fleurs non en têtes serrées; au moins douze étamines. $17^{\circ}$

$17^{\circ}$ Fleurs en épis grêles; un ou deux carpelles distincts. G. Agrimonia L., p. 64 .

Fleurs jamais en épis grêles; plus de deux carpelles. $18^{\circ}$

$18^{\circ}$ Calice à cinq divisions; tige souvent ligneuse. . . . $19^{\circ}$

Calice à huit ou dix divisions; tige herbacée. . . . $21^{\circ}$

$19 \circ$ Tige garnie d'aiguillons; fruit charnu. . . . . $20^{\circ}$

Tige sans aiguillons; fruit sec. G. Spircea L., p. 62.

$20^{\circ}$ Calice ouvert; carpelles et fruits visibles, et non renfermés. G. Rubus L., p. 62.

Calice resserré au sommet, et renfermant les carpelles. G. Rosa L., p. 65.

$21^{\circ}$ Graines ou ovaires surmontés chacun d'une longue barbe. G. Geum L., p. 62.

Graines ou ovaires sans barbè. ....... 220

$22^{\circ}$ Fruit charnu, succulent; fleurs toujours blanches. G. Fragaria L., p. 64 .

Fruit sec, ou fruit charnu avec des fleurs rouges. G. Potentilla L., p. 63. 


\section{GAMOPÉTALES.}

104 Ovaire libre, placé dans la corolle ou au fond du calice. 121 Ovaire adhérent au calice et placé sous la corolle, de telle sorte qu'il forme un renflement visible au dessous de la fleur. ............... 105

105 Feuilles verticillées, au moins les inférieures. . . . 116 Feuilles alternes ou opposées deux à deux. . . . . 106

106 Plantes munies de vrilles, ou fleurs à un seul sexe. • 107 Plantes sans vrilles. .......... 108

Fay. des Cugurbitacées.

107 Plantes munies de vrilles. . . . . . . . 10 Plantes sans villes. G. Ecballium Rich., p. 109.

$1^{\circ}$ Calice à cinq lanières; fruit toujours très gros. G. Cucumis L., p. 109.

Calice à cinq divisions très courtes ; fruit petit, globuleux. G. Bryonia L., p. 108.

108 Cinq étamines ou plus.

Moins de cinc étamines; une à quatre. . . . . 117

109 Plus de cinq étamines. . . . . . . . . . 110 Cinq étamines seulement. . . . . . . . . . 111

110 Feuilles simples. G. Vaccinium L., p. 111. Feuilles ailées. G. Sanguisorba L., p. 6\%.

111 Anthères adhérentes entre elles. . . . . . . 114 Anthères distinctes et libres. . . . . . . . 112

112 IIerbes à feuilles alternes. . . . . . . . . 113 Herbes i feuilles opposées. . . . . . . . 117 Arbrisseaux à feuilles opposées. . . . . . . . 116

113 Etamines portées sur la corolle; petites fleurs blanches. G. Samolus L., p. 113.

Etamines insérées au fond de la fleur, qui est en général blene ou rouge. . . . . . . . . . 115

114 Fleurs en tète, sans queue sur le réceptacle; étamines portées sur la corolle. . . . . . . . 118 Fleurs non en tète, ou pédiculées quand elles le sont; étamines non portées sur la corolle. . . . . . 115

Fay. des Canpanulacées.

115 Anthères adhérentes entre elles. . . . . . . . 10 Anthères libres. . . . . . . . . . $2^{\circ}$ 
10 Fleurs isolées, en grappe. G. Lobelia L., p. 110.

Fleurs réunies en tête serrée. G. Jasione L., p. 109.

20 Feuilles alternes. . . . . . . . . 3 $3^{\circ}$

Feuilles opposées. . . . . . . . . . . 116

$3^{0}$ Fleurs en tête ou en épi serré. G. Phyteuma L., p. 109.

Fleurs solitaires ou en grappe lâche. G. Campanula L., p. 109.

\section{FAM. Des Rubiacées.}

116 Arbrisseaux ou herbes à feuilles composées. . . . 10 Herbes à feuilles simples . . ....... $3^{\circ}$

$1^{\circ}$ Feuilles composées ou découpées. G. Sambucus T., p. 86.

Feuilles entières ou dentées. . . . . . . .

20 Fleurs blanches; style à trois divisions. G. Viburnum L., p. 86.

Fleurs rougeâtres ou jaunâtres; style simple. G. Lonicera L., p. 87.

$3^{\circ}$ Corolle en étoile ou en cloche. . . . . . . $4^{0}$

Corolle en entonnoir. . . . . . . . $5^{0}$

$4^{\circ}$ Corolle en cloche; souvent cinq étamines; fruit charnu. G. Rubia L., p. 83.

Corolle en étoile; quatre étamines; fruit sec. G. Galium L., p. 84 .

$5^{\circ}$ Calice à deux divisions profondes et opposées; fleurs en épi carré. G. Crucianella L., p. 86.

Calice à quatre ou cinq dents; fleurs en bouquets. . . $6^{\circ}$

60 Fruit couronné par les cinq dents du calice qui s'accroissent. G. Sherardia L., p. 86.

Fruit couronné par cinq dents presque nulles. G. Asperula L., p. 85.

FAMr. DES DipsacÉEs.

117 Quatre étamines. .................... 10 Une à trois étamines. ................. $3^{0}$

10 Fleurs en têtes serrées, avec une enveloppe commune. $2^{\circ}$ Fleurs non ainsi disposées.......... 103

20 Fleurs entremêlées de pièces épineuses. G. Dipsacus L., p. 87.

Fleurs entremêlées de poils durs qui peuvent manquer G. Scabiosa L., p. 87. 
$3^{\circ}$ Corolle distincte, en entonnoir. G. Valeriana L., p. 88. Corolle nulle ou écailleuse; fleur très ouverte. G. Alchemilla T. (RosacÉEs), p. 64.

118 Arbre à fruit mou et charnu. G. Ficus T., p. 152.

Plante herbacée ou à fruit sec.

119 Graine renfermée dans un fruit coriace, hérissé de pointes crochues. G. Xanthium T., p. 108.

Graine n'ayant pas ces caractères. . . . . . 120

\section{FAy. DES CoMrposéEs.}

120 Tètes composées de petites fleurs de deux sortes; celles du centre a corolles tubuleuses, colles du pourtour à corolles allongées en languettes planes et rayonnantes. . . . . . . . . . .

Têtes composées de petites fleurs uniformes, soit toutes a corolle tubuleuse, soit toutes à corolle en languette. ..................... 210

$1^{\circ}$ Oraire ou fruit couronné par une aigrette de poils. . $2^{\circ}$ Ovaire 'ou fruit nu, ou couronné par une membrane, mais non par des poils en aigrette. . . . . . 110

20 Feuilles opposées sur la tige. ........ $3^{\circ}$ Feuilles alternes ou toutes radicales. . . . . . $5^{\circ}$

$3^{0}$ Fleurs jaunes. . . . . . . . . . . $4^{0}$ Fleurs rougentres. G. Eupatorium L., p. 89.

$4^{\circ}$ Fenilles dentées, ou divisées. G. Bidens L., p. 92. Feuilles entières. G. Doronicum T., p. 97.

כo Languettes ou rayons de même couleur que les fleurs du milieu. . . . . . . . . . . . .

Languettes ou rayons d'une autre couleur que les fleurs du milieu..............

$6^{\circ}$ Rayons grêles, linéaires, toujours très étroits. G. Erigeron L., p. 90.

Rayons allongés et un peu élargis. G. Aster L., p. 89.

$7^{\circ}$ Ecailles des têtes disposées sur une ou deux rangées. . Ecailles des têtes imbriquées. . . . . . 10 $10^{\circ}$

80 Fenilles toutes radicales. G. Tussilago L., p. 89.

Tige garnie de feuilles et de fleurs. . . . . . 90

$9^{\circ}$ Ecailles des têtes sur une rangée ou sur deux, l'externe étant plus petite. G. Senecio L., p. 97.

Ecailles des tètes sur deux rangées égales. G. Doronicum T., p. 97. 
$10^{\circ}$ Tètes ayant de cinq à huit rayons seulement. G. Solidago L., p. 90.

Tètes ayant dix rayons ou même beaucoup plus. G. Inula L.,p. 91.

$11^{\circ}$ Feuilles découpées, à divisions nombreuses et très profondes..................... $12^{\circ}$

Feuilles entières ou seulement dentées. . . . . . $14^{\circ}$

$12^{\circ}$ Tètes petites, très nombreuses et en bouquet serré. G. Achillea L., p. 93.

Têtes solitaires ou ne formant pas un bouquet serré ni fourni. . . . . . . . . . . .

$13^{\circ}$ Réceptacle garni de paillettes entremêlées aux fleurs. G. Anthemis L., p. 92.

Réceptacle nu et sans paillettes. G. Ghrysanthemum L., p. 93.

14.0 Tige florale nue et à une seule tête. G. Bellis L., p. 91.

Tige florale feuillée et à plusieurs tètes. . . . 15 $15^{\circ}$

$15^{\circ}$ Fruits du milieu de la tète étant pourvus d'aigrettes. G. Doronicum T., p. 97.

Tous les fruits dépourvus d'aigrettes........ I60

$16^{\circ}$ Fruits courbés, plissés et irréguliers. G. Calendula L., p. 98.

Fruits droits et réguliers. . . . . . . 170

170 Feuilles toutes opposées. G. Bidens L., p. 92.

Feuilles alternes. . . . . . $18^{\circ}$

$18^{\circ}$ Réceptacle nu et sans paillettes. G. Chrysanthemum L., p. 93.

Réceptacle garni de paillettes entremêlées aux fleurs. $19^{\circ}$

$19^{\circ}$ Fleurs blanches. G. Achillea L., p. 93.

Fleurs jaunes.

$20^{\circ}$ Têtes très lar'ges; fruits surmontés par des arêtes caduques. G. Helianthus L., p. 92.

Tètes médiocres; fruits surmontés d'une membrane. G. Buphthalmum L., p. 91 .

210 Tètes à fleurs toutes tubuleuses. . . . . . 220

Têtes à fleurs toutes en languettes. ............ $49^{\circ}$

$22^{\circ}$ Oraires ou fruits couronnés par une aigrette de poils. $23^{\circ}$ Ovaires ou fruits nus, ou courohnés par une membrane, des paillettes, des dents ou des arêtes. . . . . 39०

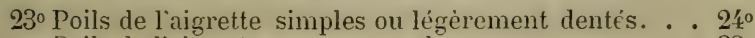
Poils de l'aigrette rameux on pluneux. . . . . 380 
$2 \ddagger^{\circ}$ Réceptacle garni d'écailles ou de paillettes, ou feuilles et têtes épineuses. . . . . . . . .

Réceptacle sans écailles ni paillettes; feuilles et tètes non épineuses. . . . . . . . . .

$25^{\circ}$ Paillettes du réceptacle allongées et visibles lorsqu'on écarte les fleurs. . . . . . . . . $26^{\circ}$

Paillettes du réceptacle tronquées et formant de petites alvéoles. G. Carduus L., p. 101.

$26^{\circ}$ Fleurs du pourtour femelles ou stériles, plus grandes que les autres............. 270

Fleurs toutes hermaphrodites et égales. . . . . . 280

$27^{\circ}$ Ecailles de la tète découpées en forme de feuilles. G. Carthamus L., p. 100.

Ecailles de la tète jamais en forme de feuilles. G. Gentaurea L., p. 99.

$28^{\circ}$ Ecailles de la tète recourbées en hameçon au sommet. G. Lappa T., p. 101.

Ecailles de la tète non recourbées en hameçon. . . $29^{\circ}$

$29^{\circ}$ Fleurs bleues. G. Carthamus L., p. 100.

Fleurs purpurines ou blanches. ...... 30 30

$30^{\circ}$ Ecailles de la tète et feuilles très épineuses. G. Carduus L., p. 101.

Ecailles de la tète et feuilles non épineuses. G. Serratula L., p. 102.

310 Fleurs jaunes. . . . . . . . . . 320

Fleurs rougeàtres ou blanchâtres. . . . . . . 35

$32^{\circ}$ Ecailles de la tète, herbacées et non membraneuses. . $33^{\circ}$

Ecailles de la tète membraneuses et colorées. G. Gnaphalium L., p. 96.

$33^{\circ}$ Fenilles très étroites, linéaires et entières. G. Linosyris Lob., p. 90.

Feuilles jamais linéaires ni étroites. . . . . 310

3\% Fleurs externes des tètes, grêles; corolle à trois dents.

G. Inula L., p. 91 .

Fleurs toutes égales; corolle à cinq dents. . . . . $9^{\circ}$

$35^{\circ}$ Feuilles opposées. G. Eupatorium L., p. 89.

Feuilles alternes. . . . . . . . 36

$36^{\circ}$ Tètes portées sur une tige garnie d'écailles colorées.

G. "Tussilago L:', p. 89.

Têtes portées sur une tige feuillée. . . . . . 370

$37^{\circ}$ Ecailles externes des tètes plus longues et imitant des rayons colorés. G. Xeranthemum T., p. 98.

Ecailles des têtes à peu près égales et non rayonnantes.

G. Gnaphalium L., p. 96. 
$38^{\circ}$ Ecailles internes des têtes, grandes, sèches et rayonnantes. G. Carlina L., p. 99.

Ecailles des tètes ni étalées ni rayonnantes. G. Carduus L., p. 101.

$39^{\circ}$ Têtes épineuses.

Têtes non épineuses.

$40^{\circ}$ Têtes globuleuses; fleurs munies chacune d'une enveloppe. G. Echinops L., p. 98.

Fleurs des têtes sans enveloppe particulière. . . . 270

$41^{\circ}$ Têtes petites, sans queue à l'aisselle des feuilles, à duvet épais. G. Micropus L., p. 91.

Têtes terminales, sans duvet. . . . . . . 420

$42^{\circ}$ Feuilles opposées. G. Bidens L., p. 92.

Feuilles alternes. . . . . . . . .

$43^{\circ}$ Fleurs bleues, pédiculées sur le réceptacle. G. Jasione L., p. 109.

Fleurs très rarement bleues, sans queue sur le réceptacle. . . . . . . . . . .

$44^{\circ}$ Ecailles internes des têtes, colorées et rayomnantes. G. Xeranthemum T., p. 98.

Ecailles internes des têtes ni colorées ni rayomnantes. $45^{\circ}$

$45^{\circ}$ Réceptacle nu ou garni de poils très courts. . . . . $48^{\circ}$

Réceptacle garni d'écailles ou de paillettes. . . . . $46^{\circ}$

$46^{\circ}$ Plante très odorante; feuilles très petites, sur quatre rangs. G. Santolina T., p. 93.

Plante peu ou point odorante; feuilles plus ou moins larges. ................ $47^{\circ}$

$47^{\circ}$ Fleurs à corolle éperonnée; plante très blanche. G. Diotis Desf., p. 93.

Fleurs à corolle sans éperon. . . . . . . . 270

$48^{\circ}$ Tètes d'un beau jaune, en bouquet plane et fourni. G. Tanacetum L., p. 95.

Têtes en grappes ou en épis. G. Artemisia L., P. 95.

$49^{\circ}$ Feuilles et écailles des têtes épineuses. G. Scolymus L., p. 102.

Feuilles et écailles des têtes non épineuses ou à poils rudes................50

$50^{\circ}$ Ovaires ou fruits couronnés par une aigrette de poils. 53० Ovaires ou fruits sans aigrettes, ou couronnés par une membrane ou par des paillettes. ...... $51^{\circ}$

$51^{\circ}$ Fleurs jaunes. G. Lapsana L., p. 102.

Fleurs bleues. 
$52^{\circ}$ Ecailles des tètes herbacées et très vertes. G. Cichovium L., p. 103.

Ecailles des têtes argentées et sèches. G. Catananche L., p. 103.

$53^{\circ}$ Poils de l'aigrette simples ou finement dentés. . . . 54 $4^{\circ}$

Poils de l'aigrette rameux ou plumeux. . . . . $62^{\circ}$

5ં́ Fruits grêles au sommet; aigrettes pédiculées, du moins en apparence. . . . . . . . . 59 $59^{\circ}$

Fruits à aigrettes non pédiculées. . . . . . . 5 5

$5 \jmath^{\circ}$ Tètes munies à la base d'écailles accessoires en forme de calice. G. Crepis L., p. 106.

Tètes à écailles imbriquées, sans apparence de calice. $56^{\circ}$

$56^{\circ}$ Réceptacle garni de poils. . . . . . . . 570

Réceptacle tout à fait nu. . . . . . . 5 $58^{\circ}$

$57^{\circ}$ Poils du réceptacle rares, plus courts que l'ovaire ou le fruit. G. Hieracium L., p. 107.

Poils du réceptacle nombreux, plus longs que l'ovaire ou le fruit. G. Andryala L., p. 108.

$58^{\circ}$ Têtes ovoïdes ou renflées à la base; aigrettes molles et blanches. G. Sonchus L., p. 106.

Tètes ni ovoïdes ni renflées; aigrettes raides, sourent rousses. G. Hieracium L., p. 107.

$59^{\circ}$ Une seule tète sur une tige creuse et nue. G. Taraxacum Juss., p. 105.

Plusicurs tètes sur une tige feuillée. . . . . . $60^{\circ}$

$60^{\circ}$ Ecailles des tètes imbriquées; fruit aplati. G. Lactuca L., p. 105.

Ecailles au nombre de sept ou huit; fruit cylindrique ou à peine compriñé. . . . . . . . 610

610 Fruit couronné de pointes écailleuses sous l'aigrette. G. Ghondrilla L., p. 105.

Fruit sans pointes écailleuses, ni couronné sous l'aigrette. G. Crepis L., p. 106.

$62^{\circ}$ Ovaire ou fruit rétréci en pédicule au sommet. . . $63^{\circ}$ Ovaire ou fruit sans pédicule au sommet. . . . . $66^{\circ}$

$63^{\circ}$ Tète entourée de cinq feuilles. G. Picris L., p. 104.

Tête sans écailles foliacées. . . . . . 64 $\mathbf{4}^{\circ}$

$64^{\circ}$ Réceptacle garni de paillettes caduques. G. Hypochoris L., p. 103.

Réceptacle nu................. 65 
$65^{\circ}$ Tète à huit'ou dix écailles, sur une seule rangée. G. Tragopogon L., p. 104.

Tête à écailles imbriquées. G. Scorzonera L., p. 104.

$66^{\circ}$ Réceptacle nu.

Réceptacle tuberculeux, muni de paillettes ou d'alvéoles

$67 \circ$ Plante garnie de poils rudes. G. Picris L., p. 104.

Plantes sans poils rudes. G. Scorzonera L., p. 104.

$68^{\circ}$ Fruit porté sur un pédicule creux et renflé. G. Scorzonera L., p. 104.

Fruit sans pédicule sur le réceptacle. . . . . 690

$69^{\circ}$ Réceptacle muni de paillettes caduques. G. Hypochoris L., p. 103.

Réceptacle marqué d'alvéoles. G. Leontodon L., p. 103.

121 Une à cinq étamines. . . . . . . . . . 122 Six étamines ou plus. . . . . . . . . . 139

122 Corolle régulière ou à divisions sensiblement égales. 131 Corolle irrégulière ou à divisions inégales, ou munie

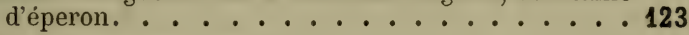

123 Une à quatre étamines. . . . . . . . . . 124

Cinq étamines ou plus. . . . . . . . . . 128

124 Un seul ovaire. . . . . . . . . . 125 Oraire divisé en deux ou quatre parties distinctes. . 171

125 Deux étamines munies d'anthères. . . . . . . 126 Trois étamines. G. Montia L., p. 38.

Quatre étamines munies d'anthères. . . . . . 127

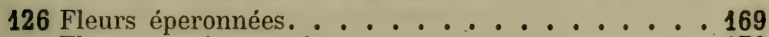

Fleurs non éperonnées. . . . . . . 170

127 Fleurs en tête terminale. G. Globularia DC., p. 138.

Fleurs non en tête terminale. ........ 170

128 Ovaire divisé en deux ou quatre parties, du milieu desquelles sort le style. G. Echium L., p. 118.

Ovaire simple............ 129

129 Etamines soudées toutes ou plusieurs ensemble. . . 143

Etamines libres. .............. 130

130 Corolle éperonnée. G. Linaria T., p. 127.

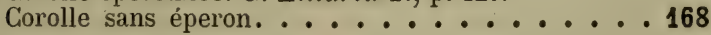

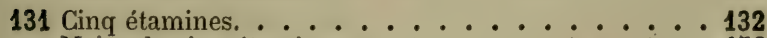

Moins de cinq étamines. ................. 150 
132 Feuilles opposées ou verticillées sur la tige; étamines placées devant les lobes de la corolle. . . . . . Feuilles opposées ou verticillées sur la tige; étamines placées devant les échancrures de la corolle. . . . 164 Feuilles nulles ou toutes radicales, ou alternes le long

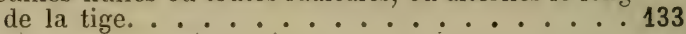

133 Un seul ovaire simple. . . . . . . . . 135 Plusieurs ovaires, ou un seul partagé en quatre. . . 134

134 Feuilles lisses et charnues. . . . . . . . . 12 Feuilles àpres et hérissées. . . . . . . . . . 167

135 Tige grimpante, ou fruit mou et charnu. . . . . 136 Tige non grimpante; fruit sec. . . . . . . . 138

136 Plante filamenteuse et parasite, sans feuilles, enroulée. G. Cuscuta L., p. 118.

Plante munie de feuilles. . . . . . . . . 137

137 Plantes aquatiques ou plantes terrestres à fleurs bleues. 166 Plantes terrestres à fleurs jamais bleues..... 168

138 Etamines placées derant les dents de la corolle. • . 169 Etamines placées devant les échancrures de la corolle. 136

139 Un seul ovaire. . . . . . . . . . . . 141 Plusieurs ovaires. . . . . . . . . . . 140

$140 \mathrm{Six}$ étamines. . . . . . . . . . . 256

Plus de six étamines. . . . . . . . . 6

141 Corolle régulière. . . . . . . . . . . 144 Corolle irrégulière. . . . . . . . . . 142

142 Feuilles simples ou a trois folioles. . . . . . . 143 Feuilles très découpées. . . . . . . . . 85

143 Feuilles simples. G. Polygala L., p. 38. Feuilles à trois folioles. G. Trifolium L., p. 48.

144 Tige ligneuse, ou tige herbacée sans feuilles vertes. . 145 Tige herbacée, portant des feuilles vertes. . . . . 146

Fam. des Ericacées.

145 Plante herbacée, charnue, à écailles jaunâtres. G. Monotropa L., p. 112.

Plante ligneuse.

$1^{\circ}$ Huit étamines; fruit sec. G. Erica L., p. 111. Dix étamines; fruit charnu. ......... . 20

$2^{\circ}$ Arbrisseau assez cilevé. G. Arbutus L., p. 111. Petite plante basse. G. Vaccinium L., p. 111. 
146 Feuilles alternes ou toutes radicales. . . . . . 147

Feuilles opposées sur la tige ou verticillées. . . . . 148

147 Calice double. . . . . . . . . . 24

Calice simple. . . . . . . . . . 25

148 Q:1atre styles; feuilles rerticillées; fruit charnu. G. Paris L., p. 166.

Un ou deux styles; fruit sec. . . . . . . . 149

149 Etamines en nombre indéterminé et soudées par faisceaux. G. Hypericum L., p. 38.

Etamines en nombre fixe et libres. . . . . . 166

150 Deux ou trois étamines. . . . . . . . . 151

Quatre étamines............................. 155

151 Un seul ovaire simple. .......... 152

Deux ou quatre ovaires. G. Lycopus L., p. 132.

152 Un style. . . . . . . . . . . . 153

Trois styles. G. Montia L., p. 38.

153 Herbes à corolle en roue. G. Veronica L., p. 124.

Arbrisseaux à corolle en tube ou en entonnoir. . . 154

FAM. DES JASMinÉES.

154 Feuilles allongées; fruit charnu. . . . . . . $2^{\circ}$ Feuilles composées, ou en cœur; fruit sec. . . . $1^{\circ}$

$1^{\circ}$ Fleurs en entonnoir, lilas ou blanches. G. Syringa L., p. 115.

Fleurs sans couleur, ou blanches avec corolle divisée. G. Fraxinus L., p. 115.

$2^{\circ}$ Fleurs blanches, en grappe terminale. G. Ligustrum L., p. 115.

Fleurs verdâtres, en petits bouquets axillaires. G. Phillyrea L., p. 114.

155 Plante filamenteuse, parasite, sans feuilles. G. Cuscuta L., p. 118.

Plante munie de feuilles. . . . . . . . 156

156 Corolle sèche et membraneuse, jaunàtre. G. Plantago L., p. 138.

Corolle colorée, ni sèche ni membraneuse. . . . 157

157 Feuilles opposées le long de la tige. . . . . . 158

Feuilles alternes ou toutes radicales. . . . . 161

158 Un seul ovaire simple. .......... 159

Quatre ovaires au fond de la fleur. . . . . . 171 
159 Deux étamines plus courtes et deux longues. G. Verbena L., p. 138.

Etamines égales entre elles. . . . . . . 160

160 Corolle en roue; fruit rond, s'ouvrant en travers. G. Centunculus L., p. 114.

Corolle en tube ou en entonnoir; fruit s'ourrant en deux valves. ...................... 166

161 Fleurs bleuâtres, en tète serrée et terminale. G. Globularia L., p. 138.

Fleurs non réunies en tête. . . . . . . . . 162

162 Arbrisseau à feuilles épineuses. G. Ilex L., p. 43.

Herbes à feuilles non épineuses. . . . . . . . 163

163 Fruit arrondi, sourrant en travers. G. Centunculus L., p. 114.

Fruit ne s'ouvrant pas ainsi. . . . . . . 170

164 Ovaire à deux divisions, mais à style simple; fruit s'ouvrant d'un seul côté. ......... 165 Ovaire simple; fruit s'ourrant en deux valves. . . 166

FAM. DES APOCYNÉES.

165 Fleurs solitaires et bleues. G. Vinca L., p. 115.

Fleurs en grappes terminales......... $1^{0}$

10 Divisions de la corolle rabattues; style émoussé au sommet. G. Asclepias L., p. 116.

Divisions de la corolle étalées; style bifide au sommet.

C. Cynanchum L., p. 116.

Fam. des Gentianées.

166 Fenilles rondes ou à trois folioles; plantes aquatiques, à corolle ciliée. G. Menyanthes L., p. 117.

Plante n'offrant pas tous ces caractères. G. Gentiana L., p. 116.

FAM. DES BorraginéEs.

167 Gorge de la corolle garnie d'écailles qui somvent ferment le tube. . . . . . . . . $4^{\circ}$

Gorge de la corolle dépourvue d'écailles. . . . . . $1^{\circ}$

10 Corolle à divisions égales ou alternativement grandes et petites. . . . . . . . . 20 Corolle à divisions inégales, tronquée obliquement. G. Echium L., p. 118. 
$2^{\circ}$ Corolle à cinq divisions, entre chacune desquelles est une dent. G. Heliotropium L., p. 118.

Corolle à cinq divisions non entremèlées de petites dents. . . . . . . . . . . $3^{\circ}$

$3^{\circ}$ Calice à cinq divisions ne dépassant pas le milieu. G. Pulmonaria L., p. 119.

Calice à cinq divisions atteignant presque la base. G. Lithospermum L., p. 119.

$4^{\circ}$ Fleurs terminales, ou en grappe, munies chacune d'une queue.................... $6^{n}$

Fleurs axillaires, sans queue ou presque sans queue. $5^{\circ}$

$5^{\circ}$ Calice très développé après la floraison, comprimé en deux feuillets. G. Asperugo L., p. 120.

Calice non dilaté, à cinq divisions. G. Lithospermum L., p. 119.

$6^{\circ}$ Corolle en roue ou à entonnoir, à limbe étalé. . . : . 70

Corolle cylindrique, ventrue, à limbe droit. G. Symphytum L., p. 120.

$7^{\circ}$ Tube de la corolle coudé vers le milieu. G. Anchusa L., p. 120.

Tube de la corolle non coudé, ou nul. . . . . $8^{\circ}$

$8^{\circ}$ Gorolle en roue, c'est-à-dire sans tube distinct. . . . $9^{\circ}$

Corolle munie d'un tube plus ou moins long. . . . $10^{\circ}$

90 Plante hérissée de poils raides; fruits ridés. G. Borrago L., p. 120.

Plante sans poils raides; fruits lisses, à bords relevés. G. Cynoglossum L., p. 120.

$10^{\circ}$ Fruits hérissés d'aiguillons crochus. G. Cynoglossum L., p. 120.

Fruits dépourvus d'aiguillons. . . . . . . $11^{\circ}$

$11^{\circ}$ Plante robuste, a poils rudes. G. Anchusa L., p. 120.

Plante grêle, à poils mous. G. Myosolis L., p. 119.

\section{FAM. DES SOLANÉES.}

168 Corolle plane, à limbe ouvert et en roue. . . . . . $1^{\circ}$ Corolle en entonnoir, en cloche ou en tube. . . . . $3^{\circ}$

10 Fruit sec; corolle à divisions un peu inégales; anthires écartées. G. Verbascum L., p. 122.

Fruit charnu; corolle à lobes égaux; anthères rapprochées les unes des autres. . . . . . . . 20 
$2^{\circ}$ Fleurs solitaires; calice se renflant après la floraison. G. Physalis L., p. 123.

Fleurs en petits bouquets; calice non renflé. G. Solanum L., p. 123.

$3^{\circ}$ Corolle à divisions inégales et obliques ; fruit s'ourrant en travers. G. Hyoscyamus L., p. 122.

Corolle parfaitement régulière. . . . . . . . $4^{0}$

$4^{\circ}$ Corolle en forme de tube ou d'entonnoir allongé. . . $5^{n}$

Corolle en forme de cloche, non rétrécie en tube. . . $7^{\circ}$

$\tilde{5}^{0}$ Arbrisseau à étamines un peu velues à la base. G. $L y$ cium L., p. 123.

Herbes à étamines glabres. . . . . . . $6^{\circ}$

$6^{\circ}$ Corolle à cinq angles ou plis; fruit épineux. G. Dotura L., p. 123.

Corolle sans angles et sans plis; fruit lisse. G. Nicotiana T., p. 121.

$7^{\circ}$ Corolle en cloche ourerte et à cinq angles; fruit sec. G. Convolvulus L., p. 117.

Corolle en clochette, peu ouverte et sans angles; fruit charnu. G. Atropa L., p. 12'.

Fam. des Primulacées.

169 Corolle irrégulière.

Corolle régulière. . . . . . . . . . . $1^{\circ}$

10 Feuilles découpées en lobes linéaires; plante aquatique. G. Hottonia L., p. 112.

Feuilles entières, sinuées et dentées, mais non fendues. $2^{\circ}$

$2^{\circ}$ Tige florale nue; feuilles toutes radicales. . . . . $3^{\circ}$

Tige florale garnie de feuilles. . . . . . . . $5^{\circ}$

$3^{n}$ Divisions de la corolle rejetées en arrière. G. Cyyclamen T., p. 113.

Divisions de la corolle droites ou étalées. . . . . . $4^{\circ}$

$4^{0}$ Fleurs très serrées en tètes terminales ou en épis unilatéraux. G. Statice L., p. 139.

Fleurs souvent en bouquet, mais jamais en tètes serrées ni en épis. G. Primula L., p. 112.

$5^{\circ}$ Fleurs à quatre divisions; quatre étamines. G. Centunculus L., p. 114.

Fleurs ả cinq divisions; cinq étamines. . . . . $6^{\circ}$

$6^{\circ}$ Fleurs jaunes. G. Lysimachia L., p. 113.

Fleurs jamais jaunes. ........ $7^{\circ}$ 
$7^{\circ}$ Feuilles alternes; fleurs en grappe làche. G. Samolus L., p. 113.

Feuilles opposées; fleurs faxillaires. . . . . . $8^{\circ}$

$8^{\circ}$ Fruit s'ouvrant en travers; corolle n'étant pas trois fois plus courte que le calice. G. Anagallis L., p. 113.

Fruit à cing valres; corolle trois fois plus courte que le calice. G. Lysimachia L., p. 113.

$9^{\circ}$ Feuilles ovales et très simples; calice à cinq divisions. G. Pinguicula L., p. 114 .

Feuilles très découpées; calice à deux divisions. G. Utricularia L., p. 114.

\section{Fam. des Personées.}

170 Feuilles réduites à des écailles, jaunâtres comme toute la plante. G. Orobanche L., p. 130.

Plantes vertes et feuillées. . . . . . . . 10

$1^{\circ}$ Deux étamines par fleur, sans filets stériles. G. Veronica T., p. 124.

Quatre à cinq étamines fertiles, ou deux étamines fertiles accompagnées de deux filets stériles. . . . . $2^{\circ}$

20 Corolle à deux lèrres bien distinctes. . . . . . . $3^{\circ}$

Corolle en roue, en cloche, en tube ou à lèvre inférieure peu apparente...........

$3^{n}$ Base de la corolle prolongée en éperon. G. Linaria T., p. 127.

Base de la corolle dépourvue d'éperon. . . . . . .

$4^{\circ}$ Feuilles ailées, à folioles distinctes et séparées. G. Pedicularis T., p. 129.

Feuilles entières ou seulement fendues. . . . . $5^{\circ}$

$5^{\circ}$ Feuilles presque toutes alternes sur la tige. G. Antirrhinum L., p. 127.

Feuilles opposées sur la tige, au moins les inférieures. $6^{\circ}$

$6^{\circ}$ Calice à cinq divisions. G. Lindernia L., p. 126.

Calice à quatre dents ou à quatre divisions. . . . $7^{\circ}$

$7^{\circ}$ Calice large, enflé et ventru. G. Rhinanthus L., p. 129.

Calice non ventru, tubuleux et en cloche. . . . $8^{\circ}$

$8^{\circ}$ Lèvre supérieure de la corolle repliée en dehors par les bords; fruit à une ou deux graines; G. Melampyrum T., p. 129.

Lèvre supérieure de la corolle non repliée en dehors par les bords; fruità graines nombreuses. G. Euphrasia T., p. 128. 
$9^{\circ}$ Feuilles presque toutes altemes ou radicales. . . . $10^{\circ}$

Feuilles presque toutes opposées sur la tige. . . . . 130

$10^{\circ}$ Tige droite et garnie de feuilles. . . . . . . 110

Tige couchée et à feuilles radicales. . . . . . $12^{\circ}$

$11^{\circ}$ Corolle assez grande et non éperonnée. G. Digitalis L., p. 126.

Corolle petite, avec un petit éperon à la base. G. Antirrhinum L., p. 127.

12॰ Fleurs blanches. G. Limosella L., p. 126.

Fleurs jaunes ou rouges. G. Sibthorpia L., p. 126.

$13^{\circ}$ Corolle étant à peu près globuleuse. G. Scroplıularia L., p. 126.

Corolle tubuleuse. . . . . . . . . 14 $14^{\circ}$

$14^{\circ}$ Fleurs solitaires a l'aisselle des feuilles supérieures. $G$. Gratiola L., p. 126.

Fleurs en épis grêles ou en bouquets, au sommet des tiges. G. Verbena L., p. 138.

\section{FAM. DES LABIÉES.}

171 Quatre étamines munies de leurs anthères. . . . 20 Deux étamines seulement munies de leurs anthères. . 10

$1^{\circ}$ Corolle tubuleuse, à lobes presque égaux. G. Lycopus L., p. 132.

Corolle à deux lèrres bien prononcées; herbes. G. Salvia L., p. 133.

Corolle à deux lèrres bien prononcées; arbrisseau. G. Rosmarinus L., p. 133.

$2^{\circ}$ Corolle à lobes presque égaux, ou à lèrre supérieure nulle ou presque nulle. ......... $32^{\circ}$

Corolle à deux lèrres bien prononcées. . . . . . $3^{\circ}$

$3^{\circ}$ Calice muni en dehors d'une bosse ou écaille saillante. G. Scutellaria L., p. 136.

Calice sans bosse ni écaille saillante. . . . . . $4^{0}$

$4^{\circ}$ Calice à deux lèrres, l'une supérieure, l'autre inférieure. $5^{\circ}$ Galice non à deux lèvres. ........ $14^{\circ}$

$5^{\circ}$ Fleurs en verticilles, en têtes, ou en grappes, naissant à l'aisselle des feuilles. . . . . . . . . $6^{\circ}$ Fleurs en tètes ou en épis terminaux non feuillés. . . 11\%

$6^{n}$ Fleurs solitaires ou en petites grappes liches. . . $7^{\circ}$

Fleurs en verticilles serrés ou en têtes. . . . . $12^{\circ}$

$7^{\circ}$ Fleurs solitaires sur leur queue. . . . . . . . $8^{\circ}$ Fleurs réunies en grappes. . . . . . . . . 90 
$8^{\circ}$ Calice large et veiné; corolle très grande. G. Melittis DC., p. 134.

Calice strié ou relevé de côtes; corolle petite ou de dimensions médiocres. . . . . . . . 9 90

$9^{\circ}$ Feuilles à bords entiers ou un peu enroulés. . . . . $35^{\circ}$

Feuilles à bords crénelés et non repliés. . . . . . 10 $10^{\circ}$

$10^{\circ}$ Calice à cinq angles ou côtes; fleurs blanchâtres. G. Melissa L., p. 133.

Galice sillonné de côtes nombreuses; fleurs souvent rougeàtres. G. Calamintha Benth., p. 133.

$11^{\circ}$ Fleurs bleues, en épis grêles à longue queue. G. Lavandula T., p. 131.

Fleurs jamais tout à fait bleues, en tète ou en épis compacts. . . . . . . . . . .

$12^{\circ}$ Feuilles florales filiformes. (S. G. Clinopodium.) G. Galamintha Benth., p. 133.

Feuilles florales élargies. . . . . . . 130

$13^{\circ}$ Plante inodore. G. Brunella T., p. 137.

Plante aromatique. G. Thymus L., p. 132.

$14^{\circ}$ Calice sillonné de stries très rapprochées. . . . . $15^{\circ}$

Galice non strié, ou relevé de còtes écartées. . . . $21^{\circ}$

$15^{\circ}$ Toutes les fleurs placées à l'aisselle des feuilles. . . . $16^{\circ}$

Fleurs en grappes ou en épis non feuillés. . . . 190

$16^{\circ}$ Fleurs nombreuses, en verticilles fournis. . . . . 170

Une à trois fleurs à l'aisselle de chaque feuille. . . $18^{\circ}$

$17^{\circ}$ Calice à cinq dents; plante d'un vert sombre. G. Ballota L., p. 136.

Galice à dix dents; plante blanchâtre. G. Marrubium L., p. 136.

$18^{\circ}$ Feuilles linéaires ou lancéolées et entières. G. Satureia L., p. 133.

Feuilles ovales ariondies, dentées ou crénelées G. Nepeta Benth., p. 131.

$19^{\circ}$ Feuilles étroites et entières. . . . . . . . $20^{\circ}$

Feuilles ovales et dentées. . . . . . . $18^{\circ}$

$20^{\circ}$ Etamines saillantes; queue de l'épi feuillée. G. Hyssopus L., p. 133.

Etamines non saillantes; queue de l'épi nue. G. Lavandula T., p. 131.

$21^{\circ}$ Feuilles découpées en trois ou cinq divisions profondes et pointues ; ovaires poilus. G. Leonorus L., p. 136.

Feuilles non ainsi découpées; oraire sans poils. . . 
220 Tube de la corolle cylindrique, arqué, à peine évasé au sommet. G. Betonica L., p. 136.

Tube de la corolle plus ou moins dilaté et évasé au

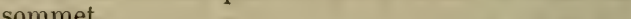

$23^{\circ}$ Corolle dépassant à peine le calice; verticilles tous axillaires. G. Leonorus L., p. 136.

Corolle beaucoup plus longue que le calice; fleurs en épis.

240 Fleurs jaunes. G. Lamium Benth., p. 13 t.

Fleurs jamais entièrement jaunes. . . . . . . $25^{\circ}$

$25^{\circ}$ Lèvre supérieure de la corolle n'offrant distinctement qu'un seul lobe échancré. G. Lamiım Benth., p. 134.

Lève inférieure de la corolle offrant trois lobes distincts, dont l'intermédiaire est quelquefois échancré.

$26^{\circ}$ Lèvre inférieure ayant à sa naissance deux dents ou deux renflements saillants; dents du calice sourent piquantes. G. Galeopsis L., p. 135.

Lère inférieure dépourvue de dents saillantes; lobes du calice peu ou point épineux. . . . . . . 270

$27^{\circ}$ Etamines rapprochées deux à deux ou déjetées sur les côtés. . . . . . . . . . . .

Etamines dressées é écartées en tous sens. . . . 30

$28^{\circ}$ Etamines déjetées sur les còtés de la corolle après la floraison; verticilles des fleurs souvent fournis et rapprochés en épi. G. Stachys L., p. 135.

Etamines jamais déjetées sur les còtés; une a trois fleurs à l'aisselle de chaque feuille. . . . . . $29^{\circ}$

$29^{\circ}$ Corolle très grande, à lèvre supérieure entière. G. Melittis DC., p. 134.

Corolle médiocre, à lèrre supérieure bifide. G. Nepeta Benth., p. 134.

$30^{\circ}$ Entrée du calice fermée par des poils après la floraison. $31^{\circ}$

Entrée du calice non fermée par des poils. . . . 32

$31^{\circ}$ Fleurs en verticilles axillaires. G. Mentha L., p. 131.

Fleurs en épis feuillés et nombreux, au sommet de la plante. G. Origanum T., p. 132.

$32^{\circ}$ Corolle à divisions presque égales et dirigées en tous sens. ............... $33^{\circ}$

Corolle offrant une lère inférieure bien prononcée. . $36^{\circ}$

$33^{\circ}$ Feuilles entières ou dentées. . . . . . . . . 34 $4^{\circ}$

Feuilies découpées; fleurs en épis très grêles. G. Verbena L., p. 138. 
$34^{\circ}$ Feuilles très entières; corolle à cinq divisions. . . . $35^{\circ}$

Feuilles plus ou moins dentées; corolle à quatre divisions. G. Mentha L., p. 131.

$35^{\circ}$ Fleurs en épis non feuillés. G. Lavandula T., p. 131. Fleurs toutes axillaires. G. Satureia L., p. 133.

$36^{\circ}$ Lèvre supérieure de la corolle remplacée par deux dents; lèvre inférieure à trois lobes. G. Ajuga Benth., p. 137.

Lèvre supérieure formée de deux divisions rejetées en bas, en sorte que la lèvre inférieure parait avoir cinq divisions. G. Teucrium L., p. 137.

\section{APÉTALES.}

172 Fleurs pourvues chacune d'une enveloppe florale, colo-

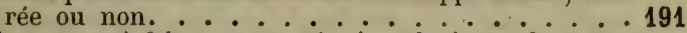
Fleurs tout à fait nues ou réunies plusieurs dans une enveloppe commune. .......... 173

173 Plantes submergées ou flottantes......... 174 Plantes non submergées ni flottantes. . . . . . 180

174 Très petites plantes flottantes, composées de disques, sans tige ni feuilles distinctes. G. Lemma L., p. 174.

Plantes pourrues de tiges distinctes et tenant à la terre par leurs racines.......... 175

175 Plantes munies de feuilles. . . . . . . . 176

Plantes sans feuilles, à rameaux articulés et verticillés. G. Chara L. (Voir le second volume.)

176 Fleurs réunies dans une gaine se terminant en feuille; plantes des eaux salées. G. Zostera L., p. 174.

Fleurs sans gaine ou gaîne ne se terminant pas en feuilles........................ 177

177 Toutes les fleurs axillaires. . . . . . . 178

Fleurs terminales ou groupées sur un long pied. . . 184

178 Deux à huit ovaires rayonnants pour chaque fleur; feuilles filiformes; plantes des eaux salées. G. Zannichellia L., p. 161.

Un seul ovaire simple ou à quatre divisions; feuilles non filiformes; plantes des eaux douces. . . . . 179

179 Fruit oroïde; feuilles ondulées, comme épineuses. G. Nä̈as L., p. 174.

Fruit se séparant en quatre parties; feuilles ni ondulées ni épineuses. G. Callitriche L., p. 150. 
180 Plante herbacée.

Plante ligneuse, arbre ou sous-arbrisseau. . . . . 187

181 Plante à suc laiteux; fleurs comme en ombelle. G. Euphorbia L., p. 147.

Plante sans suc laiteux; fleurs jamais en ombelle. • . 182

182 Tige grimpante. G. Humulus L., p. 151.

Tige non grimpante. . . . . . . . 183

183 Feuilles linéaires, très allongées. . . . . . . . 184

Feuilles non linéaires, plus ou moins élargies. . . . 186

184 Feuilles filiformes; plante des eaux saumâtres. G. Ruppia L., p. 160.

Feuilles plus larges; plante des eaux douces. . . . 185

185 Fleurs en tètes globuleuses. G. Sparganium L., p. 173. Fleurs en chatons allongés et cylindriques, assez gros. G. Typha L:, p. 17'.

186 Fleur's renfermées dans une gaîne en cornet ourert; feuilles lisses. G. Arum L., p. 173.

Fleurs non renfermées dans une gaîne; feuilles rudes. G. Xanthium T., p. 108.

187 Feuilles composées de plusieurs folioles; rameaux opposés. G. Fraximus L., p. 115.

Feuilles entières, ou découpées, mais non composées. 188

188 Filets des étamines distincts; feuilles souvent dentées et élargies; fleurs naissant souvent avant les feuilles. . 189

Filets des étamines muls ou paraissant soudés ensemble; feuilles jamais dentées, souvent persistantes, linéaires et étroites; fleurs ne précédant jamais les feuilles. . 190

\section{FAM. DES AMENTACÉES.}

189 Fleurs hermaphrodites. G. Ulmus L., p. 151.

Fleurs unisexuées, les mâles et les femelles sur le mème pied ou sur des pieds différents. . . .

$1^{\circ}$ Des fleurs mâles, femelles et à deux sexes, réunies sur le mème pied et toutes solitaires à l'aisselle des feuilles. G. Celtis L., p. 198.

Fleurs en chatons unisexués. . . . . . . $2^{\circ}$

$2^{\circ}$ Chatons màles et femelles portés par le même pied. . $3^{\circ}$

Chatons màles et femelles portés par des individus différents. ............... 90

$3^{\circ}$ Chatons måles globuleux. G. Fagus L., p 15 t.

Cihatons màles allongés et cylindiriques. 
$4^{\circ}$ Chatons mâles raides et draits; fruits épineux. G. $F a-$ gus L., p. 154 .

Chatons mâles lẩches et penchés; fruits non épineux. $5^{\circ}$

$5^{\circ}$ Etamines terminées par un poil saillant. G. Carpinus L., p. 154 .

Etamines non terminées par un poil. . . . . . $6^{\circ}$

$6^{\circ}$ Plus de dix étamines; fleurs se développant après les feuilles. G. Betula L., p. 154.

Quatre à dix étamines; fleurs se développant avant ou avec les feuilles..............

$7^{\circ}$ Chatons mâles grêles et interrompus; trois à six styles ou divisions du style; fruit placé dans une enveloppe coriace. G. Quercus L., p. 155.

Chatons mâles cylindriques et continus; deux styles ou divisions du style dans chaque fleur; enveloppe du fruit herbacée ou nulle. . . . . . . .

$8^{\circ}$ Ecailles des chatons mâles trilobées; fleurs femelles. sans pédicule; fruit dur, dans une enveloppe herbacée. G. Corylus T., p. 154 .

Ecailles des chatons mâles n'offrant pas trois lobes; chatons femelles pédiculés; fruits imbriqués, sans enveloppe. (S. G. Alnus T., p. 15\%.)

$9^{\circ}$ Fruit à deux valves; graines munies de poils; chatons sans points brillants. - - - - - - -

Fruit charnu, contenant un noyau; graines sans poils; chatons parsemés de points brillants et aromatiques. G. Myrica L., p. 152.

$10^{\circ}$ Fruit à une loge ; une à cinq étamines dans chaque fleur. G. Salix L., p. 152.

Fruit à deux loges; huit à trente étamines. G. Populus L., p. 153.

\section{Fam. des Conifères.}

190 Petites plantes ligneuses, à rameaux sarmenteux, non feuillés. G. Ephedra L., p. 158.

Arbres ou arbrisseaux feuillés. ........ $1^{\circ}$

$1^{\circ}$ Arbres à feuilles élargies en éventail, veinées et molles. G. Ginkgo L., p. 158.

Arbres ou arbrisseaux à feuilles menues ou en aiguilles. $2^{\circ}$

$2^{\circ}$ Feuilles assez longues, isolées et éparses. . . . . . $3^{\circ}$

Feuilles minimes, ou allongées, mais alors opposées, verticillées ou groupées en faisceaux. . . ..... 
$3^{\circ}$ Fructifications grosses, allongées, dures et sèches, (S. G. Abies.) G. Pinus L., p. 155.

Fructifications petites, globuleuses, rouges et charnues. G. Taxus L., p. 158.

$4^{\circ}$ Feuilles allongées et groupées en faisceaux, par deux, cinq ou beaucoup plus. G. Pinus L., p. 155.

Feuilles allongées et opposées ou verticillées, ou feuilles minimes.

$5^{\circ}$ Fructifications sèches, à écailles en tète de clou. G. Cupressus T., p. 157.

Fructifications sèches, à écailles crochues au sommet. G. Thuia T., p. 157.

Fructifications charnues, non écailleuses. G. Juniperus L., p. 157.

191 Tige grimpante ou pourvue de vrilles accrochantes. . 192 Tige non grimpante et dépourvue de vrilles. . . . . 195

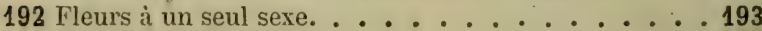

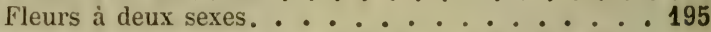

193 Feuilles glabres et luisantes. G. Tamus L., p. 169.

Feuilles hérissées de poils rudes. . . . . . . 194

194 Fleurs verdattres ou jaunâtres; étamines libres. G. Humulus L., p. 151.

Fleurs colorées en dedans; étamines adhérentes entre elles. . . . . . . . . . 107

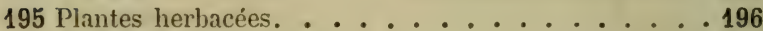

Plantes ligneuses. . . . . . . . . . . . 220

196 Fleurs à un seul sexe. . . . . . . . . 197

Fleurs à deux sexes. . . . . . . . . . . . 204

197 Un calice et une corolle bien distincts, mais soudés l'un avec lautre; plante hérissée de poils rudes. . . . 107

Une seule enveloppe florale simple, ou un calice et une corolle non soudés ensemble, ou plante n’étant pas hérissée de poils rudes. . . . . . . 198

198 Fleurs ayant au moins dix étamines, ou trois ou cinq styles................. 199

Fleurs ayant inoins de dix étamines, ou moins de trois styles. . . . . . . . . . . 204

199 Feuilles en forme de fer de flèche. G. Sagittaria L., p. 158.

Feuilles n'étant pas en forme de fer de flèche. . . . . 200

200 Fleurs disposées en tête serrée et terminale. G. Sanguisorba L., p. 64.

Fleurs non disposées en tête serrée. . . . . . . 201 
201 Plante plongée dans l'eau. . . . . . . . . 202

Plante terrestre. . . . . . . . . 203

202 Enveloppe florale a quatre divisions; fleurs en épis ou verticillées. G. Myriophyllum L., p. 70.

Enveloppe florale à dix ou douze divisions; fleurs souvent axillaires. G. Ceratophyllum L., p. 151.

203 Fleurs pourvues d'une corolle à cinq pièces. . . . 72

Fleurs n'ayant pas de corolle distincte. . . . . . 215

204 Une à six étamines ou anthères. . . . . . . 231

Plus de six étamines ou anthères. . . . . . . 205

205 Plusieurs ovaires libres, ou placés au fond de l'enveloppe

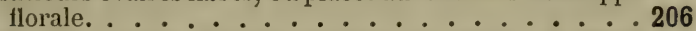

Un seul ovaire, parfois partagé en deux ou trois divisions. . . . . . . . . . 208

206 Fleurs serrées en tète terminale; deux ovaires au fond de la fleur. G. Sanguisorba L., p. 6z.

Fleurs non disposées en tète; plus de deux ovaires. . . 207

207 Six pièces colorées à l'enveloppe florale, neuf étamines et six styles. G. Butnmus L., p. 159.

Fleur r'ayant pas tout à la fois de tels organes. . .

208 Plantes aquatiques, à feuilles découpées en lobes nombreux et très étroits. . . . . . . 202

Plantes terrestres ou n'ayant pas les feuilles finement découpées lorsqu'elles sont aquatiques. . . . 209

209 Enveloppe florale à huit pièces. G. Paris L., p. 166.

Enveloppe florale nulle ou ayant deux à six divisions. 210

210 Plantes aquatiques, à feuilles flottantes, arrondies et

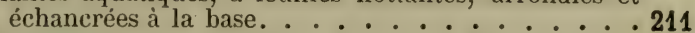

Plantes terrestres, ou plantes aquatiques n'ayant pas les feuilles arrondies, entières et échancrées a la base. . 212

211 Fleurs à un seul sexe, renfermées d'abord dans une gaîne. G. Hydrocharis L., p. 159.

Fleurs à deux sexes et sans gaîne au début. G. Nymphoea L., p. 7.

212 Fleurs composées de quatre pièces colorées et d'étamines très nombreuses. . . . . . . . .

Fleurs n'ayant pas tout à la fois quatre piéces colorées et des étamines très nombreuses. . . . . . . 213

213 Fruit charnu en forme de baie. G.Phytolacca I., p. 140.

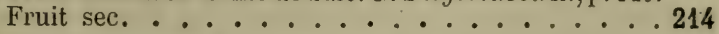

214 Plante ligneuse. G. Buxus T., p. 150.

l'lante herbacée. ..............215 
215 Fleurs en ombelle; herbes à suc laiteux. G. Euphorbia L., p. 147.

Fleurs non en ombelle; herbes sans suc laiteux. . . 216

216 Fleurs à un seul sexe. G. Mercurialis T., p. 150.

Fleurs ayant les deux sexes. ......... 217

217 Fleurs en petits corymbes d'un beau jaune. G. Chrysosplenium L., p. 73.

Fleurs jamais d'un beau jaune. . . . . . 218

218 Un seul style simple. . . . . . . . . 225

Plusieurs styles distincts ou style à divisions distinctes. 219

219 Feuilles alternes. G. Polygonum L., p. 145.

Feuilles opposées. .......... 72

220 Rameaux articulés; point de vraies feuilles. . . . 221

Tige et rameaux munis de feuilles. . . . . . . 222

221 Articulations munies d'une gaine rougeâtre. G. Ephedra L., p. 158.

Articulation ne naissant pas d'une gaine. . . . . 298

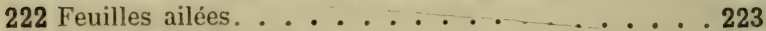
Feuilles non ailées. . . . . . . . . 230

223 Arbre à fleurs en grappe ramifiée. G. Rhus L., p. 43. Arbre élevé, à fleurs en chatons. Noyer. (AMENTACÉE.) Sous-arbrisseau grimpant. G. Clematis L., p. 1.

224 Un seul style simple. . . . . . . . . 225 Deux à six styles ou divisions du style. . . . . 226

225 Tige herbacée. G. Passerina L., p. 146. Tige ligneuse. G. Daphne L., p. 146.

226 Feuilles opposées. G. Acer L., p. 41. Feuilles alternes ou en faisceaux.

227 Fruit a deux ou trois divisions visibles en dehors. . . 214 Fruit noflrant pas de traces de divisions. . . . . 228

228 Feuilles nulles, petites ou demi-cylindriques. . . . 298 Feuilles planes. . . . . . . . . 229

229 Tige ligneuse. . . . . . . . . . 188 Tige herbacée. G. Polygonum L., p. 145.

230 Fleurs naissant à la surface des rameaux aplatis en forme de feuille piquante. G. Ruscus L., p. 166.

Fleurs ne naissant pas ainsi. . . . . . . 231

231 Enveloppe florale coloréc et ayant l'apparence d'une corolle. . . . . . . . . . 232 Enveloppe florale verte, on inembraneuse, ou écailleuse et ayant l'apparence d'un calice. . . . . . . 271 
232 Trois étamines ou plus très saillantes. . . . . . 233 Une ou deux étamines soudées au style et peu appa-

rentes. . . . . . . . . . . 270

233 Trois étamines. . . . . . . . . . . . 267

Quatre ou cinq étamines. $\ldots \ldots 234$

Six étamines ou plus. . . . . . . . 251

234 Feuilles alternes ou opposées deux à deux. . . . . 235

Feuilles en verticilles, du moins les inférieures. . . 116

235 Fleurs en ombelle. . . . . . . . . 998

Fleurs non disposées en ombelle régulière. . . 226

236 Enveloppe florale double, sur deux rangées, ou un calice doublé d'une collerette. . . . . . . 237 Enveloppe florale simple, sans collerette. . . . 246

237 Plante ligneuse. . . . . . . . . . . . 238 Plante herbacée. . . . . . . . . . 241

238 Arbrisseau parasite sur les arbres; fruits charnus et blancs. G. Viscum L., p. 198.

Arbrisseau non parasite; fruits charnus, noirs ou rouges. . . . . . . . . . . 239

239 Fenilles épineuses. G. Ilex L., p. 43.

Feuilles non épineuses. . . . . . . . . 240

240 Toutes les fleurs axillaires. G. Rhamnus L., p. 42.

Fleurs en grappe ramifiée terminale. G. Rhus L., p.43.

241 Quatre étamines. . . . . . . . . . 242

Cinq étamines. $\ldots \ldots \ldots \ldots 928$

242 Fleurs en petits corymbes. G. Alchemilla T., p. 6 t.

Fleurs solitaires, en tète, en épis serrés ou en verticilles. . . . . . . . . . . 243

243 Feuilles ailées. G. Sanguisorba L., p. 6' .

Feuilles simples. . . . . . . . . . . 244

244 Fleurs verticillées le long de la tige. . . . . . . . . 171

Fleurs solitaires, en tête, ou en épis non composés de verticilles. . . . . . . . . . 245

245 Fleurs à deux sexes, en tête ou en épis. G. Plantago L., p. 138.

Fleurs à un seul sexe, les mâles solitaires sur leur pédicule. G. Littorella L., p. 139.

246 Feuilles ailées. G. Sanguisorba L., p. 64 .

Feuilles non ailées. . . . . . . . . 247

247 Nouds des fenilles munis de stipules ou de gaines membraneuses. . . . . . . . . . . 248 Feuilles sans stipules ni gaines. $\ldots \ldots \ldots 249$ 
248 Feuilles alternes. G. Polygonum L., p. I'́́.

Feuilles opposées. . . . . . . . . . 72

249 Feuilles opposées pour la plupart. G. Glaux L., p. 113.

Feuilles alternes. ............250

250 Fleurs en épis serrés, entremèlés de feuilles florales.

G. Amarinthus L., p. 14 L.

Fleurs en grappes làches. G. Thesium I., p. 147.

251 Tige ligneuse. . . . . . . . . . . . 224 Tige herbacée. . . . . . . . . . . . 252

252 Plusieurs ovaires ou plusieurs styles. . . . . . . . . . . . . . . 253 Un seul ovaire, un seul style ou point de style. . . . 257

253 Point de tige ni de feuilles au moment de la floraison. G. Colchicum L., p. 161.

Fleurs portées par une tige feuillée, du moins à sa base. 254

254 Nouds de la tige munis de gaines membraneuses en forme de stipules. . . . . . . . 255

Feuilles sans gaines membraneuses en forme de sti-

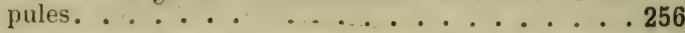

255 Flemrs munies en dehors de trois petites folioles. G. Rumex L., p. 14 '.

Fleurs dépourvues de folioles en dehors. G. Polygonum L., p. 145.

\section{Fam. des Alismacées.}

256 Carpelles libres ou faiblement accolés. . . . . . 10 Un seul carpelle ou un seul ovaire composé. . . . . $7^{\circ}$

10 Enveloppe florale à six pièces. . . . . . . . $2^{\circ}$ Enveloppe florale à quatre pièces on nulle. . . . . $5^{\circ}$

$2 \circ$ Feuilles en fer de flèche; étamines en nombre indéfini. G. Sagittaria L., p. 158.

Feuilles non en fer de flèche ; six à neuf étamines. . . $3^{\circ}$

$3^{\circ}$ Neuf étamines; enveloppe florale colorée. G. Butomus L., p. 159.

Six étamines; enveloppe florale verte. . . . . . $4^{\circ}$

$4^{\circ}$ Feuilles linéaires, étroites, fleurs en grappe ou en épis. G. Triglochin L., p. 159.

Feuilles ni linéaires ni étroites; fleurs solitaires ou verticillées en bouquet. G. Alisma L., p. 158.

$5^{0}$ Fleurs ayant les deux sexes. . . . . . . . $6^{\circ}$ Fleurs à un seul sexe; une seule étamine. G. Zanni- . cheilia L., p. 161. 


\section{ANALYSE DICHOTOMIQUE}

$6^{\circ}$ Quatre étamines. G. Potamogeton L., p. 159.

Deux étamines. G. Ruppia L., p. 160.

70 Feuilles planes, allongées. G. Vallisneria M., p. 159.

Feuilles ovales. G. Elodea Rich., p. 159.

Feuilles filiformes. G. Althenia Pet., p. 161.

Feuilles rondes, échancrées. G. Hydrocharis L., p. 159.

257 Feuilles composées, très lécoupées. G. Fumaria L., p. 8.

Feuilles simples. ............258

258 Euveloppe florale tronquée obliquement et allongée en forme de languè. G. Aristolochia Li, p. 146.

Enveloppe florale non allongée en forme de langue. . 259

259 Ovaire libre au fond de l'enveloppe. florale. . . . 260 Ovaire adhérent ou placé sous l'enveloppe florale. . . 264

260 Feuilles presque toutes radicales; tige florale nue. . 265 Tige florale garnie de feuilles nombreuses. . . . .261

261 Feuilles opposées deux à denx. G. Peplis L., p. 70. Feuilles éparses, ou verticillées, ou en touffe. . . . 262

262 Feuilles, ou ce qui paraît en ètre, filiformes, naissant par touffes sur les ratreaux. G. Asparagus L., p. 166. Feuilles ni filiformes ni par faisceaux. . . . 263

263 Fleur à divisions atteignant à peine le milieu de sa longueur. G. Convallaria L., p. 165.

Divisions de la fleur atteignant à peu près sa base. . . 265

264 Plante grimpante. G. Tamus L., p. 169.

Plante non grimpante. . . . . . . 266

FAM. DES LiliagéEs.

265 Plante ayant l'aspect d'un jonc; fleurs bleues. G. Aphyllanthes T., p. 165.

Plantes n'ayant pas l'aspect d'un jonc. . . . . 10

$1^{\circ}$ Trois styles ou divisions du style. ....... $2^{\circ}$

Un seul style simple, n'oflrant pas de divisions ni d'angles bien prononcés. ............. $3^{\circ}$

$2 \circ$ Fleur toute rayée de carreaux en losange. G. Fritillaria L., p. 161.

Fleur non rayée. . . ......... . . $5^{\circ}$

$3^{\circ}$ Pièces de l'enveloppe florale distinctes presque jusqu'i la base l'enveloppe florale soudées jusqu'au milieu et plus. 
$4^{\circ}$ Style à trois divisions au sommet. ....... $5^{\circ}$

Style simple au sommet. . . . . . . . $6^{\circ}$

$5^{\circ}$ Fleur grande sur un long pied. G. Tulipa T., p. 161.

Fleurs petites, en épi ou en grappe. . . . . . 256

$6^{\circ}$ Fleurs en tète ou en ombelle, enveloppées d'abord d'une gaine, qui se partage ensuite en deux feuillets. G. Allium L., p. 162.

Fleurs ne présentant pas ces caractères. . . . $7^{\circ}$

$7^{\circ}$ Filets des étamines garnis de poils laineux. G. Anthericum L., p. 162.

Filets des étamines non laineux. . . . . . $8^{\circ}$

$8^{\circ}$ Filets des étamines tous ou plusieurs sensiblement élargis à leu base. . . . . . . . . 9o

Filets des étamines peu ou point élargis à la base. . . $10^{\circ}$

$9^{\circ}$ Base des étamines voùtée et couvrant l'ovaire. G. Asphodelus L., p. 162.

Bitse de trois des étannines droite, et ne couvrant pas l'ovaire. G. Ornithogalum L., p. 16't.

$10^{\circ}$ Fleurs jaunes. G. Ornithogalum L., p. 16 4.

Fleurs bleues, blanches ou roses. . . . . . 110

$11^{\circ}$ Racine fibreuse; fleurs jamais bleues. G. Anthericum L., p. 162.

Plante bulbeuse; fleurs étant assez souvent bleues. G. Scilla L., p. 164.

$12^{\circ}$ Fleurs en clochette et à six divisions prononcées. 11\%

Fleurs globuleuses, ou en grelot, ou à six dents. . . . $13^{\circ}$

$13^{\circ}$ Fleurs bleues ou violettes; plante bulbeuse; feuilles linéaires. G. Muscari T., p. 165.

Fleurs blanches; racine fibreuse; feuilles ovales. G. Convallaria L., p. 165.

\section{FAM. DES AMaryllidéES.}

266 Enveloppe florale munie d'une couronme interne. . . $1^{\circ}$ Enveloppe florale dépourvue de couronne. . . . $2^{\circ}$

$1^{\circ}$ Couronne en cloche, renfermant les étamines, G. Narcissus L., p. 167.

Couronne lobée et portant les étamines au sommet. G. Pancratium L., p. 164.

$2^{\circ}$ Divisions de la fleur égales entre elles et épaissies au sommet. G. Leucoium L., p. 166.

Divisions internes de la fleur échancrées et plus courtes que les autres. G. Galanthus L., p. 166. 
267 Sous-arbrisseaux. G. Osyris L., p. 147.

Herbes. . . . . . . . . . . . 268

268 Feuilles opposées. . . . . . . . 117

Feuilles toutes radicales ou alternes. . . $\ldots 269$

FAMr. DES IRIDÉES.

269 Style à divisions aplaties et élargies. G. Iris L., p. 168. Style à divisions non aplaties ni élargies. . ..... $1^{\circ}$

10 Fleur irrégulière, comme à deux lèrres. G. Gladiolus L., p. 168.

Fleur régulière, en entonnoir. G. Ixia L., p. 168.

\section{Fanr. Des OrChidÉES.}

270 Fleur prolongée à la base en forme d'éperon ou de sac. G. Orchis. L., p. 169.

Fleur sans éperon ni base saillante. . . . . . $1^{\circ}$

10 Plante munie à la base de tubercules. . . . . . . $2^{\circ}$

Plante à racine rampante ou formée d'un faisceau de fibres simples.............. $6^{\circ}$

$2^{\circ}$ Tige à trois ou cinq angles, et à deux ou trois feuilles a la base. G. Malaxis Sw., p. 173.

Tige cylindrique et munie de plus de deux feuilles. . $3^{\circ}$

$3^{\circ}$ Fleurs blanches, petites, en épi contourné en spirale. G. Spiranthes Rich., p. 172.

Fleurs jamais tout à fait blanches; épi très rarement

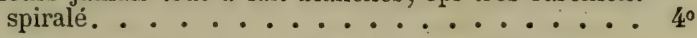

$4^{\circ}$ Ovaire tordu. G. Ophrys L., p. 171.

Ovaire non tordu.

$5^{\circ}$ Pièces externes de l'enveloppe florale étalées sur les côtés. G. Ophrys L., p. 171.

Pièces externes de l'enveloppe florale réunies en casque. G. Serapias L., p. 171.

6 Feuilles veinées en réseau. G. Neottia L., p. 172.

Feuilles nulles ou à nervures parallèles. . . . . . $7^{\circ}$

$7^{\circ}$ Plante sans feuilles ou à deux feuilles opposées; tablier bifide. G. Neottia L., p. 172.

Plante à feuilles alternes; tablier entier ou denté au sommet. G. Epipactis L., p. 172.

271 Tige ligneuse. . . . . . . . . . . 272 Tige herbacée ou à peu près. ........ 276 
272 Feuilles découpées en éventail. G. Ficus T., p. 152.

Feuilles non découpées en éventail. . . . . . 273

273 Fruit à trois cornes ou à trois loges. . . . . . 214 Fruit n'offrant ni trois cornes ni trois loges. . . . 274

274 Fruit charnu. . . . . . . . . . . 275 Fruit sec ou dur. . . . . . . . . . 228

275 Fleurs en chatons aromatiques. G. Myrica L., p. 152. Fleurs non en chatons. . . . . . . . . 238

276 Enveloppe florale ayant une à six pièces ou divisions. . 278 Enveloppe florale ayant de huit à douze pièces ou divisions. . . . . . . . . . 277

277 Feuilles découpées en parties filiformes. G. Ceratophyllum L., p. 151.

Fevilles simples et entières. G. Lythrum L., p. 70.

278 Plante pourvue de feuilles ordinaires. . . . . 279 Plante articulée, sans feuilles bien nettes. . . . . . 298

279 Fenilles ailées ou découpées en parties digitées. . . 280 Feuilles simples ou seulement découpées sur les bords. 283

280 Pieds à fleurs unisexuées; feuilles opposées. Ghanvre. (Fam. des UrTicÉes.)

Pieds à fleurs mâles et femelles; feuilles alternes sur la tige. . . . . . . . . . . . . 281

281 Herbe aquatique. G. Myriophyllum L., p. 70. Herbe terrestre.

282 Fleurs axillaires ou en tout petits bouquets. G. Alchemilla T., p. 64.

Fleurs en épi ou en tète terminale serrée. G. Sanguisorba L., p. 64.

283 Une à cinq étamines.

Six étamines. . . . . . . . . . . . 284

284 Plusieurs ovaires. . . . . . . . . . 256

Un seul ovaire. . . . . . . . . 285

285 Fleurs disposées en épis serrés et naissant sur le côté d'une tige foliacée; racine très odorante. G. Acorus L., p. 173.

Fleurs ne naissant pas en épi serré ni placé sur le côté de la tige; racine sans odeur spéciale. . . . . 286

288 Fruit à plusieurs graines; feuilles linéaires étroites, et en forme de jonc. . . . . . . . . 287 Fruit à une seule graine; feuilles ni linéaires étroites, ni en forme de jonc. . . . . . . . . 254 
287 Feuilles planes et souvent assez poilues. G. Luzula DC., p. 174.

Feuilles cylindriques ou en gouttière et glabres, G. Juncus L., p. 175.

288 Une à trois étamines....................... 306 Quatre ou cinq étamines. . . . . . . . 289

289 Un seul style ou style à peu près nul et très court. . . 291 Deux ou plusieurs styles. ........ 290

290 Deux ou trois styles. . . . . . . . . 301 Quatre ou cinq styles. ............ 72

291 Plusieurs ovaires; plante croissant dans l'eau. G. Potamogeton L., p. 159.

Un seul ovaire.

292 Ovaire adhérent à la fleur et placé au-dessous de l'enveloppe florale. . . . . . . . 293 Ovaire non adhérent et visible au fond de la fleur. . . 294

293 Feuilles opposées; plante des lieux humides. G. Isnardia L., p. 69.

Feuilles alternes; plante des lieux secs ou sablonneux. G. Thesium L., p. 147.

294 Feuilles munies de petites stipules. . . . . . . 72 Feuilles sans stipules. . . . . 295

295 Enveloppe florable double; un calice et une corolle. . 245 Enveloppe florale simple. . . . . . . 296

296 Feuilles hérissées de poils brúlants, ainsi que la tige. G. Urtica L., p. 151.

Feuilles glabres oủ à poils dont la piqûre n'est pas douloureuse. : : . . . . . . . 297

297 Enveloppe florale à pièces presque triangulaires, et s'accroissant beaucoup après la floraison. G. Atriplex L., p. 143.

Enveloppe florale à pièces non triangulaires et ne s'accroissant pas après la floraison.

299 Un style simple, plumeux au sommet; feuilles velues. G. Parietaria T., p. 151.

Deux à quatre divisions au style; feuilles glabres ou nulles. . . . . . . . . . . 299

299 Enveloppe florale à cinq divisions; plante pourvue de feuilles.

Enveloppe florale a peine divisé ; plante sans feuilles distinctes. G. Salicornia L., p. 143. 
300 Feuilles planes ou cylindriques; enveloppe florale sans appendice. G. Chenopodium L., p. 142.

Fevilles à trois angles; enveloppe florale munie d'un

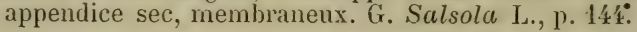

301 Tige ligneuse; fruit à trois loges ou coques. G. Buxus l., p. 150.

Tige herbacée; fruit à une loge. . . . . . . . 302

302 Feuilles opposées et munies de petites stipules. . . 72

Feuilles alternes, ou sans stipules. . . . . 303

303 Fruit s'ourrant en travers. G. Amaranthus L., p. 141.

Fruit ne s'ouvrant pas. .......... 304

304 Feuilles ou queues des feuilles munies a la base de gaines rnembrancuses. G. Polygonum L., p. 145.

Feuilles sans gaines membraneuses. . . . . . 305

305 Base de l'enveloppe florale adhérente a l'ovaire et an fruit. G. Beta T., p. 141.

Enveloppe florale tout à fait libre. . . . . . 296

306 Feuilles verticillées. G. Hippuris L., p. 70.

Feuilles non verticillées. . . . . . . 307

307 Feuilles engainantes; enveloppe florale en forme d'é-

cailles ou de glumes. . . . . . . . 314

Feuilles non engainantes; fleurs non glunacées. . . . 308

308 Enveloppe florale arant de trois à six divisions. . . . 309

Enveloppe florale nulle ou it une ou deux pièces. . . 310

309 Feuilles opposées et munies de petites stipules. . . 72 Feuilles alternes, sans stipules. ....... 310

310 Trois étamines. . . . . . . . . . . 311 Une ou deux étamines. . . . . . . . 313

311 Feuilles en forme de sabre, très allongées et un peu engaînantes. . . . . . . . . . 316 Feuilles ni en forme de sabre, ni engaînantes. . . . 312

312 Feuilles étroites, en alène. G. Polycnemum L., p. 141. Feuilles planes et élargies. G. Amaranthus L., p. 141.

313 Plante à suc laiteux; fruit à trois loges. G. Euphorbia L., p. 147.

Plante non laiteuse; fruit un peu charnu. G. Chenopodium L., p. 142.

314 Enveloppe florale composée de une ou deux pièces ou écailles. . . . . . . . 315 Enveloppe florale a six divisions. G. Juncus L., p. $175^{\circ}$ 
315 Enreloppe florale (glume) composée d'une écaille; tige sans nœuds; gaine des feuilles entière. . . . 316

Enveloppe florale composée de deux à quatre écailles; tige noueuse; gaine des feuilles fendue dans sa longueur. . . . . . . . . . . 317

\section{FAy. DES CypéracÉEs.}

316 Fleur à un seul sexe ; ovaire ou fruit renfermé dans un godet fermé et percé au sommet. G. Garex L., p. 179.

Fleur ayant les deux sexes; ovaire ou fruit non renfermé dans un godet. .........

$1^{0}$ Ovaire ou fruit entouré de soies très longues et d'un blanc brillant. (S. G. Eriophorum, p. 179.)

Fruits nus ou entourés de soies plus courtes que les écailles de l'épi. . . . . . . . . .

$2^{\circ}$ Epillets très aplatis, à écailles imbriquées sur deux rangs réguliers. G. Cyperus L., p. 177.

Epillets n'étant pas tout à la fois très aplatis et garnis d'écailles disposées sur deux rangs réguliers. . . .

$3^{\circ}$ Un seul épi simple et terminal. G. Scirpus L., p. 178. Plusieurs épillets réunis en tête ou en faisceau. . .

$4^{\circ}$ Epillets rapprochés en épi terminal, comprimé et distique. G. Scirpus L., p. 178.

Epillets non disposés comme ci-dessus. . . . . . $5^{\circ}$

$5^{\circ}$ Ecailles presque toutes fertiles. G. Scirpus L., p. 178.

Ecailles inférieures des épillets vides et stériles. G. Schœnus L., p. 177.

\section{FAM. DES GraninéEs.}

317 Fleurs en tête courte, arrondie et hérissée de pointes coriaces. G. Echinaria Desf., p. 187.

Fleurs en épi ou en panicule. . . . . . . .

10 Fleurs hérissées en dehors de petites pointes crochues. G. Tragus Hall., p. 183.

Fleurs glabres ou velues, mais non hérissées de pointes crochues. . . . . . . . . . .

$2^{\circ}$ Fleurs disposées en épis linéaires, rassemblés au sommet de la tige et comme digités. . . . . . .

Fleurs disposées en panicule ou en épis qui ne sont pas digités au sommet de la tige. . . . . .

$3^{\circ}$ Feuilles enroulées, piquantes. G. Spartina Sch.,p. 183.

Feuilles planes, non piquantes. ........ 
$4^{\circ}$ Epi parsemé de poils soyeux. G. Andropogon L., p. 183.

Epi dépourvu de poils soyeux. G. Panicum L., p. 183.

$5^{n}$ Fleurs i pédicule très net et disposées en panicule

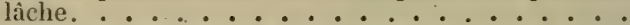

Fleurs sans pédicule, en épis, ou à pédicule si court que la panicule ressemble à un épi ou à une grappe. simple.

$6^{\circ}$ Fleurs munies a la luase de poils soyeux presque aussi longs qu'elles................. $7^{0}$

Fleurs glabres ou velues, mais à poils très courts. . $8^{\circ}$

$7^{\circ}$ Fleurs portant sur le dos une arête longue, divergente et genouillée au milieu. G. Avena L., p. 189.

Arète mulle on courte, droite el non genouillée. G. Arundo L., p. 186.

8n Epillets ag̨gromérés en plusieurs paquets ovales, serrés, aplatis et tournés tous du mème còté. G. Dactylis L., p. 192.

Fleurs solitaires ou en épillets qui ne sont pas comme ci-dessus. . . . . . . . . . 9 9

$9^{\circ}$ Epillets ne contenant qu'une seule fleur fertile. . . $10^{\circ}$

Epillets contenant deux ou plusieurs fleurs réunies dans les glumes.............. $18^{\circ}$

$10^{\circ}$ Fleurs pourvues d'une ou de plusieurs arètes. . . 110

Fleurs dépourvues d'arête. . . . . . . . $13^{\circ}$

$11^{\circ}$ Arête arant environ un décimètre de longueur. G. Stipa L., p. 187.

Arète très courte, ou longue au plus de quelques centimètres. . . . . . . . . . .

$12^{\circ}$ Un collier de poils jaunâtres à la base des épillets. G. Andropogon L., p. 183.

Epillets sans collier de poils à leur base. . . . . 130

13. Fleur pourvue d'une seule enveloppe ou glume à deux pièces. G. Leersia L., p. 183.

Fleur pourvue de deux enveloppes, une glume et une glumelle à deux pièces chacune....... $14^{\circ}$

$14^{\circ}$ Panicule unilatérale ou a peine composée de quinze à trente épillets. G. Melica L., p. 190.

Panicule composée de plus de trente épillets. . . . $15^{\circ}$

$15^{\circ}$ Glume à deux pièces avec une écaille accessoire. G. $P a-$ nicum L., p. 183.

Glume à deux pièces sans écaille accessoirc. . . . $16^{\circ}$ 
16 Glume à pièces pliées en carène et renfermant la fleur; panicule serrée. G. Phalaris L., p. 184.

Glume ouverte, à pièces convexes; panicule plus ou moins étalée. . . . . . . . . 17

$17^{\circ}$ Glumelle coriace, luisante, persistante et renfermant la graine. G. Milium L., p. 187.

Glumelle ni coriace ni persistante sur la graine. G. Agrostis L., p. 187.

$18^{\circ}$ Fleurs pourvues d'une ou plusieurs arêtes plus ou moins longues. . . . . . . . . $19^{\circ}$

Fleurs dépourvues d'arête. . . . . . . . . 25

$19^{\circ}$ Arête naissant sur le dos ou à la base de la fleur. . . $20^{\circ}$

Arête naissant au sommet ou près du sommet de la fleur. . . . . . . . . . . . $2 \mathbf{t}^{\circ}$

$20^{\circ}$ Arête presque droite, dépassant peu la fleur ou plus courte qu'elle. .................... $21^{\circ}$ Arête genouillée, divergente et très saillante. . . $22^{\circ}$

$21^{\circ}$ Epillets composés de deux fleurs semblables et munies chacune d'une arête. G. Aira L., p. 188.

Epillets composés de deux fleurs dissemblables, l'une supérieure stérile et munie d'une arète, l'autre inférieure fertile et sans arête. G. Holcus L., p. 189.

$22^{\circ}$ Epillets composés de plusieurs fleurs semblables et munies d'arête. G. Avena L., p. 189.

Epillets composés de deux fleurs seulement. . . . 23응

$23^{\circ}$ Les deux fleurs semblables. G. Aira L., p. 188.

Les deux fleurs dissemblables. G. Avena L., p. 189.

$24^{\circ}$ Arête naissant un peu au-dessous du sommet de la glume. G. Bromus L., p. 194.

Arête naissant au sommet de la glume ou dans une échancrure du sommet. G. Festuca L., p. 192.

$25^{\circ}$ Epillets composés de deux fleurs. . . . . . . $26^{\circ}$

Epillets composés de plus de deux fleurs. . . . . $28^{\circ}$

$26^{\circ}$ Epillets longs de un à deux centimètres. G. Avena L., p. 189.

Epillets n'ayant pas un centimètre de long. . . . $27^{\circ}$

$27^{\circ}$ Fleurs plus courtes que la glume. (S. G. Airopsis.) G. Aira L., p. 188.

Fleurs beaucoup plus longues que la glume. (S. G. Glyceria, p. 191.)

$28^{\circ}$ Fleurs à dos comprimé en carène. G. Poa L., p. 190.

Fleurs à dos arrondi. 
$29^{\circ}$ Feuilles plus longues que larges, obtuses, à dos demicylindrique; plantes aquatiques. (S. G. Glyceria, p. 191.)

Feuilles lancéolées ou en alène, ou un peu ventrues à la base; plantes des lieux secs. . . . . . . . 30 $30^{\circ}$

$30^{\circ}$ Epillets ovales, pendants, à fleurs sur deux rangées. G. Briza L., p. 190.

Epillets n’ayant pas tous ces caractères. G. Festuca L., p. 192.

$31^{\circ}$ Epillets tout à fait sans pédicule sur un axe commun, et réunis en épi plus on moins allongé. . . . . . .

Epillets brièvement pédiculés et réunis en forme de grappe ou d'épi souvent crlindrique. . . . . . .

$32^{\circ}$ Glume ne contenant qu'une seule fleur fertile. . . . 330

Glume contenant deux ou plusieurs fleurs réunies en épillet. . . . . . . . . . . .

$33^{\circ}$ Glume à deux pièces, avec une troisième en forme d'écaille. (S. G. Setaria.) G. Panicum L., p. 183.

Glumes à deux pièces, sans écaille accessoire. . . . 3 3 Ł $^{\circ}$

$34^{\circ}$ Glumes aiguës, renflées et globuleuses a la base. (S. G. Gastvidium.) G. Milium L., p. 187.

Glumes non renflées, ni globuleuses à la base. . . . 35"

$35^{n}$ Tiges rameuses et couchées; fleurs sans arête. G. Crypsis Ait., p. 185.

Tiges simples; fleurs munies d'arêtes. . . . . . . 36

$36^{\circ}$ Fleurs soyeuses, munies d'arêtes très longues. G. Lagurus L., p. 186.

Fleurs munies à la base de deux paillettes plus longues qu'elles. G. Anthoxanthum L., p. 185.

Fleurs sans paillettes ni arètes plus longues qu'elles. $37^{\circ}$

$37^{\circ}$ Glume convexe, à pièces terminées par une arête, ou glume pliée en carène et sans arête, la glumelle en portant toujours une. Gr. Alopecurus L., p. 185.

Glume pliée en carène et prolongée en pointe courte. G. Phleum L., p. 186.

$38^{\circ}$ Epillets munis d'une feuille florale en dents de peigne, ou disposés sur deux rangs et munis d'arêtes. G. Festuca L., p. 192.

Epillets sans feuille en peigne, non disposés sur deux rangs réguliers, sans arêtes ou à arêtes peu risibles. Epillets à deux fleurs et à arètes assez longues. . . 210

$39^{\circ}$ Fleurs à bords membraneux, risiblement pédiculées. $40^{\circ}$ Fleurs peu membraneuses et presque sans pédicule. . $41^{\circ}$ 
$40^{\circ}$ Glumes égalant presque la longueur des fleurs. G. Melica L., p. 190.

Glumes moitié plus courtes que les fleurs qu'elles entourent. G. Poa L., p. 190.

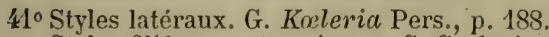

Styles filiformes, terminaux. G. Sesleria Sc., p. 188.

$42^{\circ}$ Très petite plante, à épi droit, filiforme et d'un rouge violet. G. Mibora Ad., p. 186.

Plante plus ou moins élevée; épi non filiforme. . . 430

$43^{\circ}$ Un seul épillet placé dans chaque dent de l'axe de l'épi.

Deux ou trois épillets sur chaque dent de l'axe de l'épi. $44^{\circ}$

4.'º Epillets à une seule fleur. G. Hordeum L., p. 196.

Epillets à deux ou quatre fleurs. G. Elymus L., p. 196.

$45^{\circ}$ Fleurs à trois ou quatre arêtes. G. Egilops L., p. 197.

Fleurs sans arêtes, ou à une seule. ..... $40^{\circ}$

$46^{\circ}$ Une ou deux fleurs par épillet. ........ $47^{\circ}$

Plus de deux fleurs par épillet. . . . . . . . . 50 $50^{\circ}$

$47^{\circ}$ Deux à quatre épis très rapprochés les uns des autres. G. Spartina Sch., p. 183.

Un seul épi terminal.

$48^{\circ}$ Epillets enfoncés dans des cavités de l'axe et formant un ensemble cylindrique. G. Lepturus R.B., p. 197.

Epillets non cachés dans des cavités de l'axe; épi non cylindrique. . . . . . . . . . .

pi très grèle, unilatéral; feuilles raides et enroulées. G. Nardus L., p. 197.

Epi plus long que large, non unilatéral; feuilles linéaires et planes. Seigle.

$50^{\circ}$ Fleurs portant sur le dos une arête genouillée. (S. G. Gaudinia.) G. Avena L., p. 189.

Fleurs sans arète ou à arète terminale et droite. . . 510

$51^{\circ}$ Glume à pièces inégales ou à une seule; épillets en contact par un bord arec l'axe qui les porte. G. Lolium L., p. 196.

Glume à pièces égales; épillets en contact par une face avec l'axe qui les porte. . . . . . . . 52n

$52^{\circ}$ Epillets très petits ou plante tout à fait grêle. G. Festuca L., p. 192.

Epillets longs d'un centimètre et plus ; plante robuste, souvent élevée. G. Triticum L., p. 195. 


\section{NOTA}

Ln certain nombre de plantes cultivees n'ont pas èté comprises dans l'Ax.lLSE DICHOTOMIQUe UE LAMARCK, qui précèle, ni dans l'Ax.Llse SEXLELLe DE Lrxyé, qui suit, bien qu'elles figurent dans leurs fumilles respectives. Comme ces plantes portent des noms frangais et connus, il suffira de se reporter a la TABLE des nons de PLANTES, pour trouver leur description et leur place naturelle dans les classificalions: 


\title{
ANALYSE
}

\section{DES FAMILLES ET DES GENRES}

\author{
D'APRÈS LE SYSTÈME SEXUEL DE LINNÉ
}

CLASSE I. Monandrie. - Une étamine libre dans une fleur à deux sexes, p. $\mathrm{xc}$.

Classe II. Diandrie. - Deux étamines libres dans une fleur à deux sexes, p. xar.

Classe III. Triandrie. - Trois étamines libres dans une fleur à deux sexes, p. xcri.

Classe IV. Tétrandrie. - Quatre étamines libres dans une fleur à deux sexes, p. xcrir.

Classe V. Pentandrie. - Cinq étamines libres dans une fleur à deux sexes, p. xcIv.

Cuasse VI. Hexandrie. - Six étamines libres dans une fleur à deux sexes, p. xcvir.

CLasse VII. Heptandrie. - Sept étamines libres dans une fleur à deux sexes, p. xcvir.

Classe VIII. Octandrie. - Huit étamines libres dans une fleur à deux sexes, p. xcviII.

Classe IX. Ennéandrie. - Neuf étamines libres dans une fleur à deux sexes, p. xcviIr.

Glasse X. Décandrie. - Dix étamines libres dans une fleur à deux sexes, p. xarx.

Classe XI. Dodécandrie. - Douze à dix-neuf étamines libres dans une fleur à deux sexes, p. c.

CLASSE XII. Icosandrie. - Vingt étamines ou plus, libres, insérées sur le calice, du moins en apparence, dans une fleur à deux sexes, p. c. 
Classe XIII. Polyandrie. - Vingt étamines ou plus, libres, insérées au fond d'une fleur à deux sexes, p. CI.

CLasse XIV. Didynamie. - Quatre étamines libres, dont deux plus longues, dans une fleur à deux sexes, p. Cr.

Classe XV. Tétradynamie. - Six étamines libres, dont quatre plus longues, dans une fleur à deux sexes, p. CII.

Classe XVI. Monadelphie. - Etamines toutes soudées par les filets, dans une fleur à deux sexes, p. CII.

Classe XVII. Diadelphie. - Etamines soudées par les filets, mais en deux faisceaux, dans une fleur à deux sexes, p. cir.

Classe XVIII. Polyadelphie. - Etamines soudées par les filets, en trois faisceaux ou plus, dans une fleur à deux sexes, p. CII.

Classe XIX. Syngénésie. - Cinq étamines à anthères soudées en tube; fleur's réunies en tête dans une enveloppe commune, p. cill.

Classe XX. Gynandrie. - Etamines soudées au style dans une fleur à deux sexes, p. CIII.

Cuasse XXI. Monœcie. - Fleurs à un seul sexe, les mâles et les femelles sur le mème pied, p. cirr.

Classe XXII. Diœcie. - Fleurs à un seul sexe, les mâles sur un pied, les femellẹs sur un autre, p. cV.

Classe XXIII. Polygamie. - Fleurs à un seul sexe mêlées à des fleurs à deux sexes sur le mème pied, p. crir.

CLasse XXIV. Ćryptogamie. - Plante sans fleurs ${ }^{(1)}$.

\section{Cilasse I. - MONANDRIE.}

Moxogrvie. - Un ovaire ou un seul style.

Fleurs trìs petites, à enveloppe simple; feuilles verticillées. G. Hippuris L., p. 70.

Fleurs ventrues, à enveloppe simple; plante sans feuilles. G. Salicornia L., p. 143.

Fleurs éperonnées à la base; feuilles opposées. G. Valeriana L., p. 88.

Fleurs verdâtres; feuilles à nervures en éventail. G. Alchemilla T., p. 6'.

(1) Voir le second volume. 


\section{Digrnie. - Deux ovaires ou deux styles.}

Fleurs à quatre ou cinq divisions recouvrant un fruit charnu.

G. Chenopodium L., p. 142.

Fleurs ventrues; plantes sans feuilles. G. Salicornia L., p. 143.

Fleurs à une seule enveloppe; plantes aquatiques. G. Callitriche L., p. 150.

Feuilles allongées, engainantes; herbes des lieux secs. G. Festuca L., p. 192.

\section{TÉTRA-0ctogrnie. - Quatre à huit ovaires.}

Plantes aquatiques. G. Zannichellia L., p. 161.

\section{Classe II. - DIANDRIE.}

Monogynie. - Un seul ovaire ou un seul style.

I. Enveloppe florale simple ou nulle.

Arbre élevé, à fruit ailé. G. Fraxinus L., p. 115.

Plantes sans feuilles, des lieux salés. G. Salicornia L., p. 143.

Petites plantes lenticulaires, flottant dans l'eau. G. Lemna L., p. 174.

Plantes sans feuilles, à fleurs en épi terminal. G. Scirpus L., p. 178.

Plantes à feuilles engainantes; fleurs en grappe. G. Schœenus L., p. 177.

Plante à feuilles alternes et non engainantes. G. Lepidium L., p. 18.

\section{Une corolle à pièces libres.}

Fleurs à ovaire infère. G. Circcea T., p. 69.

Fleurs à ovaire placé au fond du calice. G. Lythrum L., 70.

\section{Une corolle à pièces soudées et régulière.}

Corolle à tube court; style bifide; fruit charnu. G. Olea L., p. 114 .

Corolle courte; style simple; fruit charnu. G. Phillyrea L., p. 114.

Corolle à tube court, à divisions étalées. G. Ligustrum L., p. 115. Corolle à long tube; fruit charnu. G. Jasminum L., p. 115. Corolle à long tube; fruit sec. G. Syringa L., p. 115. Corolle très fendue; fruit ailé. G. Fraxinus L., p. 115. 
IV. Une corolle à pièces soudées et irrégulière.

1. Fruit sec, unique pour chaque fleur.

Corolle presque en roue, à divisions un peu inégales; fruit comprimé. G. Veronica T., p. 12\%.

Corolle à deux lèrres; calice à cinq divisions. G. Gratiola L., p. 126.

Corolle éperonnée; calice à cinq divisions. G. Pinguicula L., p. 114.

Corolle éperonnée; calice à deux divisions. G. Utricularia L., p. 114 .

2。 Fruils secs, deux ou quatre par fleur.

Corolle courte, à lobes presque égaux. G. Lycopus L., p. 132. Corolle saillante; plante ligneuse. G. Rosmarinus L., p. 133. Corolle saillante; plante herbacée. G. Salvia L., p. 133.

Drgrinie. - Deux ovaires ou deux styles. Fam. des Graninées, p. Lxxxirr.

\section{CLAsse III. - TRIANDRIE.}

Monogrnie. - Un seul ovaire ou un seul style.

I. Enveloppe florale simple ou nulle.

1. Ovaire infère,

Fleurs grandes et colorées. Fam. des IridÉEs, p. LxxIx.

Fleurs petites et rerditres; plante ligneuse. G. Osyris L., p. 147.

2. Ovaire supère.

Feuilles petites, non cngainantes. G. Polycnemum L., p. 1 14. Feuilles à gaine fendue. G. Nardus L., p. 197.

Feuilles à gaine non fendue. Fan. des Cipéracées, p. Lxxxm.

II. Enveloppe florale double; calice et corolle.

Plantes herbacées. Fam des Dips.ıcÉEs, p. LIII.

Digrie. - Deux ovaires ou deux styles.

Plantes herbacées. Fain. des Gramintés, p. LxxxiIr. 


\section{Trigynie. - Trois ovaires ou trois styles.}

Trois ovaires distincts dans chaque fleur. G. Tilloea L., p. 72. .Un seul ovaire à trois styles. Fam. des GaryophyLLÉES, p. XxxIx.

\section{Cíasse IV. - TÉTRANDRIE.}

\section{Monogynie. - Un seul ovaire ou un seul style.}

I. Enveloppe florale simple ou nulle.

$1^{\circ}$ Ovaire infëre.

Herbes aquatiques. G. Isnardia L., p. 69.

Herbes des lieux secs. G. Thesium L., p. 147.

Arbrisseaux. G. Rhamnus L., p. 42.

2० Ovaire supère.

Plantes herbacées, à feuilles entières. G. Parietaria T., p. 151. Plantes herbacées, à feuilles composées ou très découpées. Fam. des RosacÉEs, p. I.

Arbres à feuilles entières. G. Ulmus L., p. 151.

II. Enveloppe florale double; corolle à pièces libres.

$1^{\circ}$ Ovaire infère.

Arbrisseaux. G. Cornus L., p. 74.

Herbes flottantes. G. Trapa L., p. 69.

2. Ovaire supère.

Plantes herbacées. G. Cardamine L., p. 15.

Plantes ligneuses. G. Evonymus T., p. 42.

III. Enveloppe florale double; corolle à pièces soudées.

1. Ovaire infère.

Fleurs réunies en tête. Fam. des DipsacÉES, p. LIII.

Fleurs non réunies en tète. Fam. des RubiaCÉES, p. LIII.

\section{Ovaire supère.}

Fleurs bleues, réunies en tête. G. Globularia L., p. 138.

Fleurs jaunâtres ou verdâtres, en épi ou en tête. G. Plantago L., p. 138.

Fleurs axillaires; corolle en roue. G. Centunculus L., p. 114.

Fleurs axillaires; corolle tubuleuse. G. Gentiana L., p. 116. 


\section{Digrnie. - Deux ovaires ou deux styles.}

Arbrisseaux à feuilles menues. G. Tamarix L., p. 199. Plantes filamenteuses, sans feuilles. G. Cuscuta L., p. 118. Plantes herbacées, à feuilles alternes ou découpées. G. Alchemilla T., p. 64 .

Plantes herbacées, à feuilles opposées ; corolle à pièces soudées. G. Gentiana L., p. 116.

Plantes herbacées, a feuilles opposées; corolle à pièces libres. G. Arenaria L., p. 32.

Plantes herbacées, a feuilles rerticillées et toujours très entières. Fam. des RubiacéEs, p. LIII.

\section{Trigryie. - Trois ovaires ou trois styles.}

Plantes herlbacées, it feuilles opposées. G. Holosteum L., p. 3 '. Arbrisseaux à feuilles menues. G. Tamarix L., p. 198.

\section{TÉTRAGYNie. - Quatre ovaires ou quatre styles.}

\section{Quatre ovaires distincts.}

Plantes aquatiques. Fam. des Alismacées, p. Lxxvi.

Plantes des lieux secs et a feuilles épaisses, grasses et charnues.

Fam. des Crassulacées, p. xxxim.

2. Un seul ovaire à quatre styles.

Arbrisseaux à feuilles épineuses. G. Ilex L., p. 43.

Arbrisseaux it feuilles menues. G. Tamarix L., p. 198.

Plantes herbacíes, à feuilles opposées; calice à pièces trifides.

G. Linum L., p. 28.

Plantes herbacées, a feuilles oprosées; calice à pièces simples.

Fam. des Caryopiryllées, p. xxxix.

\section{Cíasse V. - PENTANDRIE.}

Monogrie. - Un seul ovaire ou un seul style.

I. Enveloppe florale simple ou nulle.

$1^{\circ}$ Oraire infère.

Herbe couchée. G. Thesium L., p. 147.

Arbrisseau. G. Rhamnus L., p. 42.

$2^{\circ}$ Ovaire supère.

Fleurs verdâtres. Fam. des Ciaryophyllées, p. xaxix.

Fleurs blanc rosé. G. Glaux L., p. 113. 
II. Enveloppe forale double; corolle à pièces libres.

1.0 vaire infère.

Arbrisseau non grimpant: calice en godet. G.'Ribes L., p. 73. Arbrisseau grimpant ; calice très petit. G. Hedera L., p. 74.

$2 \circ 0$ vairo supère.

Plante herbacée; calice à cinq pièces. G. Viola T., p. 23. Plante herbacée; calice à deux pièces. G. Impatiens L., p. 28. Arbrisseaux. No 50 , p. xxxviII.

III. Enveloppe florale double; corolle à pièces soudées.

$1^{\circ}$ Ovaire infère.

Arbrisseau flexueux. G. Lonicera L., p. 87.

Herbes à fleurs blanches. G. Samolı.s L., p. 113.

Herbes à fleurs bleues, bleuâtres ou rougeâtres, quelquefois rouges. Fam. des Campanulacées, p. LiI.

2॰ Ovaire supère.

Ovaire divisé en quatre parties, du milieu desquelles part le style. Fam. des BorraginéES, p. LXII.

Style terminant un ovaire simple; étamines opposées aux divisions de la corolle. Fam. des Primulacées, p. LXIv.

Style terminant un ovaire simple; étamines alternes avec les divisions de la corolle, c'est-ä-dire opposées aux échancrures. No 164, p. LXII.

\section{Digrnie. - Deux ovaires ou deux styles.}

I. Enveloppe florale simple ou nulle.

Plantes à feuilles sans stipules. No 294, p. Lxxxi.

Herbes à feuilles stipulées. Fam. des Caryophyllées, p. xxxix. Arbres ou arbrisseaux à feuilles stipulées. No 172, p. LXIX.

II. Enveloppe florale double; corolle à pièces libres.

Arbrisseau à feuilles menues. G. Tamarix L., p. 198.

Herbes à feuilles stipulées. G. Herniaria T., p. 37.

Herbes ou arbrisseaux à feuilles grandes, découpées, sans stipules. Fam. des Ombelliféres, p. XLV.

III. Enveloppe florale double; corolle à pièces soudées.

Etamines réunies en couronne par les anthères; filets courts.

Fam. des ApocynÉES, p. LXII.

Etamines libres et écartées. Fam. des RubiacÉEs, p. LIII. 
Trigynie. - Trois ovaires ou trois styles.

I. Enveloppe florale simple ou nulle.

Herbes à feuilles munies d'une gaîne rougeâtre. G. Polygonum L., p. 145.

Herbes à feuilles sans gaine. G. Beta T., p. 141.

II. Enveloppe florale double; corolle à pièces soudées.

Arbrisseaux ou herbes à ovaire infère et à feuilles opposées.

Fam. des Rubiacées, p. LIII.

III. Enveloppe florale double; corolle à pièces libres.

Arbrisseaux à feuilles menues. G. Tamarix L., p. 198.

Arbrisseaux à feuilles ordinaires et à étamines opposées aux pétales. No $\mathbf{5 0}$, p. xxxvirr.

Arbrisseaux à feuilles ordinaires et à étamines alternes avec les pétales. G. Rhus L., p. 43.

Herbes a feuilles opposées ou non. Fam. des Carropirllées, p. $\operatorname{xxxIx}$.

TÉTRAGrie. - Quatre ovaires ou quatre styles.

Plantes herbacées, a fleurs blanches. G. Parnassia L., p. 24. Arbrisseaux à feulles menues. G. Tamarix L., p. 198.

Arbrisseaux a feuilles ordinaires. G. Rhamnus L., p. 42.

Pentagrne. - Cinq ovaires ou cinq styles. 1. Ginq ovaires.

Plantes grasses. G. Sedum L., p. 71.

Plantes ordinaires, à feuilles stipulées. G. Geranium L., p. 26.

$2^{\circ}$ Cinq styles.

Plantes flottantes dans l'eau. G. Aldrovanda Mont., p. 2't.

Plantes glanduleuses, rougeâtres et à feuilles toutes radicales. G. Drosera L., p. 23.

Plantes non glanduleuses, à feuilles radicales et ả fleurs en tête ou en épi. G. Statice L., p. 139.

Plantes à très petites feuilles alternes. G. Linum L., p. 28.

Plantes à très petites feuilles opposées. G. Cerastium L., p. 34.

Polygrxie. - Ovaires ou styles nombreux.

Petite plante, à ovaires et à fruits disposés en colonne allongée, G. Myosurus L., p. 3 , 


\section{Cliasse VI. - HEXANDRIE.}

\section{Movogrnie. - Un seul ovaire ou un seul style.}

\section{Enveloppe florale simple, uniforme.}

$1 \circ 0$ vaire infère.

Fam. des Amaryllidées, p. LxxviII.

2. Ovaire supère.

Plantes a feuilles cylindriques, ou longues et minces; fleurs verdàtres. No $^{\circ}$ 287, p. LXXXI.

Plantes ligneuses, à hleurs jaunes. G. Berberis L., p. 7.

Plantes à fleurs colorées. Fam. des LILIACÉES, p. Lxxiri.

II. Enveloppe florale double; calice et corolle distincts.

Calice à pièces libres. Fam. des Caryophyllées, p. xxxix.

Calice à pièces soudées. № 74, p. XLI.

\section{Digrnie. - Deux ovaires ou deux styles.}

Plante herbacée, à feuilles engaînantes et à gaine rougeâtre.

G. Polygonum L., p. 145.

Arbre ou arbrisseaux. G. Celtis T., p. 198.

\section{Trigynie. - Trois ovaires ou trois styles.}

Petites plantes à feuilles opposées. G. Elatine L., p. 37.

Plantes à feuilles munies d'une gaine rougeâtre. G. Polygonum L., p. 145.

Plantes à feuilles alternes et sans gaine. No 191, p. Lxxir.

Hexagynie. - Six ovaires ou six styles.

Fain. des Alismacées, p. LXxvi.

\section{Cilasse VII. - HEPTANDRIE.}

Arbres à feuilles en éventail. G. Esculus L., p. 41. 


\section{Classe VIII. - OGTANDRIE.}

Monogynie. - Un ovaire ou un style.

I. Enveloppe florale simple ou nulle.

Sous-arbrisseau. G. Daphne L., p. 146.

Herbes sans feuilles vertes. G. Monotropa L., p. 112.

Herbes dressées; à petites feuilles; fleur's cn épis effilés. G. Passerina L., p. 146.

II. Enveloppe florale double; corolle it pièces libres. 1. Ovaire infère.

Reportez-rous au No 93 , p. XIv.

$2 \circ 0$ vaire supere.

Arbres à petites fleurs verdàtres ou jaunattres. G. Acer L., p. 41 . $\Lambda$ rbres a assez grandes fleurs, blanches ou rosées. G. Esculus L., p. 41 .

Herbes sans feuilles vertes. G. Monotropa L., p. 112.

Herbes feuillées, à fleurs régulières. G. Ruta L., p. 40.

Digrnie. - Deux ovaires ou deux styles.

Fleurs blanches ou verditres. Fam. des Caryophyllées, p. Xxxix.

Fleurs jaunes ou jaunatres. G. Chrysosplenium L., p. 73.

Trigynie. - Trois ovaires ou trois styles.

Plantes à feuilles munies de gaines rougeâtres. G. Polygonum L., p. 145.

TÉtRAgynie. - Quatre ovaires ou quatre styles.

Herbe des bois, à fleurs vertes. G. Paris L., p. 166. Herbes des fossés, à fleurs blanc rosé. G. Elatine L., p. 37.

\section{Classe IX. — ENNÉANDRIE.}

MoNogrnie. - Un seul oraire ou un seul style. Arbrisseau à feuilles persistantes. G. Laurus T., p. 146. 
Hexagynie. - Six ovaires ou six styles.

Herbes aquatiques, à fleurs rosées. G. Butomus L., p. 159.

\section{GLAsse X. - DÉGANDRIE.}

Monogrnie. - Un seul ovaire ou un seul style.

I. Enveloppe florale double; corolle à pièces libres.

Corolle irrégulière, rouge. G. Gercis L., p.60.

Corolle régulière; plante sans feuilles. G. Monotropa L., p. 112. Corolle régulière; fleurs jamais jaunes. G. Geranium L., p. 26. Corolle régulière, jaune; feuilles simples. G. Gentiana L., p.116. Corolle régulière, fleurs jaunes; feuilles découpées. Voyez le $\mathrm{n}^{\circ} 63$, p. $\mathrm{xxxix}$.

II. Enveloppe florale double; corolle à pièces soudées. Fam. des EricacÉes, p. Lx.

Digrivie. - Deux ovaires ou deux styles.

I. Enveloppe florale simple ou nulle.

Fleurs jaunes ou jaunâtres. G. Chrysosplenium L., p. 73.

Fleurs blanches ou verdàtres. Fam. des Caryophyllées, p. $\operatorname{xxxIx}$.

II. Enveloppe florale double; corolle à cinq pièces libres.

Calice à pièces soudées ou ovaire supère. Fam. des Car.xophyLLÉES, p. xxxix.

Calice à pièces libres ou oraire infère. G. Saxifraga L., p. 73.

Trigrnie. - Trois ovaires ou trois styles.

Fam. des Garyophyllées, $p$. xxxix.

Pentagrnie. - Cinq ovaires ou cinq styles.

$1^{\circ}$ Cinq ovaires.

Fam. des Crassulacées, p. xxxiII. 
2. Cing styles.

Arbrisseaux. G. Coriara L., p. 41.

Herbes à feuilles en trèfle. G. Oxalis L., p. 29.

Herbes à feuilles simples et opposées. Fam. des Caryophyllées,

p. Xxxix.

DÉCAGYNIE. - Dix ovaires ou dix styles.

Grandes plantes, à fruit charnu. G. Phytolacca L., p. 140.

\section{Cílasse XI. - DODÉGANDRIE.}

Monogrnie. - Un ovaire ou un style.

Fleurs jaunes; feuilles opposées. G. Gentiana L., p. 116.

Fleurs jaunes; fenilles alternes et grasses. G. Portulaca T., p. 38.

Fleurs rouges. G. Lythrum L., p. 70.

Digrnie. - Deux ovaires ou deux styles.

Plantes herbacées et à fleurs jaunes. G. Agrimonia L., p. 6k.

Trigrnie. - Trois ovaires ou trois styles.

Plantes à suc laiteux. G. Euphorbia L., p. 147.

Plantes à feuilles en éventail. G. Potentilla L., p. 63.

Plantes à feuilles opposées. G. Gentiana L., p. 116.

Plantes à feuilles alternes. G. Reseda L., p. 21.

Pentagrnie. - Cinq ovaires ou cinq styles.

Plantes à fleurs jaunes. G. Portulaca T., p. 38.

DodÉCAgrvie. - Douze ovaires ou styles et plus.

Plantes grasses. G. Sempervivum L., p. 72.

\section{Classe XII. - ICOSANDRIE.}

MoNogrivie. - Un seul ovaire ou un seul style.

1. Ovaire infëre.

Plantes ligneuses, à fleurs rouges. G. Punica T., p. 67. Plantes ligneuses, à fleurs blanches. G. Myrtus T., p. 57. 
2. Ovaire supère.

Fam. des Rosacées, p. L.

Di-Pentagrnie. - Deux à cinq ovaires ou styles.

Plantes ligneuses ou herbacées. Fam. des Rosacriss, p. L.

Polygrnie. - Ovaires ou styles nombreux.

Fam. des RosacÉES, p. L.

\section{Classe XIII. - POLYANDRIE.}

Monogrnie. - Un seul ovaire ou un seul style.

I. Enveloppe florale simple.

Plantes terrestres. Fam. des RexonculacéEs, p. xxxir. Plantes aquatiques. G. Nymphoea L., p. 7.

II. Enveloppe florale double; corolle à quatre pièces.

Fleurs régulières. Fam. des PApavéracÉEs, p. xxxiIr.

III. Enveloppe florale double; corolle à cinq pièces.

Arbres. G. Tilia L., p. 38.

Herbes ou plantes ligneuses basses. G. Cistus L., p. 22.
Di-Tri-Pentagynie. - Deux ou trois ou cinq ovaires ou styles.

Pleurs d'un beau jaune. G. Hypericum L., p. 39.

Fleurs jamais d'un beau jaune. Fam. des Renonculacées, p. XXXII.

Polygrnie. - Ovaires ou styles nombreux.

Fam, des Renonculacées, p. xxxir.

\section{Ciasse XIV. - DYDYNAMIE.}

Ovaires ou fruits à quatre parties, avec le style implanté au milieu. Fam. des LABIÉES, p. LXVI. 
Ovaires ou fruits simples, avec le style au sommet. Fam. des PERSONÉES, p. LXV.

\section{Classe XV. - TÉTRAdynamie.}

Fam. des Cruciféres, p. xxxvi.

\section{Cliasse XVI. - MONADELPHIE.}

Triandrie. - Trois étamines.

Plantes ligneuses et épineuses. G. Ruscus L., p. 166.

Plantes herbacées et munies de vrilles. Fam. des CucurbiTACÉES, p. LII.

\section{Pentandrie. - Cinq étamines.}

Plantes grimpantes. Fam. des Cucurbitacées, p. LII.

Plantes non grimpantes. Fam. des Géraniacées, p. xxxiv.

$$
\text { Décandrie. - Dix étamines. - }
$$

Fleurs régulières. Fam. des GÉraniacées, p. xxxır. Fleurs irrégulières. Fam. des LÉGunineuses, p. xLII.

$$
\text { Polyandrie. - Etamines nombreuses. }
$$

Fam. des MalvacÉEs, p. xxxiv.

\section{Cilasse XVII. - DIADELPHIE.}

Six étamines ou anthères. G. Fumaria L., p. 8. Huit étamines ou anthères. G. Polygala l., p. 38.

Dix étamines ou anthères. Fam. des LéguMinEuSES, p. XLII.

\section{Cilasse XVIII. - POLYADELPHIE.}

Trois à cinq styles. G. Hypericum L., p. 39. 


\section{Cilasse XIX. - SYNGÉNÉSIE.}

Fleurs en tête, réunies dans un involucre commun. Fam. des CoMroséEs, p. LIV.

Fleurs non réunies dans un même involucre; plantes épineuses. G. Echinops L., p. 98.

Fleurs non réunies dans un mème involucre; plantes non épineuses. Fam. des Campanulacées, p. LII.

\section{Classe XX. - GYNANDRIE.}

Une ou deux anthères. Fam. des OrChidéEs, p. Lxxix.

Six ou douze anthères. G. Aristolochia L., p. 147.

\section{Cilasse XXI. - MONCEGIE.}

Mon.sdnie. - Une seule étamine ou anthère.

Feuilles filiformes ou rubanćes. Fam. des Alismacées, p. LXXvi.

Feuilles élargies et toutes radicales. G. Arum L., p. 173.

Feuilles élargies et alternes. G. Euphorbia L., p. 147.

Feuilles élargies, opposées sur la tige et à bords entiers. G. Callitriche L., p. 150.

Feuilles élargies, opposées et denticulées. G. Naïas L., p. 174.

\section{Diandrie. - Deux étamines ou anthères.}

Petites plantes lenticulaires, flottantes. G. Lemna L., p. 174. Arbre à feuilles élargies. G. Fraxinus L., p. 115. Arbre à feuilles en aiguille. G. Pinus L., p. 155.

\section{Triandrie. - Trois étamines ou anthères.}

Feuilles à gaine fendue. Fam. des Graminées, p. LxxxiII. Feuilles à gaine non fendue et tubuleuse. G. Carex L., p. 179. Feuilles raides, en épée; fleurs en chatons cylindriques. G. Typha L., p. 174.

Feuilles raides, en épée; fleurs en têtes globuleuses. G. Sparganium L., p. 173.

Feuilles sans gaine ni en épée; arbrisseau. G. Ficus T., p. 152. Feuilles sans gaine ni en épée; petites herbes. G. Amaranthus L., p. 141. 
TÉTRANDRIE. - Quatre étaminess ou anthères. $1 \circ$ Style simple.

Enveloppe florale verdàtre. No 296, p. Lxxxr. Enveloppe florale colorée. G. Littorella L., p. 139.

2० Style bifide.

Chatons globuleux. Mûrier. Fam. des UnticÉEs.

Chatons cylindriques. G. Betula L., p. 15ł.

3० St yle trifide.

Arbrisseaux à feuilles persistantes. G. Buxus T., p. 150. $4^{\circ}$ Style à quatre divisions.

Herbes aquatiques. G. Myriophyllum L., p. 70.

Pentandrie. - Cinq étamines ou anthères.

Reportez-vous au no 172, p. Lxix.

Hexaxdrae. - Six étamines ou anthères.

Arbres ou arbrisseaux. G. Betula L., p. 15 '.

Herbes aquatiques. G. Myriophyllum L., p. 70.

Octandrie. - Huit étamines ou anthères.

Arbres ou arbrisseaux. Fam. des Amentacḱes, p. Lxx.

Herbes aquatiques. G. Myriophyllum L., p. 70 .

Herbes jaunitres, sans feuilles. G. Cytinus L., p. 147.

Pulyaxdrie. - Etamines ou anthères nombreuses.

$1^{\circ}$ Style simple.

Ilerbes terrestres, ì larges feuilles. G. Arum L., p. 173.

Iferbes aquatiques. G. Cieratophyllum L., p. 151. Arbres. Platanes. Fam. des AMENTACÉES.

\section{Style bifide.}

Herbes à ovaire infẻre. G. Sanguisorba L., p. 64. Arbres à ovaire infëre Noyer. lan. des AMENTacées.

Herbes à ovaire supère. G. Mercurialis T., p. 150.

Arbres ou arbrisseaux à ovaire supère, du moins en apparence.

Fam. des Amentacées, p. LXX.

3॰ Style ì 3-6 divisions.

Arbres. Fam. des AmextacÉES, p. LXX.

Herbes aquatiques, G. MIy,iophyllum L., p. 70. 
4.0 0vaires et styles nombreux.

Plantes aquatiques, munies de feuilles en fer de flèche. G. Sagit taria L., p. 158.

\section{Monadelphie. - Filets des étamines soudés.}

Arbres ou arbrisseaux. Fam. des Conifères, p. Lxxi.

Herbes couchées ou grimpantes, à larges feuilles. Fam. des Cucurbitacíes, p. LII.

Herbes dressées, à feuilles en érentail, Ricin. Fam. des EuphorbiacÉEs.

Herbes épineuses ou hérissées. G. Xanthium T., p. 108.

Herbes odorantes. G. Chenopodium L., p. 142.

Herbes jaunâtres, sans feuilles. G. Cytinus L., p. 147.

\section{Cilasse XXII. - DICEGIE.}

Monandrie. - Une étamine ou anthère.

Herbes marines. G. Zostera L., p. 174.

Arbres ou arbrisseaux. G. Salix L., p. 152.

DIANDRIE. - Deux étamines ou anthères.

Herbes aquatiques. G. Vallisneria Michx., p. 159. Arbres à feuilles opposées. G. Fraxinus L., p. 115. Arbres ou arbrisseaux à feuilles alternes. G. Salix L., p. 152.

TriandriE. - Trois étamines ou anthères.

Herbes à feuilles opposées. G. Valeriana L., p. 88. Herbes à feuilles engaînantes. G. Garex L., p. 179. Herbes aquatiques. G. Vallisneria Nichx., p. 159. Arbrisseaux à ovaire infëre. G. Osyris L., p. 147. Arbrisseaux piquants. G. Ruscus L., p. 166. Arbrisseaux à larges feuilles simples. G. Ficus T., p. 152. Arbrisseaux à feuilles composées. G. Pistacia L., p. 43.

\section{TÉTRANDRIE. - Quatre étarhines ou anthères.}

Arbrisseaux parasites, à ovaire infẻre. G. Viscum L., p. 198. Arbrisseaux à fleurs aromatiques. G. Myrica I., p. 152. Arbrisseaux à enveloppe florale simple. (*. Hippophä̈ L., p. 146. Arbrisseaux à enveloppe florale double. G. Khamnus L., p. 42. Herbes a feuilles opposées. G. Urtica T., p. 151. 


\section{Pentandrie. - Cinq étamines ou anthères.}

Arbrisseaux à feuilles ailées. G. Pistacia L., p. 43.

Arbrisseaux à enveloppe florale double. G. Rhamnus L., p. 42. Arbrisseaux à fleurs en châtons. G. Salix L., p. 152.

Herbes à feuilles opposées. G. Humulus L., p. 151.

Herbes à feuilles alternes. G. Bryonia L., p. 108.

\section{Hexandrie. - Six étamines ou anthères.}

Herbes à ovaire infẻre. G. Tamus L., p. 169. IIerbes à ovaire supère. G. Rumex L., p. 14 . Arbrisseaux grimpants. G. Smilax L., p. 166. Arbrisseaux aromatiques, non grimpants. G. Myrica L., p. 152.

Octandrie. - Huit étamines ou anthères. Arbres. G. Populus T., p. 153.

\section{ExNéANdrie. - Neuf étamines ou anthères.}

Arbres ou arbrisseaux. G. Laurus T., p. 146. Herbes aquatiques. G. Hydrocharis L., p. 159. Herbes terrestres. G. Mercurialis T., p. 150.

DÉctydnie. - Dix étamines ou anthères. Arbrisseaux ì feuilles opposées. G. Coriaria L., p. 41. Herbes a feuilles opposées. Fam. des CarYophýLLÉES, p. xxxix.

Polyandrie. - Plus de dix étamines ou anthères. Arbrisseaux a feuilles persistantes. G. Laurus T., p. 146. Arbres. G. Populus T., p. 153.

Herbes. G. Mercurialis T., p. 150.

\section{Moxadelphie. - Filets des étamines soudés.}

Une on deux anthères; feuilles aplaties. G. Salix L., p. 152. Une ou deux anthères; feuilles en aiguille. G. Juniperus L., p. 157.

Trois anthères; arbrisseaux à feuilles en aiguille. G. Juniperus L., p. 157.

Trois anthères; arbrisseaux en buisson épineux. G. Ruscus L., p. 166.

Trois anthères; herbes grimpantes. G. Bryonia L., p. 108. P'lus de trois anthères. Fam. des Cionifères, p. LXXI. 
- SyngénéSIE. - Anthères soudées.

Plantes herbacées. Fam. des ComposéEs, p. LIv.

\section{Glasse XXIII. - POLYGAMIE.}

Les genres de cette classe ont été répartis dans les classes précédentes, aussi bien dans celles qui ont des fleurs à deux sexes que dans celles qui n'ont que des lleurs unisexmées. De cette façon il ne peut en r'śsulter aucun inconvénient pour la recherche des familles et des genres, quelle que soit la sorte de fleurs sur laquelle on tombe. 



\section{FLORE DE BORDEAUX}

ET DU SUD-OUEST

\section{Fam. des RENONGULAGÉES Juss.}

\section{G. Clematis L. - Clématites.}

Plante glabre; feuilles composées, à folioles ovales ou lancéolées ; fleurs blanches, à pieces de l'enveloppe florale glabres en dedans. - Naturalisée dans le S.-O., surtout le long de la côte.

C. flammula L.

- Plante un peu relue; feuilles á folioles élargies, presque en cour; fleurs blanches, à pièces de l'enreloppe florale velues des deux côtés. - Les haies. - Vioche. G. Vitalba L.

\section{G. Thalictrum L. - Pigamons.}

Ce genre renferme des espèces très roisines les unes des autres, fort variables, donnant, par suite, naissance à des variétés fixes ou non qui embarrassent les descripteurs.

Fleurs dressées, à étamines droites. . . . . . . . . . 1 - Fleurs penchees, à étamines pendantes; anthères aiguëss au sommet. . . . . . . . . . . . . . .

1. Ovaires el fruits à trois faces, ailés. - Plante a fleurs roses, purpurines ou blanches. - Bois montueux; se trouve aux environs de Coutras. Th. açuilegifolium L.

- Ovaires et fruits ovales. - Tige élevée, sillonnée et creuse; fleurs d'un blanc jaunàtre, en bouquet serré. Les prés humides.

Th. flavum $\mathrm{L}$.

2. Oiaires et fruits ovales. - Plante glabre et verte, trés feuillée en bas, presque nue en haut; queues des fleurs courtes et fortes. - Les lieux secs.

Th, minus L. 
Varie : $1^{0}$ à plante velue et glanduleuse (Th. pubescens DC.); $2^{\circ}$ a queues des fleurs capillaires ( $T h$. saxatile DC.)

- Oraires et fruits allongés en fuseau. - Plante ordinairement glabre et verte, à tige feuillée jusquau sommet; queues des fleurs grèles, longues et flexueuses. - Les bois.

Th. majus Jacq.

Varie à tige faible, grêle, et à rameaux rampants ( $T h$. sylvaticum $\mathrm{K}$.)

\section{G. ANemoxe L. - Anémones.}

Collerette de la fleur à trois feuilles; ovaires et fruits terminés en pointe cou'te. . . . . . . . . 1

- Collerette à parties nombreuses; ovaires et fruits terminés en appendice long et plumeux. - Plante variable, vclue, a fleur lilas ou violet pâle. - Ça et là. - Pulsatille.

A. pulsatilla L.

Varie surtout à fleurs d'un violet foncé, noir, et à lanières des feuilles rétrécies à la base ell petite queuc (A. montana Hop.)

1. Fleurs jaunes. - Plante à tige souterraine longue, grêle et rameuse; feuilles naissant après la fleur, loin du pied fleuri; fruits velus. - Ci et li. A. ranunculoides $L$.

- Fleurs blanches ou roses . . . . . . . . . 2

2. Feuilles de la collerette munies d'une queue. - Plante grêle et courte, presque glabre; une seule fleur, rarement deux, à queve recourbée après la floraison. - Les bois sablonneux. - Sylvie.

A. nemorosa $\mathrm{L}$.

- Feuilles de la collerette sans queue.. . . . . . 3

3. Collerette à feuilles profondément découpées. - Petite plante a fleur solitaire, rouge, bleue, violette ou safranée; fruits laineux. - Naturalisce çà et là. A. coronaria L.

- Collerette ì feuilles peu ou point cécoupées. - Petite plante analogue à la précédente, à fleur pourpre, rosée ou blanche. - Nat. dans le bass, de l'Adour. A. hortensis L.

\section{G. Adowis L. - Gouttes de sang.}

Plante fort variable, ì feuilles très découpées, glabres; fleurs au sommet des rarneaux, dun rouge plus ou moins vif, rarement james. - Moissons calcaires. A. annua Mill.

Tarie : $1^{n}$ it pieces externes de la flemr velues et a fruits munis d'un point noir au sommet, disposés en épi cỵlindrique (A. flammea Jacr.); $2^{\circ}$ à fleurs d'un rouge noir et it hee des fruits court (A. autumnalis $\mathrm{L}_{\text {.. }}$ ); $3^{\circ}$ a fleurs d'un touge clair et it bee des fruits longy.1. (estivalis L.) 


\section{G. Caltha L. - Populages.}

Plante glabre, rameuse, à feuilles en forme de rein, crénelées, luisantes, et à fleurs d'un jaune d'or; fruits divergents, à bec recourbé. - Bords des eaux. - Boutons d'or, Soucis d'eau.

C. palustris $\mathrm{L}$.

\section{G. Hellebonus DC. - Hellébores.}

Feuilles à segments digités ou en pédale.-S. G. Helleborus L. Feuilles à segments ternés ou en tréfle. - S. G. Isopyrum L.

S. G. Helleborus L.

Tiges florales munies de petites feuilles ovales et espacées. ................... . 1

- Tiges florales nues, ne portant de pelites fenilles qu'à la base. - Plante glabre, à tige souterraine courte et noire; fleurs rerdàtres, à étamines non saillantes. - Descendue des montagnes:

H. viridis $\mathrm{L}$.

1. Fleurs verdalres. - Plante glabre, fétide par le frottement; étamines saillantes. - Les coteaux secs. H. fœetidus L.

- Fleurs blanches ou rosées. - Plante à feuilles toutes radicales. - Cultivée sous le nom de Rose de Nö̈l et échappée.

H. niger L.

$$
\text { S. G. Isopyinum L. }
$$

Plante glabre, à feuilles molles, découpées et à deux ou trois fleurs blanches. - Cia et lá, dans les bois couverts. (I. thalictroïdes L.)

H. thalictroides $U C$.

\section{G. Mrosurus L. - Ratoncules.}

Très petite plante glabre, à feuilles toutes linéaires et ralicales; lleurs vert jaunàtre. - Cià et là.

M. minimus L.

\section{G. Ranumculus L. - Renoncules.}

Enveloppe florale double; calice ct corolle bien distincts, les deux à cinq pièces. - S. G. Ranunculus L.

Enveloppe florale simple, a pièces nombreuses. - S. G. Ficaria DC.

S. G. Ranunculus L.

Fleurs jaunes; plantes terrestres en genéral. . . . . . I

- Fleurs blanches ou rosées; plantes aquatiques. . 13

1. Oraires et fruils disposés cu téte allongé; pélales áns 
écaille ni membrane à la base. - Plante des lieux aquatiques, à tige creuse et très ramense; fleurs petites, d un jaune pâle.

R. sceleratus L.

- Ovaires et fruits en tête arrondie; pétales munis d'une écaille ou d'une membrane à la base. . . . . . 2

2. Fevilles entières et allongées. . . . . . . . . 3

- Feuilles découpées. . . . . . . . . . . 5

3. Fruits globuleux. - Plante à racines fibreuses et renflées. - Les coteaux secs.

Fruits aplatis, avec bordure. .

4. Fleurs grandes, à queue non sillonnée. - Plante élevée, à feuilles demi-embrassantes; fleurs à calice velu et a corolle luisante. - Les marais. $\quad$ R. lingua L.

- Fleurs petites, à queue slriéc ou sillonnée. - Plante à feuilles inférieures orales et à feuilles supérieures lancéolées; fleurs d'un jaune soufre; fruits lisses, à bec court. - Les marais.

R. flammula $\mathrm{I}$.

Varie à fruits fincment tuberculeux et sans bec (R. ophioglossifolius Vill.)

5. Fleurs à queue non sillonnéc. . . . . . . . 6

- Fleurs à queue sillonnée. . . . . . . . . . . 9

6. Ovaires et fruits à pointe droite. . . . . . . 7

- Ovaires et fruits à pointe recourbée. . . . . . . . 8

7. Plante velue, étalée sur le sol. - Feuilles en cosur, a divisions dentées; fleurs petites, à queue opposée aux feuilles. - Les lieux cultivés.

Varie à pétales arortés.

- Plante glabre et dressée. - Feuilles découpées en lobes linéaires; fleurs jaume soufre; fruits hérissés d'aiguillons. - Les moissons.

Varie à fruits sans aiguillons.

R. arvensis $\mathrm{L}$. R. parviflorus 1 .

8. Plante glabre. - Tige souterraine noueuse et courte; faulles inférieures en cœur, les supérieures à divisions divergentes; fruits velus, soyeux et rentrus. - Les bois humides.

$R$. auricomus $L$.

- Plante plus ou moins velue. - Fenilles de la tige a contour polygonal, les supérieures ḋ divisions linéaires. Bords des eaux.

R. acris $\mathrm{L}$.

Varie à feuilles très découpées ( $R$. borkanus Jord.)

9. Plante à tige tuberculeuse à la base; calice rabattu. Lieux sablomneux.

R. bulbosus $\mathrm{L}$.

- Tige non tuberculeuse à la base. . . . . . 10 10. Racines de deux sortes, les unes allongées, les autres courtes et renflées. - Plante à feuilles presque toutes radicales, découpées en segments nombreux. - Iieux arides et sablomeux. R. choexophyllos I.

- Racines toutes semblables et allongées. . . . . 11 11. Iruits a fointe courlect dioite. - I lante diosite, relue, 
d'un vert jaunâtre; fleurs à corolle plus courte que le calice. - Lieux cultivés humides. R. philonotis Retz.

Varie: $1^{0}$ à plante moins velue et a corolle égalant le calice $\left(\boldsymbol{R}\right.$. trilobus Desf.); $2^{\circ}$ à plante naine, portant une à deux fleurs (R. parvulus L.)

- Fruits à pointe enroulée sur elle-mème. - Plante couchée à la base, à poils étalés; réceptacle de la fleur hérissé. - Bois secs. (R.syluaticus Thuil.) R. nemorosus DC. Fruits à pointe arquée. . . . . . . . 12 12. Fruits hérissés d'aiguillons. - Plante couchée, à feuilles en cœur, crénelées ou découpées en trois. - Lieux cultivés.

R. muricatus L.

- Fruits aplatis, suns aiguillons. - Plante dressée, à rejets rampants; feuilles ovales dans leur contour, incisées. - Lieux cultivés. $\quad$ R. repens L.

13. Plante munie de feuilles submergées à divisions capil-

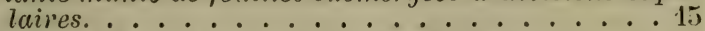

- Plante de feuilles toutes élargies et flotantes. . . 11.

1'. Feuilles a trois ou cinq divisions courtes et obtuses. Plante à fleurs trés petites; corolle dépassant à peine le calice.

R. hederaceus L.

- Feuilles à trois divisions élargies au sommet, l'intermédiaire à trois, les latérales à quatre dents arrondies. - Plante à fleurs plus grandes; corolle dépassant le calice. ( $R$. coenosus Guss.) R. Lenormandi Sch.

15. Pétales tout à fait blancs, sans base jaune. . . . . 16 - Pétales à base jaune. - Plante extrêmement variable; feuilles ordinairement de deux sortes, les unes capillaires, les autres a trois ou cing divisions plus ou moins profondes; réceptacle de la fleur velu.

R. aquatilis $\mathrm{L}$.

Parmi les nombreuses formes de cette plante, on distingue : 10 celle à feuilles toutes capillaires et à fleurs relativement grandes, à cinq ou neuf pétales ( $R$. fluitans Lam.); $2^{\circ}$ celle dont les feuilles capillaires forment pinceau au sortir de l'eau, dont les pétales sont beaucoup plus longs que le calice et dont la pointe des fruits est large et jaunatre ( $R$. aquatilis type des auteurs); $3^{\circ}$ celle a feuilles capillaires toujours étalées en cercle et dont la pointe des fruits est longue et linéaire $(R$. divaricatus Schr.); $4^{\circ}$ celle dont les feuilles capillaires s'étalent au sortir de l'eau au lieu de se réunir en pinceau et dont les étamines sont plus courtes que les carpelles ( $R$. Baudotii God.); $5^{\circ}$ celle dont les feuilles flottantes forment un cercle régulier et dont les fleurs sont petites et a courte queue $(R$. radians $R e r.) ; 6^{\circ}$ celle qui croit hors de l'eau et qui n'a pas de feuilles capillaires ( $R$. terrestris Gr. et God.); 70 celles à feuilles toutes capillaires et à fleurs trés petites (R.trichophyllus Ch. et $R$. Dronetii silh.); etc. 
16. Corolle ne dépassant pas le calice. - Plante girèle et nageante, i tiès petites fleurs; fruits peu nombreux, obtus, à bec grèle.

R. tripartitus DC.

- Corolle plus longue que le calice. - Plante à tige nageante et relue; fleur's assez grandes; fruits nombreux, à long bec.

R. ololeucos Ll.

S. G. Ficaria DC.

Plante couchée; feuilles en cour, munies de globules blancs at leur aisselle; fleurs luisantes, d'un jaune d'or. - Les haies. - (F. renunculoïles DC. $)$ R. Ficaria L.

\section{G. Nigella L. - Nigelles.}

Fleur munic d'une collerelle à pièces très découpées, sem. blables aux feuilles. - Plante à raneaux dressés; fleurs blenatres, a ovaire on fruit indivis au sommet. - Les Charentes et eit et lì dlans le S.-O. N. damascena L.

- Fleur sans collerette. . . . . . . . . 1

1. Ovcrive ou fruit indivis au sommet. - Plante a rameaux courts et ouverts; fleurs bleu clair. - Plaine de la Garonne.

N. hispanica L.

- Ovaire ou fruit divisé au sommet. - Plante a rameanx dirigés en tous sens; fleurs blentites. - Les Charentes.

N. arvensis $\mathrm{L}$.

\section{G. Agúllegia L. - Ancolies.}

Plante élevie, a fleurs munies dinerons crochus, blenes, crandes et penchées. - Les bois frais.

A. vulgaris $\mathrm{L}$.

\section{G. Delphisica L. - Pieds-d'alouette.}

Oeare ou fruil unique pour chaque fleur. . . . . 1 - Oraires ou fruits de trois à cinq par fleur. - Plante très variable, it feuilles découpées; fleurs bleues ou blimches, i ćperon souvent long. - Moissons. D. peregrinum L.

Tarie : to a pièces internes de lenveloppe florale arrondies et en cour à la base (D. eardiopetalum DC. ou 1). Garumne Lap.); $2^{\circ}$ a plantes soyeuses et à éperon de la fleur toujours très court (D. ambigumm L.); ete.

1. Fruit glabre. - Plante srèle, at rameaux dirigés en tous sens; fleurs blenes on blanches, en épi lìche. - Moissons des terrains calcaires. D. Goisolida L.

- Fruit velu. - Plante forte, velue; fleurs bleues, blanches ou roses, en grappe làche. - Dans les plaines du S. - O. D. Ajacis L. 


\section{Fam. des BERBERIDÉES Juss.}

G. Berberis L. - Épines-vinettes.

Arbuste épineux, à feuilles en faisceaux et à fleurs en grappes axillaires, jaunes; fruits charnus, rougeàtres. - Les haies.

B. vulgaris L.

\section{Fam. des PAPAVÉRAGÉES Juss.}

(Nymphéacées Salis., Paparéracées DC. ct Fumariacées DC., réunies.)

G. Nrmphe.t L. - Nénuphars et Nuphars.

Fleurs blanches. - Plante aquatique, à grosse tige souterraine; feuilles ovales et arrondies. - Nénuphar. N. alba L.

- Fleurs jaunes. - Plante aquatique, it tige souterraine plus petite; feuilles orales. - Nuphar. - (Nuphar luteum Sm.) Nr. lutea L.

\section{G. PAphyer L. - Pavots.}

Fruits glabres. . . . . . . . . . . 1 Fruits poilus, hérissés. $\ldots \ldots \ldots 3$

1. Fenilles de la tige entières, embrassantes. - Plante élevée, glabre et glauque; fleurs grandes, blanches, rosées ou rouges, arec une tache plus ou moins foncée à la base des pétales. - Cult. et échappée. P. somniferum L.

Varie a tige courte et a fruit petit et globuleux ( $P$. hortense Huss.)

- Fevilles découpées, n'embrassant pas la tige. . . . . 2

2. Fruit court et ovale. - Plante variable, à grandes fleurs d'un beau rouge. - Noissons. - Coquelicot. P. Rhœas L.

- Fruit long et en massue. - Plante à petites fleurs d'un rouge pàle.

P. dubium L.

Varie: 1o à fruits cylindriques ( $P$. Lecoquii Lamothe); $2^{\circ}$ à fruits en massue bruscruement rétrécie à la base (P. collinum Bog.)

3. Finit allongé et en massue. - Plante à petites fleurs d'un rouge violacé. - Les moissons. P. Argemone L.

- Fruil presque globuleux el arrondi à la bass. - Plante it petites fleurs ronge pîle. - Mnissons. P. hybridum L. 


\section{G. Chelidonium L.}

Fleurs violettes; fruit it une seule carité. - S. g. Rcemeria DC. Fleurs jaunes; fruit ì une cavité. - S. g. Cihelidonium Tourn. Fleur's jaunes; fruit à deux cavités. - S. G. Gilaucium Juss.

\section{S. G. Remeria DG.}

Plante grêle, rameuse, velue, at suc jaune; feuilles très découpées; fleurs grandes, violettes. - Cia et lia, dans les moissons calcaires. (R. hybrida DC.) Gh. hybridum L.

\section{S. G. Chelidonium T. - Chélidoines.}

Plante it suc jaune; feuilles découpées; fleurs jaunes, en ombelle; fruit allongé. - Les lieux habités. - Cihélidoine.

Ch. Majus L.

Varie à feuilles très découpées (Ch. laciniatum Ilill.)

S. G. Glaucium Juss. - Pavots cornus.

Fleurs jannes et fruits tuberculeux. - Plante glanque et gliabre. (G. luteum Scop.)

Gh. Glaucium L.

- Fleurs orangées et fruits hérissés. - Plante plus ou moins velue. (G. coriniculatum Curt.) Gh. corniculatum L.

\section{G. Hypecoum T. - Siliquiers.}

Plante glabre; feuilles à divisions linéaires; fleurs petites, jaumes et solitaires, it pétales découpés au sommet. - Les lieux calcaires.

H. pendulum $L$.

\section{G. Fumaria L. - Fumeterres.}

Genre de plantes très roisines les unes des autres, habitant les jardins et les champs cultivés et sounises de ce chef à une sorte de culture qui les a rendues fort variables, en ébranlant leurs caractères spécifiques. De lia, la difticulté de suivre les divers auteurs, qui ont décrit une quantité de formes locales.

Fruit allongé, s'ourrant de lui-même en deux valves à la maturité. - S. G. Corydalis DC.

Fruit globuleux, ne s'ourrant pas. - S. G. Fumaria L.

$$
\text { S. G. Corydalis DG. }
$$

Racines tuberculeuses; fleurs rouges, blanches ou panachées. - Tige écailleuse à la base; feuilles florales découpées. (G. solida Sm. ou C. bulbosa Lam.) F. bulbosa L.

- Racines fibreuses; fleurs jaunes ou jaunatres. . . . 1 
1. Des rilles rameuses. - Plante faible et grimpante, á petites fleurs en grappes courtes, opposées aux feuilles; style fugace. (C. claviculata DC.) F. claviculata T.. - Pas de virilles. - Plante dressée et rameuse; fleurs en longue grappe; style persistant. - Echappée çi et lit des cultures. (C. lutea DC.)

F. lutea 1 .

\section{S. G. Fumaria L.}

Fruit lisse, ¿̀ queue vecourbée. - Plante variable, glanque et rameuse, à queue des feuilles souvent contournée en vrille et à fleurs en grappe làche.

F. capreolata L.

Varie: 10 à fleurs blanches, noirâtres all sommet (F. speciosa Jord.); $2^{\circ}$ à pièces du calice attachies par le milieu (F. Borcei Jord.)

- Fruil plus ou moins rugueux, à queue dressée ou

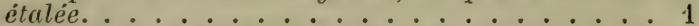

1. Fruit plus large que long et un peu déprimé ou échancié au sommet.

F. officinalis L.

- Fruit tout à fait globuleux, non déprimé ou même aigu au sommet. . . . . . . . . . . 2

2. Calice des fleurs à pièces arrondies, débordant la base de la corolle. (F. micrantha Lag.) F. densiflora DC.

- Calice à pièces ovales ou allongées, depassant peu ou point la largeur de la corolle. - Plante glauque; feuilles à divisions pliées; fleurs rosées. $\boldsymbol{F}$. parviflora Lam.

Varie a divisions des feuilles planes et à fleurs blanches, tachées de rouge au sommet ( $F$. Vaillantii Lois.)

\section{Fam. des CRUGIFĖRES Juss.}

Cetle Famille est composée de plantes qui se ressemblent beaucoup entre elles. Un calice à quatre pièces; une corolle ì quatre pièces également, figurant lorsqu'elle est épanouie une sorte de croix de Nalte; six étamines, dont deux sont plus petites; de petits fruits sees, longs ou courts; des feuilles alternes; des fleurs nombreuses, généralement en grappe, constituent une réunion de caractères très typiques, qui marchent presque toujours ensemble. C'est plutôt un raste genre quı une fimille à éléments ordinaires. De là, la difficulté deétablir des coupures nettes et précises pour en dénommer les espèces. Linné, rui a connu i peu près tontes ces plantes, puisqu'elles croissent pour la plupart dans nos climats, avait établi un certain nombre de genres qui ont été plus tard taillés en pièces par Robert Brown, De Candolle et autres botanistes. 
Les gemres de Robert Brown et de De Candolle ont éti, i leur tour, profondément remaniés plus récemment. De telle sorte qu'aujourd'hui chaque crucifère a au moins deux noms, que beaucoup en ont trois et pas mal quatre ou cinq. En présenee d'une.telle confusion et derant l'insuccès des efrorts de ceux qui se sont lirrés à la recherche à outrance du genre saisissable et mathématique, qui ne peut exister encore moins ici quailleurs, il me parait raisomable de revenir, autant que possible, aux genres de Linné.

\section{G. Rapinanus L. - Radis.}

Fruit conique, lisse, spongieux. - Plante élevée, à racine charnue, blanche ou rouge, et a fleur's grandes, blanches ou violettes. - Cultivée.

R. sativus L.

Varie à racine grosse, noire et trés âcre (R. niger DC.)

Fruit articulé ou slrié et dur. - Plante élevie, à racine grèle, et a fleurs reinées, jaunes, blanches ou lilas. - Les champs.

R. Raphanistrum L.

Varie : 10 a fleurs non veinées, a lobes des feuilles alternativement grands et petits (R. maritimus Sinith); $2^{\circ}$ i silique lisse, subéreuse (R. Landira DC.)

\section{G. Brassica Boiss.}

Calice dressé, serré contre la fleur; sraines rondes; style entier au sommet. - S. G. Brassica L.

- Calice dressé, serré contre la fleur; graines rondes; style bifide at sommet. - S. G. Eruca DC..

- Calice liche on étalé; grames rondes. - S. G. Sinapis L.

- Calice liche; Graines ovales ou aplaties. - S. G. Diplotaxis DC.

$$
\text { S. G. Brassica L. - Choux. }
$$

Feuilles entières, du moins les supérieures. . . . . 1

- Feuilles toutes piofondément découpées en lobes

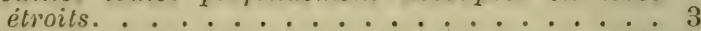

1. Etamines toutes dressées et à per près égales. - Plante très glabre, élevéc, rameuse, à fruit dressé contre le pédoncule et à graines lisses. - Rochers maritimes de lembouchure de la Gironde.

B. oleracea L.

- Etamines très inégales, les deux. plus courtes écartées. . . . . . . . . . . . 2

2. Feuilles glabres, les moyennes découpées. - Plante élevée, à racine fusiforme; fruits étalés.-Ciult.B. Napus L.

Tarie et se naturalise à racine grèle ( $B$. oleifera DC..) 
- Feuilles plus ou moins hérissées de poils, les moyennes entières. - Plante à racine fusiforme ou en toupie; fleurs jaune pâle; fruits dressés. - Ciult. - (B. asperifolia Lam.)

B. Rapa $\mathrm{L}$.

Varie à racine grêle et à fleur d'un beau jaune (B. campestris L.)

3. Feuilles velues, pennées; calice fermé. - Plante de quelques décimètres, rameuse. - Coteaux pierreux et sables maritimes. $\quad$ B. Cheiranthus L.

- Fenilles glabres ou à peu près, lobées; calice ouvert. -

Plante velue à la base; fleurs d'un beau jame, odorantes, sans petites feuilles à leur base. (Erucastrum obtusangulum Reich.)

B. Erucastruin L.

Varie à fleurs pâles, les inférieures munies d'une petite feuille (Erucastrum Pollichii Sch., B. ochroleuca S.W.)

S. G. Sinapis L. - Moutardes.

Fruits dressés et serrés contre la tige. . . . . . . 1 - Fruits étalés ou écartés de la tige. . . . . . . 2

1. Feuilles supérieures glabres; fruits à pointe grêle. Plante élevée, rameuse, à fleurs jaunes et à fruit à peu près à quatre angles. - Les inarais cultivés. - (S. nigra L.)

B. nigra Bois.

- Feuilles supérieures aussi velues que les autres.Plante élerée, rameuse, à fleurs jaunes et à fruits grêles, cylindriques. - Les champs et les endroits pierreux. (S. incana L.)

B. incana Bois.

2. Feuilles de la tige seulement dentées. - Plante rameuse, velue; fleurs jaunes; fruit cylindrique, bosselé. - Lieux cultivés. - (S. arvensis L.) B. Sinapistrum Bois.

Varie à fleurs pâles et a fruits grèles, munis de cinq nervures au lieu de trois (S. orientalis L.)

- Feuilles de la tige profondément découpées. - Plante relue, à fleurs jaunes; bec du fruit en forme de sabre. Les champs. - (S. alba L.)

B. alba Bois.

S. G. Diplotaxis DG. - Faux choux.

Fleurs blanches. - Plante hérissée de poils, rameuse, à feuilles sinuées et découpées; fleurs assez grandes, en longues grappes. - Cii et là, dans les lieux cultivés. (D. erucoïdes DC.)

B. erucoïdes.

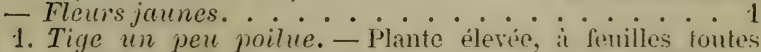
radicales; fleurs odorantes. - Lieux haljités. - (D. m!ralis DG.)

B. muralis Bois.

- Tige glabre. . . . . . . . . . .

2. Plante élevée, fétide par le frollement; tige foullée: 
fleurs d'un jaune soufie, ì longue quenc. - Iienx incultes. - (D). tenuifolia DC.) B. tenuifolia Bois.

- Plante petite, il tige nue; flewis à courte qupue. - I.ienx cultivés. - (D. viminea DC.)

B. viminea.

S. G. Eruca DC: - Rocruettes.

Plante à saveur piquante, rameuse, à fleurs blanches ou jaunatres, ravies de violet. - Echappée des cultures. (E. sativa DC.)

B. Iruca L.

\section{G. Sisymbrium L.}

Fruits courts, oroüdes ou i peine plus longs que larges. - S. C. Nasturtium R.B.

Fruits longs et grêles. - S. G. Sisymbrium L.

S. G. Sisymbrium L.

Fleurs blanches. ................ 1

- Fleurs jaunes. . . . . . . . . . . 2

1. Fenilles ovales, larges. - Plante à odeur dail, droite; fruit a quatre angles, - Lieux habités. - Eryssimum Alliaria L.)

S. Alliaria Scop.

- Fenilles découpées. - Plante sans odeur, couchée; fi'uit comprime, arrué. - Les lieux sablomeux. - (Braya supina K.) S. supinum L.

2. Feuilles à dirisions linéaires et très étroiles. . . 3

- Fevilles à divisions larges, au moins la division lerminale............... 4

3. Plante glabre, à peliles fleurs en grappe terminale, munies chacune d'une quene épaisse. - Lieux humides desséchés. - S. asperum L.

- Plante velue, à petites peurs écartées les unes des aulies au sommel des rameaux, munies chacune d'une quene filiforme. - Lieux habités. S. Sophia L.

4. Fruils bosselés, surtout sous les doigts. ...... 5

- Fruits non bosselés. - Plante velue, à rameaux dirigés en tous sens; fleurs petites; fruits en alene, serrés contre l'axe. - Lieux habités.

S. officinale Scop.

5. Fruits atténués à la base et au sommet. ... . . . 6

- Fruils atténués en cône au sommet seulemeni. - Plante glabre, rameuse; fleurs petites, jaune pale; fruits épais, durs, arqués. - Lieux incultes. S. polyceratium L.

- Fruits cylindriques d'un bout ì l'cutre. - Plante velue, d'un vert sombre; fruits espacés et étalés. - Jienx incultes. $\quad$ S. Columnæ Jacq.

6. Sépales verts, beaucoup plus longs que la quene de la fleur. - Plante glabre, it fruits nombreux. - Dans les champs.

S. Irio L. 
Varie à plante velue (S. gallicum Tilld.)

Sépales jaunes, égalant la queue de la fleur. - Plante variable, rameuse, a fruits dirigés en tous sens autour de leur axe. - Lieux pierreux.

S. austriacum Jacq.

S. G. Nasturlium R.B. - Cressons.

Fleurs blanches. - Plante d'un rert luisant, rameuse, à tiges anguleuses et creuses; feuilles a divisions inégales, ovales Les eaux courantes. - Gresson de fontaine. (N. officinale. R.B.)

S. Nasturtium L. Fleurs jaunes ou jaunâtres. . . . . . . . . 1

1. Fruits plus longs que larges. . . . . . . . 2

- Fruits très courts. . . . . . . . . . . . 3

2. Corolle dépassant à peine le calice. - Plante diffuse, à fleurs d'un jaune ordinaire. - Les marais. - (N. palustre DG.)

S. palustre Poll. Corolle dépassant le calice du double. - Plante glabre, à fleurs d'un jaune vif. - Les lieux humirles. - (N. sybvestre R.B.)

S. sylvestre L. DC.)

Varie à fruits plus courts que leur queue (N. anceps

3. Plante grêle; feuilles supérieures à divisions linéaires; fleurs en bouquet. - Les prairies sèches. - (N. pyrenaicum R.B.)

S. pyrenaicum L.

- Plante ì grosse tige creuse; feuilles entières lorsqu'elles poussent hors de l'eau. - Bords des eaux. - (N. cmphibium R.B.)

S. amphibium

G. Erysinum L. - Vélars.

Feuilles inférieures à grands lobes inégaux; fruits à quatre angles inégaux. - S. G. Barbarea R.B.

Feuilles toutes entières ou dentées: fruits à quatre angles égaux; - S. G. Erysimum L.

\section{S. G. Barbarea R.B.}

Ce sont des plantes des lieux humides qui se ressemblent beaucoup.

Feuilles inférieures à lobes décroissants du sommet $\dot{u}$ la base, le lerminal large, arrondi ou en cour; feuilles supérieures indivises. - Plante élerée, glabre, it tige anguleuse, rameuse an sommet; fruits dressés dans la jeunesse, puis étalés, anguleux et à longue pointe grèle. (B. vulgaris R.B)

E. Barbarea L.

- Feuilles inférieures comme pennées, à lobes mofonds, le terminal ovale: feuilles supérieures à divisions linéaires. .............. 1 
1. Fruts nombreux, courts, dressés contre l'axe. - Tige a trois angles. (B. intermedia Bor.) E. intermedia.

- Fruits espacés, allongés, étalés. - Tige anguleuse. (B. precox R.B.)

E. pracox Sm.

\section{S. G. Erysimum.}

Fleurs blanchitres; feuilles glabres et embiassantes. Plante glauque, it fruits très longs. - Champs calcaires secs. (E. orientale R.B.) E. perfoliatum Cr.

- Fleurs jaunes; feuilles velues, non embrassantes. Plinte élevée, diun rert gai; fleurs petites, fruits très obliques sur l'axe. - Moissons. E. cheiranthoïdes I.

\section{G. Hesperis L. - Juliennes.}

Plante hérissée de poils, it feuilles ovales ou lancéolées, i fleurs lilis et odorantes. - Cia et lit; échappée des cultures.

H. matronalis L.

\section{G. Cueinanthus L. - Giroflées.}

Plantes blanchatres dans toutes leurs parties, style bilobé. S. G. Matthiola R.B.

Plantes vertes; strle i deux lobes arrondis au sommet. S. G. Gheirainthus.

Plantes vertes ou blanches; style pointu au sommet. - S. G. Malcomia R.B.

\section{S. G. Matthiola R.B.}

Tige droite, ligneuse; feuilles entieres, arondies au sommet; fleurs violettes, it odeur suave. - Royan et Bayonne. - (M. incana R.B.) Gh. iacanus L. - Tige flexueuse, herbacée: feuilles sinuées ou divisées; fleurs purpurines, odorantes. - De Baronne it La Rochelle. (M. sinuata R.B.) Gh. sinuatus L.

\section{S. G. Malcomia R.B.}

Style vert, persistant. - Plante herbacée, gazomnante, rude au toucher; fleurs violettes. - Cultivée le long des còtes, et échappeie des jardins. - Gazon de Mahon.-(M.maritima R.B.)

Ch. maritimus L.

- Style jaurie et fugace. - Plante ligneuse et velue à la base; feuilles entieres et fleurs purpurines. - Cultivée le long des còtes. - (M. littorea R.B.) Gh. littoreus L.

Varie à feuilles lobées (Ch. trilobus L. ou M. Broussonetii DC.) 
S. G. Ciheiranthus.

Plante ligneuse à la base, velne; feuilles lancéolćes; feurs jaunes, odorantes. - Les vieux mu's et rochers. - Ciult. - Giroflée jaune.

Gh. Cheiri L.

\section{G. Arabis L. - Arabettes.}

Fenilles de la tige glabres. - Plante glauque, raide, dressir, un peu rameuse; fleurs d'un blanc jaunatre. - Lieux secs. - (Turitis glabra L.) A. perfoliata Lam.

- Feuilles de la tige velues. . . . . . . . . . 1

1. Fenilles de la tige embrassantes ou à deux oreillettes. 2

- Fenilles de la tige ni embrassantes ni i deux oreillettes. - Plante velue, à rameaux làches; fleurs petites et blanches. - Champs sablonneux.

A. thaliana L.

2. Pétales petits, allongés, dressés, d'un blanc sale ou

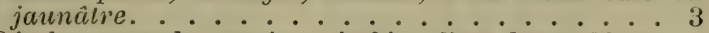

- Pétales grands, ovales, étalés, d'un beau blanc. Plante gazonnante, d'un vert pàle; fleurs en grappe droite. - Sur les rochers; cà et là, dans le S.-O. A.alpina L. 3. Fruits de un centimètre au moins; feuilles de trois centimètres environ de largeur. - Plante plus on moins velue, raide, à feuilles sinuées et dentées. - Sur les rochers, dans le Lot.

A. Turrita L.

- Fruits et feuilles n'ayant pas ces dimensions. - Plante variable.

A. hirsuta $\mathrm{L}$.

Varie : 10 à feuilles non en fer de flèche (A. hirsuta des auteurs); $2^{\circ}$ à feuilles en fer de flèche (A. sagittata DC.); $3^{\circ}$ à feuilles en fer de fleche et à oreillettes appliquées (A. Gerardi Bess.)

\section{G. Cardanine L. - Cardamines.}

Fleurs grandes, à pétales trois fois plus longs que les sépales. . . . . . . . . . . 1

Fleurs petites, à pétales dépassant à peine les sépales 2

1. Anthères violettes. - Plante à racine oblique, produisant des rejets feuillés; feuilles découpées en segments ovales. - Lieux humides.

G. amara I.

- Anthères jaunes. - Plante variable, d'un vert gai; fenilles à segments linéaires; fleurs blanc lilas, à strle terminé en tète. - Lieux humides.

C. prateosis L.

Varie : 10 à segments des feuilles dentés $(C$. denlata Sch.): $2^{\circ}$ à segments des feuilles tres fins et a fleurs hlanches ( $C$, fragilis Degl.)

2. Fevilles portant ì leur base deux oreilletles aigüs et 
en fer de flèche. - Plante élevée, très fenillée; pétales souvent nuls. - Lieux ombragés. G. impatiens I. - Fevilles sans oreilleltes à la base. . . . . . . 3

3. Fenilles glabies, it lobes ties étroils. - Plante grèle, droite. - Licux humides. C. parviflora L.

- Fenilles plus ou moins velues, à lobes élargis. - Petite plante peu fenillée. - Lieux cultivés. G. hirsuta L. Tarie à fruits écartés de laxe (C. sylualica Link.)

\section{G. Dentaria L.}

Ces deux plantes, très roisines l'une de l'autre, viennent dans les bois montueux.

Feuilles toules ailées et sans bulbilles. - Plante à grandes fleurs lilas ou blanches.

D. pinnata Lam.

- Fenilles supérieures simples, munies de bulbilles à leur aisselle. - Fleurs lilas ou blanches. D. bulbifera $L_{\text {. }}$.

\section{G. Crambe Tournef. - Choux unarins.}

Plante glauque, elevee, res toufue, ayant l'aspect d'un chou; fleurs blanches. - Rochers et sables maritimes. - Ghou marin.

C. maritima $I_{\text {. }}$.

\section{G. Cakile Tournef. - Caquiller's.}

Plante glangue, à rameaux nombreux et étalés; feuilles pemntifiles, charnues; flemrs blanches. - Sables maritimes. (C. Serapionis Lohel.)

C. manitima Sicop.

\section{G. Bunias L.}

Fruits i quatre angles ailés, munis de crites; plante rameuse, chlanduleuse, it fenilles découpées et il fleurs jaunes. Moissons.

B. Erucago L.

\section{G. Mragrum L. - Camélines.}

Fruits etranglés an milieu en deux articles. - S. G. Rapistrum Boerh.

Fruits globuleux, rilés et rugueux, i pétales égaux. - S. G. Neslia Desv.

Fruits globuleux, ridés et rugueux, à pétales incigaux. - S. C. Calepina Desv.

Fruits triangulaires, it deux bosses an sommet. - S. c. My grum L.

Fruits ovales on arrondis, unis, sourrant d'eux-mèmes. S. G. Camelina Cr. 
S. G. Rapistrum Boerh.

Plante plus ou moins velue, i queues des fleursépaisses: fleurs jaune pâle; style plus long que le dernier. article du fruit. - Les lieux pierreux; coteaux sees. (R. rugosum All.)

iv. rugosum L.

Varie: $1^{\circ}$ a fruit tout it fait glabre ( $R$. glabrum IIost.); $2^{\circ}$ à tige non feuillée (Myagrum slylosum DC.); $3^{\circ}$ it fleur d'un jaune vif (M. orientale L.)

- Plante glabre, a queues des fleurs filiformes; fleurs jaunes; style plus court que le dernier arlicie du fruit. - Croit en Espagne; plante à chercher dans le S.-O. de la France.

R. linnæanum Boiss.

S. G. Neslia Desv.

Plante velue à feuilles rudes, embrassantes; fleurs jaumes, i queue filiforme. - Les moissons. - Neslia paniculala Dest.)

IV. paniculatum L.

S. G. Calepina Desv.

Plante glabre et glauque, à feuilles embrassantes; flemrs petites, blanches, ¿t queue grêle et arquée. - Les champs. (Calepina Corvini Desv.) M. Erucæfolium Vill.

$$
\text { S. G. Myagrum. }
$$

Plante glauque, à rameaux en tous sens; feuilles embrassantes; fleur's petites jaunes, à queue épaisse. - Sur les murailles ou rochers.

M. perfoliatum L.

S. G. Camelina Cr.

Plante variable, droite; feuilles allongées; fleurs d'un jaune pâle; fruit ventru et dır. (C. sativa Cr.) M. sativum L.

Varie: $1^{0}$ à feuilles dentées (M. dentatum IVill.); $2^{\circ}$ à feuilles rudes, relues et funit non rentru (M. syluestre C.B.); $3^{\circ}$ à feuilles lisses et firuit mou (M. fortictum C.B.)

\section{G. Isitis L. - Pastels.}

Plante élevée, glauque; feuilles supérieures embrassantes par deux oreillettes aiguës; fleurs petites et jaunes.-Echappée

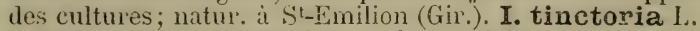

Varie: $1^{\circ}$ a feuilles velues et fruits glabres ( $T$. hirsula DC. ); $2^{\circ}$ i feuilles et fruits velus (I. lusilanica Mor')

\section{G. Cochlearia L. - Cransons.}

Grande plante, ¿̀ très larges fevilles lancéolées et pennatifides, et i grosse racine vivace. - Dans les prairies 
humides, ou elle est échappie des jardins. - Raifort de Bretagne.

G. Armonacia L.

- Plantes mojennes, à ferilles entières ou dentées. . . I

1. Fenilles péliolées, les radicales en rein ou en cocur, les suprerieures triangulaires; fleurs jetites, blanches ou rosées. - Littoral.

G. danica L.

- Feuilles inférieures largement ovales, à base tronquée ou décurrente sur le pétiole, les supérieures ovalesallongées, embiassantes par deux oreilleltes; fleurs grandes, d'un beau blane. - Se rencontre de Bayome it la Rochelle.

G. anglica $\mathrm{L}$.

- Feuilles inférieures longuement pétiolées, arondies en caur, épaisies, les supérienres embrassanles en cour; fleurs blanches, assez grandes. - Prrénces; hords de la Bidassoa. - Cultivée.

G. officinalis $\mathrm{L}$.

\section{G. Lunaria L. - Lunaires.}

Plante à feuilles supérieures sans queue; fleurs purpurines et fruits aplatis. - Cii et lit ; natur. L. biennis Monch.

\section{G. Alrssuir I. - Alyssons.}

Fleurs blanches. ............... 1 Fleurs jaunes ou jaunatres. . . . . . . . . . . 2 1. Plante herbarie, couchée, rameuse; fenilles allongées. - Biarritz et le long de la cote, ou il se naturalise. (Koniga maritima R.B.) A. maritima L.

- Plante ligneuse, ipineuse, buissonnante; flew's grandes el fruils converes. - Le Lot. A. macrocarpum DC.

2. Fleurs petites, jaune pale; slyle tries court. . . . 3

- Fleurs grandes, d'un beau jaune; slyle aussi lony que le fruit. - Plante velue, blanchitre, ligneuse it bi base. - Cià et lì.

A. montanum L.

3. Calice persistant sur le fruit. - Petite plante herbacce, cendrée. - Lieux secs.

A. calycinum L.

- Calice fugace. - Plante herbacie des sables maritimes et des lieux sablonneux.

A. campestre L.

G. Draba L.

Pélales bifides. - Très petite plante, à tige me et flexuense. - Lieux sablonneux.

D. verna $L$.

- Pétales entiers. - Plante grêle, velue, à tige feuillée. Sur les murailles et à terre. $\quad$ D. muralis $\mathrm{L}$.

\section{G. Lepidium L. - Passerages.}

Fruits à deux graines seulement. - S. ci. Lepidium L. Fruits a quatre graines an moins. - S. fi. Hutchinsia R.B. 


\section{S. G. Lepidium L.}

Anthèies violettes. - Plante glauque, dressée, rameuse, à feuilles supérieures linéaires, et ì petites fleurs blanches. - Gultivée.

L. sativum L.

- Anthères jaunes.

1. Fenilles supérieures non en fer de flèche. . . : 2

- Feuilles supérieures pubescentes et en fer de flèche. 5

2. Fevilles de la tige larges et ovales. - Plante élerée, i odeur de chou, glabre et glauque, à souche vivace et a petites fleurs blanches.

L. latifolium L.

- Fevilles de la tige linéaires et étroites. . . . . . 3

3. Fruit ovale et aigu, non échancré. - Plante glabre, à odeur de chou et a petites fleurs blanches. - Cil et li dans le S.-O.

L. graminifolium $\mathrm{L}$.

- Fruit échancrée au sommet. . . . . . . . 4

1. Pétales verdatres ou nuls, et feuilles supérieures entières. - Plante à odeur de chou, grêle et très rameuse. - Lieux stériles.

L. ruderale L.

- Pétales blancs et feuilles supérieures dentées. - Plante d'un vert gai, pubescente. - Naturalisée dans le SudOirest.

L. virginicum $L$.

5. Fruit en cosur et renflé. - Plante glauque, it fleurs blanches. - Bords des ehemins.

L. Draba L.

- Fruit ovale, échancré au sommet. . . . . ... 6

6. Style court, ne dépassant pas l'échancrure. - Plante d'un rert blanchàtre, velue, à très petites fleurs blanchâtres.

L. campestre R.B.

- Style long et dépassant beaucoup l'échancrure. Plante variable, it petites fleurs blanches; feuilles glabres.

L. heterophyllum Benth.

Varie à feuilles très velues (L..Smilhii Hook.)

\section{S. G. Hutchinsia R.B.}

Petite plante très grêle, velue, à poils courts, rameuse; feuilles découpées; fruits à quatre graines. - Lieux sees. - (H. petroea R.B.)

L. petræum L.

- Petite plante grêle, couchée, glabre; feuilles découpées; fruits it graines nombreuses. - $(H$. procumbens Desv.)

L. procumbens L.

\section{G. Thlaser L. - Tabourets.}

Fruits ovales. - S. G. Thlaspi L.

Fruits en cœur renversé. - S. G. Capsella Vent.

$$
\text { S. G. Thlaspi. }
$$

Plante à odeur d'ail quand on la froisse. . . . . . . 1 
- Plante sans odeur d'ail. - Petite plante jamense, glanque.

Th. perfoliatum L.

1. Fruit plane, échancré et à large rebord. - Plante glabre, à fleurs blanches.

Th. arvease L.

- Fruit renflé, à peine échancré et à rebord étroit. - Plante poilue à la base.

Th. alliaceum L.

S. G. Capsella Vent.

Plante rameuse; feuilles supér. embrassantes; fleurs blanches. (C. bursa-pastoris Mœench.) Th. bursa-pastoris L. Vitrie souvent it plante rougeatre (C. rubella Rent.)

\section{G. Iberis L.}

Fruts i deux graines seulement; plantes a feuilles entières ou dentées, portées sur la tige. - S. G. Iberis.

Fruits à quatre graines; plantes à feuilles découpées et radicales. - S. G. Tetsdalea R.B.

\section{S. G. Iberis.}

Fleurs disposées en bouquet serré. - Plante ligneuse, rameuse, at feuilles en coin, tres entières. - Cultivé dans les jardins.

I. semperflorens L.

Fleurs en grappe. - Plante velue, at feuilles cilices; fleurs blanches ou violettes. - Moissons du S.-O. I. amara L. S. G. Teesdalea R.B.

Petite plante pubescente, a tiges simples et nues. - Les lieux secs.- $(T$. Iberis DC. $)$

I. nudicaulis $\mathrm{L}$.

Varie à plante glabre, à pétales moins inégaux et à quatre étamines ( $T$. Lepidium DG.)

\section{G. Senebiera Pers.}

Fruil réniforme, entier au sommet. - Plante glabre, glauque, a tiges nombreuses, appliquées en cercle sur le sol, et a petites fleurs blanches, en grappes opposcies atux feuilles. - Bords des chemins. S. Coro aopus L.

- Fruit échancré et à deur lobes. - Plante ramense et diffuse, ì tiges grêles et velues. - Natmalisée sur les côtes du S.-O.

S. pinaatifia DC.

\section{G. Biscutelat L. - Lunetières.}

Plante variable, rameuse it la base, velue, et it fleur jaune; pétales dressés; fruit échancré a la base et au sommet. Lieux sees.

B. lævigata L. 
RESTEDCEES.

Tarie : $1^{0}$ ì feuilles profondément dentées (B. saxatilis DC.) ; $2^{n}$ a fenilles découpées et it lohes dirigrís en tous sens (B. coronopifolia Nll.)

\section{Fam. des RÉSÉDACÉES DG.}

\section{G. Rieseda L. - Résédas.}

Tin seul oraire ou fruit par fleur. - S. G. Reseda L.

P'lusieurs ovaires ou fruits par fleur. - S. G. Asterocarpus Neck.

S. G. Feseda L.

Toutes les feuilles entières et non découpées. - Plante glabre, à tige anguleuse et creuse, à feuilles lancéolées, munies à la base de deux petites épines; fleurs petites, jaune påle; fruit ovale. - Lieux arides. R. Iuteola L.

- Feuilles supérieures découpées. . . . . . . 1

1. Anthères orangées; fleur à odeur suave. - Plante cultivée.

R. odorata L.

- Anthères blanchàlres; fleur à odeur mulle ou fétide. 2

2. Cinq sépales et cinq pétales; quatre styles. - Plante glabre, i tige ramense, i feuilles profondément découpées, it lleurs blanches et a sćpales linéaires aigus. - Cì et là dans le S.-O.

R. alba L.

- Six sépales et six pétales; généralement trois styles. 3

3. Sépales très grands à la maturité du fruit. - Plante un peu relue, à feuilles supérıeures trifides et à fleurs longues, blanchitres.

R. Phyteuma L.

- Sépales non accrus à la maturité. . . . . . . 4

4. Fevilles pinnatifides; graines noires et luisantes. -

Plante couverte d'aspérités blanchàtres, à fleurs verdàtres.

- Lieux arides.

Varie à plante plus giêle ( $R$. gracilis Ten.)

R. lutea L.

- Feuilles trifides ou quinquefides, à girines grises, ridées et chagrinées. - Plante rameuse et lisse, à fleurs blanchàtres. - Cévennes.

R. Jacquini Rchb.

\section{S. G. Asterocarpus Neck.}

Réceptacle glabre; 7-9 étamines. - Plante gazonnante, à fenilles linéaires, les inférieures en rosette; filets des étamines glabres et isolés. - Git et là. - (A. sesamoïdes Gay).

R. sesamoïdes L.

- Réceptacle pubescent; 1?-15 étamines. - Plante non gazomnante, à feuilles non en rosette, et à filet des étanines velus et accouplés. - (A. Clusii Gay). R. Clusii Sp. 


\section{Fam. des GISTINÉES Juss.}

\section{G. Cistus L. - Cistes.}

Ovaire et fruit a cinq ralves. - S. G. Gistus L.

Oraire et fruit it trois valves; étamines toutes fertiles. - S. ri. Helianthemum T.

Oraire et fruit it trois ralres; étamines externes stériles. S. G. Fimana Sp.

$$
\text { S. G. Cistus L. }
$$

Calice ¿̀ trois sépales égaux, deur exterieurs arortés. Tige élevée, noire, à lameaux poilus; feuilles lisses en dessus, soyenses el blanches en dessous; pétales blanes, at base jaune. - Montauban et le Gers. C. laurifolius $L$.

- Calice à cinq sépales inéyaux, les deux extérieurs plus grands. - Plante a odem halsamique, tres rameuse, it feuilles chagrinées, et it fleurs blimches. - Les sables de la côte et çà et là dans le S.-O. G. salviæfolius L.

\section{S. G. Helianthemum Tournef.}

Feuilles munies de deux stipules à la base. . . . . . . 1 - Fenilles, du moins les inférieures, dépourves de sti-

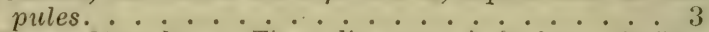

1. Fleurs blanches. - Tiges ligneuses a la base; feuilles linéaires, rertes en dessus, blanches en dessous; fleurs en épis. (H. pulierulentum DG.) G. pulverulentus I.

- Fleurs jaunes. .............. . . 2

2. Tige ligneuse et concinée à la base; flenrs d'un beau jaune. - Plante variahle, velue, it feuilles ovales, un peu roulées par les bords, opposies; fleurs en épis penchés. Lieux secs.-(H. vulgare Gori.) G. Helianthemun I.

- Tige herbacée et clressée; fleurs d'un jaune prile. Plante grèle of pubescente, à stipules lancéolées.Poitou et Aur. (H. salicifolium Per's.) G. Salicifolius L.

3. Racine et tige herbacées. - Plante dressée, poilue; fenilles lancéoleses et i trois nerrures; fleurs en irrappe liche. Lieux sablomneux. - (II. yuttalum Mil.) G. guttatus I.

- Racine el base de la tige ligneuses. . . . . . 4

4. Fenilles planes, ovales ou lancéulées. - Plante i ranncinx diffus; fleurs jaunes, il calice courert de poils blanics. Bois sablomneux. - (H. alyssü̈des V.) C. alyssö̈des I.

- Fenilles linéaires, enroulées ou convexes. - Plinte ditruse, à rameaux grêles; fleurs blanches. - Lieux sees. (H. umbellatum DG.)

G. umbellatus L. 
S. G. Fumana Sp.

Plante à rameaux étalés, couverte de poils blanes; fleurs jaunes et axillaires. - Cit et li. - (H. procumbens Dun.; $F$. procumbens Sp.) C. Fumana L.

\section{Fam. des VIOLARIÉES DC.}

G. Viold Tourn. - Violettes et Pensées.

Quatre pétales dirigés en haut et un en bas. - Plante très variable, annuelle, i feuilles découpées et i fleur tricolore, passant du jaune au violet. - Champs. V. tricolor L.

La culture indirecte à laquelle cette espèce a été sonmise, a donné naissance à un très grand nombre de formes connues sous le nom de Pensées sauvages.

- Deux pélales dirigés en haut et trois en bas. . . . . 1

1. Feuilles et fleurs naissant d'une tige grosse et courte; sépales obtus. ............. 2

- Feuilles et fleurs portèes sur des tiges longues et grêles; sépales aigus. . . . . . . . . . .

2. Plante glabre. - Fleurs bleu cendré; feuilles réniformes. Marécages.

$\mathrm{V}$. palustris $\mathrm{L}$.

- Plante velue.............. 3

3. Plante sans rejets rampants. - Tige épaisse et rameuse, à quene des feuilles hérissée. - Bois. V.hirta L.

- Plante émettant des rejets rampants, allongés et feuillés. - Plante variable, a tige dure, écailleuse, it fenilles en cceur, et ì stipules lancẻolées, ciliées; fleurs violettes ou blanches, odorantes. - Haies. V. odorata L. 4. Feuilles lancéolées, non en cœur à la base. - Plante glabre, à pétales étroits, l'inférieur plié en carène. - Bois sablonneux. $\quad$ V. lancifolia Thore.

- Feuilles plus ou moins en cœur à la base. . . . . 5

5. Capsule tronquée; feuilles obtuses. - Les lieux sablonneux. V. canina $L$.

- Capsule aiguë; feuilles acuminées, - Plante variable. Les bois.

V. sylvatica Fr.

\section{Fam. des DROSÉRACÉES DC. \\ G. Drosera L. - Rossolis.}

Plantes très voisines, des lieux humides et des pays de landes.

Feuilles arrondies, à queue poilue, appliquées sur le sol. Fleurs blanches. D. rotundifolia $L$. 
- Fenilles allongées, à queue glabre. . . . • • • • 2

2. Tige florale deuce fois ansi longue que les ferilles. Fleurs blanches.

D. Iongifolia $\mathrm{L}$.

Varie a tige florale plus courte (D. interinedia Ilayne)

\section{G. Parnassia L.}

Plante glabre, à tige simple, anguleuse, i fenilles en cocur, les radicales pétiolées, les supérieures sessiles et amplexiraules; fleur grande et blanche. - Les lieux marécageux.

P. palustris $\mathrm{L}$.

\section{G. Aldvovanda Mont.}

Plante nageante, i tige articule et chargée de feuilles rerticillées et renflées en ressie; fleurs axillaires, à pédoncule nu, penché at la maturité. - Les laes ou étanges de la còte du S.-O.

A. vesiculosa $\mathrm{L}$.

\section{Fam. des MALVAGÉES Juss.}

\section{G. MALYA L. - Mauves.}

Fleurs solitaires à l'aissel'e des feuilles qui sont profondément découpées. . . . . . . . . . . . 1

Fleurs aggloniérées it l'aisselle des feuilles qui sont peu découpées. . . . . . . . . . . 2

1. Fruits glabres et ridis; calicule a folioles ovales, aiguës. - Plinte velue, it grandes flemrs roses. - Les haies.

M. Alcea L.

- Fruits relus et lisses; calicule à folioles linéaires. - Pante glabre, sentant le muse en séchant, à grandes fleurs roses. - Les haies.

M. moschata L.

2. Feuilles forlement crépues sur les bords. - Plante a tige droite et it flen's blanchitres ou rosées. - Cultivée et naturalisée cà et lá.

I. crispa L.

- Fevilles à bords plats ou non crépus. . . . . . . . 3

3. Tige dressée ou ascendunte; fleurs rouges ou roses, veinées. - Plante ranense, couverte de poils simples, it divisions des fenilles aiguës; pièces du calicule allongées; fruits rugueux, - Lieux hahités. M. sylvestris L.

- Tige conchée, à fleurs blanchatres ou rosées. . . . 4

'́. Pieces du calicule linéaires; fruits lisses et pubescents.

- Plante couverte de poils fasciculés; feuilles en cœur, à divisions obtuses. - Lieux habités. M. rotundifolia L.

- Piéces du calicule ovales; fruits ridés et glabres. - Plante hérissée de poils raides; divisions des feuilles inférieures obtuses et celles des feuilles supérieures aiguës. - Les lieux habités.

M. nicreensis All. 


\section{G. Lavatera L.}

Fleurs agglomérées à l'aisselle des feuilles. . . . . . . 1

- Fleur's solitaires à l'aisselle des fevilles. - Plante herbacée, glabre et rameuse, à calice externe plus court que linterne, mais s'accroissant ensuite; fleurs grandes roses ou blanches. - Gultivée et échappée. L. trimestris L.

1. Plante de plusieurs mètres, sous-ligneuse, très rameuse, à calicule plus grand que le calice, qui est à divisions triangulaires aiguës; fleurs violelles. - Vendée. - I chercher sur nos rochers maritimes. I. arborea I.

- Plante herbacée, élevée et hérissée de poils fasciculés, it calicule plus court que le calice, qui est à divisions larges, brusquement aiguës. - Cótes de la CharenteInfërieure.

L. cretica L.

\section{G. Althen. L. - Guimauves.}

Calicule à six divisions anguleuses. - Plante de plusieurs mètres, à feuilles hérissées, sinućes, anguleuses, à grandes fleurs roses ou très variables. - Cinltivée sons le nom de Passerose ou de Rose trémière.

A. rosea L.

- Gálicule à sept et neuf divisions. . . . . . . . . 1

1. Feuilles blanches et tomenteuses, douces au loucher; pédoncules plus courts que les feuilles. - Plante ćlevée, a fleurs d'un blanc rosé. - Bords des eaux. - Cultivée sous le nom de Gruimance.

A. officinalis $\mathrm{L}$.

- Feuilles plus ou moins rudes, plus courtes que les pédonculles. ................. 2

2. Tige élevée et droite, à feuilles profondémenl découpées et à fleurs roses; la base des pélales est purpurine. Lieux sees.

- Tige couchée, hérissée de longs poils, à feuilles inférieures réniformes et à fleur's rose pâle. - Champs calcaires.

A. hirsuta $L$.

\section{G. Hibiscus L. - Ketmies.}

Plante herbacée, de un mètre et plus, à feuilles blanches, pubescentes en dessous, presque lisses en dessus; fleurs grandes et roses, à queue articulée. - Les marais du bas Adour; bords des lacs des Landes; embouchure de la Leyre, dans le bassin d'Arcachon. -- (H. roseus Thore.)

H. Moscheutos I.

- Plante ligneuse, arborescente, à feuilles ovales, cunéiformes, les supérieures incisées, dentées, à fleurs blanc rosé ou violacées. - Cultivée sous le nom d'Altha a en arbre.

II. syriacus $I$. 


\section{Fam. des GÉRANIAGÉES Bent. et Hook.}

\section{G. Geranium L. - Géranions.}

Toutes les étamines fertiles. - S. G. Geranium L.

Cinq étamines fertiles et cinq stériles. - S. G. Erodium Lhér.

\section{S. G. Geranium L.}

Pétales échancrés ou bifides. ............ 1

- Pétales entiers ou peu dentés. . . . . . . . . 9

1. Pédoncules uniflores; fleurs grandes et d'un beau rouge. - Plante couverte de longs poils; feuilles circulaires, à lobes trifides; pédoncules munis vers le milien de deux bractées. - Lieux secs. G. sanguineum L.

- Pédoncules portant deux ou trois fleurs pailes. . . . 2

2. Feuilles découpées jusqu'à leur base en lobes nombreux

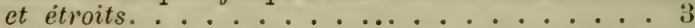

- Feuilles divisées en lobes élargis qui n'atteignent pas

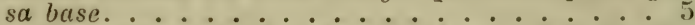

3. Racine tuberculeuse; tige nue à la base. - Plante grèle, finement pubescente, it fleurs d'un pourpre violet. Poitou.

G. tuberosum L.

- Racine fibreuse; tige feuillée à la base. . . . . . I

4. Pédoncules beaucoup plus longs que les feuilles. Plante diffuse ou couchée, velue, à poils dirigés en bas et appliqués; fleurs lilas. - Haies. G. columbinum L.

- Pédoncules plus courts que les feuilles. - Plante diffuse ou couchée, à poils réfléchis, à fleurs rougeâtres et ì fruits poilus. - Champs. G. dissectum I.

5. Pétales beaucoup plus longs que les sépales. . . . 6

- Pétales à peine plus longs que les sépales. . . . . S

6. Feuilles polygonales dans leur pourtour, à lobes losangiques. - Plante finement pubescente, à souche longue et horizontale, à tigre renflée au-dessus des nœuds; fleurs lilas, veinées. - Aur., Cér., Pyr.; cà et là. G. nodosum L.

- Feuilles cireulaires dans leur pourtour; lobes en coin. . . . . . . . . . 7

7. Trìs petite plante, d'un vert cendré, pubescente, $\dot{a}$ pédoncules floraux naissant de la souche, it feuilles petites, d'un vert pale et ì grandes fleur's rougeatres. - Prrénées; parfois descendue. G. cinereum DC.

- Plantè assez grande, velue, à feuilles d'un verl foncé et molles, a fleurs axillaires et purpurines. - Cii et lit; descendue des montagnes.

G. pyrenaïcuin L.

8. Fleurs bleucitres; fruils pubescents et lisses. - Plante it tige faible et a poils comts. - Lieux sees. G. pusillum L. 
- Fleurs rougchilies; fruits glabres ct riclés. - Plante diffuse, à longs poils mous. - Lieux cultivés. G. molle L.

Varie i pétales une fois plus longs que les sépales (G. villosum Ten.)

9. Lobes cles feuilles pétiolés. - Plante variable, fétide, rougeâtre, plus ou moins relue, à fleurs purpurines reinćes de blanc; calice dressé, pétales à pied très long. - Les lieux habités.

G. robertianum L.

Varie : $1^{0}$ à pétales dépassant peu le calice (G. Lebelii Bor.); $2^{\circ}$ à pétales moitié plus courts que le calice $(G$. purpureum Vill.)

- Feuille à lobes non pétiolés. . . . . . . . . . . 10 10. Racine épaisse, oblique; fleurs grandes.- Plante glabre, a tige pourrue d'une ou deux feuilles, a fleurs din rose

violacé. - Cà et là.
- Racine fibreuse, grêle; fleurs pelites. . sylvaticum L. . . I1

11. Calice anguleux et ridé en travers. - Plante dressée, glabre et rougeàtre, ì feuilles luisantes et à fleurs d'un joli rouge.-Les lieux pierreux. G. lucidum L.

- Calice non vidé en travers. - Plante diffise et velue, à feuilles marquées d'un point rouge dans les sinus; fleurs rougeàtres. - Lieux stériles. G. rotundifolium L.

\section{S. G. Erodium L'Hér.}

Feuilles ovales en cour, presque enticres ou simplement lobées. . . . . . . . . . . . 1

- Feuilles très découpées. . $\ldots \ldots \ldots \ldots$

1. Pédoncules à cinq ou six fleurs violacées. - Plante assez robuste, conchée ou ascendante, velue, grisâtre. - Gà et là dans le S.-0. et jusqu'à l'île de Ré. $-(D$. altheöides Jord.; E. malacoïdes Willd.) G. malacoïdes L.

- Pédoncules à une ou deux fleurs apétales. - Petite plante couchée et velue, croissant en touffes. - La côte. - (E. maritimum Smith.) G. maritimum L.

2. Pétales à peine plus longs que les sépales. . . . . 3 3

- Pétales beaucoup plus longs que les sépales. . . . . 4

3. Filets des étamines munis de cils. - Grande plante velue et glanduleuse, à fleurs purpurines. - Toulouse. - $(E$. ciconium Willd.)

G. ciconium $L$.

- Filets des élamines glabres. - Plante très variable, à feuilles découpées et incisćes; fleurs roses, en ombelle sur un pied axillaire; pétales inégaux. - Lieux habités. (E. cicutarium L'Hér.)

G. cicutarium L.

Varie : $1^{\circ}$ a pétales plus petits, roses, à étamines larges et dentées à la base et à odeur musquée (E. moschatium L'Hér. ou G. moschatum L.); 20 à pétales plus grands, plus rouges et égaux (E. romanum Willd. ou G. romanum L.); efe., ete. 
4. Fleurs en ombelle ot enurloppées d'une collevette à pieces soudies. - Basses-Pyrénées. - (E. Manescavi Boub.)

G. IVanescavi.

- Fleurs nor renfermées dans une colleretle. - Plinte assez grande, a tige renflée aux nœuds; fenilles doublement découpées; lleurs purpurines; fruits à bee trés long. - Ile dOléron. - (E. Botrys Bert.)

G. Botrys.

\section{G. Livum L. - Lins.}

Quatre sépales et quatre pétales. - Très petite plante grile, rameuse et fourchue, a feuilles ovales et opposćes et i ileu's blanches. - Lieux sablonneux. - Radiola linoüdes Gmel.)

I. Radiola L. Cinq sépales et cinq pétales. . . . . . . ... 1

1. Feuilles opposées. - Petite plante grèle, fourchne au sommet, a feuilles lanciolées et it fleurs blanches. Les bois.

I. catharticum I.

- Feuilles alternes. . . . . . . . . . . 2

2. Fleurs jaunes. . . . . . . . . . . . 3

- Fleurs bleues, roses ou blanches. . . . . . . . . 4

3. Fleurs espacées, à pédoncules grêles. - Plante ì rameanx glithres; feuilles linéaires. - Lieux sees. L. gallicum I.

- Fleurs agglonéries, i pédoncules gios et courts. -

Plante a rameatux pubescents en dedams et it feuilles linéaires, rudes. - Lieux secs. $\quad$ L. strictum L.

Varie a fleurs liches comme dans l'espece précédente (L. corymbulosum Rehb.)

1. Fleurs roses ou rougeatres; sépales glanduleux. . . 5

- Fleurs bleues; sépales non glanduleux. . . . . 6

․ Tige glabre; fleur d'un rose clair uniforme. - Plante presque ligneuse à la base, à fenilles en alène, rudes au bord. - Lieux secs. $\quad$ L. tenuifolium L.

- Tige pubescente; fleurs rouge dans le fond et en cloche. - Plante tout a fait ligneuse à la base, a écorce grise. Lieux secs. (L. salsolö̈les Lam.) L. suffruticcsum L.

6. Tige dressée, solitaire, sépales ciliés. - Plante ammuelle, it antheres en fer de flèche. - Cultivece. - Ciest le Lin ordinaire.

L. usitatissimum L.

- Tiges venant en touffe, à sépales glabres. - Plante vivace, à feuilles linéaires et à anthères grobuleuses. livux sees.

L. angustifolium DC.

\section{G. Impatiens L. - Balsamines.}

Fleurs blanches ou rosées. - Plante à feuilles lincrolées, denties, les supérieures alternes, et a flemrs agrolomérées. - Cinli. snus le nom de Balsumine. T. Balsamina l. 
- Fleurs jaunes. - Plante glabre, d'un rert gai; feuilles alternes, crénelées. - Bois frais. I. noli tangere L.

\section{G. Oxalis L. - Surelles.}

Plantes à rhizome tuberculeux. - Stipules dentées et crénelées. - Cult.

- Plantes sans tubercules à la base.

O. crenata Jacq.

1. Fleurs blanches ou rosées. - Plante à rhizome écailleux et rampant; fleurs solitaires et striées; capsule ovale. Bois sablonneux.

- Fleurs jaunes. . . . . . . . . . 2

2. Feuilles stipulées. - Plante grisàtre, pubescente, diffuse; pédoncules à 2 ou 3 fleurs, plus courts que les feuilles; capsules linéaires. - Lieux cultivés. O. corniculata L.

- Feuilles sans stipules. - Plante verte, glabre, dressée; pédoncules a trois et cinq fleurs, plus longs, que les feuilles; capsule linéaire. - Naturalisée. O. stricta L.

\section{Fam. des CARYOPHYLLÉES JusS.}

\section{G. Frankenia L.}

Plante dure, ligneuse, couchée, rameuse; fleurs roses, à calice glabre. - Bords de la mer. $\quad$ F. lævis L.

Varie a plante soyeuse et à calice relu. - A chercher sur les còtes du S.-O. (F. intermedia ou F. hirsuta DC.)

\section{G. Gypsophylla L.}

Petite plante grêle, très rameuse, à feuilles linéaires; fleurs rosées, à longue queue dépourvue d'écailles. - Lieux arides.

G. muralis L.

- Petite plante à fleurs roses, munies d'écailles sous le calice qui est à cinq angles. - Tarn-et-Garonne. (Dianthus saxifragus L.)

G. saxifraga $l$.

\section{G. Dianthus L. - Eillets.}

Fleurs agglomèvées en tête. . . . . . . . . . 1

- Fleur's solitaires ou en bouquet. . . . . . 4

1. Calice entouré d'écailles plus courtes que lui.- Plante variable, élevẻe, glabre, à tige simple et à feuilles linéaires, engainantes; fleurs élégantes, purpurines. - Les lieux arides.

D. Carthusiazorum L. 
- Calice entouré d'écailles aussi grandes ou plus grandes que lui.............. 2

2. Planle velue. - Plante rameuse dans le hant; feuilles linéaires; fleurs rouges, tichées de blane, a pétales dentés en scie. - Lieux sablonneux. D. Armeria L.

- Plante glabre. . . . • • • 3

3. Fleur's nombreuses, à pétales dentés. - Plante dlun rert foncé, à fleurs blanches ou rose ponctué de blanc. Vient dans les Prrénées; cultivée sous le nom d'Gillets cles poètes ou de Jalousies.

D. barbatus $L$.

- Fleurs paraissant une à une. - Plante grêle; tiges terminées par une tìte serrée de fleurs roses, entourée d'écailles membraneuses; pétales entiers ou échanerés. - Les lieux arides.

D. prolifer L.

4. Ecailles qui accompagnent la fleur isolées. . . 5

- Eccilles groupées deux par deux. - Plante velue, gazonnante, din vert gai; feuilles planes, at trois nervures écarties; fleurs petites roses ou blanches. -1 chercher ¿ La T'este de Buch.

Varie a plante glabre (D. glaucus L.)

5. Ecalles tries petites, n'éalant pas la moitié du calice. 6

- Ecailles égalant ou dépassant la moitié du calice. Plante viriable, à feuilles linciares, plićes en gouttière; fleurs purpurines, blanches ou panachies, tris odorantes. - Vieux murs; sur le littoral et cult. D. Caryophyllus L.

6. Plante glaurue, it feuilles obtuses. - Fleurs roses on blanches, tris odorantes. - Le littoral. D. gallicus Pers.

- Plante verte, a feuilles cuiguës. - Fleurs roses, non odorantes. - Lot-ct-Garome.

D. superbus L.

\section{G. SApoxaria L. - Saponaires.}

Calice myramidal, très anguleux. - Plante glabre, glauque, a lleur's roses. - Les inoissons. - (Grypsop) hylla Faceciria Smith)

S. Vaccaria L.

- Calice cylindrique et glabre. - Plante glabre, it griandes flenrs odorantes, rose pile on blanches, en coryuline. Git et lit et cult. - Saponaire.

S. officinalis $L$.

\section{G. SiLfine L.}

Fruit charnu. - S. G. Cucubalus Gœrtn.

Fruit see. - S. G. Silene L.

\section{S. G. Cucubalus Gortn.}

Plante élevée, accrochante, velue, at fenilles molles et a flenrs dim vert blanchitre; fruit noir. - Les haies. $-(C$. becciferus L.) S. baccifera Roth. 
S. G. Silenë L.

Fleurs verlicillées, d'un vert jaunatic. - Plante visqueuse, it tige simple; feuilles radicales en touffe; fleur's à vin $\mathrm{s}: u l$ sexe; pétales linéaires. - Lieux arides. S. Otites S.n.

- Fleurs non verticillées. . . . . . . . . . 1

1. Calice glabre. . . . . . . . . . . 2 2

- Calice velu. . . . . . . . . . . . 7

2. Calice en vessie, très renfté et veiné en réseau. - Plante très variable, glauque, à feuilles ovales ou lancéolées; fleurs nombreuses, d'un blanc pur; pétales sans appendices. - Les moissons.

5. inflata $\mathrm{Sm}$.

Varie: $1^{0}$ au bord de la mer, a pétales munis d'appendices (S. maritima With.); $2^{\circ}$ à plante très glauque et i feuilles charnues, arec des fleurs d'un blanc sale et des pétales à deux bosses. - Sables maritimes. - (S. crassifolia Thore.)

Calice ni vésiculeux, ni veiné en réseau. . . . . . 3

3. Calice non fermé au sommet ì la maturité. . . . . 4

- Calice fermé au sommet à la maturité. . . . . . 6

4. Calice en forme de cône renversé. - Plante gazonnante, d'un vert gai, a grandes fleurs blanches en dessus, vert jaunàtre ou purpurines en dessous; pétales échancrés. Parfois descendue des Pyrénées. S. Saxifraga L.

- Calice en forme de massue. . . . . . . . . 5

5. Fenilles linéaires, en goutlière. - Plante risqueuse dans le haut, à rameaux grèles et couchés; fleurs blanches en dessus, rougeatres en dessous, fermées le jour. - Sables marit. et landes. - (S. bicolor Thore). S. portensis L.

- Feuilles ovales, du moins les inférieures. - Plante glabre, glauque, un peu visqueuse au sommet, à petites fleurs roses, rarement blanches. - Les lieux pierreux.

S. Armeria L.

6. Fruit lisse et globuleux. - Plante un peu visqueuse au sommet; petites fleurs roses, à longue queue et à calice globuleux. - Pyrénées et plaines du S.-O. S. cretica L.

- Fruit ridé ct ovale. - Plante très visqueuse; petites fleur's rouges, à courte queue. - Toulouse. S. Muscipula I.

7. Pétales à deux divisiions profondes. - Plante rameuse a la base, relue et visqueuse; feuilles lancéolées; fleur's diun blanc sale, penchées. - Lieux secs. S. nutans I.

- Pétales entiers ou échanciés............ 8

8. Calice ì vingt nervures ou côles. - Plante pubescente, grisatre, à feuilles linéaires et molles, a fleurs roses et terminales; calice fructifère en forme de carafe. - Sables maritimes.

S. conica $\mathrm{L}$.

- Calice à dix nervures ou côtes. . . . . . . . . . . 9

9. Plante rameuse, a feuilles lanciolès et à fleurs axillai- 
res, groupées en épi; calice dressé, pétales roses, couleur de chair ou blancs. - Les champs sablonneux.

S. gallica L.

Varie à calice fructifère étalé ou réfléchi (S. anglica L.)

- Plante à tige en zigzag, à feuilles larges, ovales ou spatulées, ciliées à la base, les supérieures linéaires; fleur's petites, blanches en dedans et livides en dehor's, ou tout à fait revtes, disposées en grappe serrée ou en épi unilatéral; pétales à limbe en forme de coin. - Les champs.

S. nocturna L.

Varie à pétales linéaires et à fleurs écartées, en épis grêles (S. brachypetala Benth.)

\section{G. LrChNis L.}

Fleurs cn faisceau. - Plante relue, à grandes fleurs rouges. - Gultivée.

L. chalcedonica L.

- Fleurs en grappes serrées. - Plante d'un vert foncé pourpre au sommet, glabre, visqueuse, it fleurs lilas. Cultivée.

L. Viscaria L.

- Fleurs ramifiées et lâches au sommet. . . . . . i

1. Pétales profondément découpés en quatre lanières diver. gentes. - Plante risqueuse et rougeâtre, à fleurs roses. Prairies humides

L Flos-cuculi L.

- Pítales bifides; fleurs à un seul sexe. - Plante élevée, velue, rameuse, à grandes fleurs blanches, odorantes le soir. - Les haies.

L. dioïca L.

Varie à fleurs purpurines ( $L$. diurna Sibth.). - Cult.

- Pétales bifides; fleurs hermaprodites. - Plante molle, d'un vert tendre, à feuilles linéaires et à fleurs roses en dessus, pâles en dessous. - Autour du bassin d'Arcachon. - (Silene lneta. Gr. et God.)

L. corsica Lois.

- Pétales enticis; fleurs hermaphrodites. . . . . . 2

2. Calice à divisions linéaires, dépassant la corolle. Plante élevée, relue, blanchâtre, à feuilles linéaires et à fleurs pourpres. - Moissons. - Nielle. L. Githago Lam.

- Cialice a dents courtes. - Plante d'un blanc soyeux, élevée, à fleurs rouges ou blanches. - Cultivée et naturalisée çà et là.

L. Coronaria Lam.

\section{G. Arexaria L. - Sablines.}

Quatre à cinq styles. - S. G. Sagina L.

Jeux styles; quatre pétales. - S. G. Buffonia Sumr.

Trois styles. . . . . . . . . . . . 1

1. Feuilles a stipules membraneuses, - S. G. Spergularia Pers.

- Feuilles sans stipules. . . . . . . . . . . 2 
2. Fruit mủr à trois valves. - S. G. Alsine $\mathrm{K}$.

- Fruit mür à six dents au sommet. - S. G. Arenaria K.

S. G. Arenaria $K$.

Pétales plus courts que le calice. ......... 1

- Pétales plus longs que le calice. . . . . . . . 2

1. Feuilles munies d'une queue. - Plante rameuse, velue, diffuse, a feuilles ovales ayant trois nerrures; fleurs penchées après la floraison; graines noires, luisantes. - Lieux boisés.

Ar. trinervia L.

- Feuilles sans queue. - Plante variable, très rameuse et diffuse, à petites feuilles ovales et acuminées; fleurs blanches, axillaires, et en courtes panicules; fruit globuleux. - Lieux pierreux.

Ar. serpyllifolia $I$.

Varie : 10 à panicules allongées et à fruits coniques $(A r$. leptoclados Guss.); $2^{\circ}$ a plante plus verte et plus raide, hérissée de poils ( $1 \%$. Lloydi Jord.)

2. Ferilles molles, lancéolées, à bords ciliés. - Plante pubescente, à rameaux étalés. - Çà et là. Ar.montana I. Varie à feuilles orales et à pétales munis d'un pied. (Ar. ligericina Le Coq et Lam.)

- Fevilles en alène. - Plante pubescente, cendrée. - Cévennes.

Varie à plante glabre (Ar. controversa Boiss.). Plaines du S.-O.

\section{S. G. Alsine $\mathrm{K}$.}

Fruils à graines peu nombreuses, grosses et en forme de poire. - Plante fourchue, étalée à terre, à feuilles charnues et à fleurs solitaires. - Bords de la mer. - $(A l s$. peploïdes.)

Ar. peploïdes L.

- Fruits à graines petites et nombreuses. - Très petite plante fourchue, grèle et variable, à feuilles filiformes. (Als. tenuifolia Cir.)

Ar.tentifolia L.

\section{S. G. Spergularia Pers.}

Tige droite et glabre. - Plante très grêle et très petite, à pédoncules filiformes, courbés après la floraison. - Les moissons.

Ar. segetalis Lam.

- Tige étalée, pubescente au sommet. - Plante variable, rameuse, à feuilles filiformes, un peu charnue, et à fleur's roses, ell grappes làches; sépales aussi longs que la capsule. - Licux sablonneux.

A. xubra 1 .

Varie: 10 à feuilles plus charnues et it calice plus court que la capsule ( $A$. marina Roth.). - Au bord de la mer. $-2 n$ à graines bordées d'une membrane blauche ( 1 . mar)ginate DG.) 


\section{S. G. Buffonia Sauv.}

Très petite plante grèle, à feuilles en alène et à fleurs blanchàtres, en petites panicules; sépales it cind nervures. Poitou. - (B. paniculala Del.) Ar. paniculata.

\section{S. G. Sagina L.}

Queue du jeune firtit courbée au sommet. - Très petite plante glabre et couchée. - Se troure dans les lienx humides.

S. procumbens $\mathrm{L}$.

- Queue du fruit torjours droite............ 1

1. Feuilles linétives et ciliées. - Très petite plante grèle; fleurs a sépales étalés. - Champs sablomenx. - (S. apetala L.)

Ar. apetala.

Virle : 1o i sépales deni-ilresstis et it feuilles en gonttière (S. ambigua Lloỵd.); $2^{\circ}$ a scipales tout i fait dressés (S. patula Jord.)

- Fevilles linéaires, obtuses, glabres. - Tres petite plainle rongeatre ou brunatre. - Bords de la mer. - (S. maritima Don.)

Ar. maritima.

\section{G. Holosteum L.}

Tres petite plinte i fenilles lanciolies et glauques; fleurs blanches, en ornhelle, it pidoncules inégaux, rélféchis apres la floritison. - Cihamps. H. umbellatum L.

\section{G. Cierastium L.}

fruits a dix dents an somnet. - S. G. Cienastium $\mathrm{C}_{\text {. }}$.

Fruits at cing valves a denx dents. - S. G. Malachium lihth.

linuts à huit dents au sommet. - S. (i. Munchia Ehrh.

\section{S. G. Cierastium L.}

Pétales plus courls que le calire ou le dépassanl ì peine. I

- Pétales beaucoup plus longs que les sépales. . . . I

1. Pédicelles ne dépassant jamais la longueur du calice.

- Plante velue, it pétales incise's et poilus a la base. Les champs.

C. viscosum $\mathrm{L}$.

Varie a fleurs disposées en panicule serre (C.glomeratum Thuil.)

- Pédicelles bearcoup plus longs que le calice, du moins ì la maturilé. . . . . . . . . . . . . . 2

2. Plante hérissée de poils mous, is étamines et à pélales riliés a la base. - Plante à tiges genonillés on dresseer, difluse. - Les champs. C. brachypetalum Desl'.

- Flanle peu volue, a étamines ct pitales glabics. . . . S 
3. Plante ayant des rejets stériles; pétales dépassant un peu les sépales. (C. triviale Link.) G. vulgatum I..

- Plante annuelle, sans rejets; pétales souvent plus courls que le calice. . ............ 4

4. Feuilles florales membraneuses et denticules. - Plante grêle, d'un vert pâle, visqueuse ; fleurs ordinairement à cinq étamines. $\quad$ C. semidecandrum L.

- Feuilles florales vertes ou à bords membraneux entiers. - Plante variable. C. pumilum Curt.

Varie : $1^{\circ}$ au bord de la mer, à quatre étamines $(G$. tetrandrum Curt.); $2^{\circ}$ dans les terrains secs, à plante visqueuse ( $C$. glutinosum Fr.)

5. Plantes annuelles. ............. 3

- Plantes vivaces, gazonnantes. . . . . . . . . 6

6. Feuilles florales blanches, scarieuses sur les bords. 7

- Feuilles florales vertes, herbacées, du moins les inférieures. - Plante glabre, à feuilles un peu charnues. Dans les Pyrénées.

G. trigynum Vill.

7. Plante couverte d'un duvet blanc ct velouté. - Gultivéc sous le nom d'Oreille de souris.

- Plante verte, simplement pubescente.

G. repens $\mathrm{L}$. S. G. Malachium Fr.

Plante tombante ou grimpante, à feuilles ovales cn cœur et a fleurs blanches. - Dans les lieux humides. - (Mal. aquaticum Fr.)

G. aquaticum L.

S. G. Monchia Ehrh.

Très petite plante raide, à feuilles lancéolées et glauques, à fleurs blanches et à longue queue. - Pelouses sèches. (M. erecta Ehrh.)

C. erecta L.

\section{G. Spergula L. - Spargoutes.}

Feuilles dépourvues de stipules.......... 1 - Feuilles stipulées et verticillées. . . . . . . . 3

1. Pétales dépassant beaucoup les sépales. - Très petite plante à feuilles filiformes, les supérieures en faisceau. Bords de la mer.

S. nodosa $\mathrm{L}$.

- Pétales ne dépassant pas les sépales. . . . . 2

2. Plante pubescente, en petites touffes, à feuilles linéaires, ciliées à la base; fleurs solitaires, ì queues filiformes, ì pétales égaux aux sépales. - Sur les bords de la mer.

S. sabulata Sv. - Plante glabre, en touffes; pétales plus courts que les sépales. - Aurergne, Pyrénées. $\quad$ S. saginoîdes L.

3. Plante relue. .............

- Plante glabre. 
4. Nic étumines; graines noires, a papilles noire's. l'lante rameuse, diffuse, it feuilles linéaires, marquées d'un sillon en dessous. - Les champs. S. arvensis I. - Cinq étamines; graines noires, à papilles blanches. Plante plus grèle que la précédente, a feuilles linéaires ou cylindriques, olsscurément sillonnées en dessous. - Lieux cultivés.

S. vulgaris Boën.

Varie a plante plus robuste (S. maxima TV.) - Cultivée.

5. Pélales lancéolés et aigus.

- Pélales ovales el obtus.

S. pentandra $L$.

S. Morisonii Bor.

\section{G. Stellaria L. - Stellaires.}

Ce sont des plimtes ranifiées dis la base, formant sourent des toufles, a tigges fitibles on tombantes, qui viennent dans les endroits frais ou humides; elles sont annuelles ou riraces.

Fenilles inférieures ovales et munies de queue. . . . . 1

- Ferilles lancíolées, dépourvues de quene. . . . . .

1. Pélales beancoup plus longs que les sépales. - Plante ì tiges filiformes, rannjantes it la base puis dressées, pubescentes sur tout leur pourtour. - Aurergne, Céremes, Prrines et landes. - Lieux frais. S. nemorum I.

- Pélales dépassanl à peine les sépales ou muls. - Plante polymorphe, difluse, it tiges nombreuses, glabres mais parcourues par une ligne de poils. - Partout et toujours. Lieux cultivés.

S. media Vill.

Varie: 10 a tiges pen rameuses et dressées et it dix chanines (S. neglecta $\mathrm{TV}$.); $2^{n}$ a plante d'un rert clair, it pétales et à styles nuls (S. Borceana Jord.)

2. Tige cylindrique; capsules longues el cylindriques. -

Tres petite plante rameuse, coude it la hase, it feuilles linéaires.

S. viscida Bieb.

- Tirge quadrangulaire; capsules courles. . . . . . 3

3. Pétales ì peine plus longs que les sépales. . . . . 4

- Pétales beaucoup plus longs que les sépales. . . . . 5

4. Fenilles linéaires; pélales dépassant un peu les scipales. - Plante tris grele, trés faible; fleur's i bractées scitrienses et cilices. - Lienx humides. S. graminea I.

- Fevilles lancénles; pilates p'us compls que les sépales. - Plante difruse, a feuilles terminées en pointes ealleuses; flemes it pétiles profondénent divisés. - Bords des ruisseaux.

S. uliginosa Murr.

5. Fenilles rudes sur les bords, les florales rerles. - Plante raide et cassante. - Les haies.

S. Holostea L.

- Feuilles lisses sur les bords, les porales blanchr's. Plante faible et glauque. - Maríciges. S. glauca With. 


\section{G. Elatine L.}

Feuilles verticillées. - Plante à port d'Hippuris; tige élevée, fistuleuse; fl. blanches. - Marais. E. Alsinastrum L.

- Feuilles opposées. ............ 1

1. Fleurs sessiles. - A chercher dans le S.-O., où il peut se trouver.

- Fleurs pédonculées.

E. Hydropiper L.

2. Huit étamines. - Plante très rameuse, à fleurs d'un blanc rosé. - Marais.

E. campylosperma Seub.

- Six étamines. - Plante plus petite, à pétales blancs, marqués d'une raie rose. - Marais. $\quad$ E. hexandra DG.

\section{G. Illigebrum L.}

Plante couchée, rameuse et rougeâtre; fleurs blanches, rerticillées. - Lieux sablonneux.

I. verticillatum $L$.

\section{G. Herniaria Tourn.}

Plante très rameuse, grêle et appliquée en cercle sur le sol; feuilles très glabres. - Lieux secs.

Varie à feuilles velues ( $H$. hirsuta L.)

H. glabra $L$.

\section{G. Corrigiola L.}

Plante rameuse, couchée, à tige filiforme; feuilles grlauques; fleurs blanches, en corymbes feuillés. - Les lieux sablonneux.

G. littoralis L.

\section{G. Polygarpon L.}

Plante très rameuse, couchée, à feuilles quaternées ou opposées ; fleurs verdâtres. - Lieux sablonn. P.tetraphyllum L.

\section{G. Telephium L.}

Plante appliquée sur le sol, à tige simple et grèle et ì fleurs blanches. - Saint-Serer. T. Imperati L.

\section{G. Scleranthus L.}

Fleurs verdâtres; calice ouvert à la maturité. - Plante à tiges velues et fourchues, à feuilles linéaires. - Lieux sablonneux.

S. annuus $\mathrm{L}$.

- Fl. blanches; calice fermé à la maturité. S. perennis L. 


\section{G. Montia L.}

Très petite plante, à tiges dressées, raides; feuilles opposées, un peu charnues, jaunatres. - Lieux humid. M. fontana L.

Yarie a fenilles florales inégales. - Les eaux vives. (11. rivularis Gmel.)

\section{G. Pontulaca Tourn. - Pourpiers.}

Plante couchée et succulente, a fenilles en coin et ì fleurs jamnes. - Cultivée et échappée. P. oleracea L.

Varie it fleurs plus grandes et plus jaunes. - Cultivée sous le nom de Pourpier. doré ( $P$. sativa Haw.)

\section{Fam. des TILIACÉES Juss.}

\section{G. Tilia L. - Tilleuls.}

Fleur's munies d'ilamines pétaloüdes au cointact de l'ovaire. - Arbre variable, a fenilles glabres. - Originaire de l'Amerique du Nord et cultivé. T. americana L. Virrie: 1o a fenilles d'un vert foncé en dessus (T. floribunda Al.Br.); 20 ì feuilles argentées ( $T$. argentea Desf.), etc., ete.

- Fleurs sans étamines pélaloïdes en dedans. - Arbre très variathle. - Les bois des régrions montagneuses et cultivé pour les promenades.

T. europæa L.

larie: to it feuilles poilues, hérissées ( $T$. platyphylla IC(.); $2_{0}$ it feuilles glitures, ayant senlement des poils it l'imgle des nervures ( $T$. intermedia DG.); $3^{\circ}$ it feuilles du' precident, mais glanques en dessous et vert foncé en dessus (T. sylvestris DG.)

\section{Fam. des POLYGALÉES Juss.}

\section{G. Polygala L.}

diles de la fleur à nervures irrigulierement ramifies et anastomosées. - Plante variable, à tige dressée et à raneaux simples; fenilles lancéolies ou elliptiques; fleurs nombreuses, blenes, roses ou blanches, en épis terminaux; capsules débordéss par les ailes persistantes. Partout. 
Varie: 10 à capsules débordant les ailes ( $P$. oxypter $\alpha$ Reich.); $2^{\circ}$ à longues bractées, rendant les épis de fleurs chevelus ( $P$. comosa Schk.); $3^{\circ}$ à plante rameuse après la floraison, de façon à rendre les épis latéraux ( $P$. depressa TVend.); $4^{\circ}$ à pétales et à capsules ciliés ( $P$. ciliata Leb.); $5^{\circ}$ à feuilles inférieures orales, grandes et larges, et à feuilles supérieures lancéolées ( $P$. calcarea Sch.)

- Ailes de la fleur à nervure médiane simple, les latérales seules un peu ramifiées. - Plante à saveur amère, à feuilles radicales ovales ou spatulées, a petites fleurs verdàtres, blanchàtres ou bleuâtres; capsules arrondies en cour, débordant les ailes. - Vient des montagnes; cà et la dans tout le S.-O. (P. austriaca Cr.) P. amara L. Ailes de la fleur à nervures vertes, toutes rameuses et non anastomosées. - Plante à tige simple; feuilles linéaires ou lancéolées; fleurs vertes, bordées de blanc. Ile de Ré et la côte.

P. monspeliaca $\mathrm{L}$.

\section{Fam. des HYPÉRIGINÉES DG.}

\section{G. Hypericum L. - Millepertuis.}

Etam. en 5 faisceaux; fruit charnu. - S. G. Androscemum All. Etamines en 3 faisceaux; fruit sec. . . . . . . . 1 1. Fleurs tubuleuses ou en cloche; pétales munis d'un appendice à la base. - S. G. Elodes Sp.

- Fleurs ouvertes comme une rose; pétales sans appendice à la base. - S. G. Hypericum L.

\section{S. G. Hypericum L.}

Plante à odeur de bouc, fétide. - Plante élevée, glabre, à rameaux à quatre angles; fleurs jaunes et grandes, sépales lancéolés et aigus. - Bayonne, où elle est naturalisée. Souvent cultivée.

H. hircinum L.

- Plante sans odeur de bouc. . . . . . . . . . i

1. Plante rampante. . . . . . . . . . 2

- Plante droite. . . . . . . . . . 3

2. Plante à tige filiforme; fleurs petites. - Lieux sablonneux.

H. humifusum L.

- Plante ligneuse, à très grandes fleurs. - Gultivée assez souvent.

H. calycinum L.

3. Sépales entiers et non ciliés. . . . . . . . . 4

- Sépales dentés ou ciliés. .............. 6

4. Sépales obtus; feuilles dépourvies de points iranslucidles. - Plante vert foncé, tige à quatre angles peu 
marqués; feuilles elliptiques; fleurs grandes, en corymbe. - Bords des ruisseaux.

H. quadrangulum L. Sépales aigus; feuilles pourvues de points translucides. . . . . . . . . . . 5

5. Tige à 4 ailes; fenilles ovales; fleurs petites, pâles, en corymbe serré. - Bords des eaux. H. tetrapterum Fr.

- Tige cylindrique ou à deux tranchants. - Plante à feuilles lancéolées ou linéaires; fleurs grandes, en corrmbe.

H. perforatum L.

6. Plante velue. - Tige élevée, dressée, à feuilles ovales et à fleurs en panicule allongée. - Bois. H. hirsutum L.

- Plante glabre ou à peu près. . . . . . . 7

7. Sépales ovales et obtus. - Plante à tige dressée, rougeatre; feuilles ovales, en cœur, embrassantes; fleurs en panicule allongée. - Lieux sablomeux.

H. pulchrum L.

- Sépales lancéolés, aigus. . . . . . . . . . . 8

8. Fenilles linéaires. - Plante i tige ascendante et ì fleurs jaune rougeàtre. - Coteaux schisteux et région maritime.

H. linearifolium Vahl.

- Fevilles ovales, demi-embrassantes. - Plante élevée, à fleurs piles, glanduleuses, en bouquet serré. - Coteaux boisés.

H. montanum L.

S. G. Androscemum All.

Plante élevée, glabre; rameaux munis de deux lignes saillantes ; feuilles grandes et coriaces, en cour it la base. - Les bois. - (1. officinale .Ill.) H. Androsamum L.

S. G. Elodes Sp.

Plante pubescente, grisattre, à tiges failıles; feuilles ovales, arrondies; fleurs jaunes, terminales. - Lieux marécageux. - (E. palustris Sp.)

H. Elodes L.

\section{Fam. des RUTACÉES Baillon.}

\section{G. Ruta L. - Rues.}

Plante à tiges élerées, buissonmante, à odeur très forte; feuilles glauques, bipennées; fleurs jaune pâle, en corymbe. Rochers calcaires. - Gultivé; c'est la Rue ordinaire des jardins.

R. graveolens L.

\section{G. Tribulús L.}

Petite plante velue, appliquée sur le sol; feuilles pennées; fleurs jaunes, solitaires et axillaires. - Les sables maritimes.

T. terrestris L. 


\section{G. Coriaria L. - Redouls.}

Arbuste glabre, très rameux; feuilles lancéolées, aiguës, à trois nervures; fleurs petites et blanchàtres; fruit vert d'abord, puis noir. - Coteaux de la plaine du S.-O., jusqu'à Bordeaux.

G. myrtifolia L.

\section{G. Ailanthus Desf. - Verniers.}

Arbre à feuilles alternes, imparipennées, fétides; fleurs petites, verdàtres, en panicule terminale; fruit ailé, membraneux. - Cultivé et naturalisé sous le nom de Vernier du Japon.

A. glandulosa Desf.

\section{Fam. des SAPINDAGÉES Benth. et Hook.}

$$
\text { G. Acer L. - Erables. }
$$

Feuilles composées, pennées; fleurs en grappe. - Arbre cultivé.

A. Negundo L.

- Feuilles à trois lobes simples et entiers.- Arbre à fleurs vert jaunatre et à feuilles blanchàtres en dessous. - Les lieux sees.

A. monspessulanum $\mathrm{L}$.

- Feuilles palmées ou à lobes dentés. . . . . . . 1

1. Fleurs en grappes pendantes; ailes du fruit non divergentes. ............ 2 - Fleurs en bouquets dressés; ailes du fruit très écartées.................... 3

2. Feuilles à cinq lobes pointus. - Arbre à écorce lisse. Cultivé.

A. pseudoplatanus $\mathrm{L}$.

Varie à feuilles cotonneuses en dessous (A. obtusatum Will. ou A. neapolitanum Ten.)

- Fevilles à trois lobes obtus. - Arbre à écorce lisse. Cultivé.

3. Feuilles à 5-7 lobes tiès pointus; fleur's jaunes. Cultivé.

- Feuilles à lobes obtus; fleurs d'un vert jaunatre. Bois secs. A. campestre L.

\section{G. Esculus L. - Marronniers d'Inde.}

Arbre élevé, à feuilles palmées et à fleurs en panicule pyramidale, blanches, arec des taches jaunes et rouges. Originaire du nord de l'Asie, sourent cultivé et quelquefois naturalisé.

Æ. Hippocastanum L. 


\title{
Fam. des FRANGULAGÉES Lam.
}

\author{
Vitis. L. - Vignes.
}

Feuilles glabres sur leurs dewx faces. . . . . . . . 1

- Feuilles velues, laineuses en dessous. . . . . . . 3

1. Feuilles lobées et sinuées, à lobes aigus. - Vigne ordinaire.

V. vinifera $L$.

- Feuilles dentées ou obscurément lobées. . . . . 2

2. Feuilles minces, non luisantes, acuminées. - Introduite dans les cultures. $\quad$ V. cordifolia Michx.

Varie à feuilles plus larges et découpées (V.riparia Michx.)

- Feuilles luisantes des deux côlés. - Cult. V. vulpina I.

3. Feuilles continuellement velues. - Cult. V. Labrusca L.

- Fevilles devenant lisses en vieiliissant. - Introduite dans les cultures.

v. æstivalis Michx.

\section{G. Ampelopsis Michx. - Vignes vierges.}

Arbrissean grimpant, ì fenilles digitées. - Cultivé sous le nom de Vigne vierge.

A. quinquefolia Nichx.

\section{G. Evorymus Tourn. - Fusains.}

Arbuste glabre, a jeunes rameaux quadrangulaires; fenilles petites et fétides. - Les haies. E. europæus L.

\section{G. Rhamnus L. - Bourdaines.}

Fleurs hermaphrodites. - Arbrissean i feuilles ovales, entières; fleur's blanchàtres; fruits charnus, d'alsord rougeâtres, puis noirs. - Bois marécageux. R. Frangula L.

- Fleurs unisexuées et dioüques. . . . . . . . . 1

1. Feuilles opposées. - Arbrisseau épineux, it feuilles ovales, dentées en scie. - Haies sèches. R. catharticus L.

- Feuilles allernes. - Arbrisseau a feuilles persistantes et à fleurs jaunâtres, en petites grappes axillaires. - Région maritime.

R. alaternus $L$.

\section{G. Paliunus Tourn.}

Arbuste épineux, à feuilles alternes et à petites fleurs jaunes. Naturalisé à Léognan. R. aculeatus Lam. 


\section{G. Ilex L. - Houx.}

Arluuste très rameux, à feuilles coriaces et épineuses, luisantes, persistantes; fleurs blanches. - Bois. I. Aquifolium L.

\section{Fam. des TÉRÉBINTHACÉES Juss.}

\section{G. Pistacia L. - Pistachiers.}

Arbuste rameux, buissonnant, feuilles annuelles, pennées, à folioles ovales. - Se trouve dans la Dordogne et le Tarnet-Garonne.

P. Terebinthus L.

\section{G. Rhus L. - Sumacs.}

Feuilles simples. - Arbuste rameux, à fleurs jaunàtres, disposées en panicule qui s'accroît à la maturité et qui devient plumeuse. - Gult. sous le nom de Fustet. R. cotinus L.

- Feuilles composées. . . . . . . . . 1

1. Feuilles glabres des derx côtés. - Plante à folioles petites, lancéolées et dentées; fleurs en panicule làche. Cult.

R. glabrum L.

- Feuilles velues en dessous. . . . . . . . . . . 2

2. Folioles ovales, $\dot{a}$ dents obtuses. - Gult. R. Goriaria L.

- Folioles lancéol., à dents aiguës. - Cult. R. typhinum L.

\section{Fam. des LÉGUMINEUSES Juss.}

\section{G. Ulex L. - Ajones.}

Tige dressée; ailes de la fleur plus longues que la carène. - Arbrisseau très rameux, hérissé d'épines; feuilles lancéolées ou avortées. - Les landes. U. europæus L.

Varie à bractées linéaires et non ovales (U. Gallii Pl.)

- Tige couchée ou rampante; ailes plus courtes que la carène. - Arbrisseau très rameux et épineux; feuilles linéaires. - Les landes. $\quad$ U. nanus Sm.

\section{G. Genista L. - Genêts.}

Feuilles inférieures souvent à trois folioles; style roulé en spirale. - Arbrisseau à rameaux anguleux; fleurs jaunes, grandes, en épis lâches. - Les bois. - Genêt à balais. (Sarothamnus scoparius K.) G. Sarothamnus Lam. 
- Toutes les feuilles simples; style droit ou arqué. . . 1

1. Calice fendu de haut en bas. - Arbrisseau à rameaux nombreux et en forme de jonc, peu ou point feuillés; fleurs grandes, jaunes et odorantes. - Cultivé sous le nom de Genêt d'Espagne. - Cá et là, le long de la côte. (Spartium junceum L.) - G. juncea Lam.

- Calice non fendu. ............. 2

2. Tiges épineuses. . . . . . . . . . . . . 3

- Tiges non épineuses. . . . . . . . . . . . . 6

3. Epines simples. . . . . . . . . . . . 4

- Epines ramifiées. . . . . . . . . . . 5

4. Feuilles ovales. - Arbuste glabre, i rameaux nombreux, entrelacés, anguleux; fleur's jaunes, à étendard plus long que la carene. - Lieux arides. G. Scorpius DC.

- Feuilles lancéolées. - Arbuste glabre, à rameaux étalés, formant buisson; fleurs i étenulird plus court que la carene, petites et jaunes. - Lieux arides. G. anglica L. 5. Fenilles lancéolées, luisantes, ciliées; étendard pubescent, beaucoup plus court que la carine. - Arbrisseau a petites fleurs jaunes. - Licux arides. G. germanica L.

- Feuilles linéaires, du moins les supérieures, velues; étendard glabre, égalant la caréne. - Arbrisseau à petites fleurs jaumes. - Tarn-et-Gar. G. hispanica L.

6. Rameanx de la tige is trois ailes. - Plante conchée, touffue, herbacée; fleurs jaunes, en épis courts. - Bois secs.

G. sagittalis $L$.

Rameaux non ailés. . . . . . . . . . 7

7. Corolle pubescente, soyeuse en clehors. - Plante a rameaux nombreux, cannelés; lleurs jaunes, au milieu d'un groupe de feuilles. - Bois sees. G. pilosa L. Corolle glabre.

8. Pédicule des fleurs bearcoup plus long que la feuille florale. - Sous-arbrisseau it rameaux striés et à feuilles lancéolées, velues au bord; lleurs jumnes, en grappes axillaires. - Bois.

G. tinctoria L.

- Pédicule des fleurs plus court que la feville florale. 9

9. Calice glabre ou à poils couchés. - Plante ligneuse, à feuilles à trois folioles et à fleurs jaunes. - Auvergne et Cévennes.

G. purgans DC.

- Calice hérissé. - Plante étalée ou couchée, à feuilles lancéolées et velues; fleurs d'un beau jaune, en grappe tournée d'un seul còté. - A chercher dans les terrains calc. - (Gytisus decumbens Walp.) G. prostrata Lam.

\section{G. Crtisus L. - Cytises.}

Calice ou fruits couverts de glandes. - S. G. Aderocarpus DC. Calice et fruits relus ou hérissés. - S. G. Ciytisus L. 


\section{S. G. Adenocarpus DG.}

Calice simplement velu, à lèvres sensiblement égales. Arbrisseau à rameaux grèles, blanchâtres; feuilles d'un vert gris; fleurs jaunes. - Cér. - (Adenocarpus commutatus DG. ou A. cebennensis Del.) C. commutatus DC.

- Calice tuberculeux, à lèvies très inégales. - Arbrisseau à rameaux blanchàtres; à feuilles d'un rert foncé; fleurs jaunes. - Poitou, Pyrénées et plaines du S.-O. - (Adenocarpus parvifolius DG.) C. complicatus DG.

\section{S. G. Cytisus L.}

Fleurs en grappes non feuillées. ......... 1

- Fleurs en tête ou rapprochées au sommet en grappes fenillées. . . . . . . . . 2

1. Grappe pendante. - Arbre á écorce lisse et verte; feuilles à trois folioles, pàles en dessous; fleurs grandes et jaumes. - Cult. sous le nom de Faux-ébénier. C. Laburnum L.

- Grappe dressée. - Arbrisseau glabre, à écorce brume: folioles des feuilles arrondies, presque sessiles. - Cultive sous le nom de Trifolium.

C. sessilifolius $L$.

2. Lèvre supérieure du calice fendue. - Petite plante a tiges ligneuses, couchées; feuilies glauques, garnies en dessous et sur les bords de poils blanes et soyeux; fleurs jaunes. - Se trouve dans le Poitou. - Argyrolobium linnoeanum Walp.)

C. argenteus L.

- Lèvre supérieure du calice tronquée ou à deux dents. 3

3. Tige droite, à rameaux raides et dressés. - Arbrisseau à feuilles d'un vert sombre et a fleurs jaunes. - Toulouse. - Cultivé.

G. capitatus DC.

- Tige couchée, à rameaux lâches et tombants. . . . 4

4. Fleurs en tête terminale. - Plante velue, à poils étalés. Bois sees.

- Fleurs en fäisceaux latéraux et terminaux. - Dans le Poitou.

G. prostratus Scop.

\section{G. ONonis L.}

Fleurs blanches ou rouges. . . . . . . . 1

- Fleurs jaunes. . . . . . . . . . . . 3

1. Queves des fleurs articulées. - Petite plante à tiges grêles et diffuses; fleurs purpurines. - La côte, de Biarritz à la Vendée.

- Queves des fleurs non articulées. . . . . . . . 2

2. Fruit plus court que le calice qui persiste. - Plante très variable, velue et visqueuse, a longue racine rampante; folioles ovales; fleurs roses. - Champs. O. repens L. Varie: 10 à plante épineuse $(O$. arvensis $\mathrm{Sm}) ;$.20 à rameaux ascendants $(O$. procurrens Wall.); etc. 
- Fruit égalant ou dépassant le calice. - Plante buissonnante, à rameaux épineux; folioles linéaires. - Champs. - (O. campestris Wall.) O. spinosa L. 3. Queues des fleurs articulées. - Plante très variable, velue et glanduleuse, à folioles dentées en scie; fleurs jaunes et fruits linéaires, pendants. - Terrains calcaires et sables de la côte.

O. Natrix L.

- Queues des fleurs non articulées. . . . . . 4

4. Fleurs ayant une queue; corolle plus longue que le calice. - Petite plante couchée, diffuse, à folioles en coin arrondi; fleurs en têtes feuillées. - Poitou, Cévennes, Pyrénées.

O. striata Gouan.

- Fleurs sans queue; corolle sensiblement égale au calice. -Petite plante diffuse, à folioles lancéolées; fleurs jaunes, en épis feuillés. - Lieux calcaires. O. Columnæ All.

Varie à fleurs en capitules serrés (O. minutissima L.) - Cévennes, Pyrénées et Lot-et-Garonne.

\section{G. Anthyluis L. - Vulnéraires.}

Plante velue, couchée, très variable, à folioles des feuilles peu nombreuses et très inégales et à fleurs jaune pâle ou jaunes.

A. vulneraria L.

Varie surtout a fleurs rouges ou variées (A. Dillenii Sch. ou rubiflora DC.)

\section{G. Medicago L. - Luzernes.}

Fruit hérissé d'épines. . . . . . . . . 5 5 - Fruit glabre ou pubescent, sans épines...... 1

1. Fruit enroulé en hélice et formant un disque. . . . 4

- Fruit enroulé en cylindre et muni ou non sur les bords. de petits tubercules. - Plante couchée, velue, à tige anguleuse. - Bords de la mer. M. striata Bast.

- Fruit arqué ou enroulé en forme de cercle et d'annear. ............... 2

2. Fleurs très petites, en têtes ovoüdes; fruit court et réniforme. - Plante couchée, à folioles en coin à la base, dentées au sommet. - Lieux arides. - Cultivée comme fourrage - Lupuline.

M. Iupulina L.

Varie, au bord de la mer, it plante pubescente et blanchâtre.

- Fleurs assez grandes, en grappe. . . . . . 3

3. Fruit à deux tour's de spire, contourné en cercle. Plante à racines très longues et à tige anguleuse. Cultivée - Luzerne; souvent échappée. IM. sativa L.

- Fruit courbé en faucille. - Plante un peu velue, ì souche 
ligneuse, et à tige couchée à la base, puis redresssée; fleurs jaunes. - Prairies sèches.

M. falcata L.

Varie à fleurs verdàtres ou violacées (M. media Pers.)

4. Stipules dentées; fruit en disque hémisphérique.-

Plante velue, glanduleuse, à fleurs d'un jaune orangé. -

Plante méridionale qui se retrouve dans les cultures de luzerne.

IM. scutellata DC.

- Stipules déchiquetées en lobes sétacés; fruit aplali des

deux côtés. - Plante couchée, glabre; gousse noircissant

à la maturité. - Coteaux calc. M. marginata Wild.

5. Fruits glabres. . . . . . . .... 6

- Fruits plus ou moins velus. . . . . . . . . 9

6. Stipules déchiquetées, ¿̀ lanières sétacées. . . . . 7

Stipules dentées. . . . . . . . . . 8

7. Epines des fruits en tous sens; graines lancéolées. -

Plante glabre, à tiges couchées, anguleuses; trois à quatre fleurs. - Charente-Inférieure. M. lappacea Lam.

Varie à spires du fruit plus nombreuses, cinq généralement (M.pentacycla DC.)

Epines du fruit non en tous sens; graines réniformes. - Plante glabre, à tiges couchées, anguleuses; quatre à huit fleurs.

IM. polycarpa Willd.

Varie: 10 à épines droites et courtes (M. apiculata Willd.); $2^{\circ}$ a épines fines et longues, crochues (M. denticulata Willd.)

8. Folioles en cour'; fruit ovale, à épines réfléchies.-Plante conchée et diffuse, a poils épars, à folioles sourent marquées d'une tache noire au milieu. - Prairies; bords des chemins.

M. maculata Willd.

- Folioles triangulaires; fruit cylindrique, subéreux, $\dot{a}$ épines arquées. - Plante velue, ì 2-1 fleurs james. Le littoral.

M. littoralis $R$.

9. Fruit cylindrique, à poils épars. - Plante velue; folioles triangul.; 1-2 fleurs jaunes. - Plante méditerranéenne; se trouve dans la $\mathrm{Ch}^{\text {te }}$-Infre.

M. tribuloïdes Lam.

- Fruil discoïde, très velu.

10. Stipules en lanières. - Plante couchée; 1-2 fleurs jaune clair. - Les champs. - (M. villosa DC., M. cinerescens Jord.)

M. Gerardi Willd.

- Stipules ovales et presque entières. . . . . . . . 11

11. Fruit velu, à épines courtes, entourées de duvet. - Plante couchée, toute cotonneuse, blanchàtre; 6-9 fleurs. Sables maritimes.

M. marina L.

- Fruit pubescent, à épines clépourvues de duvet. - Plante pubescente, étalée ou dressée; 3-6 fleurs. - Lieux sablonneux.

M. minima Lam.

Varie: 10 à plante blanchàtre, dans les sables maritimes; $2^{\circ}$ i longues épines ( $M$. longiseta Lloyd.) 


\section{G. Trigonelia L. - Fenugrees.}

Fleurs axillaires et sessiles. - Plante glabre ou à peu près, i tige dressée, rameuse et à fleurs blanchâtres. - Les champs. - Cultivée.

T. fœnum græcum L.

- Fleurs en grappes. - Plante glabre, à tiges nombreuses, couchées ou ascendantes; fleurs jaunes. - Toulouse et l'Ariège.

T. hybrida DG.

Fleurs en ombelle.

1. Ombelle sessile. - Plante plus ou moins velue, d'un vert pâle, a petites fleurs jaunes. - Dans la Charente-Inféiieure.

T. monspeliaca DC.

- Orizelle pédonculée. - Plante glabre, ì fleurs rougeâtres. - Pyr., La Teste de Buch. T. ornithopodiö̈des DC.

\section{G. Melilotus Tourn. - Mélilots.}

Plantes tris rariables, it especes peu distinctes, dont les fleurs passent du jaune foncé au jaune pàle et mème au blanc.

stipules des feuilles culières.

M. officinalis L.

Varie : 10 it fleurs blanches ( $M$. alba Desr.); $2^{\circ}$ à tige couchée et à fruits glabres ( $M$. arrensis Wall.); 30 à tige élevée et à fruits velus ( $I$. altissima Thuil.); L $^{\circ}$ à fruits a une seule graine au lieu de deux (M. palustris Kit.)

- Stipules des feuilles dentelées, surtout à la base. - Sur le littoral.

M. indica L.

Varie: $1^{0}$ i fruits irrégulièrement ridés (M. parviflora Desf.); $2^{\circ}$ à fruits marqués de stries parallèles concentriques (M. sulcata Desf.)

\section{G. Trifolium L. - Trèfles.}

Fleurs rouges, roses, blanches ou d'un blanc jaunatre. 1 - Fleurs jaunes. . . . . . . . . . . 26

1. Corolle plus courte que le calice. - Plante en rosette sur le sol; feuilles longuement pétiolées; fleurs très petites, blanches, en tète globuleuse. - Pelouses des coteaux maritimes. $\quad T$. suffocatum L.

- Corolle plus longue que le calice. . . . . . . . 2

2. Cálice velu ou hérissé, du moins sur les dents. . . 3

- Calice tout à fait glabre. . . . . . . . . . 21

3. Plante couchée sur le sol; pédoncule it 4-5 fleurs. Plante velue; fleurs blanches, réflćchies aprés la fécondation et s'enfon'ant clans la terre. - Les lieux sablonneux.

T. subterraneum L.

- Plante plus ou moins dressée; pédoncules portant un épi ou une tête de lleurs nombreuses. . . . . . . 4 
4. Fleurs d'un blanc jaunâtre. - Plante velue, dressée; folioles elliptiques; stipules en alène. - Les prairies sèches. T. ochroleucum L. Fleurs rouges, roses ou blanches. . . . . . . 5 5

5. Fleur's en épi cylindrique ou allongé. . . . . . . 6

- Fleurs en tête ovoüde ou arrondie. . . . . . . . . 10

6. Folioles des feuilles linéaires ou lancéolées. . . . . 7

- Folioles arrondies ou en cœur renversé. - Plante dressée, velue; folioles ovales ou arrondies; fleurs en épi cylindrique, d'un rouge vif. - Cultivée sous le nom de Trèfle incarnat ou farouche. $\quad T$. incarnatum L.

Varie à fleurs blanches ou roses (T. Molinerii Balb.)

7. Epis sessiles entre les feuilles supérieures qui sont par deux. - Très petite plante pubescente, à tiges simples; folioles en coin ; stipules en alène; graine jaune pâle, très petite. - Lieux secs.

T. Bocconii Sav.

- Epis terminaux et plus ou moins pédonculés. . . 8

8. Calice $\dot{a}$ dents velues et $\dot{a}$ tube glabre; dents infévieures beaucoup plus longues que les autres. - Plante glabre, à tiges dressées, à peu près simples; folioles lancéolées, coriaces, à nervures et à dents nombreuses; fleur's rouges. - Lieux calcaires. T. rubens L.

- Calice à tube velu; dents inférieures ne dépassant pas beaucoup les autres. . . . . . . . . . . 99

9. Dents du calice raides; pointe des feuilles entiere et aiguë. - Plante dressée, raide, velue; fleurs roses. Lieux arides.

T. angustifolium $\mathrm{L}$.

- Dents du calice molles; pointe des feuilles dentée et obtuse. - Plante très variable, velue, dressée ou diffuse; fleur's blanchàtres, en épi très velu, mou, presque cylindrique; calice it dents plumeuses. T.arvense L.

Varie : $1^{\circ}$ à plante grèle et tout à fait glabre $(T$. gracile Thuil.); 20 à plante très rameuse et très velue, á épi ovale (T. perpusillum DC.); etc.

10. Têtes de fleurs portées sur des pédoncules. . . . 11

- Têtes de fleurs toutes sessiles à l'aisselle des fenilles. 19

- Têtes de fleurs au nombre de deux, l'une pédonculée, l'autre sessile. - Plante couverte de poils fins; feuilles ovales, à petites stipules sétacées; petites fleurs roses. - Bayonne.

T. ligusticum Ball,.

11. Calice renflé, vésiculeux après la floraison. . . . 12

- Calice ni renflé, ni vésiculeux. . . . . . . . . . 13

12. Fleur's renversées, l'étendard en avant. - Plante à tiges ascendantes, striées et glabres; folioles ovales, dentées en scie; fleurs roses.

T. resupinatum 1 .

- Fleurs droites, l'élendard en arrière. - Plante rampante et gazomnante; fleurs roses. - Se trouve dans les lieux secs.

T. fragiferum L. 
13. Dents du calice égales à la corolle. - Plante couchée, à folioles en coin; fleurs blanc rosé. - Se troure daris les landes.

T. lappàceum L.

- Dents du calice plus longues que la corolle. . . . 9

- Dents du calice beaucoup plus courtes que la corolle. 14

14. Feuilles denticulées; fleurs pourvues chacune d'une petite queue. ....................

- Feuilles à peine dentées; fleurs en têtes et sans queue. 16

15. Calice grêle, conique, à dents à peu près égales, à la fin courbées en dehors. - Petite plante couchée, à fleurs en petite tète ronde, portées sur une queue fine. - Les landes. T. Perreymondi Gr.

- Calice companulé, à dents inégales, dressées. - Plante d'un vert pile, a fleurs blanches ou rarement purpurines.

T. montanum L.

16. Dents du calice divergentes, crochues ou piquantes. 17

- Dents du calice non divergentes. . . . . . . . . . . 18

17. Calice fermé à la gorge par de longs poils laineux, $\dot{a}$ dents égales, s'accroissant à la maturité el s'étalant en étoile. - Ile de Ré.

T. stellatum L.

- Calice fermé à la gorge par deux levres latérales, à dents foliacées, étalées à la malurité, l'inférieure plus grande et à trois nervures; fleurs couleur de chair. Dans les prairies, surtout aux bords de la mer. - (T. irvegulare DC.)

T. maritimum Huds.

Varie : $1^{\circ}$ à dents du calice égales ( $T$. Tatardii DC.); $2^{\circ}$ a tètes et it lleurs plus grandes, it dents inférieures du calice réfléchies (T. panormitanum Prels. ou $T$. squarrosum DC.) - Dax, Bayonne.

18. Tube du calice glabre. - Plante it tige ascendante, flexueuse; stipules linéaires et très longues; fleur's rouges. - Bois sees.

T. medium L.

- Tube du calice hérissé ou velu. - Plante à stipules ovales, terminées par une arête poilue au sommet et it fleurs rouges. - Cultivée comme Tréfle.

T. pratense L.

19. Têtes toutes placées au sommet de la tige ou des rameaux. ............ 16

- Plusieurs têtes placées latéralement le long de la tige. 20

20. Calice fermé ì la gorge par deux lèrres. - Plante couchée, couverte de poils couchés; fleurs blanc rosé; dents du calice inégales, lancéolées, recourbées et raides à la maturité. - Lieux arides.

T. scabrum L.

- Calice à gorge pubescente, mais ouverte. - Plante plus ou moins relue; stipules reinées; fleurs blanc rosé; calice ovale, ventru, très velu, à dents droites et à peu pres égales. - Lieux arides.

T. striatum L.

Varie a dents du calice épineuses et étalćes (T. tenuiflorum Ten.) 
21. Têtes de fleurs latérales et sessiles. - Plante glabre et couchée; stipules ovales ou lancéolées; fleurs blane rosé. - Lieux arides. T. glomeratum L.

- Tétes de fl.toutes terminales ou munies d'une queue. 22

22. Dents du calice plus longues que la corolle. . . . . 9

- Dents du calice plus courtes que la corolle. . . . . 23

23. Fleurs sessiles, sans pédoncules particuliers. - Plante lisse; feuilles supérieures à folioles linéaires; fleurs blane rosé. - Lieux secs.

- Fleurs pourvues chacune d'un pédoncule. . . . . 2't 2'. Tige creuse; queues des jeunes fleurs plus courtes que les feuilles. - Plante faible, ascendante, à tige fortement striée; fleurs mélangées de verditre. - Les bords de la mer. $\quad$ T. michelianum Sav.

- Tige pleine; queues des fleurs plus longues que les

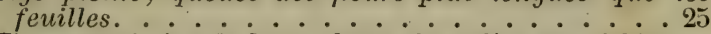

25. Tige enracinée à la base; dents du calice lancéolées. Plante a fleurs blanches, en tètes globuleuses et serrées. - Prairies.

T. repens L.

- Tige non enracinée; dents du calice en alène. - Plante a folioles dentées tout autour; fleur's roses, en tètes serrées. - Cultivée.

T. elegans L.

26. Stipules supérieures courtes et ovales. . . . . . . 27

- Stipules allongées et aiguës. - Plante d'un vert pàle, à fleurs d'abord jaunes, puis brumes. - Auvergne, Pyrenées.

T. aureum Poll.

27. Fleur's d'un beau jaune doré; folioles naissant toutes les trois au même point. - Plante faible, ascendante. (T. parisiense DC.)

T. patens Schr.

- Fleur's d'un jaune clair; foliole terminale séparée des

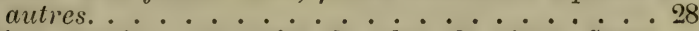

28. Têtes serrées, composées de plus de vingt fleurs. Petite plante très rameuse, diffuse; étendard de la fleur étalé, courbé en cuillère au sommet, fortement strié. Les lieux incultes.

T. agrarium $\mathrm{L}$.

Varie à fleurs plus pâles, ayant des queues plus longues (T. pseudo-procumbens Gmel.)

- Títes lâches, composées de deux à quinze fleurs. . . 29

29. Têtes de 3-6 fleurs. - Plante grêle, à folioles ovales, toutes sans queue; queue de la fleur flexuense. - Les prairies.

T. filiforme L.

- Tétes de 5-15 fleurs. - Plante moins grèle que la précédente; foliole terminale munie d'une queue; quenes des fleurs raides et droites. - Dans les prairies. (T. minus Sm.) T. procumbens L.

Nота. - Ces cinq dernières espèces de trèfles, qui sont à fleurs jaunes, sont très roisines les unes des autres. 


\section{G. Lotus L. - Lotiers.}

Ailes de la fleur renflées en bosse. - S. G. Dorycnium Tourn. Ailes de la fleur sans bosse. - S. G. Lotus L.

$$
\text { S. G. Lotus L. }
$$

Fleur's réunies au nombre de 8-12 sur le pédicule. . 1

- Fleurs réunies au nombre de D-6 sur le pédicule. . 2

- Fleurs solitaires sur chaque pédicule. - Plante velue et couchée, à fleur janne paile; fruit bordé de quatre ailes. (Tetragonolobus siliquosus R.) L. siliquosus L.

1. Dents du calice linéaires. - Plante ligneuse, à branches herbacées et anguleuses; fleurs nombreuses, en tète. Biarritz et Blave.

L. rectus $\mathrm{L}$.

- Dents du calice réflechies arant la floraison. - Plante faillle, dressée, à tigre longue et creuse. - Les lieux marécageux.

L. uliginosus Sch.

2. Dents du calice inégales; fruit comprimé. - Plante converte de poils, verte on d'un vert blanchatre, a fortes racines ligneuses; fleur's jaunes; fruit linéaire, bosselé. Plante du Midi qui se retrouve à La Teste de Buch. -(L. Allionii Desv.) L. cytisoüdes DC.

Dents du calice égales; fruit cylindrique. . . . . . 3

3. Dents du calice lancéolées ou en alène, Loujours plus lonques que le tube. - Plante très variable, hérissce de poils mous; étendard a limbe plus large que long, ne dépassant pas les ailes; rarene courtre a angle droit, saillante an sommet et par langle. L.angustissimus L.

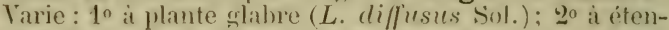
dard à limbe ovale, dipassant les ailes, it earene courbre it ingle très oltus, entierement deigagée des ailes ( $L$. hispidus Lois.); $3^{\circ}$ i petites fleurs plus nombreuses et it firuit court ne dépassint pas le calice (L.porviflorus Desf.)

- Dents du calire triangulaires à la base, brusquement amincies en alène, égalant le tube. - Plinte variable, glahre ou ì poils épars; tiges ingulenses; étendard arrondi; carène courbée presque it angle droit, saillante en dessous.

I. conniculatus L.

Virrie: $1^{\circ}$ a folioles linéaires (L. temuifolius Pol.); 20 it - plante très velue ( $L$. villosus Thuil.)

\section{S. G. Dorycnium Tourn.}

Plante sous-ligneuse, luissonnante. soveuse; fenilles linéaires; flen's blimches, en tète terminale. - Les lienx sees. (D. suffrulicosum Til.)

L. Dorycnium L. 


\section{G. Glycyrnhiza L. - Réglisses.}

Plante sous-ligneuse, à très longues racines, douces au goùt; folioles ovales, visqueuses; fleurs violacées, à étendard blanchàtre._-Cultivée sous le nom de Réglisse. Echappée des jardins, près de Blaye.

G. glabra L.

\section{G. GaLega L.}

Plante élevée, droite, rameuse; folioles lancéolées, glabres; fleurs blanches, rosées ou bleuâtres, en grappes axillaires. - Cultivée; naturalisée à Bayonne. G. officinalis L.

\section{G. Robrnia L. - Robiniers.}

Fleurs blanches. - Arbre à rameaux épineux (stipules transformées en épines); folioles nombreuses, orales; fleurs en grappes liches et penchées. - Originaire de l'Amérique du Nord; cultivé sous le nom de Robinier ou d'Acacia.

R. pseudo-acacia L.

- Fleur's grandes et d'un beau rose. - Nèmes caractères. Cultivé.

R. hispida L.

\section{G. Colutea L. - Baguenaudiers.}

Arbrisseau à feuilles pennées arec impair; fleurs jaunes, marquées d'une ligne rouge en forme de cœur. - Cultivé sous le nom de Baguenaudier. C. arborescens L.

\section{G. Psoralea L.}

Plante à odeur bitumeuse; feuilles à trois folioles ovales; fleurs d'un bleu pâle. - Se trouve ça et la dans la plaine du S.-O.

P. bituminosa L.

\section{G. Astragalus L. - Astragales.}

Fleurs jaunes ou blanches. . . . . . . . . 1 Fleurs rouges ou bleues. . . . . . . . . . 2 1. Feuilles à 14-26 folioles, pubescentes en dessous. - Plante blanchâtre et poilue; gousse recourbée en hamecon. - Charente-Inférieure.

A. hamosus L.

- Fevilles à 9-13 folioles, larges et presque glabres. Plante longne, faible et couchée: fleurs jaune verdàtre; gousse lincaire.

A. glycyphyllos L.

2. Plante acaule; jousse cylindrique. - Tige sous-ligneuse, à rameaux couchés; fleurs purpurines, en épis courts, 
portées sur un pédoncule plus long que les feuilles et nu. - Coteaux calcaires. A. monspessulanus L.

- Plante à tige feuillée; gousse munie d'un sillon sur le dos.

3. Fleurs $3-8$, en petite grappe lâche - Plante blanchàtre, à petites folioles linéitires; fleurs d'un bleu pâle. Sables maritimes.

A. bayonnensis Lois.

- Fleurs 10-20, en grappe courte et serrée. - Petite plante d'un vert cendré, à folioles elliptiques et à fleurs purpurines. - Céremnes, Pyrénées et ģả et lả dans la plaine du S. -0 .

A. purpureus Lam.

\section{G. Scorpiurus L.}

Plante couchée, un peu velue, à feuilles lancéolées ou spatulées ; 1-2 fleurs jaunes sur des pédoncules anguleux; gousse hérisscie d'épines crochues. - Ile d'Oléron et çi et lit dans le S. -0 .

Sc. subvillosa L.

\section{G. Cononilla Neck. - Coronilles.}

Fleurs mêlées de blanc el de rose. - Plante tombante et diffuse, i racine rampante; 17-21 folioles allongées; fleurs en tète. - Les bois.

C. varia $L$.

- Fleurs jaunes. . . . . . . . . . . . 1

1. Arbrisseau it pied des pétales dépassant beaucoup le calice. - Rimneatux anguleux, pédoncules axillaires; étendaril rayé. - Ciultivé et échappé.

- Plante à pied des pétales ne dépassant pas le calice. 2

2. Tige sous-ligneuse, élalée; pédicelle de la longueur du calice. - Fleurs 7-10, en tète sur une très longue queue; gousse à quatre angles. - Lieux sees. G. minima L.

- Pétite plante a rameaux en lous sens. - Trois folioles glauques, cjpaisses; gousse it quatre angles, arquée, striée. - Les moissons. C. scorpioïdes Koch.

\section{G. Orsithopes L.}

Plante glabre; calice sans feuilles à sa base. - Plante grèle, conchíe ou redressée; quatre paires de folioles; pédoncule a 1-3 fleurs jaunes. O. ebracteatus DC.

- Planle pubescente; calice muni de ferilles à sa base. 1

1. Fleurs jaunes; fruit terminé par une longue pointe crochue. - Plante velue et blanchitre; pédoncules i 3-4 fleurs. - Terrains de landes. O. compressus $\mathrm{L}$.

- Fleurs rosées ou blanchatre mêlè de rose; pointe du fruit courte ou presque droite. .........2 
2. Fruit pubescent; /leur's blanches mêlées de v'ose.-Plante conchée; pédoncules à $3-4$ petites fleurs; calice il dents trois fois plus courtes que le tube; gousse arquée. - Pied d'oiseau. - Terrains de landes. O. perpusillus L.

- Fruit glabre; fleurs roses. - Plante conchée; pédoncules a 3-4fleurs; calice à dents égalant le tube; gousse droite, i bec droit. - Terrains de landes.

O. roseus Duf.

\section{G. Hippocrepis L.}

Plante couchée, à tiges nombreuses; folioles linéaires; fleurs jaunes, en ombelle. - Partout.

H. comosa L.

\section{G. ONobrychis Tourn. - Sainfoins.}

Calice plus long que la moitié de la corolle. - Plante couchée, a fleur's petites, blanchâtres, rayées de rouge. Auvergne, Pyrénées.

O. supina DC.

- Calice plus court que la moitie de la corolle. - Plante a tige simple, sillomnée, à fleur's roses reinées de rouge. Cultivée.

O. sativa Lam.

\section{G. VICIA L.}

Dents du calice presque aussi longues que la corolle. - S. G. Ervum L.

Dents du calice beaucoup plus courtes que la corolle. - S. G. Vicia L.

$$
\text { S. G. Ervum L. - Lentilles. }
$$

Ovaire et fruit glabres. . . . . . . . . . I - Ovairs et fruit hérissés. - Plante grêle et grimpante, à flem's blanc bleuâtre; fruit à deux graines olivàtres et tachées de pourpre. - Les lieux cultivés. - Jerzeau. (E. hirsutum L.)

V. hirsuta K.

Tarie a fruits glabres et à graines tachées de noir (V. Terronii Ten.)

1. Feuilles velues. - Fruit court, élargi et un peu convexe; tiges dressées, anguleuses et ramenses; folioles ovales; fleurs d'un blanc bleuàtre. - Cultivéa comme Lentille. (E. Lens.)

V. Lens L.

- Feuilles glabres. - Fruit allongé et bosselé; tiges dressées, anguleuses; folioles linéaires; fleurs blanches, veinées de violet. (E. Ervilia L.)

V. Ervilia Willd.

$$
\text { S. G. Vicia L. - Vesces. }
$$

Fleurs portées sur un pédicule lrès allongé. . . . . . 1

- Fleurs sans queue ou d̀ queue plus courte qu'elles. . 9 
1. Une à quatre fleurs sur chaque pédicule. . . . . 2

- Un grand nombre de fleurs sur chaque pédicule. . 5

2. Stipules en demi-fer de flèche ou à deux divisions. 3

- L'une des stipules découpée en longues et fines lanières. - Plante glabre ou à peu près, élevée, a vrilles accrochantes; une fleur blanchàtre rayée de violet, à carène pourpre au sommet. - A chercher. V. monanthos L.

3. Fruit velu. - Plante élevée, grimpante, à tiges anguleuses; fleurs assez grandes; à étendard violacé et à ailes blanchatres. - Plaines du S.-O. V. bithynica L.

- Fruit glabre. . . . . . . . . . 4

4. Pédicules des fleurs plus longs que les férilles; fruit à six graines. - Tiges grèles, grimpantes, anguleuses; folioles linéaires; fleurs bleutitres et fruits linéaires. Les moissons. $\quad$ V. gracilis Lois.

- Pédicules des fleurs égaux aux feuilles ou à peu près; fruit ì quatre graines. - Tiges glabres, grèles et grimpantes; folioles linéaires; fleurs blane bleuatre, à étendard ravé de violet; fruits lancéolés. V. tetrasperma L.

- Pédicules des fleurs plus courls que les feuilles.-Plante d'un rert gai, i petites stipules bifides et i fleurs allongées, d'un violet pâle.

V. calcarata DC.

5. Trille mulle ou très courte et en pointe. - Flante élevée, d'un vert pille, velue, i racines dures; fleurs blanches, veinées ou maculées de violet. - La Roche-Chalais (Dordogne) et environs.

V. Orobus DC.

Tarie a plante moins velue, ì folioles veinées et it pédicules des fleurs plus courts que les feuilles ( $V$. cassubica L.) - Coutras (Gironde.)

- Vrille développée et accrochante. . . . . . . . 6

6. Stipules fortement dentécs, en croissant. - Plante élevie, glabre, d'un rert sai, at souche vivace; fleurs d'abord jurpurines, puis dun jame sale. - Se trouve dans les Pyrénées.

V. dumetorum L. Slipules entieres ou pou dentées, allongées. . . . 7

7. Vrille simple; 4-6 pleurs. . . . . . . . . 4

- Trille rameuse; fleurs plus nombreuses. . . . . 8

8. Six à douze fleurs en grappe lâche; stipules un peu dentées. - Plante a"souche ligneuse et tulíreuse, it tige grimpante; fleurs violettes, granles. - Tient dans les Cévennes.

V. onobrychioides L.

- Fleurs nombreuses en grapre surve; stipules entières.Plante très variable, it tige grimpante, anguleuse; fleurs blenes; lame de l'étendard ćgalant sa hase. V. Grácca L. Varie: 10 à lame de l'étendard une fois plus longne rque sa base et it folioles plus petites ( $V$. tenuifolia Roth.); 20 a lame de l'étentard une fois plus courte que sa base, i fleurs en épi unilatéral (V. varia Host.); $3^{\circ}$ à ailes de la 
corolle plus claires que l'étendard et à plante couverte de poils grisàtres, et aussi à lame de l'étendard une fois plus courte que sa base ( $V$. villosa Roth.); $4^{\circ}$ à plante très hérissée, arec la queue de la fleur plus longue, c'est-à-dire dépassant la longueur du calice (V. Gerardi Gr. God.)

9. Fleurs jaunes. . . . . . . . . . . 10

- Fleurs purpurines, bleuâtres ou blanches. . . . . 11 10. Etendard glabre. - Plante couchée, à tige anguleuse, à folioles linéaires ou lancéolées; fleurs jaune pâle; gousse hérissée de poils bulbeux.

- Elendard velu en dehors. - Plante ressemblant à la précédente; fleurs jaunes, veinées ou non de pourpre; gousse à poils couchés. - Aux environs de Toulouse et de Montauban.

11. Ville très courte, droite ou nulle. . . . . . 12

- Vrille accrochante. . . . . . . . . 13 12. Folioles tries larges. - Plante glabre, i grandes fleurs blanches, munies de taches noires sur les ailes. - Cultivée et naturalisée; c'est la Fève ordinaire. V. Faba L.

- Folioles petites et étroites. . . . . . . . 17 13. Folioles très larges. - Plante robuste, à tige à quatre angles ; fleurs pourpre foncé; fruit couvert de tubercules sur les sutures. - Cia et là, dans le S.-O. - (V. serratifolic Jacq.)

V. narbonensis $L$.

- Folioles très étroites. . . . . . . . . . . 14

14. Corolle velue en dehors. - Plante grimpante, un peu velue, à fleurs purpurines, striées. - Auvergne. - (Vicia purpurascens DC.)

V. pannonica Jacr.

- Corolle glabre en dehors. . . . . . . . . . 15

15. Fleurs en petites grappes; dents supérieures du calice trois à quatre fois plus courtes gue le tube. - Plante grimpante, anguleuse, à folioles ovales; fleurs violet sale; gousse velue. - Les haies. V. sepium L.

- Fleurs solitaires ou par deux; dents supérieures du calice n'étant pas deux fois plus courtes que le tube. 16

16. Tige couchée, à vrilles presque nulles. . . . . . 17

- Tige accrochée aux autres plantes par ses villes. 18

17. Oiaire et fruit glabres; graines cubiques. - Petite plante grêle et conchée, à petites fleurs bleuâtres et sessiles, et a gousse linéaire. - Se trouve dans les lieux sablomneux.

V. lathyroïdes L.

- Fruit pubescent dans sa jeunesse; graines arondies. 18

18. Calice comme à deux lèves, à cause de ses dents supérieures lancéolées et courbées en haut. - Plante pubescente, i tiges grêles, angulenses. - Les moissons.

V. peregrina L.

- Dents du calice en alène et projetées en avant. . . . 19

19. Toutes les folioles ovales. - Plante plus on moins velue, 
à fleurs riolettes ou bleues, et à fruit bosselé, velu. Cultivée comme fourrage.

- Folioles des feuilles supérieures linéaires. - Plante très variable, a tiges faibles et anguleuses; stipules des feuilles munies en dessous d'une tache ronde, généralement noire; fleurs violacées, rouges ou rosées ; fruit cylindrique, noir à la maturité.

V. angustifolia Roth.

\section{G. PIsum L. - Pois.}

Fleurs blanches. - Plante glauque, grimpante; fleurs grandes, blanches ou i étendard blanc bleuàtre et à ailes violet noir; graine globuleuse, de couleur uniforme.-Cultivée; c'est le Pois ordinaire.

P. sativum $L$.

- Fleurs rouges ou violettes. . . . . . . . . 1

1. Fleur's petites; étendard bleuatre ou violet. - Plante urèle, flexueuse, à 2-1́ folioles ovales, crénelées; graine lisse, comprimée et anguleuse. - Cultivée sous le nom de Pois carré.

P. arvense L.

- Fleurs grandes, ì élendard rose. - Plante élevée, robuste, grimpante et glatuque; graine lisse, d'un brun noirâtre. Cultivée.

P. elatum DC.

Tarie a graine marbre et finement granuleuse ( $P$. Tuffetii Lesson). - Les bois de la Charente-Inférieure.

\section{G. Lathyrus Gr. et God. - Gesces.}

Feuilles simples ou plante munie de vrilles.-S. G. Lathyrus L. Feuilles composées de folioles et sans rilles. - S. G. Orobus L.

$$
\text { S. G. Lathyrus L. }
$$

Ferilles mulles ou simples et sans pétiole distinct. . . . 1 - Feuilles composées de deux ou plusieurs folioles et pétiolées. . . . . . . . . . . . 2 1. Stipules en forme de feuilles ovales, en fer de flèche; fleurs jaunes. - Plante faible et grlauque, it pétioles filiformes et en ville. - Moissons. L. Aphaca L. - Fenilles linéaires; fleurs rouges. - Plante élancée, à pétiole lancéolé, linéaire, simulant la feuille. - Les moissons.

L. Nissolia L.

2. Fleurs à ndeur suav et très prononcée. - Tige élevée, grèle, anguleuse, ailée; 1-3 fleurs pourpre, mèlées de blanc et de bleuitre. - Gultirée sous le nom de Pois de senteur.

L. odoratus L.

- Flems à odeur nulle ou très faible. ....... 3

3. Pédicules à une, deux ou trois fleurs au plus. . . . 4

- Pédicules à plusieurs fleurs en grappo. . . . . 8 
4. Pédoncules munis d'un filet 'grêle qui fait paraître la fleur latérale. . . . . . . . . . 5

- Pédone. sans filet ou à filet très court ;l. terminale. 6

5. Pédoncule court, à peu près égal au pétiole; graine globulsuse. - Tige anguleuse, à trois angles au sommet; deux folioles linẻaires ou lancéolées, à cinq nervures; 1-2 fleurs rouge vif; gousse linéaire, presque bosselée, très veinée en long. - Champs calc. L. sphæxicus Retz.

- Pédoncules égalant ou dépassant les ferilles; graine anguleuse. - Tige grêle, à trois angles; deux folioles linẻaires; fleurs bleuâtres; gousse linéaire, non veinée. Champs sablonneux.

6. Ovaire et fruit très hérissés. - Tige tombante, hérissée, à deux ailes foliacées; 1-2 fleurs bleuâtres. - Les moissons.

L. hirsutus L.

- Ovaire et fruit glabres. . . . . . . . . . 7

7. Fleur's souvent blanches; fruit portant sur ie dos deux ailes membraneuses. - Plante glabre, a grandes fleurs blanches, roses ou bleuàtres. - Gultivée. L. sativus L.

- Fleurs souvint rouges; fruit creusé en canal sur le dos. Tige dressée et anguleuse; deux folioles lancéolées. Cultivée.

L. Gicera L.

- Fleurs jaunes. - Plante glabre, à tige grimpante; deux folioles linéaires. - Toulouse, Agen. L. annu us L.

8. Fleurs jaunes. - Tige tombante, anguleuse; deux folioles lancéolées. - Prairies.

L. pratensis L.

- Fleurs rouges, bleuâtres ou blanches. . . . . . . . 99

9. Feuilles à deux folioles. . . . . . . . . 10

- Feuilles à 4-8 folioles. - Plante grimpante, à 3-4 fleurs bleuâtres; fruit comprimé, allongé et glabre. - Prairies marécageuses.

10. Tige simplement anguleuse. - Plante à racines garnies de tubercules aplatis; fleurs rose vif; gousses bosselées, marquées sur le dos de trois còtes. - Se trouve dans les champs calcaires.

L. tuberosus L.

-Tige ailée. ....................

11. Ailes de la tige plus larges que celles des pétioles. Tige très longue, grimpante; fleur's rose sale mèlé de vert. - Les haies.

L. sylvestris L.

- Ailes de la tige aussi larges que celles des pétioles. Belle plante variable, à grandes fleurs d'un beau rose pur.

L. latifolius L.

S. G. Orobus L.

Tigs ailée. - Plante it racine renflée en tubercule arrondi; 3-t fleurs rouge violacé. - Se trouve dans les bois. (O. tuberosus L.)

L. macrorhizus Win. Varie à folioles linéaires (O. tenuifolius Roth.) 
Tige non ailée. . . . . . . . . . . . . 1

1. Folioles linéaires. - Plante à racines tuberculeuses, en fuseau et en faisceau; fleur's d'un blanc jaunâtre. $(O$. albus L.)

L. asphodeloïdes God.

- Folioles ovales. - Tige rameuse, à fleurs violacées; style linéaire, barbu dans sa moitié supérieure. - Les bois. (O. niger L.)

L. niger TVim.

\section{G. Phaseolus L. - Haricots.}

Plante élevée, grimpante; folioles ovales, acuminées, rudes. - Cultivée; Haricot ordinaire. P. vulgaris L.

- Plante peu élevée, non grimpante; bractées plus grandes que le calice. - Cultivée.

$P$. nanus $L$.

\section{G. Lupinus L. - Lupins.}

Folioles à bords relevés; graine marbrés de noir sur un fond blanc. - Plante dressiee, it fleurs d'un bleu clair, lérre inférieure du calice dentée. - Cultive et naturalisée.

L. reticulatus Desv.

- Folioles planes; graine tache de blanc sur un fond brun. - Plante dressée, à fleur's bleuatres et a lèvre infér. du calice entière, - Cult. L. angustifolius L.

\section{G. Cercis L.}

Arbre a rameaux flexueux; feuilles simples; fleurs roses, naissant du tronc et des grosses branches. - Cultivé sous le nom d'Arbre de Judee. $\quad$ C. siliquastrum L.

\section{Fam. des ROSACÉES Juss.}

\section{G. Pruvus Tourn. - Pruniers, ete.}

Fruit chamu-coriace, vert, à noyau marqué de sillons irréguliers. - Arbre à feuilles lancéolées et at fleurs blanches ou roses. - Cultivé ; c'est l'Amandier ordinaire. - (Amygdalus communis L.) Prunus amygdalus H. Varie a chair mangeable (A. ou $P$. persicoîdes Duh.).

- Fruit globuleux, velu, succulent, à noyau creusé d'anfractuosités profondes. - Arbre a feuilles lancéolées, dentées en scie, à fleurs d'un rouge vif. - Ciultivé comme I'êcher. - (Amygdalus Persica L.) P. Persica II.

Varie à fruit lisse (Brugnon.) 
- Fruit succulent, pubescent; noyau lisse, sillonné sur un seul bord. - Arbre à feuilles ovales, en cœur à la base, et à fleurs blanches, à peine rosées. - Cultivé comme Abricotier.

P. Armeniaca L.

- Fruit succulent, glabre, à noyau lisse, sillonné sur les deux bords. . . . . . . . . . . 1

1. Jeunes feuilles enroulees par les bords; fruit couvert d'une poussière glauque. - (Prunier's). . . . . . 2

- Jeunes feuilles pliées en long; fruit sans poussière glauque.-(Cerisiers). .......... 4

2. Jeunes rameaux glabres. - Arbre ou arbrisseau non épineux, à pédoncules solitaires ou par deux, pubescents; fruit allongé. - Cultivé.

P. domestica L.

Varie à pédoncules glabres et à fruits rouges, pendants (P. cerasifera Ehrh.)

- Jeunes rameaux pubescents. ........... 3

3. Pédoncules finement pubescents; arbrisseau peu épineux. - Plante à rameaux tortueux, les plus jeunes veloutés, grisâtres; feuilles ovales, velues en dessous. Cà et là, dans les haies.

P. insititia L.

- Pédoncules glabres; arbrisseau très épineux. - Plante à rameaux en tous sens, les plus jeunes pubescents; feuilles ovales ou lancéolées, à la fin glabres. - Les haies, dans les terrains calcaires.

P. spinosa L.

Varie : $1^{0}$ à feuilles toujours pubescentes ( $P$. pubescens Lloyd); $2^{\circ}$ à arbrisseau peu épineux et à feuilles velues en dessous ( $P$. fruticans Reich.)

4. Fleurs en bouquets latéraux ou en ombelle. . . . . 5

- Fleurs en grappe ou en corymbe. . . . . . . . . 6

5. Fleur's naissant sur de petits rameaux ligneux et sortant de bourgeons à écailles non foliacées; feuilles un peu velues en dessous; fruit petit, amer. - Bois montagneux. - Vulg. Guignier.

P. avium L.

- Fleurs naissant sur les branches et de bourgeons à écailles foliacées; feuilles glabres et luisantes; fruit rouge, acide. - Cultivé; c'est le Cerisier ordinaire, échappé çà et là.

6. Fleurs en corymbes courts. - Arbrisseau à bois odorant; feuilles ovales, en cœur à la base; fruits noirs. - Terrains calcaires très secs.

P. Mahaleb L.

- Fleurs en grappe. . . . . . . . . . 7

7. Grappes allongées, pendantes. - Arbrisseau ḋ rameaux bruns, ponctués de blanc; feuilles caduques. - Dans l'Auvergne.

P. Padus L.

- Grappes plus courtes que les feuilles, qui sont coriaces, luisantes et persistantes. - Cultivé comme arbuste d'agrément; vulg. Laurier-cerise; arbuste à fruits noirs, vénéneux.

P.Lauro-cerasus L. 
G. Spiræa L. - Spirées.

Tige herbacée. . . . . . . . . . . 1

- Tige ligneuse. . . . . . . . . . . . 2

1. Folioles des feuilles larges et dentées. - Plante à feuilles tomenteuses en dessous; fleurs blanches, en panicule rameuse; carpelles glabres. - Les prairies. - Reine des prés.

S. Ulmaria L.

- Folioles des feuilles étroites et pennatifides. - Plante à racines tuberculeuses; fleurs blanches; carpelles velus. - Lieux secs. - Filipendule.

2. Feuilles ovales, à bords entiers - Petit arbicsendula L. fleurs blanches, en bouquets axillaires. - Charente-Inférieure.

S. obovata Willd.

- Feuilles lancéolées, dentées en scie. - Plante buissonnante; fleurs en panicule terminale. - Cultivée dans les jardins.

S. salicifolia L.

\section{G. Geum L. - Benoites.}

Tête de fruits pédiculée. - Plante dressce, à feuilles de la tige très petites; pétales en cocur, ciliés à la base, dépassant beaucoup les sépales. - Les Céremnes et le Tarn.

G. sylvaticum Pourr.

Varie : 10 a tète de fruits non pédiculée - I'yrénées (G. pyrenaïcum Willd.); $2^{\circ}$ it styles très longs - Pyrénées - (G. inclinatum Schl.)

- Têle de fruits non pédiculée. - Plante dressée, à rhizome court et sentant la giroflée; pétales en coin, dépassant à peine les sépales. - Les haies.

G. urbanum L.

Varie à fleurs penchées et non dressées, et à calice rougeatre, horizontill à la maturité (G. intermedium Ehrh.)

\section{G. Rubus L. - Ronces.}

Feuilles inférieures pennées; fruit rouge, aromatique.Plante i feuilles molles, blanches en dessous; petites fleurs blanches. - Bois montagneux. - Cultivée comme Framboisier.

R. Idæus L.

- Feuilles palmées. . . . . . . . . . . . 1

1. Fruits noirs, luisants. - Tiges eouchées ou accrochées; 3-5 folioles; fleurs blanches ou rosées; plante très variable. - Les haies.

R. fruticosus L.

- Fruits bleuatres, couverts d'une poussière glauque. Tiges couchées; trois folioles; fleurs blanches. - Haies; bords des eaux.

R. cæsius L. 


\section{G. Potentilla L. - Potentilles.}

Fleurs à cinq pétales. . . . . . . . . . . . 1

- Fleurs à quatre pétales. - S. G. Tormentilla L.

1. Fleurs rouges. - S. G. Gomarum L.

- Fleurs jaunes ou blanches. - S. G. Potentilla L.

S. G. Potentilla.

Fleurs blanches. ................

- Fleurs jaunes. . . . . . . . . 2

1. Pétales dépassant peu les sépales, échancrés en cœur. -

Plante très velue, à tiges grêles; folioles soyeuses en dessous, dentées sur les bords. P. fragariastrum Ehrh.

Varie à divisions du calicule égales à celles du calice, et à pétales entiers ou émarginés, plus courts que les sépales (P. micrantha Ram.)

- Pétales une fois plus longs que les sépales, émarginés. -

Tiges grêles; folioles soyeuses en dessous et sur les bords. - S.-O. et Pyrénées, d'ou cette plante parait être descendue. - ( $P$. splendens Ram.) P. Vaillantii Nestl.

2. Feuilles ailées ou découpées de chaque côté. . . . 3 3

- Feuilles digitées ou découpées en éventail. . . . . 4 4

3. Ferilles soyeuses, argentées en dessous; fleurs d'un beau jaune. - Lieux humides. - Ansérine. P. Anserina L.

- Feuilles non soyeuses, presque glabres; fleurs petites, d'un jaune pále. - Lieux sablonneux. P. supina L.

4. Feuilles cotonneuses en dessous et roulées par les bords. - Plante dressée, à tige rougeàtre; fleur's petites, en corymbe terminal. - Lieux arides. P. argentea L.

- Feuilles seulement velues et vertes en dessous. . . . 5 5

5. Tiges courtes, un peu redressées; queue des fleur's rameuse au sommet. - Plante variable, gazonnante; pétales tachés ou non à la base. - Se trouve dans les lieux calcaires secs. $\quad$ P. verna $L$.

Varie à plante plus robuste et à fleur d'un jaune très vif (P. Chaubardiana T.L., P. vubens St-A.)

- Tiges longuement rampantes; queue des fleurs simple, n'en portant qu'une seule. - Dans les champs. Quintefeuille.

P. reptans L.

\section{S. G. Tormentilla L.}

Feuilles sans queue. - Plante à rhizome épais, brun, rou. geâtre à l'intérieur; stipules incisées et dentées. - Les bois. - (Tormentilla erecta L.) P. Tormentilla Nestl.

- Feuilles avec queue. - Plante à longues tiges couchées, rameuses; stipules entières ou à deux et trois divisions au sommet. - Se trouve dans les marais. - (Tormentilla reptans $\mathrm{L}$.)

P. mixta Reich. 
S. G. Comarum L.

Plante pubescente, à feuilles à segments dentés; fleurs d'un pourpre foncé; pétales lancéolés, plus courts que les sépales; réceptacle velu. - Les marais tourbeux. - $(C$. palustre L.)

P. Comarum Scop.

\section{G. Fragaria L. - Fraisiers.}

Calice étalé ou renversé à la maturité. - Plante stolonifère, a 2-3 fleurs blanches, terminales; pédoncules à poils couchés. - Fraisier des bois.

F. vesca $L$.

Varie a pédoncules hêrissés ( $F$. elatior Ehrh.) et beaucoup par la culture.

- Calice redressé sur le fruit. - Plante à feuilles plus soreuses et it péloncules plus grèles que dans l'espèce précédente; aussi variable.

F. collina Ehrh.

\section{G. Agrimonia L. - Aigremoines.}

Plante poilue; tige simple; fleurs jaunes, écartées, en épi terminal, entourées i la base de trois petites feuilles. Eupatoire ou Aigremoine.

A. Eupatoria L.

Varie it plante plus roluste et it épines extérieures du calice recourbées; feuilles it odeur de térébenthine ( $A$. odorata Mil.)

\section{G. Alchemlla Tourn. - Alchemilles.}

Fleurs sessiles, en petits paquets à l'aisselle des feuilles. Très petite plinte velue, couchée; feuilles en coin i la base; fleurs rerditres. - Les champs et pelouses. (Aphanes arvensis L.)

A. arvensis Scop.

Fleurs pédonculées, en corymbe trminal. . . . . 1

1. Fenilles vertes, it lobes arrondis. - Plante dressée, à petites fleurs diun rert jamintre; divisions du calicule aussi grandes et à peine distinctes de celles du calice. La plaine et la montagne.

A. vulgaris $\mathrm{L}$. Varie a fenilles munies de poils soyeux et brillants (A. hybrida L.)

- Feuilles argentées en dessous, à lobes lancéolés ou en coin. - Plante dressée, à souche ligneuse et brune; fleurs en verticilles nombreux. - Cai et lit. A. alpina L.

\section{G. Sanguisorba L. - Pimprenelles.}

Quatre étamines. - Plante glabre; folioles lancéolées, en cœur; lleurs ronges, noiratres, en tète terminale. Prairies humides.

S. officinalis $\mathrm{L}$. 
- Vingt étamines et plus. - Plante glabre ou velue, à tige anguleuse, rougeâtre; folioles arrondies ; fleurs verdâtres, en tête globuleuses, terminales; fruit à quatre angles. Pimprenelle.

S. Poterium L.

Varie à fruit bordé de quatre ailes (S. muricatum Sp.)

\section{G. Rosi L. - Eglantines.}

Stipules étroites, toutes semblables. . . . . . . 1

- Stipules des rameaux fleuris dilatées, celles des rameaux stériles linéaires. . . . . . . . . . . . 4 4

1. Styles libres, non soudés en colonne. . . . . . . 2

- Styles soudés en colonne. . . . . . . . . 3

2. Feuilles doublement dentées, glanduleuses. - Petit arbuste d'un mètre, à racine rampante; fleurs grandes, odorantes, purpurines. - Auvergne, Toulouse, et naturalisé cà et là. - Cultivé. - Rose de Provins. $\quad$ R. gallica L.

- Feuilles simplement denteies. - Plante très variable, à tiges très rameuses, courerte d'aiguillons; 5-7-9 folioles ovales, arrondies, ressemblant à celles de la Pimprenelle. - La côte et çà et là. $\quad \mathbf{R}$. pimpinellifolia L.

3. Feuilles vertes et brillantes sur les deux faces, persistantes. - Plante à longs rameaux tombants, flagelliformes; fleurs blanches; stylles hérissés. - Se trouve dans tout le S.-O.

R. sempervirens L:

- Feuilles cendrées en dessous, non persistantes. - Plante très variable; fleurs blanches; lobes du calice peu divisés. - Les haies.

R. arvensis L.

4. Feuilles simplement dentées. - Plante très variable, non glanduleuse, à folioles ovales; fleurs roses ou blanches. Les haies.

R. canina $L$.

- Feuilles doublement dentées. - Plante en buisson touffu, variable; folioles ovales, arrondies, glanduleuses et odorantes en dessous; fleurs petites, rose vif; style velu ; fruit rouge vif. - Les haies.

R. rubiginosa $L$.

\section{G. Pyrus L. - Poiriers, etc.}

Ovaire à 5 loges cartilagineuses et parcheminées. . . • . 1

- Ovaire à 3-5 loges membraneuses, fragiles (G. Sorbus L.). . . . . . . . . . . 3

- Ovaires a 5 loges membraneuses, fragiles, un peu bilocu-

laires. - Arbrisseau à feuilles ovales, lancéolées; fleurs en grappes pauciflores, blanches; fruit noir bleuâtre. (Amelanchier vulgaris MI.) P. Amelanchier DG.

1. Styles soudés entre eux; fruit ombiliqué à la base. Arbre ou arbrisseau robuste, à rameaux épineux; bourgeons cotonneux; feuilles blanches en dessous; pédoncules 
velus, en ombelle. - Espèce qui a donné naissance $\dot{a}$ nos Pommiers.

P. Malus L.

- Styles libres; fruit non ombiliqué à la base. . . . . . 2

2. Feuilles développées glabres en dessous, luisantes, ovales; bourgeons glabres. - Arbre ou arbrisseau à rameaux épineux; pédoncules grêles, en corymbe. - Espèce ancestrale des Poiriers.

P. communis $\mathrm{L}$.

- Feuilles développées cotonneuses en dessous, ovales; bourgeons velus. - Arbre ou arbrisseau non épineux; pédoncules forts, en corymbe.-Aur. P. salvifolia DC.

3. Feuilles pennées avec impair. . . . . . . . . .

- Feuilles dentées, lobées ou segmentées. . . . . . . 5

4. Bourgeons glabres et visqueux; fruits en poire et v'erdâtres. - Arbre élevé, it folioles blanchâtres et velues en dessous; fleurs blanches, en corvmbe. - Dans les bois. - Cormier.

P. domestica Sm.

- Bourgeons velus; fruits globuleux, d'un rouge vif. Arbre grisâtre; folioles dentées en scie; fleurs blanches, nombreuses, en corymbe. Sorbier. P.aucuparia Gœrtn.

5. Pétales dressés. - Arbuste élégant, très rameux, à fleurs roses; fruit ovale, rouge jaunatre. - Auvergne et Pyrénées.

P. Chamæmespilus Lindl.

- Pétales étalés. . . . . . . . . . . 6

6. Feuilles vertes, non tomenteuses. - Arbre a feuilles ovales, en cœur à la base, à sept lobes dentés; fleurs blanches, en corymbe; fruit brun. - Alisier. P. torminalis Ehrh.

- Feuilles tomenteuses en dessous. . . . . . . . 7

7. Feuilles profondément découpées à la base. - Bel arbre à feuilles ovales, obtuses; fleurs blanches, en corvmbe convexe; fruit rouge, globuleux. - Aurergne. P.hybrida L.

- Feuilles simplement dentées ou lobées. . . . . . 8

8. Jeunes feuilles d'un blanc éclatant en dessous, au moins deux fois aussi longues que larges. - Arbre à fruit d'un rouge orangé. - Auvergne, Prrénées. $\quad$ P. Aria L.

- Feuilles d'un blanc jaunâtre en dessous, n'étant pas deux fois aussi longues que larges. - Fruits orangés. A chercher.

P. latifolia Lam.

\section{G. Gydonia Tourn. - Cognassiers.}

Arbrisseau peu éleré, à rameaux tortueux; feuilles ovales, entières, blanches en dessous; fleurs grandes, blanches ou rosées. - Cultivé et naturalisé.

C. vulgaris Pers.

\section{G. Crategus Tourn, - Alisiers, etc.}

Calice à cinq divisions ou lanières. - S. G. Crateegus L. Calice à cinq petites dents. - S. G. Cotoneaster Tourn. 
S. G. Cratoegus L.

Fruit très ouvert, en toupie. - Arbrisseau épineux, à feuilles lancéolées; fleurs blanches, sessiles, solitaires. - Néflier. - (Mespilus germanica L.) C. Mespilus L. - Fruit globuleux, fermé. . . . . . . . 1

1. Plante glabre dans toutes ses parties. - Arbrisseau épineux, à fleurs blanches ou rosées; fruit rouge et fade. Aubópine.

C. Oxyacantha L.

Varie à fruit à un seul noyau (C. monogyna Jacq.)

- Plante velue dans toutes ses parties. - Arbrisseau épineux, à fleurs blanehes; fruit rougeàtre ou jaunâtre, à gout agréable. - Cultivé. $\quad$ C. Azarolus L.

S. G. Cotoneaster L.

Fenilles crénelées. - Arbrisseau épineux, très rameux, à fleurs blanches, en corymbe; fruit globuleux, de la grosseur d'un pois, rouge écarlate. - Se trouve dans la plaine du S.-O.

C. Pyracantha Sp.

- Feuilles très entières. - Sous-arbrisseau non épineux; feuilles ovales; fleurs en petits bouquets axillaires, d'un blanc verditre; fruits rouges, penchés. - Auvergne, Prrénées. $\quad$ C. vulgaris Lindl. Varie à pédoncules et calices pubescents, et à fruits non penchés ( $C$. tomentosa Lindl.)

\section{Fam. des MYRTAGÉES R.B.}

G. Punica Tourn. - Grenadiers.

Arbuste glabre, à écorce cendrée et fendillée; feuilles lancéolées, coriaces, luisantes; fleurs d'un rouge vif. - Gultivé dans les jardins.

P. Granatum L.

G. Myntus Tourn. - Myrtes.

Arbuste aromatique; feuilles lancéolées, aiguës, persistantes; fleurs blanches.- Gultivé. IM. communis L.

\section{Fam. des ONAGRARIÉES Juss.}

\section{G. OEnothera L. - Onagres.}

Plante ligneuse, à tige rouge; sépales pourpres au sommet; fleur's jaunes. - Cultivée. 
- Plante sous-ligneuse; fleurs grandes, blanches. - Cultivée.

CE. speciosa Nutt.

- Plante herbacée. . . . . . . . . . . . 1

1. Fleurs roses. - Plante à rameaux grèles et à port d'un Epilobium; feuilles orales; fruit en massue à huit angles. - Cultivée et naturalisée depuis longtemps aux sources du Gers, à Béhobie et à Bayonne. FE. rosea Ait.

- Fleurs jaunes. . . . . . . . . . . 2

2. Pétales grands, dépassant bearicoup les étamines. Plante élevée, à tige rameuse, rude, poilue; fenilles orales, lancéolées; fleurs jammes, ne s'ourrant que le soir, it pétales en cœur. - Cultivée et naturalisée presque partout.

OE. biennis L.

Varie à odeur d'oranger et à pétales grands, échancrés, égralint presque le tube du calice ( $C E$. suaveolens Desf.)

- Pétales petits, égalant les étamines, ou plus courts qu'elles. - Jante élevée, à tige purpurine, rude; feuilles lancéolées, aignës, pubescentes, dim vert luisant. Introduite et naturalisée dans la vallée de la Loire; i chercher dans le S.-O.

CE. muricata L.

Virie it pétales quatre fois plus courts quie le tube du calice (OE. parviflora L.)

\section{G. Leilobium L. - Epilobes.}

Fleurs irregulières; pétales entiers; étamines et style penchés. . . . . . . . . . . . 1

- Fleurs régulières; pétales échancrés; étamines et style dressés. . . . . . . . . . . . 2

1. Fenilles florales très courtes, parlant de la base des fleurs; fenilles de la tige lancéolées. - Tige éleiée, rougeattre; fleurs grandes, d'un rouge violacé, en bel épi terminal. Les bois. - (E. spicatum Lam.) E. angustifolium L.

- Fenilles florales vertes, insérées sur la queue de la fleur; feuilles de la tige linéaires. - Plante dressée, à tige eflilée; fleurs purpurines, en srappe terminale. - Cit et lit, dans le S.-O. $\quad$ E. rosmarinifolium Hôk.

2. Styles libres et étalés au sommet. . . . . . . 3

- Styles soudés en massue au sommet. . . . . . . 6

3. Feuilles décurrentes sur la tige. - Plante à tige élevée, tres rameuse, poilue, et it racine stolonifêre; fleurs grandes, rosées. - Bord des eaux. \$. hirsutum L.

- Feuilles non décurrentes. . . . . . . . . . . 4

4. Feuilles mollement velues. - Tige élevée, simple, relue, à racine fibreuse; fleurs petites, rosées. - Bord des eaux. - (E. parviflorum With.) E. molle Lam.

- Feuilles glabres ou très peu velues. . . . . . . 5

5. Feuilles rétrécies à la base en queue, lancéolées. - 
Tige souvent rougeâtre; fleurs d'abord penchées et blanches, à la fin d'un rose vif. - Les haies fraîches des endroits pierreux.

E. lanceolatum Sebast.

- Feuilles sans queue, arrondies à la base ou ovales. Plante à tige velue et à feuilles glabres, ovales ou lancéolées; fleurs petites, lilas. - Les bois et endroits rocailleux humides.

E. montanum L.

6. Tige absolument cylindrique. - Plante à tige simple, duvetée sur deux ou quatre lignes, à racines filiformes; lleurs petites, rosées; graines surmontées d'un appendice. - Marais.

E. palustre L.

- Tige à deux ou quatre lignes saillantes. . . . . . 7

7. Feuilles à longue queue. - Plante rameuse; tige ì deux lignes saillantes; feuilles lancéolées; fleurs blanchâtres, striées de rose.

E. roseum Schreb.

- Ferilles sans queue ou à queue très courte. - Plante à tige à quatre angles, raide, rameuse; fleurs lilas foncé. -

- Bords des eaux.

E. tetragonum L.

Varie : $1^{0}$ dans les terrains secs, à feuilles à petite queue

et à angles moins saillants (E. Lamyi Sch.); $2^{\circ}$ au bord des eaux, à stolons filiformes et feuillés ( $E$. obscurum Sch. ou $E$, virgatum Fr.)

\section{G. Jussioea L.}

Plante aquatique; tiges creuses, enracinces a la base; feuilles ovales, spatulées ou lancéolées, entières; fleurs jaunes à pétales échancrés, stériles. - Plante de l'Amérique du Nord introduite à Bayonne.

J. repens L.

\section{G. IsNARdia L.}

Plante couchée, glabre, rougeâtre, à tige enracinée; feuilles ovales, aiguès; fleurs petites, verdàtres, axillaires et sans queue. - Marais.

I. palustris L.

\section{G. Circea T.}

Plante traçante, à tige velue, renflée aux nœuds; feuilles ovales, aiguës ; fleurs en grappe terminale, à pétales bifides, blanc rosé. - Bois frais.

G. Iutetiana $L$.

\section{G. Trapa L. - Mâcres.}

Plante aqquatique; feuilles submergées capillaires, feuilles flottantes en rosette et à queue renflée; fleurs blanches, axillaires; fruit à quatre épines. - Dans les eaux dormantes. 


\section{G. Myriophyllum L.}

Plantes très variables, passant d'une espèce ou d'une forme à l'autre par une série de transitions.

Fleurs axillaires. - Tige simple, raide; feuilles en dents de peigne; fleurs verticillées, dépassées par les feuilles florales découpées. - Fossés.

M. verticillatum $L$.

Varie beaucoup, notamment à feuilles florales courtes et à fleurs presque en épi ( $M$. pectinatum DG.)

- Fleurs en épis grêles et nus. . . . . . . . . 1

1. Epis composés de fleurs verticillées, toujours droits. Tiges rameuses, submergées; feuilles en dents de peigne; fleurs rosées, it feuilles llorales plus courtes qu'elles. Eaux dormantes. $\quad$ M. spicatum L.

- Epis composés de fleurs alternes, penchées dans leur jeunesse. - Plante grèle; feuilles capillaires; fleurs jaunatres. - Etangs. $\quad$ M. alternifolium DG.

\section{G. Hippuris l. - Pesses.}

Plante à tige simple, raide, comme articulée; feuilles linéaires et verticillées; fleurs axillaires et sans queue. - Les marais.

H. vulgaris $L$.

\section{Fam. des LYTHRARIÉES JusS.}

\section{G. Lythnum L. - Salicaires.}

Fleurs verticillées et en épi. - Tige élevée, à quatre angles; feuilles lancéolées et sans queue; fleur's d'un rouge violacé. $\quad$ L. Salicaria L.

- Fleur's axillaires. - Très petite plante glabre et étalée; fenilles linéaires; fleurs petites, solitaires; pétales lilas', blanes à la base. $\quad$ L. hyssopifolia L.

Virrie ì plante plus grèle, rameuse et diffuse, à tige plus anguleuse, et i dents externes du calice courtes et non lancéolées ( $L$. bibracteatum Salzm.)

\section{G. Peplis L.}

Très petite plante glabre, conchée, rougeâtre, munie de glandes entre les feuilles; fleurs solitaires, axillaires, lilas clair. Bords des eaux.

P. Po?tula L.

Varie à plante velue ( $P$. Borœi Jord.) 


\title{
Fam. des FICOÏDÉES.
}

\author{
G. Cactus L.
}

Plante grasse, composée d'articles comprimés et placés bout i bout; feuilles avortées; fleurs grandes, sans queue, jaunes, placées sur le tranchant des articles supérieurs. - Cultivée et naturalisée çà et là. $\quad$ G. Opuntia L.

\section{Fam. des GRASSULAGĖES Juss.}

\section{G. TILlæa L.}

Fleurs blanchâtres et sans queue à l'aisselle des feuilles. - Très petite plante rougeàtre et rameuse. - Les sables de la côte et les landes.

T. muscosa L.

- Fleurs rosées et à petite queue à l'aisselle des feuilles, solitaires. - Très petite plante fourchue et rougeaitre. Rochers inondés. - $A$ chercher dans le S.-O. - (Bulliardia Vaillantii DG.

T. aquatica $L$.

\section{G. Sedum L.}

Fleur's jaunes...............8 8

- Fleurs jamais jaunes. . . . . . . . . . . . . . 1

1. Feuilles larges et plates. . . . . . . . . . . . . 2

- Fenilles renflées, étroites et souvent cylindriques. . 3

2. Feuilles très entières. - Plante faible, velue; feuilles en spatule, ordinairement par quatre; fleurs blanches, en grappe ramifiée; pétales roses sur le dos. - Les lienx sablonneux.

S. Cepæa L.

- Ferilles plus ou moins dentées. - Tige simple, élevée, rougeàtre; fleurs rouges, à pétales bordés d'une ligne blanche. - Les haies. - Orpin. S. Telephium L.

3. Plante glabre dans toutes ses parties. . . . . . 4

- Plante velue et glanduleuse ar sommet. . . . . . . 5

4. Feuilles cylindriques, allongées; pétales obtus. - Plante à tige couchée à la base, puis redressée, it rejets stériles rampants et peu feuillés; fleurs blanches, en bouquet serré. - Lieux pierreux.

L. album L.

Varie à plante plus petite et à feuilles des rejets courtes et serrẻes (S. micranthum Bast.)

- Feuilles ovoides, courtes; pétales aigus. - Plante a fleurs d'un blane rosé, lâchement groupées. S. anglicum L. 
5. Fleurs sans queue le long des rameaux. - Plante á fleurs d'un blanc sale; pétales à carène rougeâtre; cinc étamines; fruits tuberculeux. S. rubens L.

- Fleurs pourvues chacune d'une queue. . . . . . . 6

6. Fevilles glabres et glauques. - Très petite plante venant en touffes, à tiges filiformes; pétales blanchâtres, à carène purpurine. - Aurergne.

S. dasyphyllum L.

- Feuilles velues ou hérissées. . . . . . . . 7

7. Feuilles radicales en rosette; pétales effilés. - Très petite plante gazomnante, à feuilles hérissées et ì fleur's roses, - Bayomne.

S. hirsutum All.

- Feuilles éparses; pétales non effilés. - Très petite plante

a fleurs rosées, peu nombreuses, groupées au sornmet. Aurergne, Pyrénées et S.-O.

S. villosum $L$.

Varje à fleurs à cinq étamines (S. pentandrum Bor.)

8. Tige diu décimèlre au plus; feuilles obtuses. . . .9

- Tige assez élevée; ferilles aiguës. . . . . . . 10

9. Fleurs en cyme courte. - Plante très piquante au goût; feuilles ovoïles, sur six rangs; carpelles bossus à la base. - Vieux murs et lieux arides. S. acre L. Tarie ì plante à peine àcre et à feuilles linéaires ( $S$. sexangulare L.)

- Fleurs unilatérales, sans queue le long des rameaux. - Plante trés glabre, ordinairement rougeatre; fleurs jaune pàle, blanchissant par la suite. - Les Sables-d'Olomne; a chercher le long des còtes. S. littoreum Guss. 10. Pétales droits et d'un jaune blanc. - Plante à tige ascendante; feuilles glauques, cylindriques; fleurs sans queue et compactes. - Lieux secs. S.anopetalum DC:

- Pétales étalés, nettement jaunes. . . . . . . 11

11. Fleurs munies de queue. - Plante à tige dressće, couchée a la base; rejets stériles rampants; fleurs d'abord penchées, puis redressées.

S. reflexum $\mathrm{L}$.

Tarie: 10 à plante grèle, rougeâtre, à feuilles petites, verditres (S. elegans Leg.); 20 i plante plus robuste et à feuilles glauques (S. rupestre L.)

- Fleurs sans queue. - Plante ì souche épaisse; fenilles rentrues; étamines poilues

S. altissimum Poir.

\section{G. Sempervivum L. - Joubarbes.}

Plante i tige élevée, relue et glanduleuse; fetilles glabres, ciliées aux bords. - Vieux murs. S. tectorum L.

\section{G. Umailicus DG.}

Tige simple; feuilles arrondies ou en coin; fleurs jaunattres, pendantes, en long épi terminal. U. pendulinus $\mathrm{DC}$. 


\section{Fam. des SAXIFRAGÉES Baillon.}

\section{G. SAxifraga L. - Saxifrages.}

Ferilles petites, en coin. - Petite plante visqueuse, annuelle, à fleurs blanches. - Lieux sablonn. S. tridactylites L.

- Feuilles larges, entières ou découpées. . . . . . 1

1. Fleurs blanches, en bouquet terminal. - Plante vivace, assez élevée; tige pubescente et munie de bulbilles à la base. - Çà et là.

S. granulata L.

- Fleurs en grappe ramifiée. . . . . . . . . . 2

2. Tige florale nue. - Plante à feuilles en forme de rein, arrondies. - Cá et là dans les landes, d'après SaintAmant.

S. Geum L.

- Tige florale un per feuillée. - Plante gazonnante, à feuilles bordées de poils articulés. - Cà et là, dans la région du S.-O.

S. hypnoïdes L.

\section{G. Chrysosplenium L.}

Plante d'un vert pâle, à sommet jaunâtre; tige à trois angles; feuilles arrondies, à limbe crénelé, alternes. - Bois des montagnes.

G. alternifolium L.

- Plante d'un vert foncé, à tige à quatre angles; feuilles demilunaires, sinuées au bord, opposées. - Dans les bois des montagnes et descendue.

C. oppositifolium L.

\section{G. Ribes L. - Groseilliers.}

Plante épineuse; 1-3 fleurs par groupe. - Arbuste variable, très rameux, à fleurs verditres ou rougeàtres; fruits gros. - Les inontagnes. - Cette espèce a donné naissance aux variétés cultivées.

R. Uva crispa $L$.

Varie a fruit couvert de poils glanduleux ( $R$. G'rossularia L.) ou Groseillier à gros fruits.

- Plante non épineuse; fleurs en grappes. . . . . . 1

1. Feuilles aromatiques; fruits noirs. - Plante à larges feuilles en cœur, à la base et lobées; fleurs rougeâtres; fruit aromatique. - Cultivée, sous le nom de Cassis, dans les jardins.

R. nigrum L.

- Feuilles sans odeur; fruits jamais noirs. - Plante ì grandes feuilles en cœur à la base; fruits rouges ou jitninatres, aciles. - Cultive sous le nom de firoseillier à grappe.

R. rubrum L. 


\section{Fam. des OMBELLIFẺRES Adanson.}

(Araliacées Juss, et Ombelliferes Juss, réunies)

\section{G. Hedera L. - Lierres:}

Arbrisseau grimpant à l'aide de racines adrentires; feuilles persistantes, luisantes; fleurs verditres, en ombelle; fruit noir. - Lierre.

\section{G. Connus L. - Cornouillers.}

Fleurs blanches. - Arbrisseau rougeâtre; feuilles ovales, velnes en dessons; fruit petit, globuleux, noir. - Dans les haies.

G. sanguinea L.

- Fleurs jaunes, naissant avant les fenilles. - Arjore grisittre; leuille's ovales, aiguës, páles en dessons; fruit rouge. - Les haies.

\section{G. Hydrogotyle T.}

Plante rampante, délicate; fenilles en honclier, crénclées, i queue poilue; fleurs petites, blinchities ou rosies, en paruets axillaires. - Lieux lumides. H. vulgaris L.

\section{G. SAnigula T. - Sanicles.}

Plante a tige simple; feuilles palmilobées, à lohes trifiles et dentés; fleur's blanches, en ombelles globuleuses. - Les bois frais.

S. europæa L.

\section{G. Enyngium L. - Panicauts.}

Feuilles très découpées. - Plante coriace, it fleurs blanchitres. - Chardon Roland. E. campestre L.

- Feuilles lobées ou sinuées. - Plante glanque el filinchitre, ì lleurs bleuitres, dépatssées par lés fenilles llorales. Saljles maritimes. $\quad$ E. maritimurn L.

\section{G. Cicuta L. - Cicutaires.}

Plante robuste, élevéc, rameuse; folioles dentées cu scie; fleurs blanches, en ombelle oplyosée it la feuille. - Danıs les lieux marécageux.

C. virosa $L$.

Plante vénéneuse dont il faut se méfier. 


\section{G. Apium L.}

Ombelle sans collerette à la base. - S. G. Apium L.

Ombelle avec une collerette de petites feuilles à la base. - S. (i. Petroselinum Hoffm.

$$
\text { S. G. Apium L. - Aches. }
$$

Plante élevée, à tige cannelée; feuilles blanchâtres, en ombelles axillaires; fruit petit.

A. graveolens L.

$$
\text { S. G. Petroselinum Hoffm. - Persils. }
$$

Fleurs jaunâtres. - Plante à odeur aromatique; tige striée; feuilles luisantes, deux ou trois fois découpées. - Cultivée. - (P. sativum Holf.) $\quad$ A. Petroselinum L.

- Fleurs blanches. - Plante a rameaux filiformes, nus; fenilles une fois découpćes. - Dans le Sud-Ouest. (P. segetum K.)

A. segetum.

\section{G. Trinid Hoffm.}

Plante à racine épaisse, garnie au collet d'un chevelu noir, filamenteux; feuilles à segments linéaires; fleurs en ombelles nombreuses.

T. vulgaris DG.

\section{G. Sium L. - Berles.}

Pétales entiers. - S. G. Helosciadium K.

Pétales échancrés.

1. Ovaire et fruit allongé. - S. a. Falcaria Hort.

- Ovaire et fruit globuleux. - S. G. Sirum L.

S. G. Helosciadium K.

Ombelle à 2-3 rayons. - Plante rampante ou aquatique; feuilles capillaires lorsqu'elles sont submergées, et pennées à folioles en coin lorsqu'elles flottent; collerette nulle. (H. inundalum K.) S. inundatum Roth.

- Ombelle à quatre rayons et plus. - Plante rariable; feuilles pennées, a folioles ovales ou lancéolées; fleur's blanc-verdàtre; collerette nulle ou à une pièce. (II. nocliflorum $\mathrm{K}$.

S. nodiflorum $\mathrm{L}$.

Varie : 10 à queue des feuilles dilatée î la base en gitne membraneuse (H. ochreatum DC.); 20 a flenrs blanches et à collerette à $4-5$ pièces (H. repens DC.)

S. G. Falcaria Riv.

Plante it racine en fusean; tige striée, it rameaux dirigís en tous sens; fleurs blanches. ( $F$. Rivini Ilost.) S. Falcaria L. 


\section{S. G. Sium L.}

Ombelles latérales, opposées aux feuilles. - Tige élevée; feuilles pennées, à folioles ovales ou lancéolées, dentées; fruit globuleux.

S. angustifolium L.

Ombelles terminales.

1. Racine fibreuse; ombelle $\dot{a}$ rayons très nombreux. Tige élevée, robuste, sillonnée et creuse; fruit elliptique, à côtes blanchâtres.

S. latifolium L.

- Racine tuberculeuse; ombelle à 6-12 rayons. - Plante à feuilles lancéolées, aiguës, dentées en scie. - Cultivée sous le nom de Chervi.

S. Sisarum L.

\section{G. Sison L.}

Plante à odeur désagréable; tige élevée; collerettes de l'ombelle et de l'ombellule à trois folioles chacune. S. Amomum L.

\section{G. Аммі L.}

Base de l'ombelle non dilatée à la maturité. - Plante variable, glauque, à rameaux étalés; feuilles inférieures à folioles orales ou lancéolées; ombelle à rayons nombreux. - Les champs.

A. majus L.

Varie à feuilles toutes découpées en seginents linéaires (A glaucifolium L.)

- Base de l'ombelle dilatée à la maturité. - Plante à tige dressée et à feuilles toutes découpées en lanières. - Les champs.

A. Visnaga Lam.

\section{G. OEgopodium L.}

Plante a racine rampante; tige creuse et sillonnce; folioles ovales ou lancéolées aiguës, dentées; fleurs blanches. Lieux habités.

CEg. Podagraria L.

\section{G. Carum L.}

Ombelle sans collerette. - Plante à racine en fuseau, odorante, élevée, d'un vert gai; fleur's blanches. - Auvergne, Pyrénées. - Cultivée comme Anis.

C. Carvi L.

- Ombelle munie d'une collerette. - Plante élevée, glabre; feuilles à divisions courtes et capillaires; fleurs blanches. - Tout le S.-O.

G. verticillatum K.

\section{G. Gonopodium Koch.}

Plante a racine tuberculeuse; tige flexueuse; fenilles cn lanieres; collerette nulle ou a une foliole; fleurs blanches. - Bois sablonneux. G. denudatum K. 


\section{G. Pimpinella L.}

Tige anguleuse; folioles des fenilles inférieures munies de queue. - Plante à grandes folioles ovales, lobées. - Les haies et bois.

P. magna L.

- Tige cylindrique; folioles des feuilles inférieures sans queue. - Plante à tige velue ou glabre, striée, peu feuillée dans le haut.

P. saxifraga $L$. Varie à feuilles très découpées ( $P$. dissectifolia Lloyd.)

\section{G. Buplevrum L.}

Arbrisseau. - Plante a feuilles persistantes, coriaces; fleurs jaunes; fruit brun, luisant. - Cultivée et naturalisée cá et là.

B. fruticosum $\dot{L}$. Herbes.

1. Collerette de l'ombelle nulle; feuilles englobant la tige. - Plante glabre et glauque; collerette de l'ombellule verte; fruit noir et lisse. - Noissons. B. rotundifolium L.

Varie à collerette jaune et à fruit tuberculeux (B. protractum Link.)

- Pas de collerette à l'ombelle; feuilles n'entourant pas la tige. . . . . . . 2

2. Collerette de l'ombellule dressée, $\dot{a}$ folioles en arête. Plante très petite, à tige fourchue; feuilles linéaires lancéolées, à trois nervures. $\quad$ B. aristatum Bart.

- Collerette de l'ombellule étalée. . . . . . . 4

4. Feuilles à nervure marginale. - Plante élevée, d'un vert gai, grêle et flexueuse; feuilles lancéolées, un peu arquées.

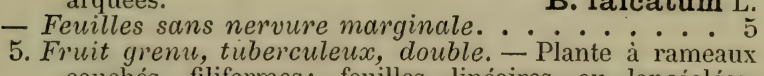
couchés, filiformes; feuilles linéaires ou lancéolées, aiguës. $\quad B$. tenuissimum L.

- Fruit muni de fines côtes, ovoïde. - Plante grêle et dressée; feuilles linéaires et lancéolées. B. afrine Sad.

\section{G. OEnanthe L. - CEnanthes.}

Fleur's des ombellules égales entre elles, toutes fertiles. Plante élevée, verte et glabre; ombelle latérale et opposée aux feuilles. - Ruisseaux. CE. Phellandrium Lam.

- Fleurs centrales sans queue; fleur's de la circonférence munies de queue et stériles. . . . . . . . 1

1. Ombelle composée de 3-4 rayons. - Plante élevée, à tige creuse; fleurs blanches, rayonnantes, en ombellules globuleuses. - Marais. 
— Ombelle à plus de cinq rayons. . . . . . . . . 2

2. Lobes des feuilles supérieures en forme de coin, incisés. - Plante à grosse racine en fuseau; tige élevée et robuste. - Bnrds des ruisseaux.

CE. crocata L.

- Lobes des feuilles supérieures linéaires. . . . . . 3

3. Point de collerelte ù l'ombelle. - Plante à racine tuberculeuse.

CE. peucedanifolia.Poll.

- Une collerette à l'ombelle. . . . . . . . . . 4

4. Tige cylindrique, slriée. - Plinte a racines filiformes ou Jentles en massue it leur cxtrcinité; pétales extérieurs des llenrs extérieures atroulis. - Lieux marécageux, sur nos còtes.

CE. Lachenalii Gmel.

- Tige an!nulense el cannelée. - Plante a racines tuberculeuses; folioles en roin; fruit crlindrique. - Les prés secs.

QE. pimpinelloïdes $\mathrm{L}$.

\section{G. Etriusa l.}

Hante assoz élevés, diun vert sombre; folioles de la collerette de lombellule au nombre de trois, longues et capillaires. - Petite Ciguë.

ZE. Gynapium L.

\section{G. Anethum L.}

Plante i tigre rameuse, très glabre; feuilles i segments filiformes: fleurs jaunes. - Cultivée sous le nom d'Ecarlate ou d'Aneth.

A. graveolens $\mathrm{L}$.

- Plante glauque, élevée; fenilles capillaires: flem's jaunes; fruits it odeur d'anis. - Fenouil. - (Foniculum of/icinale All.)

A. Fœuiculum $\mathrm{L}$.

\section{G. Seseli L.}

Feuilles inférieures it folioles ovales, les supérieures capillaires et divergentes. - S. G. Ptychotis K.

Toutes les feuilles linéaires, mais ni capillaires ni dirergentes. - S. G. Seseli L.

S. G. Seseli L.

Colleretle it pièces nombreuses; dents du calice allongées en aline. - Plante variable, it racine dure, chevelue an collet; fimit convert de poils ritiles. - Auvergue, Pyotnées et cà et là.

S. Libanotis $K$.

Virie à fruits glabres. - Bayomne. - (Libanotis verlicillata DGi)

- Collenelte mulle on it quelques pieces; dents du calice courtes. . . . . . . . . . . . . 1

1. Folioles de la colleretle de l'mminclude bordées de 
blanc. - Plante variable, grêle, peu rumense. - Dans le S.-O.

S. montanum L.

Varie à folioles de la collerette blanches avec une nervure rerte et à plante souvent colorée de rougeâtre (S. coloratum Ehrh.)

S. G. Ptychotis K.

Collerette mulle ou à 2-3 folioles caduques. - Plante à rameaux dirigés en tous sens, glabre et à fleurs blanches. (P. heterophylla K.)

S. saxifragum L.

- Collerette à 3-5 folioles persistantes. - Plante à tige simple, rameuse au sommet seulement, glabre, i petites fleurs blanches. (P. Thorei Gir. et God.) S. Thorei.

\section{G. Crithaum L. - Criste marine.}

Plante rameuse, glauque; folioles des feuilles linéaires, aiguës, charnnes; fleurs blanchàtres; fruits spongieux. - Rocher's maritimes. $\quad$ G. maritimum L.

\section{G. Levisticum Koch. - Livêches.}

Plante lisse, luisante, d'une odeur forte, très élevée; fleurs jaunâtres. - Cultivée. $\quad$ L. officinale K.

\section{G.. Selinum L.}

Plante à racine munie de fibres épaisses; tige élevée, i angles saillants; fleurs blanches. - Auvergne. S. Garvifolia L.

\section{G. Angelica L. - Angéliques.}

Feuilles à lobe terminal divisé en trois parties. - Tige striée et succulente; gaîne des feuilles renflée en sac; fleur's verdâtres.

A. Archangelica L.

- Feuilles à lobe terminal non divisé en trois parlies. Plante rariable, à tige élevée, glauque et rougeàtre; fleurs blanches ou rosées.

A. sylvestris L.

Varie: $1^{0}$ à folioles supérieures décurrentes sur le pétiole et à fruit plus petit (A.montana Sch.) - Aurergne; $2^{\circ}$ à folioles plus étroites, à fleurs plus précoces et à fruit très variable (A. helerocarpa Lloyd.) - Embouchure des fleuves.

\section{G. Peucedanum L.}

Fruit sans bordure. - S. G. Silans Bess.

Fruit muni d'une bordure. - S. G. Peucedanum L. 
S. G. Silaus Bess.

Plante a tige anguleuse; fleur's jaune pâle. - Dans les prés humides, - (S. pratensis Bess.) P. Silaus L.

\section{S. G. Peucedanum L.}

Fleurs jaunes ou jaunâtres. . . . . . . . . . 1 - Fleurs blanches ou rosées. . . . . . . . . . . . 2 1. Folioles linéaires; ombelle de 20-30 rayons. - Plante à racine chevelue au sommet et a tige élevée, striée; ombelle à rayons glabres; ombellule à rayons capillaires, inégaux. - Bois humides.

P. officinale L.

- Folioles ovales, divisées; ombelle à moins de 20 rayons. - Plante élevée, d'un vert rougeâtre; tige creuse en luas, un peu anguleuse dans le haut; folioles rudes au bord. Bois secs.

P. alsaticum $\mathrm{L}$.

2. Pas de collerette à l'ombelle; collerette de l'ombellule à 2-4 pièces. - Plante variable, glabre, à tige sillonnée, rameuse au sommet. - Se trouve dans les prés humides.

P. carvifolium Vill.

- Une collerette sur les jeunes ombelles; collerette de l'ombellule à plus de quatre pièces. . . . . . . . 3 3. Tige creuse et fortement sillonnée. - Plante à racine épaisse, à lobes des feuilles rudes au bord, veinés. Bords des eaux.

P. palustre Hoff.

- Tige ferme et striée. . . . . . . . . . 4

4. Folioles linéaires, allongées. - Plante à racine chevelue au sommet et à tige élevée, striée; rayons de l'ombelle rudes et pubescents en dedans. - Vient dans les bois et les prairies sèches de la région. $\quad P$. parisiense DC.

- Folioles des feuilles ovales, dentées ou lobées. . . . 5 5. Folioles des feuilles larges et ovales, dentées. - Plante à racine cherelue au sommet; tige élerée, striée et glauque; feuilles glauques en dessous. - Vient dans les bois secs et calcaires du S.-O.

P. Cervaria Lap.

- Folioles des feuilles en forme de coin et trilobées. Plante à racine épaisse, á tige élevée et striée; ramifica. tions de la feuille dirigées en tous sens. - Dans les bois sablonneux.

P. Oreoselinum M.

\section{G. Pastinaca L. - Panais.}

Plante aromatique, élevée, à tige très anguleuse; ombelle centrale plus grande. - Partout. P. sativa $L$.

Varie: 10 à racine grêle et à feuilles pubescentes ( $P$. sylvestris DC.); 20 à racine charnue et à feuilles glabres (P. edulis DC.); 30 à feuilles opaques en dessus et non luisantes ( $P$. opaca Bern.) 


\section{G. Heracleum L.}

Fleurs jaune verdâtre, égales, non rayonnantes. - Plante élevée, à tige sillonnée, anguleuse, creuse, hérissée et rude à la base. - Cévennes.

H. sibiricum L.

Varie à pétales ovales ou lancéolés, non échancrés $(H$. Lecoquii Gr. et God.)

- Fleurs blanches, celles du pourtour rayonnantes. -

Plante élevée, velue et variable. - Les prairies et les bois.

H. Sphondylium L.

\section{G. Tordylium L.}

Plante velue; tige élevée, à poils dirigés en bas; fleurs blanches. - Les champs.

T. maximum L.

\section{G. LASERPitium L.}

Plante élerée, variable, à fleurs blanches. L. latifolium I.

\section{G. Daugus L. - Carottes.}

Racine en fuseau; tige velue et rude; fleurs blanches, la centrale rouge. - C'est la plante ancestrale des carottes cultivées.

D. Carota L.

Varie à plante courte, à tige en zig-zag, rameuse, velue sur les nervures, luisante du reste (D. gummifer Lam.)

\section{G. Scandix L.}

Fruit terminé par une très longue pointe. - S. G. Scandix. Fruit terminé par une pointe courte ou nulle. - S. G. Anthriscus.

\section{S. G. Scandix L.}

Plante pubescente, à folioles linéaires; fleurs blanches. - Les champs cultivés.

S. Pecten Veneris L.

\section{S. G. Anthriscus Pers.}

Fruits hérissés d'aiguillons crochus et blanchâtres. - Plante très rameuse, glabre; style très court. S. vulgaris Pers.

- Fruits lisses ou sans aiguillons. . . . . . . . 1

1. Ombelles terminales, pédiculées et à plus de 5 rayons.Plante élevée; tige sillonnée, à nœuds renflés et pubescents; fruits linéaires.

S. sylvestris Hoff.

- Ombelles latérales, sessiles et à 4-5 rayons. - Plante à feuilles aromatiques; fruits linéaires, à bec sillonné. Cultivée sous le nom de Cerfeuil. S. Cerefolium L. 


\section{G. Cherophyllum L.}

Plante à tige élevée et sillonnce; feuilles d'un vert sombre; fleurs blanches, en ombelles d'abord nenchées. - Les haies.

G. temulum L.

\section{G. Mrrrhis Scop.}

Plante élevée, à oteur d'anis; feuilles molles, velues; fleur's blanches. - Auvergne et Pỹénées: - Cultivée sous le nom de Cerfeuil musque.

M. odorata ścop.

\section{G. Conium L.}

Plante fítide, it tige très élevée, marquée, surtout dans le bas, de taches brimes; folioles de la collerette de l'ombellule unilatérales, ovales et an nombre de trois; fleurs blanches. - Grande Giguë.

C. maculatum L.

\section{G. Smyrnium L.}

Plante à tige élevée, robuste, sillonnée; fleurs jaune pâle; fruit gros, noir à la maturité. - Haies. S. Olusatrum L.

\section{G. Caucalis L.}

Poils ou pointes du fruit rangés régulièrement sur les cótés. I Poils ou pointes courrant toute sa suface. - $\mathbf{S}$. (i. Torilis Gœert.

1. Riayons de lombelle hérissés de poils rudes. - S. (i. Turgenia Hoff.

- Ravons de l'ombelle dépourvus de poils ruiles. . . . . . 2

2. Onibelle a cinq rayons au moins, munie d'une collerette. S. G. Orlaya Hofr.

- Ombelle de deux à quatre rayons an plus, presque sans collerette. - S. G. Caucalis.

$$
\text { S. G. Orlaya Hofr. }
$$

Plante rameuse dès la base; fleurs blanches, à pétales externes très grands. - Dans les moissons. - (O. grandiflora Hoff.)

\section{S. G. Caucalis L.}

Fruits à aiguillons lisses et à un seul cllochet; tige striée, à rameaux dirigés en tous sens; fleurs rosées.-Les champs cultivés.

G. daucoïdes L.

Varie à fruits à aiguillons chargés daspérités et à plusieurs crochets ( $G$. leptophylla L.) 
S. G. Turgenia Hoff.

Plante velue, à tige raide; fleurs blanches, rosées ou rouges, en ombelle à trois rayons; fruits à aiguillons rougeâtres. ( $T$. latifolia Hoff.)

G. latifolia L.

\author{
S. G. Torilis Gœrt.
}

Ombelles sans pied, opposées aux feuilles. - Plante faible, étalée; folioles étroites. - Surtout au bord de la mer. (T. nodosa Gœrt.)

G. nodiflora Lam:

Ombelles pédiculées et terminales. . . . . . . 1

1. Collerette à 4-5 pièces. - Plante rameuse, élancée; fruits à aiguillons courbés, aigus. - Les champs incultes. (T. Anthriscus Gmel.)

C. Anthriscus.

- Collerette nulle ou à une seule pièce. - Plante à rameaux étalés, à feuilles toutes incisées et à fruits hérissés d'aiguillons. ( $T$. helveticum Gm.)

G. helvetica Jacq. Varie à feuilles supérieures linéaires ( $T$. heterophylla Guss.)

\title{
G. Coriandrum L. - Coriandres.
}

Fruit doublement globuleux. - S. G. Bifora Hoff.

Fruit simplement globuleux. - S. G. Coriandrum L.

S. G. Bifora Hoff.

Plante fétide; tige à angles aigus; folioles à lobes linéaires, dirigés en tous sens; ombellules à 2-3 fleurs blanches. Moissons. - (B. testiculata Spr.) G. testiculatum L.

S. G. Goriandrum L.

Plante glabre, fétide, d'un vert gai; feuilles luisantes; fleurs blanches ou rougeâtres. - Cultivée. G. sativum L.

\section{Fam. des RUBIACÉES Baillon.}

\section{G. Rubia L. - Garances.}

Fenilles veinées en réseau en dessous; anthères linéaires. - Plante non ligneuse it la base, amnuelle; feuilles non persistantes; lobes de la corolle insensiblement rétrécis en pointe. - Cultivée et naturalisée çi et li dans le S.-0. Garance tinctoriale. $\quad \boldsymbol{R}$. tinctorum L.

- Feuilles non veinées en dessous; anthères arrondies. - 
Plante grimpante; fenilles persistantes, hérisscées daigruillons crochus; fleurs jaune pàle, a lobes de la corolle subitement rétrécis en pointe.-Haies. R. peregrina L. Varie : 10 à larges feuilles ovales ( $R$. lucida L.); $2^{\circ}$ ì feuilles étroites et lancéolées ( $R$. angustifolia L.)

\section{G. Galium L. - Gaillets.}

Fenilles ì trois nervures. . . . . . . . . . . 1

- Feuilles à une seule nervure. . . . . . . . . . 3

1. Fleurs jaunes. . . . . . . . . . . . . 2

- Fleurs blanches. - Tige à quatre angles, raide, très feuillée; fleur's en panicule très serrée. - Bois. G. boreale L.

Varie: 10 a fruits velus (G. nervosum Lam.); 20 à fruits glabres (G. vubioïdes DC.)

2. Queue de la flew muie de pelites ferilles. - Herbe d'un vert jaunatre, hérissće, al tige simple; feuilles par quatre, ovales; des fleur's unisexuees et hermaphrorlites mêlées. - Haies.

G. Cruciata Scop.

- Queue de la fleur dépourure de pelites fúlles. - Plante variable, glabre ou velue; feuilles par quatre; des fleurs unisexuées et hermaphrodites mèlées. - Dans les Prrénées et le S.-O.

G. vernum Scop.

Tarie: 10 i feuilles ovales ef a fleurs tout a fait jaunes (G. Bauhini Lois.); $2^{\circ}$ à feuilles étroites et à fleurs d'un jaune pâle (G. Halleri Lois.)

3. Fleurs jaunes ou jaunatres. . . . . . . . . 4

- Fleurs blanches, blanchatres, roussâlres ou rosées. . 6

4. Tige couchée, glabie. - Plante à racine rampante; feuilles linéaires, épaisses, roulées en dessous par les bords. Sables maritimes. G. arenarium DC.

- Tige dressée et plus ou moins velue. . . . . . . 5

5. Fleurs jaunes, en grappe seriée. - Plante ì feuilles linéaires, roulées en dessous par les bords. - Caillelait.

G. verum $L$.

- Fleurs jaunatres, en grappe lâche. - Plante à racine rampante, rougeitre; tige à quatre angles, à nœuls renflés; feuilles orales ou lancéolées, à bords très rudes, roulés en dessous. - Sabl. mar. G. neglectum Le Gall.

6. Tige bordée d'uspérités ou d'aiguillons crochus. . . 10

- Tige sans aiguillons crochus. . . . . . . . 7

7. Feuilles toujours rerticillées pur 4. . . . . . In

- Feuilles verticillées par 4-6-12. . . . . . . 8

8. Tige grile, tombante; fleurs en grappe ramifiée, étalée ou diffuse. . . . . . . . . . . . 9

- Tige dressée; fleurs en grappe ramifiée, dressée. Plante élevée, forte; feuilles ovales ou lancéolées, verticillées par 6 ou 8 . 
9. Fruits tuberculeux; fleurs en bouquet serrć. - Petite plante couchée, gazonnante, glabre; anthères jaunes. - Parmi la mousse.

G. saxatile L.

- Fruits lisses ou un peu chagrinés; fleurs non serrées. Plante à tige lâche; feuilles lancéolées ou linéaires; fruits d'un gris brun.

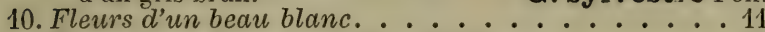

- Fleurs d'un blanc sale ou verdatre. . . . . . . . 12 11. Fruits tuberculeux; feuilles d'un vert tendre et très rudes sur les bords. - Tige faible, très accrochante; anthères jaunes. - Prés marécageux. G. uliginosum L.

- Fruits lisses; feuilles tr̀ès peu rudes sur les bords. Plante variable, diffuse; feuilles obtuses; anthères purpurines.

G. palustre L.

Varie : 10 à plante couchée, appliquée sur le sol ( $G$. rupicola Desm.); $2^{\circ}$ à feuilles aiguës ( $G$. constrictum Chaub.); $3^{\circ}$ à feuilles munies en dessous de deux rangs d'aiguillons ( $G$. elongatum $\mathrm{Pr}$.)

12. Fleurs en grappe. . . . . . . . . . . . 13

- Fleurs axillaires, plusieurs sur un même pédicule. 14

13. Rameaux de la panicule longs et presque capillaires. Plante à feuilles verticillées par 7; corolle très petite, un peu rougeâtre.

G. divaricatum Lam.

- Rameaux courts et non capillaires. - Plante à feuilles verticillées par 6 , d'abord étalées, puis réfléchies; fleurs roussâtres; fruits hérissés. $\quad G$. parisiense L.

Varie à fruits glabres (G. anglicum Huds.)

14. Pédicules des fleurs recourbés après la floraison.Très petite plante, à tige simple, très rude de bas en haut; fruits gros, à verrues.

G. tricorne With.

- Pédicules des fleurs toujours droits. - Plante élevée, accrochante, à tige renflée et hérissée aux nœuds; fruits gros, hérissés de poils crochus et tuberculeux. - Gratteron.

G. Aparine L.

Varie : 10 à fruits hérissés de poils non tuberculeux (G. Vaillantii DC.); $2^{\circ}$ à fruits noirâtres, chagrinés et -glabres (G. spurium L.)

\section{G. Asperula L. - Aspérules.}

Fleurs bleues. - Plante rameuse; feuilles linéaires; fleurs en tête terminale; feuilles florales bordées de longs cils blancs. - Les champs. $\quad$ A. arvensis L. Fleurs blanches ou roses. .

1. Fruits hérissés. - Plante à racine rampante; feuilles larges, lancéolées; fleurs blanches, odorantes, en corymbe terminal. - Les bois.

A. odorata L.

- Fruits glabres. - Plante à tiges nombreuses, grêles et 
couchées; feuilles linéaires; corolle couverte en dehors de papilles.

A. cynanchica L.

Varie à feuilles florales orales et i corolle glabre, souvent à trois divisions (A. tinctoria L., A. pyrenaïca L.)

\section{G. Sherardia L.}

Plante couchée, velue; feuilles ovales, lancéolées; fleurs hilas ou roses.

S. arvensis $\mathrm{L}$.

\section{G. Crucianella L.}

Plante grêle, un peu glauque; tige à quatre angles; fenilles en alène; fleurs en épis carrés, à feuilles florales blanches, vertes sur le dos.

C. angustifolia $\mathrm{L}$.

Tarie it fleurs en épis linéaires, très longs et à feuilles plus larges (C. lalifolia L.) - Montauban.

\section{G. SAmbucus Tourn. - Sureaux.}

Plante herbacée. - Tige élerée; folioles lancéolées et dentées; fleurs blanches, rosées en dehors; fruits noirs. Yèble.

S. Ebulus L.

- Tige ligneuse. . . . . . . . . . . . i

1. Fleurs en bounuets planes; fruits noirs, rarement rerts ou blancs. - Arbrisseitu it folioles ovales, aiguës; fleurs blane jamitre, tris odorantes. - Sureau. S. nigra L.

Varie à feuilles très découpées en lobes allongés.

- Fleurs en grampe orale el serree. - Arbrissean a folioles ovales, aiguis; fleurs blanchitres; fruits d'un rouge écarlate. - Prínées. - Ciultivé. S. racemosa L.

\section{G. Virurnum L. - Viornes.}

Corolle à divisions inégales. - Arbrisseau rameux; feuilles a trois lolies; flemr's blanches, en bouquet; fruit rouge, luisant. - Lieux frais.

V. Opulus L.

Tarie, par la culture, à fleurs stériles, amplifićes et en bouquet arrondi. - Boule de neige.

- Corolle à divisions égales.

1. Calice à dents obtuses. - Arbrissean courert de poils; feuilles ovales, veinées et ridées; fleurs blanches, odorantes, en corymbe terminal; fruit aplati, rouge, puis noir.

T. Lantana L.

- Calice à dents aiguës. - Arbrissean i fuulles ovales et aiguës, très entieres, velues et persislantes; flems blanclies, inodores. - Gultivé. 


\section{G. Lonicera L. - Chèvrefeuilles.}

Flaurs en bouquets terminaux. . . . . . . . . 1 - Fleurs par deux à l'aisselle des feuilles. - Arbrisseau à rameaux dirigés en tous sens, grisâtres; fleurs jaunâtres; fruits rouges.

L. Xylosteum L. 1. Feuilles distinctes ì la base. - Arbrisseau grimpant; feuilles ovales; fleurs odorantes, en tète pédiculée. Ghèvreferille. $\quad$ L. Periclymenum L.

- Feuilles supérieures soudées par paires. - Arbrisseau volubile, à fleurs purpurines ou d'un blanc jaunâtre, odorantes. - Cultivé. L. Gaprifolium L.

\section{Fam. des DIPSACÉES Juss.}

\section{G. Dipsacus L. - Cardères.}

Tige élevée, robuste, hérissée d'aiguillons; feuilles sans quene; têtes grosses et allongées; écailles de la tète arquées; fleurs lilas clair.

D. sylvestris L.

Varie : 10 à feuilles pennatifides, ciliées et à flenrs blanchâtres (D. laciniatus L.); $2^{\circ}$ à écailles de la tète linéaires, inermes, à feuilles toujours entières et sans aiguillons, à fleurs lilas - Cultivée comme Chardon à foulon - (D. fullonum Mill.)

\section{G. Scabiosa L. - Scabieuses.}

Fleurs munics à leur base d'une paillette. . . . . . . . 1 - Fleurs munies à leur base de soies. - Plante velue, à tige élevée; feuilles vert blanchàtre, les supérieures découpées; fleurs lilas. - Les champs cultivés et calcaires. - (Knantia arvensis Coult.)

S. arvensis L.

1. Feuilles entières ou seulement dentées. - Plante à racine tronquée; tige simple; feuilles ovales ou lancéolées ; fleurs d'un bleu ciel. - Landes et prés humides. S. Succisa I.

- Fevilles supérieures découpées en lobes allongés. . 2

2. Calice muni d'une gaîne et à limbe porté sur un long pied. - Plante très variable, annuelle; fleurs roses, blanches ou pourpres. - Le S.-O.

S. maritima L.

Varie, par la culture, à fleurs très grandes et d'un pourpre très foncé. - Fleur de veuve. - (S. atropurpurea L.)

- Calice à limbe sans pied. - Plante dressée, raide, à flenrs d'un bleu clair. - Auvergne, Pyrénées et dans la plaine du S. -0 .

S. Golumbaria L.

Varie à feuilles rapprochées et luisantes (S.lucida Vill.) 


\section{G. Valeriana L.}

Fruit couronné par une aigrette plumeuse. - S. G. Valeriana L. Fruit sans aigrette, denté au sommet. - S. G. Valerianella T.

\section{S. G. Valeriana L. - Valérianes.}

Corolle à tube éperonné. - Plante lisse et glauque, à tige creuse; feuilles ovales ou lancéolées, entières; fleurs rouges, en corymbe terminal; une étamine. - Vieux murs. - Gultivée sous le nom de Valériane rouge. (Centranthus ruber DC.) V. rubra L.

Varie à feuilles linéaires et à éperon court ( $V$. angustifolia DC.)

- Corolle à tube bossu à la base. . . . . . . . . . 1

1. Fleurs à deux sexes; tige dépassant $0^{m} 50 . . . .2$

- Fleurs souvent à un seul sexe; tige n'atteignant pas $0^{m} 50$. - Plante à tige cannelée; fleurs rougeâtres; fruits ovales. - Plaines du S.-O.

V. dioica L.

2. Feuilles radicales pennatifides. - Plante a racines fasciculées, fétides; fleurs blanc rosé, en corymbe terminal; fruits glabres. - Grande Valériane. V. officinalis L.

- Feuilles radicales entières ou incisées, ovales. - Plante à rhizome tronqué, odorant; fleurs blanches ou rosées, odorantes; fruits relus sur deux lignes. - Cultivée et cà et là échappée.

V. Phu L.

\section{S. G. Valerianella Tourn. - Mâches.}

Fruit couronné par une ou plusieurs dents droites. . . 1 - Fruit couronné par des dents crochues. - Tige droite, bifurquée au sommet; fleur's en tête serrée; fruit ovale. Charente-Inférieure. V. hamata Bast.

1. Dents du fruit séparées ou presque nulles. . . . . . 2

- Une des dents du fruit plus saillante que les autres. 3

2. Fruil marqué d'un sillon sur le bord et de deux côtes latérales. - Plante à rameaux étalés; fleurs en tète globuleuse. - Les champs. V. olitoria Nonch.

- Fruit creusé en nacelle d'un côté et relevé en carìne de l'aulre. - Plante à rameaux étalés et à fleurs en tète globuleuse, comme la précédente. V. carinata Lois.

3. Fruits à deux sillons et à trois côtes sur le dos, la côte médiane plus scillante. - Plante à feuilles d'un vert plombé. - Charente-Inférieure.

v. pumila DG.

- Fruit à couronne en forme d'oreille. - Tige dressée, bifurquée au sommet; fruit orale, arrondi. - Dans les champs.

V. Auricula DG.

- Fruit n'ayant pas ces caractères, et è cinq côtes. . . 4 
4. Couronne du fruit évasée et large. - Plante à rameaux raides, dirigés en tous sens; fruits ovales. - Cultivée et natur. - Miche de Hollande. V. eriocarpa Desv. - Couronne du fruit oblique et étroite. - Tige dressée, bifurquée au sommet; fruit conique, aigu. - Dans les champs.

\section{Fam. des COMPOSÉES Vaill.}

\section{G. Eupatorium L.}

Plante élevée, à tige rougeàtre; feuilles opposées, à trois folioles; fleurs rosées, en corymbe terminal. — Bords des eaux. - Eupatoire.

E. cannabinum L.

\section{G. Tussilago L. - Tussilages.}

Tête de fleurs à rayons. - Plante à racine rampante; tige florale naissant avant les feuilles, garnie d'écailles et à une seule tète terminale. - Pas d'áne. T. Farfara L. Tête de fleurs sans rayons.
1. Tige florale naissant en méme temps que ies feuilles; écailles des têtes égalant les fleur's. - Plante it fevilles en cour, arrondies; fleurs d'un blanc rosé, à odeur de vanille; fleurs externes des tètes presque en languette. - Cà et là, naturalisée. - Cultivée sous le nom d'Héliotrope d'hiver.

T. fragrans Vill. Tige florale naissant avant les feuilles; écailles des têtes plus courtes que les fleurs. - Plante à rhizome charnu et rampant; feuilles en forme de rein; fleurs roses ou purpurines. - Bords des eaux.

T. Petasites L.

\section{G. Aster L.}

Ecailles des têtes plus ou moins étalées. . . . . . . 1

- Ecailles des têles dressées ou simplement arquées en

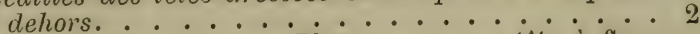

1. Feuilles avec quierie. - Plante rameuse; tète à fleurons jaunes et à rayons bleus, rougeâtres ou pourpres.-- Cultivée sous le nom de Reine-Marguerite. A. chinensis L.

- Feuilles sans quere. - Plante à tige élevée, rameuse au sommet; têtes disposées en corymbe. - Cultivée et échappée.

A. Novi Belgii L.

Varie à feuilles embrassantes par deux oreillettes ( $A$. brumalis Nees.)

2. Têtes à rayons stériles. - Plante glabre, à tètes en 
corymbe compacte; feuilles fortement ponctuées. - Vient dans le Midi.

A. acris $L$.

Varie à feuilles non ponctuées et toutes à trois nervures. - Cévennes. - (A. trinervis Desf.)

- Têtes à rayons fertiles et femelles. . . . . . . . 3

3. Plante glabre et lisse. - Tige élevée; feuilles lancéolées et charnues; rayons blancs ou lilas. - Sur les bords de la mer.

A. Tripolium L.

- Plante plus ou moins velue ou rude. - Plante à souche dure et noueuse; têtes en corymbe. - Auvergne et plaines du S.-O.

A. Amellus L.

\section{G. Erigeron L. - Vergerettes.}

Tètes de fleurs à réceptacle bombé. - S. G. Erigeron L. Tètes de fleurs à réceptacle plat. - S. G. Vittadinia Rich.

S. G. Vittadinia Rich.

Plante rameuse, à tige hérissée; feuilles à trois lobes; rayons blancs ou pourpres. - Cultivée et naturalisée à Bayonne. - (V. triloba DC.)

E. triloba.

S. G. Erigeron L.

Têtes d'un blanc jaunâtre, en grappe le long des rameaux. - Tige élancée, velue; feuilles linéaires ou lancéolées, ciliées.

E. canadensis L.

- Têtes pourpres, solitaires ou peu nombreuses. - Plante velue et rougeàtre; feuilles linéaires ou lancéolées. - Les lieux stériles.

E. acris L.

- Têtes blanches. - Plante velue, à tige droite. - Toulouse. -(Conyza ambigua DG.) E. linifolium Willd.

\section{G. Solidago L. - Verges d'or.}

Feutilles très entières. - Plante élerée, velue; têtes jaunes, unilatérales. - Plante de l'Amérique du Nord naturalisée en Auvergne.

- Feuilles plus ou moins dentées. . . . . . . . 1

1. Têtes en grappes arquées. - Plante élevée, droite; fleurs d'un beau jaune. - Plante du Canada naturalisée dans le S.-O., le long des rivières.

- Têtes en grappes dressées. - Plante variable, à tige droite et simple; feuilles orales ou lancéolées. - Se trouve dans les bois.

S. Virga aurea L.

G. Linosyris Lob.

Plante à tige simple, effilée, à feuilles linéaires et ponctuées; tètes jaunes, en corymbe.

L. vulgaris Cass. 
G. Bellis L. - Pâquerettes.

Tige florale feuillée. - Petite plante annuelle; tête à rayons blancs ou rougeâtres en dessous. - Vient cà et là dans les landes.

B. annua L. Tige florale nue.

1. Feuilles ovales. - Plante à racine rampante; feuilles en rosette; fruit sans aigrette. - Partout. - Petite Marguerite.

B. perennis L.

- Feuilles lancéolées. - Plante à racine tronquée; fruit couronné par des soies. - Les lieux secs. (Charente-Inférieure).

B. pappulosa Bois.

\section{G. Mrcropus L.}

Plante blanche et cotonneuse; feuilles lancéolées; tétes axillaires et terminales, entourées d'un épais coton. Les lieux arides.

M. erectus L.

\section{G. Buphthalmum L.}

Plante couverte de longs poils; tige rougeâtre, raide; écailles des têtes épineuses; fleurs jaunes. (Pallenis spinosa Cass.)

B. spinosum L.

\section{G. InvLA L. - Aunées.}

Feuilles fortement décurrentes le long de la tige. - Plante élevée, à têtes jaunes, agglomérées au sommet des rameaux. - Auvergne. I. bifrons L.

- Feuilles point ou peu décurrentes.

1. Rayons trifides et peu saillants. - Plante élevée, velue, raide et rougeâtre. - Lieux pierreux. I. Gonyza DG.

- Rayons entiers et saillants. . . . . . . . 2

2. Ecailles des têtes larges et ovales. - Plante élevée, à grosse tige, à grandes feuilles et à grandes fleurs. Grande Aunée.

I. Helenium L.

- Ecailles des têtes lancéolées òu linéaires. . . . . . 3

3. Têtes très visqueuses. . . . . . . . . . . 4

- Têtes non visqueuses ou solitaires. . . . . . 5

4. Rayons d'un jaune pâle. - Plante très fétide, ramifiée en pyramide; feuilles lancéolées ou linéaires. - Les lieux sablonneux.

I. graveolens Desf.

- Rayons d'un beau jaune. - Plante à odeur forte, lignense à la base; feuilles demi-embrassantes. - Se trouve dans les landes. I. viscosa L.

5. Feuilles glabres ou à quelques poils. . . . . . . 6

- Feuilles très velues surtout en dessous. . . . . . 8 
6. Feuilles charnues, linéaires ou trifides. - Plante it tige lisse. - Bords de la mer. I. crithmoïdes L.

- Feuilles non charnues et larges. . . . . . . . . 7

7. Feuilles en cxur, embrassantes. - Plante à tige striée; écailles des têtes glabres et ciliées; fruit glabre. - Lieux secs.

I. salicina L.

- Feuilles arrondies à la base et sans queue.-Plante ressemblant à la précédente, à écailles des tètes recourbées. - Lieux secs.

I. squarrosa L.

8. Rayons très petits, dépassant à peine les écailles. Petite plante très rameuse, à tètes globuleuses. - Lieux humides.

I. Pulicaria L.

- Rayons allongés, dépassant beaucoup les écailles. . 9

9. Fevilles non embrassantes; têles solitaires. - Petite plante soveuse; feuilles lancéolées; fleur's d'un beau jaune. - Lieux sees. I. montana L.

- Feuilles embrassantes; têtes de fleurs en bouquet. : 10

10. Fruit à aigrette simple. - Plante élevée ct velue; feuilles planes; écailles des tètes allongées et linéarres. - Lieux humides.

- Fruit à aigrelte dionble. - Plante élevée, cotonneuse; feuilles ondulées; écailles des tètes courtes et sétacées. Lieux frais.

1. dysenterica $L$.

\section{G. Helianthus L.}

Fenilles pétiolées et en caur ; têtes tries grandes. - Plante trés devée, droite; tige renflée sous la tète penchie. Plante du Pérou cultivée sous le nom de Girand-Soleil ou Tournesol.

H. annuus L.

- Feuilles supérieures sessiles ou lancéolées: têtes médiocres, en bouquet. - Plante a racine tuberculense; tiges nombreuses, élerées; tètes dressées. - Plante du Brésil cultivie comme Topinambour.

H. tuberosus L.

\section{G. Bidens L.}

Feuilles à 3-5 folioles. - Plante rameuse; tige épaissie sous les têtes; tètes droites et sans rayons. - Les lieux humides.

B. tripartita L.

- Feuilles simples et lancéolées. - Plante élevée; tètes penchées et i rayons. - Lieux humides. B. cernua L. Varie it plante grèle et à tètes fort petites ( $B$. minima $L$.)

\section{G. Axthemis I. - Camomilles.}

Rayons jaunes i la base. - Plante diffuse; feuilles relues, blanchitres; fruits envelople's par une reaille. - Ies champs.

A. mixta L. 
- Rayons blancs en dessus, pourpres en dessous. - Plante à racine charnue, en fuseau et à saveur brûlante; tige couchée. - Cultivée sous le nom de Pyrèthre. - (Anacyclus Pyrethrum DG.)

A. pyrethrum L.

1. Rayons tout a fait blancs. $\cdot \cdots \cdot \cdot 1$ neuse.

- Ecailles sans pointe épineuse. . . . . . . . 2

2. Plante inodore ou à peu près. - Tige diffuse; fleurs des têtes entremêlées d'écailles presque aussi longues qu'elles. - Champs sablonneux.

Plante très odorante.

A. arvensis $\mathrm{L}$.

3. Odeur aromatique; feuilles velues et grises. - Plante couchée. - Lieux sablonneux.

A. nobilis L.

Varie, par la culture, à fleurs doubles. - Camomille romaine.

- Odeur fétide; feuilles glabres. - Plante rameuse. - Les lieux cultivés. - Maroute.

A. Cotula L.

\section{G. Achillea L. - Millefeuilles.}

Feuilles découpées en lobes fins et nombreux - Plante variable, à fleurs blanches, grises ou purpurines; fruit tronqué au sommet.

A. Millefolium L.

Varie à plante naine et presque laineuse $(A$. candicans Le Gal.)

- Feuilles simples et dentées. - Plante glabre, à tige droite.

A. Ptarmica L.

\section{G. Diotis Desf.}

Plante toute blanche, cotonneuse, à tiges nombreuses; tètes jaunes, en corymbe terminal. - Se trouve dans les sables maritimes.

D. candidissima Desf.

G. Santolina Tourn. - Santolines.

Plante extrêmement variable, ligneuse à la base, plus ou moins velue, buissonnante; feuilles linéaires, sur quatre rangs; têtes jaunes. - Çà et là; plantée en haies sur la côte. Sanguenite. S. Chamæ Cyparissus L. Varie à plante glabre et à dents des feuilles aiguës (S. viridis DG.)

\section{G. Chrysanthemum L. - Chrysanthèmes.}

Réceptacle conique. - S. G. Matricaria.

- Réceptacle plane ou convexe. . . . . . . . 1 
1. Tètes disposées en corymbe. - S. G. Pyrethrum.

- Têtes solitaires au sommet des rameaux. . . . . . . 2

2. Fruits tous cylindriques et sillonnés. - S. G. Leucanthemum.

- Fruits de deux sortes : ceux du centre, cylindriques ou coinprimés; ceux du pourtour, à trois angles ou à trois ailes. - S. G. Ghrysanthemum.

\section{S. G. Matricaria.}

Fleurs aromatiques; réceptacle creux. - Plante glabre, à odeur agréable et forte; tige dressée; fleurs blanches, à centre jaune, en corymbe.

G. Ghamomilla L.

- Fleurs inodores; réceptacle plein. - Plante glabre et diffuse; fruits munis au sommet de deux glandes arrondies. - Lieux cultivés.

C. inodorum L.

Varie à fruits munis de deux glandes allongées (G.maritimum L.)

\section{S. G. Pyrethrum.}

Feuilles sans queuc. - Plante velue, à tige cannelée; feuilles pennées ou pennifides; tètes en corrmbe làche. - Les coteaux secs.

G. corymbosum L.

- Feuilles munies d'une queue. . . . . . . . . 1

1. Fevilles toutes composées. - Plante à odeur forte, à tige ilevie, pubescente, raneuse. - Naturalisée antour des jardins. - Matricaire. $\quad$ G. Parthenium Pers.

- Feuilles inférieures pennifides, à dents nombreuses, les supérieures entières. - Plante rameuse, à feuilles inolles; tètes très variables pour la couleur, le volume et la forme de la corolle. - Cultivée sous le nom de Chrysanthème ou de Marguerite d'aulomne. C. indicum L. Varie à feuilles coriaces $(G$, sinense Sab.)

\section{S. G. Leucanthemum.}

Feuilles linéaires et étroites, entières. - Plante glabre et gazomnante; fruits du centre sans couronne; ceux de la circonférence, munis d'une couronne complète. - A l'cmhonchure de la Gironde. G. graminifolium Lam.

- Fcuilles de la tige lancéolées, dentées ou incisées. Plante rariable, à tige dressée et simple; feuilles inférieures orales, crénelées. - Les prairies. - Grande Marguerite.

\section{S. G. Chrysanthemum}

G. vulgare L.

Rayons jaunes ou jaunâtres. . . . . . . . . . 1 - Rayons blancs. . . . . . . . . . . . . 2

1. Fevilles dentées ou pennifudes. - Plante rameuse; tètes d'un beau jaune, srandes; fruits nus. - Dans les moissons.

G. segetum L. 
- Feuilles très découpées. - Plante rameuse; fruit couronné de trois dents épineuses. - Cultirée sous le nom de Marguerite dorée.

C. coronarium L.

2. Feuilles charnues, à lobes linéaires. - Plante ligneuse, qui fleurit en hiver. - Cultivée. C. frutescens L.

- Feuilles planes, à lobes en coin ou lancéolés. - Plante fleurissant toute l'année. - Cult. G. grandiflorum W.

\section{G. TANacetum L. - Tanaisies.}

Ecailles des têtes toutes obluses. - Plante élevée, odorante; feuilles découpées en lobules aigus; têtes jaunes, en corymbe serré. - Tanaisie.

T. vulgare L.

- Ecailles des têtes lancéolées en dehors, allongées et obtuses en dedans. - Plante élevée, odorante, relue; feuilles lancéolées, entières et obtuses; tètes en cory̧mbe terminal. - Gultivée sous le nom de Ienthe-Coq, dans les jardins.

T. Balsamita $L$.

\section{G. Artenisia L. - Absinthes.}

Style filiforme jusqu'au sommet. . . . . . . . 1

- Style élargi au sommet en disque cilié. - Plante herbacée, velue et blanche, d'une odeur désagréable; tètes réfléchies, en grappe à rameaux étalés; écailles des tètes membraneuses au bord. - La côte.

A. maritima L.

Tarie à rameaux de la panicule et à tètes dressés en pyramide très fournie (A. gallica WVild.)

1. Feuilles d'un vert foncé et glabres, au moins en dessus. .............. 2

- Feuilles grisâtres ou velues. . . . . . . . 3

2. Fenilles entières et lancéolées. - Plante glabre, à tige dressée; tètes globuleuses, en petites grappes. - Plante de Russie cult. comme Estragon. A. Dracunculus L.

- Ferilles pennatipartites, blanches en dessous. - Plante élevée, très amère, odorante; tètes ovoüdes, en longues grappes. - Armoise.

A. vulgaris $L$.

3. Plante grise, non soyeuse. - Tige ligneuse à la base, très rameuse, formant buisson, d'une odeur aromatique agréable; fenilles découpées en lobes linéaires aigus. Auvergne, Cérennes, Charente-Inférieure. - Dans les lieux rocailleux et arides.

A. camphorata Vill.

- Plante blanche et soyeuse. . . . . . . . . . . 4

4. Tige très rameuse. - Plante élevée, amère et odorante, à feuilles découpées en lobes lancéolés, obtus. - Auvergne, Prrénées, littoral et cà et là dans tout le S.-0. - Cultivée comme Giande Absinthe. A. Absinthium L.

- Tige simple. 
5. Plante ligneuse, à rameaux étalés, à tige d'abord couchée, variable.

A. campestris L.

Varie, au bord de la mer, à plante conchée et soyeuse et à feuilles charnues (A. crithmifolia DG. ou A. maritima Lloyd.)

- Plante herbacée, à tiges grêles et nues. - Cultivée comme Petite Absinthe.

G. pontica L.

\section{G. Gnaphalium L.}

Têtes jaunes; écailles membraneuses. - S. G. Helichrysum DG. Têtes anguleuses, coniques ou pointues. - S. G. Filago L. Têtes demi-globuleuses ou cylindriques et obtuses. - S. G. Gnaphalium L.

\section{S. G. Gnaphalium L.}

Têtes feuillèes ou axillaires. ........... 1

- Têtes non feuillées ou terminales. - Plante à tige simple et dressée; feuilles linéaires; écailles des tètes transparentes, d'um jaune pàle. - Se trouve dans les lieux sablonneux. $\quad$ G. luteo album L.

1. Têtes agglomérées en paquets terminaux. - Plante rameuse, diffuse, cotomneuse. - Se trouve dans les lieux inondés.

G. uliginosum L.

- Têtes disposées en grappe ou en épi allongé. - Plante à tige simple, ascendante; feuilles à une nervure; écailles verditres ou brun clair.

G. sylvaticum L.

$$
\text { S. G. Filago L. }
$$

Têtes de fleurs réunies $8-10$ en paquets hérissés de pointes colorées. ................ 1

- Têtes de fleurs réunies 3-4 en paquets sans pointes. 2

1. Têtes à cinq angles saillants, entourées de feuilles plus longues qu'elles. - Plante blanchatre, fourchue. - Les lieux secs.

G. spathulata Pr.

- Têtes ì angles peu marqués, sans écailles ou d̀ écailles plus courtes qu'elles. - Plante velue, jaunâtre ou blanchâtre, fourchue. G. germanica L.

2. Feuilles en aline, dépassant les paquets de fleurs. Plante peu cotomneuse, à rameaux grêles. - Dans les champs secs.

G. gallica L.

- Feuilles lancéolées, plus courtes que les paquets de

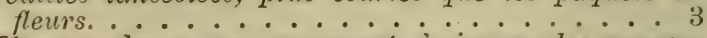

3. Têtes membraneuses au sommet, à cinq angles prononcés; feuilles étroites et serrées contre la tige. - Les lieux sablonneux.

G. montana L.

- Têtes très cotonneuses, à angles peu prononcés; feuilles larges et lâches. G. arvensis L. 
S. G. Helichrysum DG. - Immortelles.

Tige ligneuse à la base et diffuse. - Plante grise ou blanche; feuilles linéaires, roulées en dessous par les bords. Sables marit. et lieux arides de l'intérieur. G.Stœchas L. - Tige à peu près herbacée. - Plante cotonneuse, à feuilles lancéolées ou linéaires, planes. - Cult. G. orientale L.

\section{G. Doronicum Tourn.}

Feuilles opposées. - Plante velue; feuilles sans queue et entières; tête solitaire, jaune ou orangée. - En Auvergne, dans les Cévennes et dans les Pyrénées. - (Arnica montana L.) $\quad$ D. arnica Desf. Varie à feuilles lancéolées. - Dax. - $(D$. angustifolia Dub.)

- Feuilles alternes. ............ 1

1. Feuilles radicales rétrécies à la base. - Plante à souche noueuse et velue; tige élevée, portant une seule tête jaune. - Poitou.

- Feuilles radicales en cour à la base. - Plante d'un vert pâle, à feuilles radicales en cœur, arrondies, les supérieures embrassantes. - Auvergne, Cévennes, Pyrénées et le S.-O.

D. Pardalianches Wild.

\section{G. Senecio L.}

Têtes munies d'une sorte de calice à la base. - S. G. Senecio L. Têtes munies de deux écailles seulement à la base. - S. G. Ligularia Cass.

Tètes sans écailles à leur base. - S. G. Cineraria L.

$$
\text { S. G. Senecio L. - Seneçons. }
$$

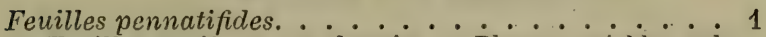
- Feuilles entières or dentées. - Plante variable, velue; fleurs d'un jaune vif ou orangées. - Cà et là, descendue des montagnes.

1. Rayons nuls ou très petits, enroulés sur eux-mêmes. $\frac{2}{5}$

- Rayons planes et non enroulés. . . . . . . 5

2. Rayons tout à fait nuls. - Plante rameuse, à écailles noirâtres au sommet. - Seneçon. $\quad \mathrm{S}$. vulgaris $\mathrm{L}$.

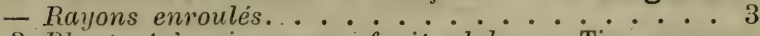

3. Plante très visqueuse; fruit glabre. - Tige rameuse, fétide.

$\mathrm{S}$. viscosus $\mathrm{L}$.

- Plante non visqueuse; fruit velu. . . . . . 4

4. Têtes très nombreuses. - Plante très élevée, d'un vert blanchàtre.

S. sylvaticus L.

- Têtes peu nombreuses. - Plante à odeur de fenouil. - La Teste de Buch (Gir.) 
5. Plante couverte d'un cluvet blanc. - Plante à racine rampante et à fruit velu.

S. erucifolius L.

- Plante glabre et verte, à écailles noires au sommet. . 6

6. Feuilles de la tige à lobes égaux. - Plante à racine tronquée; fruits du centre velus et rudes; ceux du pourtour glabres. $\quad$ S. Jacobæa L.

- Feuilles de la tige à lobe terminal plus grand que les autres. - Plante à racine tronquée et à fruits glabres.

S. aquaticus $\mathrm{L}$.

S. G. Ligularia Cass.

Plante élevée, à tige simple, pourpre à la base; feuilles en forme de rein ou de cour; tètes jaunes, en grappe allongée. - Sur le plateau central. - (L. sibirica Cass.)

S. sibiricus L.

S. G. Cineraria L. - Cinéraires.

Plante laineuse et blanche; têtes jaunes et en boucquet; feuilles radicales en spatule. - Bords de la mer. - (C. spalhulafolia L.)

S. spathulæfolius DC.

\section{G. Galendula L.}

Têtes de fleurs d'un jaune pâle. - Plante à odeur forte et à feuilles lancéolées. - Champs cultivés. - Souci sauvage. $\quad$ C. arvensis $L$.

- Têtes d'un jaune doré, très grandes. - Plante trés rameuse, à feuilles allongées. - Cult. G. officinalis L.

\section{G. Echinops L. - Chardons bleus.}

Têtes munies à la base d'écailles velues. - Plante élerée, couverte de duvet, a fleurs d'un bleu pâle. - Ciit et lit dans le S.-O. E. sphærocephalus L.

- Têtes munies à la base d'écailles glabres. - Plante cotonneuse, peu élerée; fleurs d'un beau bleu. - Plaine du S.-0. jusque près de Bordeaux.

国. Ritro L.

\section{G. Xeranthemum Tourn.}

Ecailles des têtes velues sur le dos. - Plante velue et grise, à fleurs purpurines. - Lieux arid. $\mathbf{X}$. cylindraceum Sm.

- Ecailles des têtes glabres. . . . . . . . . . 1

1. Têtes hémisphériques; aigretle du fruit à peine aussi lonyue que lui. - Plante élevée, rameuse, a écailles internes de la tète purpurines et rayomnantes. - Cultivée comme Immortelle rouge. 
- Têles ovoïdes; aigrette du fruit plus longue que lui. Plante peu élevée, blanchàtre, i écailles des tètes à peine rayonnantes, purpurines. - Se troure dans les lieux arides. $\mathbf{X}$. inapertum Wild.

\section{G. Garlina L. - Carlines.}

Fruits couverts de poils blancs, à aigrette anssi longue qu'eux. - Plante raide, velue; écailles des têtes terminées en épines planes en dessus. $\quad$ G. vulgaris $L$.

- Fruits couverts de poils d'un jaune doré, à aigretle une fois plus longue qu'eux. - Ecailles des tètes sillonnées en dessus. - Descend la vallie de la Garonne jusqu'à Agen.

G. corymbosa L.

\section{G. Centaurea L. - Centaurées.}

Fruits comprimés, munis d'une côte sur chaque face. - S. G. Leuzea DG.

Fruits comprimés et lisses, à ombilic latéral. - S. G. Centaurea L.

Fruits cylindriques, munis de côtes fines, à ombilic latéral. S. G. Cnicus Vaill.

Fruits ovoüdes, velus et sans côtes, à ombilic basilaire. - S. G. Crupina Cass.

Fruits presque quadrangulaires, at base amincie et à ombilic latéral. - S. G. Amberboa Pers.

S. G. Centaurea L.

Ecailles des têtes terminées par une ou plusieur's pointes piquantes............... 1

- Ecailles des têtes sans épines or à pointe molle. . . 4

1. Fleurs jaunes.. . . . . . . . . . 2

- Fleurs rouges ou blanches. . . . . 3

2. Têtes pédiculées, sans écailles. - Plante blanchàtre, venue du Midi, introduite dans les prairies artiricielles et naturalisée.

G. solsticialis L.

- Têtes sans queve et entourées d'écailles. - Plante du Midi, qui s'est également introduite dans les prairies artificielles.

C. melitensis L.

3. Tètes à longues épines dont l'une très longue. - Plante à saveur amère, á rameaux nombroux et dirigés en tous sens. - Chausse-trape.

C. Calcitrapa L.

- Têtes à cinq épines égales. - Tige anguleuse et rude, à rameaux nombreux et dirigés en tous sens, couchés. Région maritime.

4. Toutes les feuilles découpécs en lanières étroites. Plante élevée, à tige sillonnée; têtes grosses et rouge foncé. - Lieux arides. 
- Feuilles entières ou n'étant pas toutes pennatifides. 5

5. Fleurs d'un beau bleu. . . . . . . . . . . 6

- Fleur's n'étant pas d'un beau bleu. - Plante extrêmement variable, à têtes rougeâtres, munies d'écailles sans pointes distinctes. (G. amara L., G. Jacea L., G. nigra L. réunies.) - C. vulgaris Gr. et God.

6. Plante annuelle; tige rameuse, à plusieur's têtes de fleurs. - Plante velue et blanchàtre, à feuilles linéaires ou lancéolées; têtes à écailles noirâtres au sommet. Moissons. - Bleuet.

G. Gyanus L.

- Plante vivace, à tige simple, portant une seule tête.Çà et là.

C. montana L.

\section{S. G. Amberboa Pers.}

Plante à têtes d'un beau jaune; fruits à aigrette plus courte qu'eux. - Cultive sous le nom d'Ambrette jaune. - (Amb. odorata DG.)

C. amberboi Lam.

- Plante à têtes blanches ou violettes, musquées; fruits sans aigrette. - Cultivée sous le nom de Barbea: musqué. - (Amb. moschata DC.) G. moschata L.

S. G. Crupina Cass.

Plante à tige grêle et sillomnée; têtes roses, en panicule très làche. (Cr. vulgaris Cass.)

G. Crupina L.

\section{S. G. Cnicus Vaill.}

Plante à racine grêle, rameuse; feuilles à nervures blanches. Ghardon bénit. - ( Cn. benedictus.) G. benedicta L. S. G. Leuzea DC.

Plante basse, laineuse, à une seule tête rouge, munie d'écailles membraneuses et arrondies. - Gà et là. - (L. conifera DC.)

C. conifera L.

\section{G. Garthamus L. - Carthames.}

Etamines à filets glabres. - Plante glabre et blanchâtre; feuilles ovales et veinées; têtes jaune safran. - Cultivée sous le nom de Safran batard. C. tinctorius L.

- Etamines munies de poils vers leur milieu. . . . . 1

1. Ecailles des têtes découpées, épineuses, coriaces.Plante à odeur de girofle, cotonneuse; feuilles épineuses, têtes jaunes, terminales. (Kentrophyllum lanatum DG.)

C. lanatus L.

- Ecailles des têtes vertes et molles. - Plante a tigre florale courte ou nulle, à une seule tète, grande, blene et odorante. - Les coteaux secs. - (Garduncellus mitissimus DC.)

C. mitissimus L. 


\section{G. LApPA Tourn. - Bardanes.}

Plante robuste, à tige sillonnée, rameuse et pubescente; feuilles cotonneuses en dessous; têtes globuleuses, rougeâtres. Bardane.

L. communis Coss. et Germ.

Varie : 10 à têtes petites, ayant les écailles glabres et colorées en violet (L.minor DC.); $2^{\circ}$ à têtes grosses, ayant les écailles glabres et vertes (L. major DC.); $3^{\circ}$ à têtes grosses et à écailles velues ( $L$. tomentosa Lam.)

\section{G. Gynara L. - Artichauts.}

Plante robuste, à feuilles blanchâtres et à écailles des têtes épineuses. - Naturalisée çà et là et cultivée sous le nom de Gardon ou de Chardonnetle. G. Gardunculus L.

Varie, par la culture, à écailles des têtes non épineuses (G. Scolymus L.); c'est l'Artichaut ordinaire.

\section{G. Garduus L. - Chardons.}

Aigrette du fruit à poils plumeux. . . . . . . . . 1

- Aiqrette du fruit à poils dentelés, non plumerix. . . 2

1. Filets des étamines soudés et papillewx. - Plante velue, rameuse, à têtes pourpres. - Descend la vallée de la Garonne jusqu'it Bordeaux. - (Galactites tomentosa Mœnch.) C. Galactites Chaub et Bor.

- Filets des étamines libres et velus. - S. G. Cirsium L.

2. Filets des étamines soudés et papilleux. - Plante robuste et élerée, à feuilles épineuses, tachées de blanc; tètes très grosses et rougeâtres. - Ghardon-Marie. - (Silybum marianum Gœrt. $\quad$ C. marianus L. Filets des étamines libres. . . . . . . . . . . 3

3. Réceptacle aivéolé et nu. - Plante élevée, à tiges ailées; têtes pourpres, globuleuses, entourées de poils en toile d'araignée. (Onopordon Acanthium L.) C. Acanthium L.

- Réceptacle muni de soies ou de paillettes. - S. G. Carduus L.

\section{S. G. Cirsium L.}

Têtes de fleurs rouges ou blanches. ........ 1 - Tètes de fleurs jaunâtres. - Plante élevée, à tige raide, feuillée jusqu'au sommet; têtes sessiles au sommet des rameaux. - Lieux humides. G. oleraceus Vill.

1. Fenilles plus ou moins décurrentes le long de la tige. 2

- Feuilles non décurventes. . . . . . . . . 3

2. Têtes grosses, solitaires, à épines acérées et piquantes. Lieux pierreux.

G. lanceolatus L. 
- Têtes assez petites, agglomérées et peu piquantes. - Les marais.

C. palustris L.

3. Têtes de fleurs très épineuses. - Plante robuste, très rameuse, à têtes globuleuses, comme entourées de toile d'araignée. - Lieux pierreux. G. eriophorus L.

- Têtes de fleurs peu ou point épineuses. . . . . . 4

4. Fleurs nombreuses, en grappe. - Plante glabre, à feuilles sans queue et épineuses; fleurs rouges. C. arvensis L.

- Têtes solitaires ou au nombre de 2-4. . . . . .. 5

5. Tige florale nulle ou très courte; dans ce dernier cas, feuillée dans toute sa longueur. - Plante à tête rougeâtre, solitaire. $\quad$ C. acaulis L.

- Tige florale plus ou moins élevée, mue en haut. - Plante cotonneuse, à tige simple et à fleur's rougeâtres. - Les marais.

C. anglicus Lam.

Varie à racines renflées et à feuilles profondément pennatifides (G. tuberosus Vill.)

\section{S. G. Carduus L.}

Têtes solitaires au sommet de pédicules nus. - Plante élevée, ailée et épineuse; têtes grosses, globuleuses et penchées. - Lieux habités.

C. nutans L.

- Tétes de fleurs agglomérées ou à pédicules épineux jusqu'au sommet............. 1

1. Ecailles des têles munios sur le dos de petites glandes dorées. - Plante à tètes cylindriques, agrégées en assez grand nombre et à épines droites. C. tenuiflorus Curt.

Varie a tètes ovales, par 2-4 (G. pycnocephalus Jacq.)

- Ecailles des têtes non glanduleuses. - Plante tris variable, à têtes sans pied, munies de feuilles florales très petites.

C. crispus L.

\section{G. Serratula L.}

Plante très variable, à feuilles vertes, finement dentées en scie; fleurs purpurines.

S. tinctoria L.

\section{G. Scolymus L. - Scolymes.}

Plante robuste, rameuse; feuilles coriaces, épincuses; têtes jaumes, sans pied et axillaires.

S. hispanicus $L$.

\section{G. LAPSANA L.}

Ecailles des têtes s'accroissant à la maturité. - Plante très variable; fruits arqués, étalés en étoile. - Tallée de la Garonne et Auch. 
Varie à fruits de l'intérieur des tètes pubescents ( $L$. Rhagadiolus L.)

- Ecailles ne s'accroissant pas à la maturité. . . . 1

1. Fruits it 5 angles, surmontés d'une petite couronne. Plante à tiges nombreuses, nues, creuses, épaissies et striées sous la tête, qui est jaune. - Lienx sablonneux. (Arnoseris pusilla Giert.) $\quad$ L. pusilla Vild. - Fruits non amincis au sommet, à vingt stries. - Plante rameuse, à fleurs jaunes. - Se trouve dans les lieux cultivés.

\section{G. Ciatananche L. - Catananches.}

Plante élevée, rameuse, velue; fenilles linéaires, à trois nervures; lleurs bleues, en têtes solitaires. C. cærulea L.

\section{G. Crchorium L. - Chicorées.}

Feuilles de la tige entières. - Plante à feuilles très velues sur la còte dorsale, à tètes axillaires ou terminales; fleurs grandes, bleues. - Chicorée sawvage. G. Intybus L.

- Feuilles de la lige sinuées, dentées; écailles largement ovales. - Plante cultivée, originaire de l'Inde. - Ghicorée des jardins.

c. Endivia L.

\section{G. Hypochoeris L. - Porcelles.}

Tige et têtes hérissées de poils. - Plante robuste, élevée, à une feuille embrassante, située à la base de la tige et à deux grandes tètes de fleurs jaunes. - Se trouve dans les bois et les landes.

H. maculata L.

- Tige et têtes à peu près glabres. - . . . . . . . 1

1. Feuilles vudes et hérissées. - Plante rameuse, à longue racine; fleurs jaunes, en assez grosses tètes. - Prairies sèches. $\quad H$. radicata $L$.

- Feuilles lisses et à peu près glabres. - Plante annuelle, variable, à fleurs jaunes, en petites tètes. - Les lieux arides.

H. glabra L.

\section{G. LEONTodon L.}

Fruits du pourtour couronnés par une membrane au lieu d'une aigretle. - Plante à racines tronquées et à fibres fasciculées; feuilles lancéolées, velues; tige florale à une seule tète de fleurs jaunes. - Lieux sablonneux. - (Thrincia hirta R.)

L. hirtus L.

- Tous les fruits couronnés par une aigrette. . i 1. Tige rameuse, à plusieurs têtes jamuis penchées. Lieux stériles. 
- Tige simple, à une seule tête penchée avant la floraison. - Plante variable, à feuilles d'un vert gai. - Les lieux incultes et les pelouses.

L. proteiformis Vill.

Varie à plante glabre (L. hastile L.) ou à plante velue (L. hispidum L.)

\section{G. Picris L.}

Aigrelle du fruit comme pédiculée. - Plante rameuse, hérissée de poils raides; têtes jaunes, en corymbe terminal. (Helminthia echioïdes Giert.)

P. echioides $L$.

- Fruit à aigrette sans pédicule. - Plante rameuse, relue, à têtes jaunes. - Lieux pierreux. P. hieracioides L.

\section{G. Scorzonera L. - Scorzonères.}

Fruit ¿̀ aigrette pédiculée. - Plante à feuilles découpées en lobes linéaires, très variable; tètes jaune pâle et termimales. - Terrains calcaires. - (Podospermum laciniatum DC.)

S. laciniata L.

- Fruit à aigrette sans pédicule. . . . . . . . 1

1. Fruits glabres. . . . . . . . . . . . 2

- Fruits trés velus. - Plante à souche épaisse, émettant plusieurs tigres arquées à la base ; feuilles très étroites, en gouttière, laineuses au bord. - Cérennes et Charenteinférieure.

S. hirsuta L.

2. Tige rameuse, feuillée et à têtes nombreuses. - Bois calcaires. $\quad$ S. hispanica L.

Varie à feuilles linéaires (S. glastifolia Wild.)

- Tige simple, presque nue, à 1-2 fleurs. - Plante variable, plus ou moins cotonneuse, ì racine écailleuse, non chevelue au sommet. - Lieux marécagreux. S. humilis L.

Varie: 10 à racine cherelue au sommet (S. austriaca Wild.); 20 à fleurs pourpres. - Cévemnes. - (S'. purpurea L.)

\section{G. TragopogoN L. - Salsifis.}

Fruits tuberculeux, surmontés d'un long bec creux.Plante velue, a fleurs d'un jaune soufré, portées sur un pérloncule renflé au sommet. - Vallée de la Garoune. (Urospermum Dalechampii Desf.) T. Dalechampii L. - Fruits rayés en long, à long bec grêle. . . . . 1

1. Fleurs rouges. - Plante robuste et rameuse, à feuilles linéaires ou lancíolées, glauques. - Les prairies. Cultivée comme Salsifis. T. porrifolius L. Varie à fleurs jaume citron ( $T$. major Jacq.) 
- Fleurs jaunes. - Plante à tige simple; feuilles lancéolées ou linéaires; écailles des têtes égalant ou dépassant les fleurs. - Prairies.

T. pratensis L.

Varie a écailles des têtes plus courtes que les fleurs (T. orientalis L.)

\section{G. Lactuca L. - Laitues.}

Fleurs bleues ou purpurines. - Plante dressée, rameuse au sommet, glabre et glauque; tètes en corymbe làche. Lieux pierreux.

L. perennis $\mathrm{L}$.

- Fleurs jaunes ou jaunâtres. . ........ 1

1. Feuilles non décurrentes sur la tige. . . . . . 2

- Feuilles décurrentes sur la tige. - Plante blanchâtre, à rameaux simples, distants; feuilles pennatifides et linéaires. - Agen.

L. viminea $L$.

Varie à rayons d'un beau jaune, à plante à rameaux nombreux, effilés et dirigés en tous sens. - Les Charentes et les Prrénées. - (L. Ghondrillaeflora Bor.)

2. Feuilles linéaires. - Plante blanchàtre et effilée; têtes petites, en grappe ou en épi effilé. - Les lieux pierreux.

L. saligna $L$.

Feuilles élargies. . . . . . . . . . . . . 3

3. Feuilles glabres, à lobe terminal très grand, en cour et à cinq angles. - Plante à tige simple; tètes petites, à pédicule filiforme et en panicule terminale. - Les lieux ombragés.

L. muralis L.

- Feuilles velues, ou dentées sur la côte médiane, ou sans le lobe terminal ci-dessus. . . . . . . . . . . . 4

4. Fruit noir et glabre. - Plante élevée, hérissée d'aiguillons, surtout sur la nervure des feuilles; têtes petites, en grappe étalée. - Laitue vireuse. $\quad$ L. virosa L. Fruit de couleur claire et velu au sommet. . . 5

5. Feuilles glauques, fermes, hérissées au bord de poils, ainsi que la tige; têtes en panicule pyramidale. Cultivée et sauvage.

L. scariola L.

- Feuilles molles, glabres, ainsi que la tige; iêtes en corymbè. - Cultivée.

L. sativa.L.

G. Chondrilla L.

Fruit à bec entouré de cinq dents; plante hérissée de poils raides, rameuse, jonciforme; têtes jaunes, terminales ou sans queue le long des rameaux.

G. juncea L.

G. Taraxacum Juss. - Pissenlits.

Plante très variable; feuilles toutes radicales, à larges dents; tige florale à une seule tête jaune. T. officinale Wiğg. 
Varie surtout: 10 à écailles étalées dans les lieux secs (T. lovigatum DC); 20 à écailles dressées dans les lieux humides ( $T$. palustre DC.)

\section{G. Sonchus L. - Laiterons.}

Racines annuelles, grêles et fibreuses. - Plante ramense, d tige creuse; feuilles embrassantes par deux oreillettes, aiguës; fruits rugueux en trarers. - Dans les lieux habités.

S. oleraceus L.

Varie : 10 à fenilles très découpées (S: lucerus Wild.); 20 a feuilles embrassantes par deux oreillettes arrondies, piquantes (S. asper Vill.)

- Racines rivaces, épaisses et rampantes. . . . . 1

1. Têtes peu nombreuses, à écailles glabres. - Plante ḋ feuilles étroites, entières et sinuées. - Lieux humides de

la côte.

S. maritimus L.

2. Feuilles de la Plante élevée, à tige creuse. - Se trouve dans les champs humides.

S. arvensis L.

- Feuilles de la tige en fer de flèche, à oreillettes longues et aiguës.

S. palustris L.

\section{G. Crepis L.}

Réceptacle à paillettes capillaires. - Plante hérissée, à plusieurs tiges dressées, portant 1-5 têtes; feuilles toutes radicales. - Plante du Midi introduite dans le S.-O. par les cultures. - (Pterotheca nemausensis Cass.; Hieracium sanctum L.)

G. nuda Lam.

- Réceptacle nu. • . . - • .

1. Fruits à aigrette pédiculée. - S. G. Barlihausia Mœnch.

- Fruits à aigrette sans pédicule. - S. G. Crepis DC.

\section{S. G. Barkihausia M.}

Ecailles des têtes hérissées de longues soies jaunâtres. Plinte diun rert gai, souvent rougeitre a la base; strles livides au sommet.

C. setosa Hall.

- Ecailles à poils courts. . . . . . . . . . 1

1. Têtes touiours dressées. - Plante clevée, rougreâtre, relue, à ticre sillonnée; feuilles à larges dents. - Lienx cultirés et prairies. G. taraxacifolia Thuil.

- Têtes penchées avant la floraison. . . . . . . 2

2. Tige assez élevée; aigrelte du fruit scillante à la maturilé. - Plante velue el grisitre, à ollem tlanandes anères; flen's rongeitres en úchors. C. foetida I. 
Tige très basse; aigrette du fruit non saillante. - Plante d'un vert sombre, hérissée dans le bas, presque glabre au sommet. - Région maritime. C. Sư⿱宀㠯eniana Lloyd.

S. G. Crepis DC.

Ecailles des têtes tout à fait glabres. - Plante élevée, à tige raide et sillonnée; tètes en corymbe ou en panicule nue. - Les lieux pierreux. G. pulchra L.

- Ecailles velues ou hérissées. . . . . . . . 1

1. Tige florale nue. . . . . . . . . . . . 2

Tige florale feuillée. . . . . . . . . . . . 3

2. Plante à longues racines terminées par un tubercule. Feuilles glabres et lisses, un peu charnues; tiges a une seule tète. - Sables maritimes. $\quad$ c. bulbosa Cass.

- Plante à racines grêles. - Tige un peu rameuse, effilée; tètes jaune clair, brunes ou non au milieu; fruits presque quadrangulaires. (Tolpis barbata Willd.) G. barbata L.

3. Fruits à stries rudes et tuberculeuses. - Plante rameuse, à tige sillonnée; tètes en corymbe. G. tectorum L.

- Fruits à stries lisses. . . . . . . . . . . . 4

4. Eccilles des têtes velues en dedans. - Plante à tige dressée et anguleuse; tètes jaunes et en corymbe. - Les prairies.

C. biennis $L$.

- Ecailles des têles glabres en dedans. . . . . . . . 5

5. Têtes arrondies, à écailles étalées. - Plante à tige sillonnée, hérissée; tètes en corymbe; styles livides au somrnet.

C. nicæensis Balb.

- Têtes ovoïdes, à écailles appliquées. - Plante variable, à

fleur's en corymbe; styles jaunes au sommet. - Prairies de l'intérieur et sables maritimes. $\quad$ G. virens Vill.

Varie: 10 à plante rude et hérissée ( $G$. agrestis Bor.); $2^{\circ}$ à plante diffuse et couchée $(C$. diffusa DG.)

\section{G. Hieracium L. - Epervières.}

Tige nue, à stolons; fruit crénelé au sommet, aigrette d̀

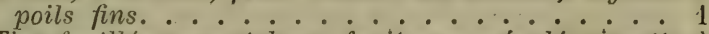

- Tige feuillée, sans stolons; fruit non crénelé, aigrelte à poils raides et inégaux. . . . . . . . . 3

1. Tétes en corymbe, nombreuses et serrées. - Plante élancée; tige à 2-3 ieuilles, qui sont lancéolées, munies de poils noirs à la base; stỹle jaune au sommet. - La Rochelle.

II. pratense Tausch.

- Une à cinq têtes au plus. . . . . . . . . . . 2

2. Feuilles blanches en dessous; toujours une seule tête. llante à fenilles lancéolées et à écuilles des tètes couvertes de poils noiràtres; fleurs jaune citron, rougeàtres en dessous. - Lieux secs.

H. Pilosella L. 
Varie à tètes hérissées de longs poils blancs ( $H$. pelleterianum Lois.)

3. Tige florale naissant au milieu d'une rosette de feuilles............... 6

- Tige florale sans rosette à la base. . . . . . . 4

4. Styles bruns. ............. 5

- Styles jaunes. - Plante élevée, raide; feuilles lancéolées ou linéaires, parfois contournées; tètes en ombelle, it écailles recourbées.

H. umbellatum L.

Varie, dans les dunes, a plante blanche et laineuse (H. eriophorum $\mathrm{S}^{\mathrm{t}} \mathrm{Am}$.)

5. Ecailles des têtes aiguës. - Plante à tige élevẻe, raide, très feuillée; feuilles lancéolées, à plusieurs grosses dents. - Les prairies.

H. tridentatum Fr.

- Ecailles des têles obluses. - Plante à tige raide, très feuillée; feuilles ovales, sans queue, les supérieures embrassantes. (II. boreale Fr.) H. sabaudum L.

6. Tige élevée et feuillée; feuilles des rosettes souvent flétries à la floraison. - Plante très variable. - Les bois et vieux murs.

H. sylvaticum Sm.

- Tige nue ou d̀ $1-2$ fenilles; rosette persistante a la floraison. - Plante également très rariable. - Les bois et les vieux murs.

H. murorum L.

\section{G. Andryala L.}

Plante velue, d'un blanc jaunâtre; tige simple; feuilles sans queue, lancéolées, sinuées ou entières; tètes en corrmbe terminal; fleurs jaune citron. A. integrifolia L.

\section{G. Xaxthium Tourn.}

Tige épineuse. - Plante à feuilles blanches en dessous. Introduite sur nos còtes du S.-O. X. spinosum L.

- Tige non épineuse. ............. 1

1. Fruits à deux pointes courbées en dedans. - Plante rude; feuilles en coin à la base. - La còte, et cii et lit dans lintérienr.

X. macrocarpum DC.

- Fruits à deux pointes droites. - Plante velue, a feuilles en cœur à la base. - La còte. X. strumarium L.

\section{Fam. des GUGURBITAGÉES Juss.}

\section{G. Bryonia L. - Bryones.}

Plante it fleurs d'um seul sexe, à tris grosse racine charnue; tige grimpante; fruit rouge - Les haies. B. dioïca L. 


\section{G. Ecballium Rich.}

Plante hérissée de poils durs, couchée; tleurs jaune pàle; fruit allongí. - Bords de la mer.

E. Elaterium Rich.

\section{G. Gucumis L.}

Feuilles à angles aigus. - Plante couchée, à fruits tuberculeux. - Cultivée. - Concombres. C. sativus L. - Feuilles à angles obtus. - Plante conchée, à ovaire velu. - Cultivée. - Melons.

\section{Fam. des CAMPPANULAGÉES R.B.}

\section{G. JASIONE L.}

Plante velue, ramense et diffuse; feuilles linéaires; fleurs bleues, en tête longuement pédiculée. J. montana L.

Varie: $1^{\circ}$ an bord de la.mer, à plante grisàtre et couchée (J. maritima Lloyd.); $2^{\circ}$ à écailles des tètes dentées en scie et à plante stolonifëre - Aurergne, Pyrénées (J. perennis Lam.)

\section{G. Phyteuma L.}

Fleurs en tête courte et arrondie. - Plante à feuilles ovales ou lancéolées, dentées.

P. orbiculare L.

- Fleurs en épi d'abord ovale, puis allongé et cyllindrique. - Plante à lleurs jaunâtres ou bleues. P. spicatum L.

\section{G. Gampanula L.}

Etamines dilatées ì la base. - S. G. Campanula L.

Etamines non dilatées à la base. - S. G. Specularia Heist.

$$
\text { S. G. Campanula L. }
$$

Fruils s'ourrant en trois values. - Plante délicate, grêle et couchée; tige filiforme; fleurs bleu pàle. - (Wahlenbergia hederacea Richb.) $\quad$ G. hederacea L.

- Fruits s'ouvrant par des trous latéraux. . . . . 1

1. Fleurs sans queue et en tête. - Plante à feuilles infśrieures ovales, arrondies on en cœur it la base; tige simple et anguleuse.

C. glomerata L.

- Flevers munies d'une queue, solitaires, ou en grappe. 2

2. Fruits penchés, s'ouviant à la base. . . . . . . 5 
- Fruts diessés, s'ouvrant au milieu ou au sommel. . 3

3. Corolle à divisions arrondies et courtes. - Plante i tige élancée et à feuilles longuement atténuées en queue, glabres. $\quad$ C. persicifolia L. Corolle à divisions aiguës et longues. . . . . \&

4. Queue des fleurs latérales munie de deux petites feuilles vers le milieu. - Panicule étalée, it raneaux làches et divergents.

C. patula L.

- Queue des fleurs latérales munie de deux petites feuilles d̀ la base. - Panicule serrée, à rameaux courts. - Les prairies.

C. Rapunculus L.

5. Fleurs nombreuses; divisions du calice ovales, lancéolées. . . . . . . . . . . 6

- Fleurs peu nombreuses; divisions du calice linéaires. - Plante très rariable; feuilles inférieures en cour à la base, en forme de rein ou ovales; fleurs étalées. - Les lieux secs.

G. rotundifolia $\mathrm{L}$.

Varie: $1^{0}$ à fleurs penchées du mème còté et à feuilles inférieures toujours ovales (C. rhomboüdalis L.); 20 a feuilles de la tige linéaires et aiguës ( $C$. linifolia Lam.)

6. Fleurs en grappe unilatérale, non feuillée. - Plante élevée, a lleur's bleues; corolle en entonnoir, a lobes triangulaires.

C. rapunculoïdes L.

- Fleurs par deux ou par trois sur des pédicules courts. - Plante velue, a tige anguleuse et a feuilles en cœur; fleurs bleues.

C. Trachelium L.

- Fleurs solitaires aux bifurcations de la tige ou au sommet des rameaux. - Petite plante à feuilles en coin, velues, et it corolle petite, bleu pâle, dépassant à peine les sépales.

C. Erinus L.

$$
\text { S. G. Specularia Heist. - Spéculaires. }
$$

Corolle muverle; divisions du calice longues el linéaires. - Plante rameuse; feuilles allongées; fleurs en panicule. (S. Speculum DC.)

C. Speculum L.

- Corolle fermée; divisions du calice courtes et lancéolées. - Plante rameuse dès la base; fleurs violettes, à gorge verdatre. (S. hybrida DC.)

c. hybridra L.

\section{G. Lobelia L. - Lobélies.}

Fleurs bleues. - Plante brùlante au goût; tige simple, anguleuse, feuillée.

L. urens L.

- Fleur's blanchatres. - Plante à tige nue; feuilles linéaires, nombreuses, en rosette radicale. - Bords des lacs de la côte.

L. Dortmanna L.

- Fleurs écarlates. - Plante pubescente, at tige simple; fenilles lancéolées. - Cultivée.

L. cardinalis L. 


\title{
Fam. des ERICACÉES Juss.
}

\author{
G. Arbutus L.
}

Arbrisseau élevé; feuilles lancéolées, coriaces, dentées en scie; fleurs verdatres ou rosées, en panicule penchée; fruits tuberculeux, rouge vif à la maturité. - Se trouve sur la còte. - Arbousier.

A. Unedo L.

\section{G. Vaccinium L. - Myrtilles.}

Corolle en roue, à quatre divisions très profondes. - Plante très rameuse, à tige filiforme, couchée et enracinée; tleurs roses et fruits rouges. - Auvergne. V. Oxycoccos $\mathrm{L}$.

- Corolle en clochette. - Plante dressée, lignense, à fleurs blanches on rosées et a fruits rouges. - Se trouve en Auvergne.

V. Vitis idæa L.

- Corolle ovoïde ou globuleuse. . . . . . . . . 1

1. Feuilles denticulees; calice entier. - Plante ligneuse, buissonnante, à rameaux anguleux et ailés; fleurs blanc verdàtre et rosées; fruits noirs. - En Auvergne et dans les Pyrénées.

V. Myrtillus L.

- Feuilles entières; calice à quatre divisions. - Plante ligneuse, buissomnante, à rameaux arrondis; fleurs blanches ou rougeâtres; fruits noirs. - Auvergne, Pyrénées.

V. uliginosum $\mathrm{L}$.

\section{G. Erica L. - Bruyères.}

Calice coloré, dépassant la corolle et doublé d'un calicule. - Sous-arbrisseau à feuilles imbriquées sur quatre rangs ; fleurs roses, luisantes. - Les lieux sablomeux. - (Calluna vulgaris Sal.)

E. vulgaris $L$.

- Calice petit et verdatre. . . . . . . . . 1

1. Corolle $\dot{a}$ quatre dents rabaitues. - Plante ligneuse, à rameaux velus; feuilles ovales, alternes, roulées en dessous par les boids, vertes en dessus, blanches en dessous; tleurs violettes. - Pyrénées occidentales et ça et lit dans le S.-O._- (Dabocia polifolia Don.) E. Dabœecii L.

- Corolle à dents ou a lobes droits. . . . . . . . 2

2. Etamines saillantes hor's de la corolle ou à peu près. 3

- Etamines renfermées dans la corolle. . . . . . 4

3. Calice à divisions lancéolées. - Tige rameuse et dressée; feuilles par 4; fleurs roses. - Les environs de Pauillac (Gironde), - (E. mediterrenea L.) E. carnea L. 
- Calice à divisions arrondies. - Tiges rameuses et touffues; feuilles verticillées par 4-5; fleurs rosées, en épi feuillé, à queue munie de trois petites feuilles; anthères noirâtres. - Le S.-O.

E. vagans $L$.

4. Fleurs d'un jaune verdâtre. - Arbrisseau élevé, à rameaux dressés; feuilles verticillées par 3-4. - Bruyère $\dot{a}$ balais.

- Fleurs purpurines ou blanches. . . . . . . . 5

5. Feuilles glabres. . . . . . . . . . . . 6

- Feuilles ciliées . . . . . . . . . . . 7

6. Calice à divisions ovales. - Arbrisseau rameux, grisâtre; feuilles verticillées par 3-4; fleurs blanches ou légèrement rosées; anthères it appendices filiformes et hérissés. - La còte, d'Arcachon a Mimizan. - (E. polytrichifolia Sal.; E. lusitanica Rud.)

E. arborea $\mathrm{L}$.

- Calice ù divisions lancéolées. - Plante cendrée; feuilles par trois; fleurs rouge violacé, en verticilles; anthères it appendices en forme de soies.

E. cinerea $L$.

7. Fleurs en tête ou en ombelle. - Plante grisitre; feuilles par quatre; fleurs rose tendre, à style très peu saillant. - Lieux humides des landes.

E. Tetralix L.

- Fleurs en grappe allongée, unilatérale. - Plante it feuilles par trois, orales, roulées en dessous par les bords; fleurs rouges, à corolle allongée, renflée au milieu; style saillant.

E. ciliaris L.

\section{G. Monotropi L.}

Plante parasite, jaunâtre, à petite tige simple, succulente et écailleuse; fleurs jaunâtres. - Bois. Mr. Hypopitys L.

\section{Fam. des PRIMULACÉES Vent.}

\section{G. Primula L. - Primevères.}

Plante variable, à feuilles rétrécies en queue à la base; fleurs jaunes.

$P$. veris $L$.

Varie : $1^{0}$ à fleurs partant de la base, jaune pâle $(P$. acaulis Jacq.); 20 a fleurs en ombelle, sur un long pied ( $P$. officinalis Jacq.); $3^{\circ}$ a fruits dépassant le calice persistant (P. elatior Jacq.)

\section{G. Hottonia L.}

Plante aquatique; feuilles rerticillées, en dents de peigne; fleurs blanches, à gorge orangée. 


\section{G. Cyclanen Tourn.}

Plante à fleurs odorantes, penchées et solitaires au bout d'un long pédicule, roses, à gorge purpurine; divisions de la corolle longues, d'abord contournées en spirale, puis rabattues. - Cultivée et naturalisée. G. europæum L.

Varie à feuilles anguleuses, et à gorge de la corolle à dix dents. - Çà et lit. $\quad$ G. neapolitanum Ten.

\section{G. GLAUX L.}

Plante couchée, à tige enracinée; petites feuilles sans queue et opposées; fleurs axillaires, solitaires, d'un blanc rosé. Bords de la mer. $\quad$ G. maritima L.

\section{G. SAMOLUS L.}

Plante glabre; feuilles entières, d'un vert foncé; fleurs blanches. $\quad$ S. Valerandi $L$.

\section{G. Lysimachia L.}

Corolle plus courte que le calice. - Très petite plante à feuilles lancéolées; fleurs blanches, axillaires et solitaires. - Sables maritimes. L. Linum stellatum $L$.

1. Plante élevée et droite, à fleurs jaunes, en grappe ramifié; feuilles ovales, par 2-3-4. - Sur le bord des eaux.

- Plante couchée; fleurs toutes axillaires. . . . . 2

2. Feuilles arrondies; calice à divisions ovales et en cœur. - Plante à fleurs jaunes, qui ne donne des fruits que très rarement.

L. Nummularia $L$.

- Feuilles ovales, aiguës; calice à divisions linéaires. Plante à fleurs jaunes.

L. nemorum L.

\section{G. Anagallis L.}

Feuilles alternes. - Plante glabre et luisante, à tige couchée et enracinée; feuilles épaisses; fleurs blanches. - Se trouve à Dax. $\quad$ A. crassifolia Thore.

- Feuilles opposées ou par trois. . . . . . . . . 1

1. Plante ligneuse à la base; fleurs grandes, rouges ou bleues. - Cultiyée. A. collina Sch.

- Plante herbacée. . . . . . . . . . . . 2

2. Plante couchée; corolle en entonnoir. - Petite plante à fleurs rose tendre. - Narais A. tenella L. 
- Petite plante diffuse, à tige anguleuse; feuilles ovales, sans queue; fleurs rouges, roses ou bleues, axillaires. - Lieux cultivés.

A. arvensis $\mathrm{L}$.

\section{G. Centunculus L.}

Très petite plante à feuilles ovales, alternes, presque sans queue; petites fleurs blanchitres, axillaires et solitaires.

G. minimus L.

\section{G. Utricularia L.}

Corolle à éperon long et conique. - Plante aquatique, à fenilles capillaires, portant des vésicules; fleurs jaunes, bilabiées.

U. vulgaris $\mathrm{L}$.

Varie: $1^{0}$ a plante plus grêle et à lèvre inférieure de la corolle plane (U. neglecla Lelım.); $2^{\circ}$ à vésicules naissint sur des racines rameuses et non sur les feuilles ( $U$. intermedia Hayn.)

- Corolle jaune pale, á éperon tiès court. - Plante analogue à la précédente.

\section{G. Pinguicula L.}

Flenrs blenes ou violettes, it quene glabre. - Plante variable, it feuilles vert jaunitre, en rosette, courertes de poils papilleux. $\quad$ P. vulgaris L.

- Fleurs d'un blanc rosé, à queue velue. - Plante à tube de la corolle roussâtre et rayé de pourpre. - Lienx maréca geux des landes.

P. lusitanica L.

\section{Fam. des JASMINÉES JusS.}

\section{G. Olea L. - Oliviers.}

Arbre ou arbrisseau grisattre; feuilles lancéolées, coriaces; fleur's blanches, en grappe axillaire. - Cultivé çà et. lá dans le S.-O.; murrit ses fruits à Saint-Jean-de-Luz et au pied des coteaux de Bourg-sur-Gironde. O. europæa L.

\section{G. Phillyrea L.}

Feuilles linéaires, lancéolées, très entières. - Dans tout le S.-O.

P. angustifolia $\mathrm{L}$.

- Feuilles ovales, dentées. - Dans la Charente-Inférieure et cia et li.

P. media L. 


\section{G. Ligustrum L. - Troënes.}

Feuilles lancéolées; fleurs blanches et en grappe terminale; fruits noirs,

L. vulgare L.

- Feuilles ovales, aignës; fleurs en panicule étalée. - Cultivé.

L. japonicum Thumb.

\section{G. Syringa L. - Lilas.}

Feuilles ovales en cœur; fleurs lilas, violettes, pourpres ou blanches, groupées en panicule. - Lilas. - Natur. à

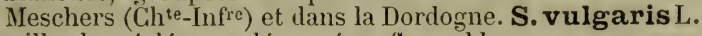
- Feuilles lancéolées ou découpées; fleurs bleues, pourpres ou blanches. - Cult. - Lilas de Perse. S. persica L.

\section{G. Fraxinus L. - Frênes.}

Arbre variable, à bourgeons noirs ou bruns; fleurs dépourvues de pétales.

F. excelsior $L$.

- Arbre à bourgeons velus et soyeux. - Cultivé sous le nom de Frêne fleuri.

F. Ornus L.

\section{G. Jasminun L. - Jasmins.}

Fleurs blanches. - Arbrisseau grimpant, à feuilles pennées. - Echappé çà et lả et cultivè. $\quad J$. officinale L.

- Fleurs jaunes. . . . . . . . . . . . 1

1. Dents du calice en alène. - Arbuste buissonnant, à rameaux anguleux; feuilles simples ou à trois folioles. Vallée de la Garonne jusqu'à Bordeaux; échappé des jardins, dans les Charentes.

J. fruticans L.

- Dents du calice petites ou nulles. - Arbrisseau à feuilles alternes, à 3-5 folioles ovales; fleurs jaunes, inodores. Cultivé.

J. humile L.

\section{Fam. des APOCYNÉES Juss.}

\section{G. VincA L. - Pervenches.}

Feuilles glabres, rétrécies aux deux bouts. - Fleurs solitaires, à lobes du calice courts et glabres. - Vient dans les bois.

V. minor L.

- Feuilles ciliées, larges, en cour à la base. - Fleurs à lobes du ealice longs et ciliés. - Naturalisée et cultivée.

V. major L. 


\section{G. Nerium L.}

Arbrisseau à feuilles coriaces, opposées ou par trois; fleurs roses ou blanches, en corymbes terminaux. - Cultivé. Laurier-rose. N. Oleander $\mathrm{L}$.

\section{G. Asclepias L.}

Fleurs rosées, odorantes, penchées. - Plante relue. - Cultivée et naturalisée çà et là.

A. Cornuti Derie.

- Fleurs rouge pourpre, à odeur de vanille. - Plante dressée, velue sur deux lignes, à feuilles lancéolées, opposées ou par trois. - Cultivee. A. incarnata L.

\section{G. Cynanchum L.}

Plante grimpante; feuilles en cœur, aiguës; fleurs blanches, en petite ombelle. - La côte du S.-O., où cette plante ne fructifie pas. $\quad$ C. acutum L.

- Plante pubescente, à feuilles ovales, lancéolées, en cœur á la base et allongées au sommet. G. Vincetoxicum R.B. Varie à fleurs d'un pourpre noir.

\section{Fam. des GENTIANÉES Juss.}

\section{G. Gentiana L. - Gentianes.}

Fleurs bleues. - S. G. Gentiana Tourn.

Fleurs jaunes, à 8 divisions. - S. G. Chlora L.

Fleurs rouges ou jaunes, à 5 divisions. - S. G. Erythrcea Ren. Fleurs blanc jaunâtre, it 4 divisions. - S. G. Cicendia Ad.

\section{S. G. Gentiana Tourn.}

Plante à tige grêle, simple et dressée; feuilles linéaires; fleurs grandes, bleues et terminales. G. Pneumonanthe L.

\section{S. G. Ghlora L.}

Plante glianque, à tige raide, dressée, et à feuilles soudées par lat base; calice divisé jusqu'à la base. - Cà et là. - ( $C$. perfoliata L.) G. perfoliata L.

Varie, au bord de la mer, à calice divisé jusqu'aux trois quarts (C. imperfoliata L. fils.)

S. G. Erythroea Ren.

Fleurs jaunes. - Très petite plante raide, à tige à quatre angles, simple ou fourchue. - Bords de la mer. $-(E$. maritima Pers.)

G. maritima L. 
- Fleurs rouges ou blanches. . . . . . . . . 1

1. Fleurs en épis läches le long des rameaux. - Tige à quatre angles; feuilles elliptiques. - Région maritime. (E. spicata Pers.)

G. spicata L.

- Fleurs en corymbe resserré, munies de feuilles ḋ la base; feuilles ovales. - Petite Centaurée. - (E. Centaurium Pers.)

G. Centaurium L.

- Fleurs axillaires ou terminales. - Très petite plante, rameuse dès la base, étalée, à tige dressée. - La còte. (E. chloodes God.) G. chloodes Brot. Varie à tige droite (E. littoralis Fr.)

S. G. Cicendia Adanson.

Très petite plante à tige simple; fleurs jaunes. ( $C$. filiformis Del.)

G. filiformis $\mathrm{L}$.

- Très petite plante à rameaux nombreux, dirigés en tous sens; fleurs lilas ou blanchitres. - Les landes humides. (C. pusilla Gris.)

G. pusilla Lam.

\section{G. Menyanthes L. - Ményanthes.}

Fleurs blanches ou rosées, à lobes de la corolle frangés. Plante à rhizome rampant; feuilles à trois folioles; fleurs en épi. - Trèfle d'eau.

M. trifoliata L.

- Fleurs jaunes, barbues ou écailleuses à la gorge. -

Plante aquatique; feuilles arrondies en cour, flottantes;

fleurs en ombelle. (Limnanthemum nymphoïdes Link.; Villarsia nymphoïdes Vent.) M. nymphoïdes L.

\section{Fam. des CONVOLVULAGÉES DG.}

\section{G. Convolvulus L.}

Calice entouré de deux larges feuilles. . . . . . . 1

- Calice non entouré de feuilles. . . . ...... 2

1. Plante élevée, enroulée, à feuilles en fer de flèche et aiguës; fleurs blanches.

G. sepium L.

- Plante couchée, à feuilles en forme de rein ou arrondies; fleurs roses. - Sables maritimes. G. Soldanella L.

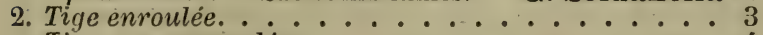

- Tige non enroulée. . . . . . . . 4

3. Fleurs blanches ou rosées. - Tige faible; feuilles en fer de flèche. - Vrillée.

G. arvensis $\mathrm{L}$.

- Fleurs pourpres. - Grande plante volubile, velue, a feuilles en cœur. - Cultivée sous le nom de Volubilis. C. purpureus L. 
4. Fleurs bleues. - Plante étalée, velue, à feuilles ovales. - Indiquée par Thore à La Teste de Buch. G. siculus L. - Fleurs blanches ou rosées. . . . . . . . 5

5. Feuilles aiguës et poilues. - Plante blanchàtre; fleurs roses, sur des queues axillaires plus longues que les feuilles.

G. Gantabrica L.

- Feuilles obtuses et soyeuses. - Plante soyeuse, ascendante; fleurs roses ou blanches, sur des queues axillaires plus courtes que les feuilles.

c. lineatus L.

\section{G. Guscuta L. - Cuscutes.}

Queue de la fleur plus longue que le calice; styles gobuleux au sommet.

G. suaveolens Ser.

- Queue nulle ou plus courte que le calice; styles aigus ou en massue au sommet. . . . . . . . . . . 1

1. Corolle globuleuse, blanc jaunâtre; fleurs en tête serrée, dépourvues d'écailles. $\quad$ G. epilinum Weih.

- Corolle cylindrique. . . . . . . . . . 2

2. Corolle fermée par des écailles; styles rapprochés. Tige grêle et rougeâtre.

G. minor $\mathrm{L}$. Varie: to it calice aussi long que la corolle (C. Trifolii Bab.); 20 à corolle divisée jusqu'à la moitié ( $G$. Kotskyi Desm.)

- Corolle non fermée par des écailles; styles divergents dès la base.

C. major DC.

\section{Fam. des BORRAGINÉES Juss.}

\section{G. Heliotropium L. - Héliotropes.}

Fleur's blanches. - Plante velue et diffuse; feuilles ovales et entières. - Lieux cultivés.

H. europæum L.

- Fleurs bleu clair, à odleur de vanille. - Plante hérissée; feuilles blanchitres, marquées de lignes. - Cultivée dans les parteries.

H. peruvianum L.

\section{G. Echium L. - Vipérines.}

Feuilles munies en dessous de nervures latérales saillantes. - Plante à plusieurs tiges ascendantes; fleurs formant par leur ensemble une panicule làche. - Cà et lit dans le S.-O.

E. plantagineum $L$.

- Fevilles à nervure dorsale seule apparente. . . . I

1. Fleur's bleues, en lonque grappe linéaire. - Plante rariahle, hérissée. - Vipérine.

E. vulgare I. 
- Fleurs rosées, en grande panicule pyramidals. - Plante hérissée, rameuse, buissonnante et à tige ponctuée de rouge.

E. italicum L.

\section{G. ONosma L. - Orcanettes.}

Plante velue; tige simple; feuilles lancéolées; fleurs jaunâtres, en panicule. - Orcanette jaune. O. echioïdes L.

\section{G. Pulmonaria L. - Pulmonaires.}

Feuilles radicales, en cour à la base; fleurs rouges, puis violettes. - A chercher.

P. officinalis $\mathrm{L}$.

- Feuilles insensiblement atténuées en queue. - Plante velue, à fleurs d'un beau bleu. P. angustifolia $L$.

Varie: $1^{\circ}$ a feuilles ovales ( $P$. ovalis Bast.); $2 \circ$ à feuilles lancéolées ( $P$. tuberosa Schr.); $3^{\circ}$ à tube de la corolle velu (P. azurea Bess.)

\section{G. Lithospermum L. - Grémils.}

Tige presque ligneuse. - Plante couchée; feuilles linéaires, roulées par les bords; fleurs blenes, peu nombreuses; corolle trois fois plus longue que le calice, à gorge fermée par des poils. - Se troure autour de Bayonne et dans l'île d'Oléron.

L. prostratum Lois.

- Tige herbacée. . . . . . . . . . . 1

1. Fleurs bleues, beaucoup plus grandes que le calice. Plante à tiges florales dressées et à tiges stériles couchées; feuilles lancéolées. $\quad$ L. purpureo cœruleum L.

- Fleurs blanches, jaunes ou jaunatres, à peine plus grandes que le calice. . . . . . . . . . . . 2

2. Trés petite plante à fleurs jaunes. - Dans la CharenteInférieure.

L. apulum Vahl.

- Fleurs blanches. - Plante simple ou peu rameuse; feuilles non veinées; fruits ridés et tuberculeux. L. arvense L.

- Fleurs blanc jaunâtre. - Plante très rameuse; feuilles veinées en dessous; fruit lisse, blanc, très dur. - Haies et bords des chemins.

L. officinale $L$.

\section{G. Mrosotis L. - Myosotis.}

Calice du fruit à poils tous couchés. - Plante variable, un peu rampante à la base; corolle grande, bleu de ciel, a gorge jaune.

M. palustris $L$.

- Calice du fruit hérissé de poils crochus. ..... 1

1. Corolle plane.

M. sylvatica Hoff.

Varie à ealice nuvert à la maturité (M. alpestris Sch.) 
- Corolle concave ou en entonnoir. . . . . . . . 2

2. Qu:ue des fleurs beancoup plus longue que le calice. Lieux cultivés.

M. intermedia Link.

- Cueue des fleurs plus courte que le calice ou l'égalant à

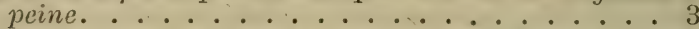

3. Corolle jaune, ai moins dans quelques fleurs. - Lienx cultivés.

M. versicolor Pers.

- Point de corolle tout ì fait jaune. . . . . . . 4

1. Calice fructifère ourert.

- Calice firuclifère fermé.

M. hispida Schl. M. stricta Link.

\section{G. Bornago L. - Bourraches.}

Plante hérissée, rameuse; flenrs bleu de ciel. B. officinalis L.

\section{G. Srmphytum L. - Consoudes.}

Tige rameuse; feuilles supérieures lies décurrentes; fleurs blanches on rougecilres, en grampe terminale. - Les lieux humides.

S. officinale $\mathrm{L}$.

- Tige simple: feuilles à peine décurrentes. - Plante it racine chinlune; fleurs jamitres.

S. tuberosum L.

\section{G. Axchusa L. - Buglosses.}

Tube de la corolls courbe. - l'linte ramense, hérissée de froils blanes; fleurs blen chair, it gorge blanche. (Lycopsis (irensisis L.)

A. arvensis Rib.

- Tube de la corolle droit. . . . . . . . . i

1. Fruits munis d'un appendice a leur base. - Plante élevéc, rameuse an sommet, à tige épaisse; fleurs blenes. $\quad$ A. sempervirens L.

- Fruits sans appendice à la base. . . . . . . 2

2. Jicailles de la corolle sumomtées de poils en pinceau. -

Plante riniense, élerie; fenilles lancéolées. - Les lieux habités.

A. italica Retz.

- Ecailles de la corolle velontées. - Plante élevée, rameuse; fenilles linciaires. A. officinalis $L$.

\section{G. Asperugo L.}

Plante enurlie; ferilles lancéolées, alternes, les florales opposées; lleurs bleues.

A. procumbens L.

G. Grxoglossum L. - Cynoglosses.

Corolle tris petite, en somoupe; strle tris cout. - S. G. Echinospermum Sw. 
Corolle grande, en entonnoir; style allongé et persistant. . 1

1. Fruits aplatis ou convexes. - S. G. Cynoglossum L.

- Fruits déprimés en corbeille. - S. G. Omphalodes T.

$$
\text { S. G. Echinospermum Siv. }
$$

Plante couverte de poils blancs; feuilles linéaires; fleurs bleu clair. (E. Lappula Lehm.) G. Lappula Scop.

$$
\text { S. G. Cynoglossum L. }
$$

Fleur d'un rouge vineux. - Plante rameuse, à feuilles lancéolées; fruits hérissés de pointes courtes. - Les lieux habités. - Cynoglosse.

C. officinale L.

- Fleur bleu päle, reinée. - Plante rameuse, it feuilles linéaires; fruits hérissés de pointes et de tubercules coniques.

\section{S. G. Omplatodes T.}

G. pictum Ait.

- Fleurs bleues; feuilles ovales. - Petite plante, a tiges grèles. - Cultivée dans les parterres. - (Omphalodes virna Mœnch.)

- Fleurs blanches; feuilles étroites.

G. Omphalodes L.

1. Fleurs naissant ì l'aisselle de petites ferilles. - Petite plante glauque. - Sables maritim. C. littorale Spreng.

- Flevirs sans petites fevilles à la base. - Plante assez élevée, rameuse. - Cultivée sous le nom de Gazon blanc.

C. linifolium L.

\section{Fam. des SOLANĖES Juss.}

\section{G. Nicotiana Tourn. - Tabacs.}

Plante ligneuse, glabre et glauque; feuilles ovales, aiguës; fleur d'abord verte, mis jaune. - Cultivée conme plante d'ornement.

N. glauca Grah.

- Plante herbacée, velue et visqueuse. . . . . . . 1

1. Fleur rosée, en entonnoir. - Plante élevée, rameuse au sommet; feuilles larges, décurrentes. - Cultivée dans le S.-O. pour la production du Tabac.

N. Tabacum L.

- Fleur jaune, en clochette. - Plante moins élevée, à feuilles munies d'une queue. - Cultivée.

N. rustica L.

$$
\text { G. Petunia J. - Pétunias. }
$$

Plante velue et visqueuse, diffuse; feuilles sans quene; fleurs blanches; corolle évasée. - Cult. P. nyctaginiflora J.

Varie i corolle pourpre ou violette, dont le tube est renflé ( $P$. violacea Lindl.) 


\section{G. Hroscramus L. - Jusquiames.}

Fleur's solitaires, munies d'une queue. - Plante à rhizome épais; feuilles glabres, épaisses; fleurs rousses, livides, jaunes ou vertes. - Gultivée. H. Scopolia Willd. - Fleurs enroulees, sans queue. . . . . . . . . i 1. Feuilles de la tige sans queue, à lobes aigus. - Plante velue, rameuse, fétide; fleurs à fond jaunàtre, veiné de noir. - Jusquiame.

H. niger $L$.

- Feuilles toutes munies d'une queue. - Plante à fleurs faune pâle.

H. albus $\mathrm{L}$.

\section{G. Datura L. - Daturas.}

Plante rameuse, fétide; feuilles ovales, sinuées et dentées; fleurs blanches; fruit épineux. D. Stramonium L.

Varie à tige pourpre et à fleurs bleuâtres $(D$. Tatula L.)

\section{G. Verbascum L. - Bouillons blancs.}

Poils des étamines blancs ou jaunâtres. . . . . . . 1

- Poils des étamines violets ou pourpres. . . . . . . 5

1. Feuilles décurrentes. . . . . . . . . . . . 2

- Feuilles non décurrentes. . . . . . . . . . . 4

2. Corolle petite, d'un jaune pâle, concave, en entonnoir. - Plante cotonneuse, a tige simple; anthères toutes en rein.

V. Thapsus L.

- Corolle grande, d'un beau jaune, plane ou en roue. 3

3. Feuilles toutes sans queue; épi gros et serré. - Fleurs à deux étamines glabres. $\quad$ V. thapsiforme Schr.

- Feuilles inférieures munies d'une queue. - Plante cotonneuse, î tige simple.

4. Plante griscitre, a feuilles vertes et glabres en dessus, velues en dessous.

V. Lychnitis 1 .

- Plante blanche et cotonneuse. V. floccosum Waldst.

5. Feuilles sans queue, embrassantes, sinuées ou dentées.

- Fleurs en petits paquets sur des rameaux effilés, petites et jaunes.

V. sinuatum L.

- Feuilles munies d'une queue. . . . . . . . . . 6

6. Anthères à peu près égales; fruit ovoïde. - Plante à tige anguleuse, d'un brun noiràtre; fleurs en petits faisceaux. $\quad$ V. nigrum L.

- Anthères inégales; fruit globuleux. - Fleurs écartées, solitaires, à queue dépassant la petite feuille qui l'acconpagne.

v. Blattaria L.

Varie à fleurs agglomérées, à queue plus courte ( $V$. blattarioïdes Lam.) 


\section{G. Lycium L. - Lyciers.}

Divisions de la corolle aussi longues que le tube; calice à deux lèvres. - Arbrisseau à tige grèle, très rameux; fleurs d'un violet clair; fruits allongés. L. barbarum L. Divisions de la corolle de moitié plus courtes que le tube; calice à cinq dents. - Arbrisseau à tige droite; fleur's blanches ou purpurines; fruits globuleux. - Surtout lo long du littoral.

S. europæum L.

\section{G. Solanum L. - Morelles.}

Tíge grimpante, ligneuse à la base; fleurs violettes. Plante à feuilles ovales et en cœur, divisées à la base. Douce-amère.

S. Dulcamara L.

Plante grimpante, mais herbacée; fleurs jaunes. Plante poilue, feuilles découpées; fruit bosselé, rouge, jaune ou blanc. - Tomate. S. Lycopersicum L.

- Plante herbacée, non grimpante. . . . . . . . . i

1. Feuilles composées. - Plante à tubercules souterrains; tige anguleuse; fleurs blanches ou violettes, en bouquet.

- Pomme de terre.

S. tuberosum L.

- Feuilles simples. . . . . . . . . . . . 2

2. Fleur's blanches. - Plante variable, rameuse; feuilles ovales; fruit ordinairement noir, mais variant de couleur. - Morelle.

S. nigrum L.

- Fleurs violettes, jaunes au milieu. - Plante à feuilles ovales, aiguës; fruit gros, luisant. - Cultivée comme Aubergine.

S. Melongena L.

\section{- G. Capsicum L. - Piments.}

Plante à feuilles ovales, aiguës, glabres; fleurs blanches; fruit lisse, conique. - Gult. comme Piment. G. annuum L.

Varie à fruits globuleux ou tronqués au sommet $(G$. grossum Willd.)

\section{G. Physalis L. - Coquerets.}

Plante à feuilles ovales, sans queue; fleurs jaunâtres, axillaires; fruit et calice rouge vif à la maturité. P. Alkekengi L.

\section{G. Nicandra Ad.}

Plante dressée, à rameaux anguleux; feuilles ovales, glabres; fleurs bleues ou violettes, à fond blanc. - Cultivée et naturalisée. N. physaloïdes Gærtn. 


\section{G. Atropa L. - Belladones.}

Plante élerée, velıe; feuilles ovales, aiguës, entières; fleurs axillaires, d'un brun sale; fruits globuleux, noirs et luisants. - Bois montueux.

A. Belladona L.

\section{Fam. des PERSONÉES JusS.}

\section{G. Veronica T. - Véroniques.}

Plante liryneuse, élevée; feuilles allongées, sans queue; fleurs bleues ou violettes, en grappes serrées. - Cultivée.

V. speciosa R.C.

- Plante herbacée, du moins au sommet. . . . . . 1

1. Fleurs axillaires, en grappe, ou en épi terminal. . . 2

- Fleurs en épis latéraux, nés à l'aisselle d'une feuille. 13

2. Plantes couchées et étalées ì terre, annuelles; fleurs solilaires à l'aisselle des feuilles. . . . . . . . 3

- Plantes plus ou moins dressées; fleurs groupées en épis au sommet des rameaux. . . . . . . . . . 5

3. Fevilles à lobes bien distincts. - Plante velue; fleurs bleu très pàle; divisions du calice en cœur à la base. Les lieux cultivés. $\quad$ V. hederæfolia $L$.

Varie a fleurs blanches et a divisions du calice lancéolées (V. Cymbalaria Bod.)

- Fevilles ovales ou arrondies, dentées ou crénelées. . 4

4. Queue de la fleur plus courte que la feuille qui l'accompagne; fruit arrondi et velu. - Plante d'un vert jaunitre; fleurs blanches on rosées; divisions du calice obtuses.

V. agrestis $\mathrm{L}$.

Tarie i fleurs blenes et i lobes du calice aigus ( $V$. polita Fr.)

- Queue des fleurs supérieures dépassant la feuille qui l'accompagne; fruit plus large que long, veiné en réseau. - Plante i fleurs bleues, assez grandes; corolle veince. - Plante d'Orient aujourd'hui naturalisce dans tont le S.-O. - ( V. Buxbaumii Ten.) V. persica Poir.

5. Feuilles de la tige découpées. . . . . . . . . . 6

- Feuilles de la tige entières ou dentées. . . . . . . 7

6. Feuilles digitées; fleurs en grappe très lache; fruit ren/lé. - Très petite plante, a fleurs blen foncé. - Les lienx sablomnenx.

V. triphyllos $\mathrm{L}$.

- Feuilles pinnatifides: fleurs en grappe droite et fournie; fruits comprimés. - Trés petite plante relue, à fleurs bleu pâle.

V. verna $L$. 
7. Fleurs très nombreuses, en longues grappes ou épis. 8

- Fleurs en grappe lâche et feuillée. . . . . . . . 9

8. Feuilles obtuses, entières à leur sommet, dentées en scie vers leur base. - Plante pubescente, à tige raide et dressée.

V. spicata $L$.

- Feuilles aiguës, à dents fines et aigǘs. - Plante glabre, i fleurs bleues, blanches ou roses, variant beaucoup dans les jardins. - Cultivée.

V. longifolia L.

9. Queue des fleurs nulle ou plus courte que le calice. 10

- Queue très visible, égale au calice ou plus longue. . 11

10. Feuilles allongées, entières et un peu charnues. - Plante glabre, dressée, rameuse; fleurs bleues ou bleutitres. - A chercher dans le S. -0 .

V. peregrina L.

- Feuilles ovales, crénelées, non charnues. - Plante velue, diffuse; fleurs bleues. V.arvensis L. 11. Feuilles fortement dentées ou crénelées; fruits allongés et renflés. - Petite plante velue, à fleurs bleues et reinées.

V. præcox All.

- Feuilles très peu dentëes. . . . . . . . . . 12

12. Fleurs bleues, à queue bien plus longue que le calice. Plante rameuse, couverte de poils glanduleux. - Les lieux cultivés.

V. acinifolia $\mathrm{L}$.

- Fleurs blanchatres, à queue à peu piès égale au calice. - Plante glabre, à style long. $\quad$ V. serpyllifolia L. 13. Feuilles plus ou moins velues et dentées. . . . . 14

- Feuilles très glabres ou linéaires, entières. . . . . . 17 14. Feuilles à longue queue. - Plante rampante à la base; lleurs bleu pàle; fruits très larges, échancrés aux deux bouts.

V. montana L.

- Feuilles sans queue ou à queue très courte. . . . . 15े 15. Plante couchée ou courte. - Plante velue, rameuse; feuilles finement dentées; fleurs très pàles; fruit triangulaire.

V. officinalis $\mathrm{L}$.

- Plante dressée. . . . . . . . . . . 16

16. Calice à quatre lobes; tige poilue sur deu lignes. Fleurs bleu ciel.

V. Ghamædrys L.

- Calice a cinq lobes; tige velue tout autour. - Plante dure; fleurs bleues, a calice velu. V. Teucrium L.

Varie à plante plus grêle, à fleurs plus pâles et à calice glabre ( $V$. prostrata L.)

17. Feuilles linéaires et étroites. - Plante grèle et tombante; fleurs blanches, à raies roses ou blenes. V. scutellata $\mathrm{L}$.

- Feuilles ovales ou lancéolées, aiguës, sans queue. Plante à tige creuse; fleurs rosées ou hlenatres, veinćes. - Marais.

V. Anagallis L.

- Feuilles ovales ou lancéolées, obtuses, munies d'une queuc. - Plante à tige pleine; fleurs bleu foncé. Ruisseaux. 


\section{G. Sibtiorpia L.}

Très petite plante grèle et velue; fleurs blanches, rosées à la base. - Lieux humides.

S. europæa L.

\section{G. Linosella L.}

Très petite plante gazommante, it fleurs blanches, solitaires. Bords des eaux.

L. aquatica L.

\section{G. Digitalis L. - Digitales.}

Fleurs joune pale. - Plante glabre.

D. Iutea L.

- Fleurs rouges ou blanches. - Plante pubescente; fleurs frudintes, en ćpi unilatéral; corolle velne en dedans et minrfuce de taches foncées.

D. purpurea L.

\section{G. Scrophularia L. - Scrofulaires.}

Fenillo: diconupres. - Plante it plusienrs tiges simples, buissmmante; llems petites, marrom noiratre, it loles latéranx hanchitris. - Iescrul patfois les Pren. S. canina L.

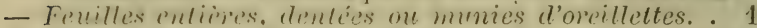

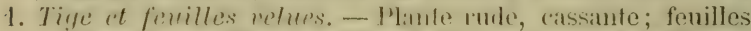

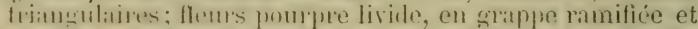
fenillée. - Liemx habités. S. Scorodonia L.

- Tige el fenilles glabres. . . . . . . . . . . 2

2. Divisions du calice bovdées de blanc. . . . . . . 3

- Dirisions du calié nom bordées de blane. - Plante it tige simple; fenilles en cour; fleurs rouge brum, en srappe terminile. - Ditx et ('ii et lit.

S. peregrina L.

:). Fenilles aiguës. - Plitute it rane noueuse. S. nodosa L.

- Férilles obluses, di yucue vilie. - Plante it racine fibrense.

- Bords des eaux.

S. aciuatica L.

\section{G. Gratiola l. - Gratioles.}

Plante a tige simple; fenilles lancéolées, sans queue, a trois nervures; fleurs axillaires, blane lilas. G. of ficinalis L.

\section{G. Lindernia L.}

Plante a liges conchies. titragones; feuilles ovales, a trois nervures; fleurs rosées, solitaires. - Embouchure de l'Adour.

L. pyzidaria AlI.

Virie it ileux ettmines senlement pomvos d'antheres et it fruit hipassant le calice (L. gratioluäcles L.) - Plante américane introdinite à l'embouchure de la Loire. 


\section{G. Antinrhivum L. - Mufliers.}

Corolle à gorge ouverte. - Plante à tige dressée; feuilles radicales en rosette; fleurs violacées, à éperon grêle et recourbé, serrées en épi grêle ou en panicule. (Anarrhinum belliclifolium Desf.)

A. bellidifolium $\mathrm{L}$.

- Corolle à gorge fermée.

1. Feuilles linéaires ou lancéolées. $\ldots \ldots$

- Fevilles ovales, arrondies ou en rein. . . . . . 3

2. Fleurs toutes axillaires et sans queue. - Plante velue, rameuse; fleurs rosées, petites, à lobes du calice égalant la corolle.

A. Orontium L.

- Fleurs en grappe terminale. - Plante glabre et rameuse; fleurs grandes, rouges, à gorge jaune ou variée; lobes du calice courts. - Cultivée et naturalisée çà et là. Grand Muflier.

A. majus L.

\section{G. Livaria Tourn. - Linaires.}

Toutes les feuilles munies de queue et élargies. . . . . 1

- Fenilles de la tige linéaires et sans queue. . . . . . 4

1. Feuilles glabres, plus courtes que leur queue. - Plante étalée; tleurs bleu clair, it grorge blanche, tachée de jaune.

- Cultivée et naturalisée cit et lit. L. Gymbalaria Mil.

- Feuilles velues, plus longues que leur queue. . . . 2

2. Feuilles ovales, arrondies; fleurs à queue velue. - Plante couchée, à fleurs jaunes, at éperon courbé et à lèvre supérieure noiràtre.

- Feuilles ovales, on fleche; fleurs à queue presque glabre. . . . . . . . . . . 3

3. Fleurs jaunâtres, à éperon droit. - L. Elatine vir.

- Fleurs blanchatres, à éperon crochu. (L. commutata Bern.)

L. græca Char.

- Fleurs très petites, bleuâtres. - Plante rameuse, très grêle. - Environs de St-Savin-de-Blaye. L. cirrhosa L.

4. Fleurs jaunes, . . . . . . . . . . . . 9

- Fleurs jamais jaunes. . . . . . . . . . . 5

5. Fleurs axillaires, à queue plus longue qu'elles. - Plante velue, à fleurs violet clair.

L. minor Desf.

- Fleurs à queue courte, rapprochées en grappes. . 6

6. Fleurs d'un rouge foncé, à éperon très aigu, plus long que la corolle. - Plante glabre; feuilles inféricures par trois, les supérienies alternes. L. pelisseriana DG.

- Fleurs jamais rouges. . . . . . . . 7

7. Fleurs violelles, it gorge jaune et à lère supérieure partagée. - Plante glabre, dressée; éperon grèle. Ciultivée.

L. bipartita Willu.

- Fleurs blenes ou blanches, striées. 
8. Queue des fleur's et calice poilus, glanduleux. - Plante à fleurs bleu pâle, à stries plus foncées; graines à aile membraneuse.

L. arvensis Desf.

- Queue des fleurs et calice glabres. - Plante à fleurs blanchâtres, rayées de violet; graine triangulaire. - Les lieux pierreux.

L. striata DC.

9. Fleur's très petites. - Petite plante vert jaunatre, velue et visqueuse. - Sables maritimes. L. arenaria DC.

- Fleurs longues d'un centimètre ou plus. . . . . . 10 10. Tige droite et simple.-Plante glabre; feuilles alternes, nombreuses; fleurs jaunes, à gorge orangée, en épi serré.

L. vulgaris Mil.

- Tiges couchées et étalées ou très rameuses. . . . . 11

11. Feuilles alternes. - Plante à tige effilée, très rameuse; fleurs jaunes, à gorge plus foncée; graine triangulaire. Lieux sablonneux.

L. spartea Hoffm.

- Feuilles verticillées, du moins les inférieures. . . . 12

12. Feuilles ovales. ou larges. - Plante glabre et glauque, par 3 ou par 2. - Sables maritimes. L. thymifolia DC.

- Feuilles linéaires, par 4 ou alternes. - Plante glauque, variable; fleurs jaune pâle, à gorge plus foncée. - Sables maritimes.

L. supina Dest.

\section{G. Euphrasia T. - Euphraises.}

Fleurs en grappes terminales, entremêlées de petites feuilles. S. G. Odontites Hall.

Fleurs toutes placées it l'aisselle d'une feuille. . . . . . 1 1. Fleurs rouges, violettes ou rougeatres. - S. G. Bartsia L. - Fleurs jamais rouges. - S. G. Euphrasia L.

\section{S. G. Euphrasia L.}

Plante tres variable, rameuse, munie de poils glanduleux et étalés; feuilles ovales, dentées; fleurs blanches, a stries violettes et à gorge jaune.

E. officinalis $L$. Pers.)

Varie surtout i poils de la tige couchés ( $E$. nemorosa

\section{S. G. Odontites Hall.}

Fleurs rougeatres. - Plante relue, rude; feuilles sans queue; fleurs en épis feuillés, plus courtes que les feuilles qui les accompagnent.

E. Odontites L.

Varie it feuilles florales plus courtes que les flegurs $(E$. scrotina Reich.)

- Fleurs jaunes. . . . . . . . . . . . . 1

1. Etamines saillantes; feuilles florales plus courtes que les fleurs. - Plante finement pubescente, à rameaux ouverts; fleurs d'un beau jaune.

E. lutea L. 
- Etamines renfermées dans la corolle; feuilles florales plus longues que les fleurs. - Plante visqueuse; fleurs d'un jaune pâle. - Toulouse. $\quad$ E. viscosa L. Varie à plante non visqueuse (E. jaubertiana Bor.)

\section{S. G. Bartsia L.}

Fleurs pourpres. - Petite plante velue; feuilles sans queue, les supérieures palmifides. (Eufragia latifolia Gris.; B. latifolia Sib.) E. latifolia L.

- Fleurs jaunes. - Plante velue et visqueuse; feuilles lancéolées, dentées en scie; fleurs en épi làche et terminal. (Eufragia viscosa Gris.; B. viscosa L.)E. maxima Lam.

\section{G. Rininanthus L.}

Lèrre inférieure de la corolle plane. - Plante rameuse, glabre dans le haut; fenilles lancéolées, dentées en scie; fleurs jaunes, en épi làche; feuilles florales jaunàtres; ealice glabre. $\quad$ Rh. Grista galli L.

Varie: $1^{\circ}$ à plante moins élevée et à feuilles florales vertes ( $R$. minor Ehr.); $2^{\circ}$ a calice velu, ainsi que le haut de la plante (R. hirsutus Lam.)

- Lève inférieure de la corolle à deux bosses vers la gorge. - Plante à tige simple, raide, poilue; feuilles linéaires ou lancéolées; fleurs blanc jaunâtre, en épi terminal carré. (Trixago apula St.) Rh. Trixago L.

Varie à lèrre inférieure blanche, à lèvre supérieure rosée ou pourpre (Bartsia bicolor DG.)

\section{G. Pedicularis T.}

Tige couchée; calice glabre, à cinq dents. - Plante à fleurs roses.

P. sylvatica $L$.

- Tige droite; calice velu. - Plante glabre, rougeatre, a grandes fleurs purpurines.

$P$. palustris $L$.

\section{G. Melampynum Tourn. - Mélampyres.}

Fleurs en épi feuillé et imbriqué. . . . . . . . . . . 1

- Fleurs par deux, en grappes unilatérales. . . . . 2

1. Epi serré et à quatre angles très prononcés. - Plante à rameaux étalés; feuilles linéaires ou lancéolées; fleurs jaune paile, à gorge plus foncée et à tube de la corolle rose.

M. cristatum L.

- Fleurs et feuilles florales imbriquées en tous sens. Plante velue et rameuse; fleurs rougeâtres, it gorge jaume; feuilles florales rougeàtres, à dents effilées. - Les champs calcaires.

M. arvense L. 
2. Corolle très ouverte, dépassant peu le calice. - Plante à rameaux grèles, étalés; fleurs jaune pàle. - Auvergne et Pyrénées.

M. sylvaticum L.

- Corolle tubuleuse, bien plus longue que le calice. - Plante à rameaux étalés; fleurs jaunûtres, à tube blanc. - Dans les bois.

M. pratense L.

\section{G. Orobanche L. - Orobanches.}

Galice tubuleux, à 4-5 divisions ou dents. (G. Phelipaca Ney.). . . . . . . . . . 1

- Calice à deux pièces latérales. (G. Orobanche Mey.). . 3

1. Fleurs purpurines, à anthères laineuses. - Sur Artemisia campestris.

O. arenaria Bork.

- Fleurs bleues ou jaunatres, d̀ anthères glabres ou à peu près. . .............. 2

2. Tige simple, violacés; fleurs bleues ou violettes; calice $\dot{a}$ cinq lobes. - Sur Achillea millefolium. O. cæruleaV.

- Tige rameuse; fleurs jaunatres ou bleuâtres, petites; calice à quatre lobes. - Sur le Chanvere. O. ramosa L.

3. Etamines glabres. - Plante d'un roux fauve, à tige robuste. - Sur Genista Sarothamnus. O. Rapum Thuil.

- Filet des étamines plus ou moins velu à la base. . . 4

4. Corolle d'un rouge sang à l'interieur. - Plante à sépales bilides et à étamines insérées à la base de la corolle. - Sur des Légumineuses.

O. cruenta Bert.

Varie à sépales entiers et à corolle quelquefois toute jaune (O. Ulicis Desm.)

- Corolle n'étant pas rouge sang à l'intérieur. . . . . 5

5. Lève supérieure de la corolle entière. . . . . . 6

- Lèrre supérieure de la corolle échancrée ou découpée. 8

6. Etamines insérées à la base de la corolle. - Plante jaune rougeàtre, à poils visqueux. - Sur Teucrium Chamodrys.

o. Teucrii Holl.

- Etamines insérées plus haut. ........ 7

7. Corolle cylindrique, arquee. - Style à deux lobes james. - Sur le Lierre.

- Corolle en clochette, non arquée; style à deux lobes pourpires. - Sur Picris hieracioides. O. Picridis Sch.

8. Etamines très velues à la base. . . . . . . . . . 99

- Etamines à quelques poils seulement. . . . . . 10

9. Style rouge ou violet au sommet. - Sur quelques Galium, dans les haies.

O. Galii Dub.

- Style rougecitre ou jaune au sommet. - Sur la Luzerne, dans les champs.

o. rubens Wall.

10. Etamines insérées à la base de la corolle. - Plante jaune ou rougeàtre, renflée a la base. - Sur le Serpolet, dans les lieux calcaires.

o. epithymum DC: 
- Etamines insẻrées beaucoup plus haut. - Tige rouge on violette, poilue; corolle genouillée à la base, bordée de petites dents aiguës. - Sur les Eryngium campestre et maritimum.

O. amethystea Thuil.

Varie à corolle arquée et bordée de dents obtuses. - Sur le Trèfle. (O. minor Sutt.)

\section{G. LAthrea L.}

Fleurs pourpre violacé, en paquets, à fleur de terre. - Tige souterraine, rameuse, couverte d'écailles blanches. Bords des eaux. $\quad$ L. Glandestina L.

- Fleurs blanchátres ou rosées, en épis unilatéraux. Tige souterraine, écailleuse; tige florale dressée. - Sur le Lierve.

L. Squamaria L.

\section{Fam. des LABIÉES Juss.}

\section{G. Ocimum L.}

Queue des ferilles ciliee. - Plante rameuse; feuilles ovales, glabres; fleurs blanches ou purpurines. - Cultivée. Basilic.

O. Basilicum L.

- Queue des feuilles non ciliée. - Plante à feuilles de la grandeur de celles du serpolet. - Cultivée. - Petit Basilic.

o. minimum L.

\section{G. Lavandula Tourn. - Lavandes.}

Plante rameuse, buissomnante, sous-ligneuse; feuilles linéaires, blanchâtres, roulées par les bords; fleurs bleues, velues, en épis grèles et à long pied. - Cầ et là dans le S. O. et cultivée: - Lavande.

L. Spica L.

\section{G. Mentha L. - Menthes.}

Calice bilabié, à gorge velue. - Plante à odeur très forte, couchée à la base; feuilles petites, ovales; fleurs lilas ou roses, en verticilles écartés. - Pouliot. M. Pulegium L.

- Calice à cinq dents, nu à la gorge. . . . . . . . 1

1. Fleurs accompagnées de feutlles. - Plante velue, à odeur forte; feuilles ovales, toutes munies d'une queve, dentées en scie; fleurs rosées, en verticilles écartés; calice it dents triangulaires, allongées en alène.

M. sativa $L$.

Varie : 10 à plante couchée, diffuse, et à calice court, à dents aussi larges que longues (M. arvensis L.); 20 it 
feuilles florales sessiles ( $M$. gentilis L.); $3^{0}$ a plante glabre et à feuilles luisantes - Cultivée - (M. rubra Sm.)

- Fleurs terminales, dépourvues de feuilles. . . . . 2

2. Feuilles munies d'une queue. . . . . . . . 3

- Fevilles sans queue. . . . . . . . . . . . 4

3. Fleur's en épis serrés, aigus; feuilles ovales, allongées, dentées. - Cultivée.

M. piperita L.

- Fleurs en tête obtuse. - Plante très variable, velue; feuilles ovales, dentées en scie; dents du calice en alène. - Bords des eaux.

Varie surtout à plante grisattre (M. hirsuta L.)

M. aquatica L.

4. Fevilles arrondies, obtuses. - Plante grisâtre, à odeur forte; fleurs blanches ou rosées. M. rotundifolia L.

- Feruilles ovales ou lancéolées, aigü̈s. - Plante velue et grisitre, i odeur forte; fleurs rosees. M. sylvestris L.

Varie a plante glabre et a odeur suave - Cultivée (M. viridis L.)

\section{G. Lrcopus L.}

Plante élevée; tige simple ou rameuse au sommet; feuilles ovales ou lincéolées, dentées ou découpées; fleurs blanches, ponctućes de rose.

L. europæus L.

\section{G. Oniganum Tourn. - Origans.}

Calice à cinq dents, relu à la goige. - Plante à tiges dressies; feuilles ovales, velues; fleurs rosées, en panicule. - Marjolaine. O. vulgare L.

- Calice bilabié, nu à la gorge. . . . . . . . . 1

1. Fleurs purpurines, en ëpis penchés. - Plante diffuse, laineuse: feuilles molles, épaisses; feuilles florales colorées. - Cultivée.

O. Dictamnus L.

- Fleurs purpurines ou blanches, en épis dressés. - Plante ligneuse a la base; feuilles blanches, cotomneuses. - Cultivée.

O. Majorana L.

\section{G. Thymus L. - Thyms.}

Feuilles roulées en dessous, blanchâtres. - Plante sousligneuse, buissomnante, blanchatre; fleurs roses ou blanches. - Toulouse. - Cultivée. T. vulgaris L.

- Fenilles vertes et planes. - Plante variable, couchee, gazomnante; fleurs purpurines, roses ou blanches. Serpolet.

T. Serpyllum L.

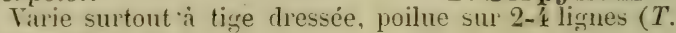
Chamadr!ls Fr.) 


\section{G. SAtureia L. - Sarriettes.}

Plante très odorante, rámeuse; fleurs roses ou blanches. - Cia et là dans le S.-0. — Gultivée.

S. hortensis L.

\section{G. Hrssopus L. - Hyssopes.}

Plante aromatique, touffue; tige ligneuse à la base; feuilles linéaires ou lancéolées; ileurs d'un beau bleu, en épi terminal. - Naturalisée cì et là. H. officinalis $L$.

Varie à plante blanchẩtre, couverte de poils serrés Charente-Inférieure - $(H$. canescens $\mathrm{DG}$.)

\section{G. Calamintha Benth.}

Fleur's en verticilles entourés de petites feuilles sẻtacées, qui forment une collerette. - Plante velue, feuilles ovales; fleurs rosées. - Terrains sablonneux. - (Glinopodium vulgare L.)

G. Glinopodium Benth.

- Fleurs axillaires, par deux ou par trois. G. Acinos Bent.

- Fleurs en petits bouquets axillaires. . . . . . i

1. Feuilles larges, vertes; dents du calice inégales. Plante éleveee, dressée, à lleurs hérissées de poils blancs, égalant leur feuille florale.

G. officinalis Monch.

- Feuilles petites, grisâtres; dents du calice à peu près égales. - Plante velue, à odeur forte; fleurs petites, bleu clair, dépassant leur feuille florale. G. Nepeta Link.

\section{G. Melissa L. - Mélisses.}

Plante rameuse, velue, à odeur de citron; feuilles ovales; fleurs blanches ou rosées. - Autour des habitations. - Mélisse ou Citronelle.

IM. officinalis $\mathrm{L}$.

\section{G. Rosmarinus L. - Romarins.}

Plante ligneuse, buissonnante; feuilles linéaires, coriaces, roulées en dessous; fleurs bleues. - Cá̀ et là dans le S.-O. Cultivée.

R. officinalis $\mathrm{L}$.

\section{G. Salvia L. - Sauges.}

Tube de la corolle muni en dedans d'un anneau de

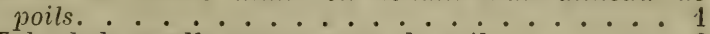

- Tube de la corolle sans anneau de poils. . . . 2

1. Plante sous-ligneuse; feuilles rugueuses, finement crènelées. - Plante buissonnante, blanchattre; fleurs violettes. - Sauge.

$\mathrm{S}$. officinalis L. 
- Plante herbacée, rameuse et fétide; feuilles molles, vertes, inégalement crénelées. - Fleurs violettes. Çà et là.

S. verticillata $\mathrm{L}$.

2. Feuilles florales larges, plus grandes que le calice. . 3

- Feuilles florales petites, plus courtes que le calice. . 4

3. Feuilles inférieures ovales. - Plante blanche et laineuse, à fleurs blanches. - Auvergne, Cévenn. S. Athiopis L.

- Fevilles inférieures en cour. - Plante fétide, velue; flenrs d'un blanc lavé de violet.

S. Sclarea L.

4. Feuilles échancrées à la base. - Plante velue, glanduleuse au sommet; fleurs grandes, d'un beau bleu et en épi. Les prairies.

S. pratensis $\mathrm{L}$.

- Feuilles peu ou point échancrées à la base. - Plante à feuilles sinuées ou pennifides; fleurs petites, violettes, dépassant peu le calice.

S. verbenaca $L$.

Varie à corolle bleu clair, dépassant beaucoup le calice (S. pallidiflora Chaub.)

\section{G. NePETA Benth.}

Fleurs axillaires. - Plante rampante, rameuse; feuilles en rein ou en cœur; fleurs violettes, tachées de pourpre. Les haies fraiches. - Lierve terrestre. - (Glechoma hederacea L.)

- Fleurs en épis terminaux. - Plante velue et grisâtre, fétide; feuilles en cœur, blanchâtres en dessous; fleurs Jlanches, ponctuées de rouge, à tube de la corolle renfermé dans le calice. - Chataire. N. Cataria L.

\section{G. Melittis DC.}

Plante à odeur forte; tige simple, velue; feuilles ovales; fleurs grandes, blanches, à lèrre inférieure rougeâtre au milieu.

M. Melissophyllum L.

\section{G. Limium Benth. - Lamiers.}

Anthères glabres; lère inférieure de la corolle à trois lobes aigus. - Plante à tiges florales dressées, les autres couchées; fenilles ovales, en cœur; fleurs jaunes. (Galeob(lolon luteum Ituds.)

L. Galeobdolon Cr.

- Inthères barbues; lève inférieure de la corolle à lobes tronqués ou échancrés. . . . . . . . . . 1

1. Toutes les feuilles plus ou moins pédiculées. . . . . 2

- Fevilles supérieures sans queue et embrassantes. Plante ascendante; feuilles inférieures arrondies et incisées; corolle rouge vif, à tube grèle, allongé. - Les lieux cultivés. L. amplexicaule L. 
2. Tube de la corolle droit, dépassant peu le calice. -

Plante couchée a la base, feuilles ovales, en cœur, les supérieures plus grandes; corolle rose, poilue en dedans.

- Les lieux cultivés. $\quad$ L. purpureum L.

Varie à feuilles supérieures triangulaires, découpées, et à corolle glabre en dedans ( $L$. incisum Willd.)

- Tube de la corolle courbé, dépassant beaucoup le calice. . . . . . . . . . . 3

3. Fleurs rouges, ou rarement blanches. - Plante a fenilles triangulaires, en cœur, les premières tachées de blanc.

- Les lieux frais. $\quad$ L. maculatum L.

- Fleurs blanches. - Plante à feuilles ovales, en cœur, aiguës; corolle poilue. - Ortie blanche. L. album L.

\section{G. Galeopsis L.}

Tige renflée sous les nœuds, hérissée de soies piquantes. Plante rameuse, à feuilles ovales, aiguës; lleurs roses, en verticilles rapprochés.

G. Tetrahit L.

Varie à fleurs blanches et jaunes (G. versicolor Curt.)

- Tige non renflée ou non hérissée de poils piguants. -

Plante ramifiée en pyramide, à poils mous; feuilles lancéolées; corolle rouge, à lèvre inférieure tachée de jaune.

G. Ladanum L.

Varie à corolle jaune pâlé ou rose (G. ochroleuca Lam.)

\section{G. STAchýs L.}

Fleurs d'un blanc jaunâtre. ............. 1

- Fleurs rouges ou rougeâtres. . . . . . . . . . . 2

1. Tige droite; feuilles glabres. - Fleurs blanches, a lère inférieure jaune. $\quad S$. annua $L$. Tige couchée à la base; feuilles velues. - Fleurs jaune blanchâtre, ponctuées et rayées de rouge. S. recta $L$.

2. Plante grêle, peu élevée; feuilles de deux centimètres au plus; fleurs petites, roses, ponctuées de rouge. Les lieux cultivés.

S. arvensis $\mathrm{L}$.

- Plante assez élevée et robuste; feuilles de trois centimètres au moins. . . . . . . . . . 3

3. Feuilles florales aussi longues que la fleur. . . . . . 4

- Feuilles florales nulles ou très petites. . . . . . . . 6

4. Dents du calice ovales. - Plante couverte de poils mous; fleurs rouge brun, tachées de blanc. S. alpina L. Dents du calice aiguës et piquantes. . . . . . . 5

5. Plante couverte d'un coton blanc, soyeux; fleurs rosées, en verlicille rapproché.

S. germanica I.

- Plante verte, poilue; fleurs rosées, en verticilles écartés. 
6. Feuilles glabres en dessus. - Fleurs roses, tachées de blanc, en verticilles rapprochés. S. palustris L.

- Feuilles velues sur les deux faces. - Plante fétide; fleurs rouge vineux, tachées de blanc, en verticilles écartés. Les lieux frais.

S. sylvatica $\mathrm{L}$.

\section{G. Betonica L. - Bétoines.}

Plante dressée; fleurs roses ou rouges, a calice non veiné. Dians les bnis.

B. officinalis $\mathrm{L}$. Varie ì plinte converte de poils jaunes et a calice veiné - Pyrénées - (B. hirsuta L.)

\section{G. Marnubium L. - Marrubes.}

Plante ramense, hlanche et cotomeuse; feuilles arrondies et en comr; flem's blanches. - Autour des habitations. Marrube blanc.

M. vulgare $L$.

\section{G. Sideritis L.}

l'lande herbacie; calice à dents inégales. - Plante hérissée, latmeuse dis lat base; flems blanches, a lobes de la corolle épineux.

S. romana L.

- Plante lignense il la base; calice à dents égales. Plante pilus on moins velue; feuilles ovales ou laneéolées; lleurs jatume pille, en grappe courte. S. hyssopifolia L.

\section{G. Ballota L.}

Plante ramcuse et fétile; fenilles ovales; fleurs rougeâtres. Marrube noir.

B. nigra L.

\section{G. Leonurus L.}

Tube de la corolle muni d'un anneau de poils. - Plante rameuse, diun vert sombre; feuilles divisées; fleur's roses, tachées de brun.

L. Cardiaca L.

- Corolle sans anneau de poils. - Plante élevée, rameuse; feuilles arrondies ou lancéolées; fleur's petites, blanchâtres. - Dans les haies, au Lord des eaux. - (Chaiturus Marrubiastrum Ehr.)

L. Marrubiastrum L.

\section{G. SCUtelaliria L.}

Feuilles en fer de fiecle à la base. - Plante faible, à fleurs violettes. - Charente-Inférieure.

- Fuilles niales, arrondies en cosur a la base. - Plante 
faible; feuilles dentées tout autour; corolle blen clair, à tube courbé.

S. galericulata L.

Varie à tige dressée, à feuilles dentées à la base seulement, à corolle rose dont le tube est droit (S. minor L.)

\section{G. Brunella Tourn. - Brunelles.}

Feuilles linéaires, très entières, sans queue. - Plante hérissée, à tige dressée; fleurs lilas clair. - La CharenteInférieure. $\quad$ B. hyssopifolia L.

- Feuilles ovales, entières ou découpées, pédiculées. Plante très variable, à tiges velues, couchées à la base; fleurs violacées, rougeâtres ou blanches. B. vulgaris L. Varie : $1^{0}$ à feuilles toujours découpées $(\boldsymbol{B}$. laciniata $L.) ; 2^{\circ}$ à fleurs bleues et très grandes (B. grandiflora Monch.); 30 à fleurs toujours blanches ( $B$. alba Pall.)

\section{G. AJUGA Benth.}

Fleur's jaunes; feuilles très découpées. - Plante couchée, très poilue. $\quad$ A. Chamæpitys Sch.

- Fleurs jamais jaunes; feuilles non découpees. . . 1

1. Tige glabre sur deux faces, à rejets rampants. - Plante a tige simple; fleurs bleues, roses ou blanches, en épi terminal.

A. reptans L.

- Tige velue sur les quatre faces, cépourvue de rejets. Plante à fleurs d'un beau bleu, rapprochées en épi serré.

A. genevensis L.

\section{G. Teucrium L. - Germandrées.}

Fleur's en têtes terminales. - Plante à odeur agréable; tiges nombreuses, couchées en cercle, nues; feuilles vertes en dessus, blanches en dessous, roulées par les bords; fleurs blanc jaunâtre. $\quad$ T. monicanum L.

- Fleurs axillaires ou en grappe. . . . . . . 1

1. Fleurs jaunâtres, en grappe grêle et allongée. - Plante velue, dressee.

T. Scorodonia L.

- Fleurs rouges et toutes axillaires. . . . . . . 2

2. Feuilles découpées. - Plante velue; fleurs rosées. - Les lieux pierreux. T. Botrys $\mathbf{R}$.

- Feuilles entières ou dentées. . . . . . . . . 3

3. Feuilles sans queue. - Plante velue, grisitre, à odeur d'ail; fleurs rosées, par deux. T. Scordium $\mathbf{L}$.

- Feuilles pédiculées. - Plante à tiges couchées, velues, presque ligneuses; fleurs rosées, en verticilles. - Petit Chêne. T. Chamædrys L. 


\title{
Fam. des VERBÉNACÉES Juss.
}

\section{G: Verbena L.}

Fleurs rouge vif. - Plante rameuse, hérissée; fleurs en épis solitaires. - Gultivée.

V. chamædryfolia J.

- Fleurs lilas. . . . . . . . . . . . 1

1. Corolle à tube un peu courbé, glabre en dedans. - Plante à tige élevée, carrée; feuilles dentées ou découpées; fleur's bleu pite, à gorge blanche, en épis interrompus. Verveine. $\quad \mathbf{v}$. officinalis $\mathrm{L}$.

- Corolle a gorge munie d'un anneau de poils. - Plante basse, hérissée; feuilles découpées; fleurs lilas, en bouquet. - Cultivée.

V. Aubletia L.

\section{Fam. des GLOBULARIÉES DG.}

\author{
G. Globularia L.
}

Plante glabre, ì souche vivace; feuilles inférieures en rosette; tige feuillée; fleurs bleues, en tète. - Vient sur les coteaux stériles.

G. vulgaris L.

\section{Fam. des PLANTAGINÉES Juss.}

\section{G. Plantago L. - Plantains.}

Tige florale munie de ferilles. . . . . . . . 1

- Tige florale nue; fenilles toutes radicales. . . . . 2

1. Tige couchée, un peu ligneuse; feuilles florales dépassant à peine les fleurs. - Plante à feuilles opposées ou verticillées lpar trois; épi dense, ovale. - Vallée de la Garonne

P. Cynops L.

- Tige droite, herbacée; feuilles forales inférieures plus longues que les fleurs. - Plante velue, un peu visqueuse; feuilles opposées; fleurs en épi ovale, longuement pédiculé. - Lieux sablonneux.

P. arenaria IV.

2. Feuilles larges et ovales. . . . . . . . . . . 3

- Fenilles bearcoup plus longues que larges, lancéolées. linéaires ou découpées. 
3. Feuilles sans queue, pubescentes sur les deux faces. Plante à feuilles en rosette, appliquées contre terre; épi cylindrique; fruit à deux graines.

P. media L.

- Feuilles pédiculées, glabres ou peu velues. - Plante ì tige florale droite; épi cylindrique; fruits i huit graines.

P. major L.

Varie a tige florale arquée et étalée (P. intermedia Gil.)

4. Tige florale anguleuse, à épi court, ovale. - Plante à feuilles lancéolées, beaucoup plus courtes que la tige florale.

P. lanceolata L.

Varie à feuilles couvertes de longs poils soyeux - Dans les sables maritimes - (P. eriopliora Hoffm.)

- Tige florale cylindrique, ì épi très allongé. . . . . . 5

5. Feuilles découpées ou à grandes dents. - Plante à feuilles en rosette.

P. Coronopus L.

- Feuilles entières ou tres peu dentées. . . . . . . 6

6. Feuilles très étroites, à trois angles. - Plante gazonnante, à tiges florales nombreuses. $\quad$ P. carinata Sch.

- Feuilles planes ou à trois nervures, canaliculées. Plante it racine charnue; épi cylindricpe, liche ì la base. - Bords de la mer.

P. maritima L.

\section{G. Littorelin L.}

Très petite plante à feuilles linéaires et it fleurs blanchàtres. - Bords des eaux. L. lacustris $L$.

\section{Fam. des PLOMBAGINÉES Juss.}

\section{G. Plumbago L.}

Plante dressée, ramense; feuilles vertes, les moyennes embrassantes par deux larges oreillettes; fieurs riolettes. - Plante du Midi naturalisée cì et li. $\quad$ P. europæa L.

- Plante grimpante, à tige anguleuse; feuilles ponctuées de blanc; fleurs bleues, en épi. - Cult. P. Capensis Th.

\section{G. Statice L. - Statices.}

Fleurs en épis unilatéraux. - S. G. Statice L.

Fleurs en tête terminale. - S. G. Armeria Willd.

$$
\text { S. G. Statice L. }
$$

Feuilles à une seule nervure rameuse. - Plante élevée, robuste; fleurs nombreuses, en épillets serrés et en large 
corrmbe sur des rameaux arqués en dehors. - Vases maritimes. S. Limonium L.

Varie: 10 à rameaux floraux très étalés et flexueux (S. serotina Rchb.); $2^{\circ}$ à fleurs écartées sur des rameaux droits ou ascendants (S. rariflora Drej.)

- Feuilles à 3-5 nervures. . . . . . . . . . . . 1

1. Ecailles florales, membraneuses, non verles. - Plante glabre; feuilles molles, spatulées; rameaux floraux dirigés en tous sens.

S. bellidifolia Gouan.

Varie à rameaux floraux étalés ou dressés, régulièrement disposés - La côte - (S. Dubyei Gren. et God.)

- Ecailles florales vertes, au moins sur le dos. . . . . 2

2. Feuilles quatre fois aussi longues que larges. - Plante grèle, i feuilles lancéolées ou spatulées, terminées en pointe. - Rochers maritimes. S. occidentalis Lloyd.

- Feuilles n'étant pas quatre fois aussi longues que larges. ................ . . 3

3. Feuilles obtuses et en spatule. - Plante robuste, à tige lisse et fourchue. - La còte. S. Dodartii De Gir.

- Feuilles aiguës et ovales. ........... 4

4. Epis courts, dressés et en petit corymbe. - Se trouve sur la côte.

S. ovalifolia Poir.

- Epis arqués et étalés. - Plante à rameaux sur deux rangées.

S. lychnidifolia De Gir.

S. G. Armeria Wild.

Feuilles munies de 3-7 nervures. - Plante gazonnante, à fleurs roses; calice it divisions lancéolées et en alène. (A. plantaginea Willd.)

- Fevilles à une seile nervure. - Plante à fleurs rosées et à tige florale pubescente; calice a divisions très courtes. La còte. - (A. maritima Willd.) S. Armeria L.

Varie à tube du calice velu sur les côtes, glabre dans les sillons (S. linearifolia Laterr.)

\section{Fam. des PHYTOLAGGÉES R.B.}

\section{G. Phytolacca L.}

Plante élevée, glabre, rouge, rameuse en haut; feuilles ovales, aiguës; lleurs jaunatres ou pourpres, en grappes. Naturalisée dans le S. -0 . Ph. decandra $L$. 


\title{
Fam. des AMARANTHACÉES R.B.
}

\author{
G. Cielosia L.
}

Plante dressée, slabre; feuilles ovales; fleurs en épis épais, dilatés et aplatis, de couleur variable. - Cultivée dans les parterres.

G. cristata L.

\section{G. Amaranthus L. - Amaranthes.}

Fleur's axillaires, non en épis. . . . . . . . . . 1

- Fleurs en épi non feuillé. . . . . . . . . . 2

1. Feuilles florales épineuses, plus longies que les fleurs. - Plante dressée, glibre, blanche; feuilles petites; fleurs d'un vert pâle.

A. albus $L$.

- Feuilles florales non épineuses, ne dépassant pas les fleurs. - Plante dresscée, glabre, verte; feuilles ovales; fleurs verditres.

A. syivestris Desf.

2. Plante dressée; furilles florales aiguës, plus longues que les fleurs. - Plante velue, à fleurs verdàtres et a écailles florales en alène.

A. retroflexus L.

- Plante couchée ou inclinée; feuilles florales ne dépassant

3. Plante glabre, à vameaux couchés è à fleurs verdátres. - Autour des jardins.

Varie à rameaux dressés (A. ascendens Lois.)

- Plante velue, couchée, diffuse; fleur's verdâtres. - Pied des murs.

A. deflexus L.

\section{G. Polygnemum L.}

Plante très rameuse, couchée; feuilles en alène; fleurs blanchâtres, axillaires, à écailles florales plus longnes que la fleur.

P. arvense L.

Varie à plante plus petite et i écailles ne dépassant pas la fleur ( $P$. verrucosum Lang.)

\section{Fam. des CHÉNOPODÉES Vent.}

\section{G. Beta Tourn.}

Plante dressée, élevée, à tige anguleuse; feuilles luisantes, vertes ou rougeitres. - Cultivée.

E. vulgaris L. 
Varie beaucoup par la culture: 10 à còtes des feuilles charnues (B. Cicla L.); 20 à tiges couchées et à styles lancéolés au sommet - Bords de la mer - (B. maritima L.), ete.

\section{G. Chesopodium L. - Ansérines.}

Feuilles planes. - S. G. Chenopodium L.

Feuilles cylindriques. - S. G. Suceda Forsk.

S. G. Suceda Forsk.

Plante herbacée, vert clair ou rougeatre; feuilles linéaires. Vases salées. (S. maritima Poix.) C. maritimum L. - Plante ligneuse, rameuse, élevée; fenilles linéaires. - Vases salées. (S. fruticosa.)

G. fruticosum $\mathrm{L}$.

S. G. Chenopodium L.

Féuilles entières, ni divisées ni dentées. . . . . . 1

- Feuilles plus ou moins sinuées, dentées ou divisées. 3

1. Feuilles triangulaires, en fer de flèche ì la base. -

Plante vivace, a souche épaisse; fleurs en panicule terminale.

C. Bonus Henricus L.

- Fevilles ni triangulaires ni en fer de flèche. . . . 2

2. Feuilles ovales, glauques el farineuses. - Plante à odeur

fétide, blanchitre; fleur's en grappes serrées. - Les lieux cultivés. - Vu!vaire.

G. Vulvaria $L$.

- Feuilles ovales, du moins les inférieures, vertes, non

farineuses. - Plante non fétide, rameuse, couchée; lleurs en grappes axillaires. $\quad$ C. polyspermum L.

Varie à feuilles supérieures aiguës ( $C$. acutifolium Sm.)

3. Plante plus ou moins velue, à odeur aromalifue. . . 4

- Plante non velue, à odeur désagréable ou nulle. . 5

4. Fleurs accompagnées de feuilles.-I'lante élevée, rameuse, feuilles rert clair. - Cultivée sous le nom d'Ambroisie, de Thé vert. $\quad$ G. ambrosioïdes L.

- Fleurs nues. - Plante élevée, à feuilles découpées; fleurs très velues.

G. Botrys L.

5. Fenilles minces, vertes de's deux côtés. - Plante fétide, à

tige camnelée; feuilles triangulaires, à longue pointe. -

Les lieux cultivés.

C. hybridum L.

- Feuilles charnues ou farineuses en dessous. . . . . 6

1. Feuilles farineuses jusqu'ii en être blanches. . . . . 7

- Feuilles peu farineuses. . . . . . . . . 8

7. Feuilles allongées; tige un peu couchée; fleurs en grappes simples. $\quad$ C. glaucum L.

- Feuilles ovales; tige droile; fl. en grappes vamifiées. 8

૪. Fleurs en grappes dressées contre la tige. . . . . . !

- Fleurs en grappes terminales étalées. . . . . . . 10 
9. Grappes liches, allongées, non ferillées. C. urbicum L.

- Grappes serrées, courtes et feuillées. C. rubrum L.

10. Graines luisantes, lisses. - Plante très variable, à tige striée de vert ou de rouge; feuilles ovales. C. album L.

Varie: 10 a leuilles arrondies ( $C$. opulifolium Sch.);

$2^{\circ}$ à feuilles à trois divisions ( $C$. ficifolium Sın.), etc.

- Graines opaques, à carène circulaire. - Planle rameuse,

a feuilles ovales, luisantes.

C. murale L.

\section{G. Atriplex L. - Arroches.}

Plante ligneuse. . . . . . . . . . . . 1

- Plante herbacée. . . . . . . . . . . . . 2

1. Feuilles alternes. - Arbrisseau buissomnant, à rameaux effilés; feuilles persistantes; fleurs jaunàtres. - Cult. en haies, au bord de la mer. - Fessecul. A. Halimus L.

- Feuilles opposées. - Sous-arbrisseau rameux; fleurs jaunatres, en grappe terminale et allongée. - Bords de la mer. (Obione porlulacoïdes M.) A. portulacoïdes L.

2. Fleurs axillaires ou en grappes non feuillées. - Plante

d rameaux dirigés en tous sens; feuilles triangulaires, à peine blanches en dessous. - Sables marit. A. rosea L. Varie à feuilles argentées et furineuses (A. crassifolia Mey.)

- Fleurs en grappes grêles, allongées, non feuillées. . . 3

3. Fevilles lancéolées ou linéaires. . . . . . . . 5

- Feuilles triangulaires, en fer de flèche, du moins les inférieures. ............ 4

4. Enveloppe florale $\dot{a}$ divisions arrondies ou ovales. -

Plante verte ou rougeâtre, dressée, rameuse. - Cultivée dans les jardins.

A. hortensis L.

- Enveloppe florale à divisions triangulaires, aiguës, ou en fer de flèche. ............ 5

5. Enveloppe florale blanche argentée, coriace $\dot{a}$ la matuvité.

A. laciniata L.

- Enveloppe florale verte et herbacée à la maturité. - Les champs.

A. hastata L.

Varie beaucoup : $1^{\circ}$ à enveloppe florale lisse et dépassant beaucoup la graine (A. patula L.); $2^{\circ}$ à feuilles toujours linéaires (A. littoralis L.), etc.

\section{G. Salicornia L. - Salicors.}

Plante herbacée, d'un vert clair ou rougeàtre, dressée, rameuse. - Narais salants.

- Plante ligneuse, glauque et grisàtre, buissonnante, assez variable. - Marais salants.

Varie à rameaux enracinés (S. radicans $\mathbf{S m}$.) 


\section{G. SAlsola L. - Soudes.}

Plante velue; fenilles en alène, épineuses. - Dans les sables maritimes.

S. Kali L.

- Plante glabre; feuilles obtuses. - Marais salants. S. Soda L.

\section{Fam. des POLYGONÉES Juss.}

\section{G. Riumex L. - Patiences et oseilles.}

Feuilles en fer de flèche à la base. . . . . . . . . . 1

- Feuilles à base arrondie ou lancéolée. . . . . . . 4

1. Fleurs à deux sexes ou unisexuées, les mailes el les femelles étant sur le même pied. . . . . . . . 2

- Fleurs uniseruées, les mâles et les femelles étant sur des pieds différents. . . . . . . . . . 3

2. Feuilles ovales arrondies, anssi larges que longues. Plante couchée.

R. scutatus L.

- Feuilles inférieures orales, petites, insensiblement attémuées en queue, les supérieures lanciolíes. - Plante tris ramense et rariable. $\quad R$. bucephalophorus l.

3. Enveloppe florale à divisions non tubereuleuses ni écailleuses ì la base, à la maturité. $\quad \mathbf{R}$. acetosella L.

- Enveloppe florale ie divisions tuberculense's ou écailleuses ì la base. à la maturité. - Plante it feuilles reinées et a srine déchiquetée.

R. acetosa $\mathrm{L}$.

4. Fruit entouré d'une enveloppe florale à divisions forlement dentées à la base. . . . . . . . . . 5

- Fruil entouré d'une enveloppe florale à divisions entières ou à peine denticulées. . . . . . . . . . 7

5. Fevilles radicales échanciées sur les côtes comme un violon; rameaux peu feuiliés et lies divergents. - Les bords des chemins. $\quad$ R. pulcher L.

- Fenilles inférieures non échancrées sur les cûtés: rameaux peu ou point divergents. . . . . . . 6

6. Fenilles inférieures rétrécies a la base et n'ayjant pas 3 centimètres de large.

R. maritimus L.

Varie à épis plus grèles et at dents de i'enveloppe florale plus courtes (R. palustris Sm.)

- Fevilles inférieures en crur à la base, obluses et ayant plus de 3 centimètres de largeur. R. obtusifolius L.

Varie à feuilles aiguës ( $R$. pratensis Koch.)

7. Fenilles inférieures de 4-8 rentimitres. - Dans les marais

R. Hydrolapathum Huds.

- Fenilles inférieures n'ayant pas 4 centimétres. . . . 8 
8. Enveloppe florale à lobes allongés, à la maturilé. Plante très variable.

R. conglomeratus Sch.

Varie: $1^{0}$ à plante ramifiée, au sommet, en branches courtes et serrées (R. rupestris Le Gall.); $2^{\circ}$ à une seule division de l'enveloppe florale granuleuse, à la maturité (R. nemorosus Sch.); $3^{\circ}$ à tige et à feuilles pourpres sur les nervures ( $R$. sanguineus L.)

- Enveloppe florale à divisions en cœur et arrondies, $\dot{a}$ la maturité. . . . . . . . . . . . . . . . 9

9. Fevilles crépues; toutes les divisions de l'enveloppe florale tuberculeuses, à la maturité. R. crispus L. - Feuilles planes; une seule division de l'enveloppe florale tuberculeuse, à la maturité. - Cultivée et sauvage. Patience. R. Patientia L.

\section{G. Polygonum L. - Renouées.}

Fleurs en grappes ramifiées. - Plante rameuse, à fleurs blanches ou rosées, en corymbe terminal. - Cultivée comme Sarrazin.

P. Fagopyrum L.

Varie à fleurs jaunâtres, en panicule (P. tataricum L.)

- Fleurs en grappes simples, en épi ou axillaives. . . . 1

1. Fleurs presque toutes axillaires. . . . . . . . 2

- Fleurs en épis terminaux. . . . . . . . . 5

2. Plantes couchées, à feuilles allongées. . . . . . 3

- Plantes enroulées, à feuilles en cour ou en fer de flèche................ 4

3. Fruit gros, lisse et luisant - Plante a feuilles roulées en dessous par les bords. - La côte. P. maritimum L.

- Fruit ponctué et strié, terne. - Plante variable, à feuilles planes.

P. aviculare L.

4. Tige cylindrique; enveloppe florale persistante, ailée. - Lieux cultivés. $\quad$ P. dumetorum L.

- Tige anguleuse; enveloppe florale non ailée, à la maturité.

5. Feuilles en cour à la base. - Plante nageante, à fleurs roses, en épis solitaires, serrés. P. amphibium L.

Varie à plante terrestre et à feuillles velues $(P$. terrestre M.)

- Feuilles rétrécies à la base. . . . . . . . . . 6

6. Gaîne des feuilles non ciliée; fleurs vudes, glanduleuses. P. Lapathifolium $\mathrm{L}$.

Varie à nœuds de la tige renflés ( $P$. nodosum Pers.)

- Gaîne des feuilles ciliee. . . . . . . . 7

7. Epis ovales et épais. - Plante rameuse, à fleurs non glanduleuses.

- Epis filiformes, grêles et lâches. - Plante à saveur poivrée et à fleurs glanduleuses. P. Hydropiper L. 
Varie : $1^{\circ}$ à gaîne des feuilles poilue et à saveur herbacée $\left(P\right.$. dubium St.); $2^{\circ}$ à feuilles linéaires et à cinq étamines au lieu de six (P. minus Huds.), et forme des hybrides avec les espèces précédentes.

\section{Fam. des LAURINÉES Juss.}

\section{G. Laurus Tourn.}

Arbre ou arbrisseau à feuilles persistantes, lancéolées, aromatiques; fleurs jaunâtres; fruit charnu, noir. - Cultivé: Laurier d'Apollon. $\quad$ L. nobilis L.

\section{Fam. des DAPHNAGÉES Mey.}

\section{G. Daphne L.}

Fleurs lalérales ou axillaires. . . . . . . . . 1

- Fleurs terminales. . . . . . . . . . 2

1. Fleurs roses, naissant avant les feuilles. - Plante élevée, rameuse, à écorce grise, ponctuée de brun. - Cultivée et sauvage.

D. Mezereum L.

- Fleurs jaunatres, naissant après les feuilles, munies de queue. - Plante rameuse, à écorce d'un jaune brunàtre. - Les bois montueux. D. Laureola L.

2. Flur's pédiculées, en grappe. - Plante élevée, buissonnante; feuilles lancéolées; fleurs jaunàtres; fruits rouges. - Embouchure de la Gironde. $\quad$ D. Gnidium L.

- Fleurs sans queue. - Sous-arbrisseau diffus, à rameaux velus et à feuilles glabres; fleurs roses; fruit jaunâtre dabord, brun ensuite.

D. Gneorum L.

\section{G. Passerina L. - Passerines.}

Plante glabre, herbacée, à tige grêle, droite; feuilles linéaires; fleurs sans queue, jaune verdatre, accompagnées à leur base de deux petites folioles; fruit en forme de poire. Les champs cultivés et les moissons. P. annua Sp.

\section{G. Hippophae L.}

Arbrisseau buissomnant, épineux, grisàtre; feuilles linéaires; fleurs verdâtres; fruits jaunàtres. - Embouchure de la Gironde. H. rhamnoïdes L. 


\section{Fam. des SANTALACÉES R.B.}

\section{G. OsYris L.}

Sous-arbrisseau rameux; feuilles linéaires; fleurs jaunes, a odeur de miel; fruit rouge, charnu. - Se trouve sur la côte.

O. alba $\mathrm{L}$.

\section{G. Thesium L.}

Plante à tiges filiformes, rameuses; fruit à còtes saillantes; enveloppe florale persistante, beaucoup plus courte que le fruit.

T. humifusum DC.

\section{G. Cytinus L. - Cytinets.}

Plante jaune, parasite sur les Cistes, couverte d'écailles; fleurs velues, en tête.

C. Hypocistis L.

\section{Fam. des ARISTOLOCHIÉES Juss.}

\section{G. Amistolochia L. - Aristoloches.}

Feuilles échancrées au sommet. - Plante à racine globuleuse; fleurs solitaires, axillaires; fruit globuleux. A. rotunda L.

- Feuilles arrondies au sommet. ......... 1

1. Fleurs jaunâtres, en faisceaux axillaires. - Plante fétide, à racine rampante; feuilles larges; fruit en poire. - Les champs.

A. Clematitis L.

- Fleurs brunâtres, solitaires et axillaires. - Plante à racine en fuseau; feuilles odorantes, plus petites; fruit en poire.

A. longa $L$.

\section{Fam. des EUPHORBIAGÉES Juss.}

\section{G. Euphorbia L. - Euphorbes.}

Plante tout à fait couchée et étalée en rosette sur le sol. 1

- Plante dressée et non étalée sur le sol. . . . . . 3

1. Feuilles arrondies; graines tuberculeuses. - Petite plante glabre, à fleurs axillaires. - Çit et là ; introduite; vient des bords de la Méditerranée.

Varie à plante velue (E. canescens L.) 
- Feuilles non arrondies, à base plus ou moins oblique; graines lisses. . . . . . . . . . . . 2

2. Fenilles ovales, obtuses, à base très oblique. - Petite plante rougeàtre, à fleurs axillaires. - Vient dans les sables maritimes.

E. Peplis L.

- Feuilles linéaires ou lancéolées, terminées en très courte pointe, presque en cour à la base. - Petite plante jaunâtre, à rameaux renflés à leur base; fleurs axillaires. - Sables maritimes, où elle est naturalisée; vient de l'Amérique du Nord.

E. polygonifolia L.

3. Feuilles linéaires très étroites. . . . . . . . 4

- Feuilles élargies, du moins les supérieures, c'est-à-diré ayant au moins cinq millimètres de largeur. . . 7

4. Ombelle de deux à cinq rayons. . . . . . . . 5

- Ombelle à plus de cinq rayons. . . . . . . . . . 6

5. Graines cendrées, ovoüdes, creusées de fossettes. . . 17

- Graines presque carrées, tuberculeuses. - Plante grèle; glandes de la fleur en croissant et à deux pointes. - Les moissons.

E. exigua L.

6. Collerette de la base de l'ombelle à pièces ubluses. Plante à racine rampante et à rameaux stériles nombreux. - Cà et là.

E. Cyparissias L.

- Collerette de la base de l'ombelle à pièces pointues. Plante glabre. - Lienx incultes.

E. Esula L.

7. Fevilles de la tige opposées et disposées sur quatre rangs. - Plante élevée, dressée, à tige simple en bas, ramifiée et fourchue dans le haut. - Gultivée sous le nom d'Epurge, et échappée.

E. Lathyris L.

Feuilles alternes ou ćparses. . . . . . . . 8

8. Rayons de l'ombelle terminés par deux petiles feuilles soudées entre elles par la base. . . . . . . . . 9

- Rayons de l'ombelle terminés par deux petites feuilles distinctes et non soudées. . . . . . . . . 10

9. Glandes de la fleur jaunatres; fruits glabres.-Plante à tige velue, ordinairement rougeatre; feuilles relues, persistantes. (E. sylvatica Jacq.) E. amygdaloides L.

Tarie à feuilles des rayons libres (E. ligulata Ch.)

- Glandes de la fleur noiratres; fruits relus. - Tige presque ligneuse, épaisse, à feuilles coriaces et persistantes. Lot-et-Garonne.

E. Characias L.

10. Ombelle principale à cinq ou six rayons ou moins. . 13

- Ombelle principale à plus de six rayons. . . . . . . 11

11. Fruits gros et couverts de verrues; rayons de l'ombelle trifurqués, puis bifurqués. - Plante élerée, roluste, à tiges épaisses et rougeâtres; glandes de la fleur jaune fauve. - Bords des rivières.

E. palustris $\mathrm{L}$.

- Fruits médiocres, seulement ponctués; rayons de l'ombelle seulement bifurqués. . . . . . . . . . . 12 
12. Glandes de la fleur entières. - Plante à tiges nombreuses; feuilles raides, très glauques; graines blanchâtres, lisses. - Lieux pierreux et sablonneux. E. gerardiana Jacq. Glandes de la fleur échancrées en croissant. - Plante glabre et glauque, à fruits à trois angles. - Les lieux incultes.

Varie à fruits globuleux - Dans le Lot-et-Garonne (E. niccensis All.)

13. Fruits velus, chargés de verrues, dı moins sur les angles................. 16

- Fruits lisses, sans verrues. . . . . . . 14 14. Glandes de la fleur échancrées en croissant. - Plante à graines blanchâtres, marquées de chaque côté de deux rangs transversaux de fossettes linéaires. - Vient dans les lieux pierreux.

E. falcata L.

- Glandes de la fleur entières. . . . . . . . . 15 15. Fevilles en coin. - Plante d'un vert clair, à tige simple; ombelles a cinq rayons trifurqués. - Se trouve dans les lieux cultivés.

E. Helioscopia L.

- Feuilles lancéolées, dentées en scie. - Plante à graines lisses. - Les champs.

E. serrata L.

16. Graines ridées en réseau. - Plante rougeàtre, à feuilles lancéolées, élargies au sommet. E. Portlandica L.

Varie à feuilles très étroites ( $E$. segetalis L.)

- Graines lisses ou d̀ peine ponctuées. . . . . . . . 17

17. Feuilles coriaces, dures et très glauques, imbriquées sur. la tige. - Sables maritimes.

E. Paralias L.

- Feuilles non coriaces, non imbriquées sur la tige. . 18 18. Feuilles munies d'une petite queue et très glabres. Plante rameuse et diffuse; fruits à deux carènes sur les angles. - Lieux cultivés. E. Peplus L.

- Feuilles sans queue ou à peu près, un peu velues. . 19 19. Feuilles rétrécies à la base en semblant de queue. Plante à glandes florales rougeâtres et à graines jaune rosé. - Les bois.

E. dulcis L.

Varie à tiges grêles et anguleuses dans le haut $(E$. angulata Jacq.)

- Feuilles tout à fait sans queue. . . . . . . . 20

20. Tige très rameuse au-dessous de l'ombelle. . . . . . 21

- Tige peu ou point rameuse au-dessous de l'ombelle. 23

21. Feuilles obscurément denticulées, mollement velues en dessous et jamais rabattues sur la tige. - Plante élevée, buissonnante. - Les bois.

E. pilosa L.

- Feuilles finement dentées en scie, parsemécs seulement de poils, les inférieures rabattues sur la tige. . . 22

22. Graines d'un gris brillant et métallique; ombelle souvent à cinq rayons. - Plante simple à la base, dressée.

- Lieux pierreux.

E. platyphyllos L. 
- Graines très petites et rougeâtres; ombelle souvent d trois rayons. - Lieux arides.

E. stricta L.

23. Feuilles très entières et longues. - Plante glabre ou à peu près, à tige simple. - Se trouve cà et la dans la plaine du S. -0 .

E. hiberna L.

- Feuilles dentées eri scie. - Plante à souche dure, émettant plusieurs tiges; fleur's d'un beau jaune. - Se trouve dans les bois.

E. verrucosa $L$.

Varie a fruits couverts de tubercules dentés et non cylindriques - Cérennes - (E. papillosa Pouz.)

G. Mercurialis Tourn. - Mercuriales.

Tige rameuse; feuilles lisses. - Plante annuelle, glabre, à feuilles opposées; fleurs axillaires, dioïques; fleurs vertes; fruit double, hérissé de pointes vertes.

Varie à fleurs polygames (M. ambigua L.)

- Tige simple; feuilles rudes au toucher. - Plante vivace, d'un vert foncé; feuilles opposées, bleuissant par la dessication; fleurs vertes; fruit double, courert de poils courts. - Bois ombragés.

M. perennis L.

\section{G. Buxus Tourn. - Buis.}

Arbuste élevé ou buissomnant, à feuilles opposées, luisantes, persistantes; fleurs petites, blanchâtres, fétides, en petits paquets à l'aisselle des feuilles supérieures des rameaux, unisexuées, la fleur femelle au milieu. - Cultivé et spontané dans la Dordogne.

B. sempervirens $L$.

\section{Fam. des CALLITRICHINÉES Link.}

\section{G. Callitriche L.}

Feuilles supérieures ovales, élargies, formant une rosette

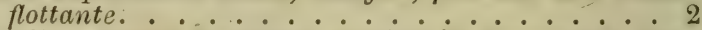

- Feuilles toutes linéaires, étroites et immergées dans l'eau. . . . . . . . . . 1

1. Fruits sans queue.

- Fruits inférieur's pédiculés.

C. hamulata Kïtz.

2. Fruits sans queue.

- Fruits inférieur's pédiculés.

G. truncata Guss.

- Toutes les feuilles ovales.

4. Styles dressés.

- Styles recourbés et divergents.

G. stagnalis Scop. G. vernalis $\mathrm{K}$. C. platycarpa líitz. 


\title{
Fam. des CÉRATOPHYLLÉES Gray.
}

\author{
G. Ceratophyllum L.
}

Plante d'un vert sombre, à feuilles filiformes et á fruit portant deux pointes à sa base. - Les eaux. G. demersum $L$.

- Plante d'un vert gai, à feuilles fines comme des cheveux, et à fruit dépourvu de pointes à sa base. - Se trouve dans les eaux.

G. submersum L.

\section{Fam. des URTIGÉES Juss.}

G. Untica Tourn. - Orties.

Fleurs femelles en têtes globuleuses. - Se trouve au pied des murs.

U. pilulifera $L$.

- Toutes les fleurs en grappes. . . . . . . . 1

1. Feuilles en cour à la base; grappes longuement pédiculées. - Plante variable, élevée. - Vient autour des habitations et des lieux fréquentés. U. dioica L.

- Feuilles arrondies à la base, profondément dentées; grappes courtement pédiculées. - Plante plus petite.- Vient aussi autour des lieux habités. U. urens L.

\section{G. Parietaria Tourn. - Pariétaires.}

Plante à rameaux dressés, velue; feuilles lancéolées; fleurs en paquets axillaires. P. of ficinalis $\mathrm{L}$. Varie à rameaux diffus ( $P$. diffusa Koch.)

\section{G. Humulus L.}

Plante élevée, grimpante; feuilles opposées, stipulées, en cœur; fleurs jaunâtres. - Les haies; souvent cultivée. - Houblon. H. Lupulus L.

\section{G. Ulaus L. - Ormes.}

Arbre élevé, à branches lisses ou subéreuses; feuilles ovales; fleurs rougeâtres, sessiles; fruit glabre, ailé, portant la graine au sommet.

U. campestris L.

Varie à feuilles plus grandes et à graine occupant le milieu du fruit - Gultivé - (U. montana Sm.) 


\section{G. Ficus Tourn. - Figuiers.}

Arbre ou arbrisseau grisâtre; feuilles rudes ou relues; fruit en forme de poire. - Cultivé.

F. Carica L.

\section{Fam. des AMENTAGÉES Juss.}

\section{G. Mrrica L. - Ciriers.}

Arbrisseau aromatique, à feuilles lancéolées, dentées au sommet; chatons dressés. - Laurette.

M. Gale L.

\section{G. SALIX L. - Saules.}

Fruits glabres. . . . . . . . . . . 1

- Fruits velus... . . . . . ....... 3

1. Petites fleur's à trois étamines. - Arbrisseau à rameaux noiràtres; feuilles très glabres, à dents glanduleuses et à stipules en demi-cour; écailles des chatons glabres au sommet. - Bords des eaux. $\quad$ S. triandra L.

Varie à feuilles glauques en dessous (S. amygdalina L.)

- Petites fleur's à deux étamines. . . . . . . . 2

2. Stipules des feuilles mulles. - Arbrisseau à rameaux pourpres; feuilles linéaires, glabres en dessus, blanches et velues en dessous. - Bords de la Garonne. S. incana Sch.

- Stipules des feuilles lancéolées. - Arbre élevé, à feuilles aiguës, soyeuses, blanchàtres, surtout en dessous. - Bords des eaux.

S. alba $\mathrm{L}$.

Varie: $1^{\circ}$ à feuilles presque glabres (S. ccerulea LI.); $2^{\circ}$ à jeunes rameaux jaunes (S. vitellina L.) - Osier jaune des cultures.

- Stipules des feuilles en demi-cour. - Arbre élevé à rameaux luisants, très fragiles; feuilles glabres, de couleur uniforme. - Bords des eaux. $\quad$ S. fragilis L.

Varie à feuilles glauques en dessous (S. russelliana Sm.)

3. Petites fleurs à une seule étamine, munie d'une anthère à quatre loges. - Arbrisseau à rameaux grisâtres ou jaunâtres, les jeunes pousses rougeàtres; feuilles lancéolées, élargies vers le haut, glabres. - Bords des eaux et cultivé.

Varie à feuilles allongées (S. Helix L.)

- Petites fleurs à deux étamines. . . . . . . . 4 4

4. Stipules des feuilles en demi-cœur ou réniformes. . 6

- Stipules linéaires ou lancéolées. . . . . . . . . 5 
5. Feuilles longues, linéaires, soyeuses et luisantes en dessous. - Arbrisseau à rameaux jaunâtres ou brunâtres. - Bords des eaux et cultivé.

S. viminalis $\mathrm{L}$. Feuilles courtes, ovales, luisantes et veinées en dessus. - Sous-arbrisseau à rameaux couchés ou buissonnant. - Lieux humides, surtout au bord de la mer. S. repens L. 6. Feuilles glabres et luisantes en dessus, velues et molles au toucher en dessous. - Arbre ou arbrisseau à rameaux épais, glabres et luisants. - Lieux boisés. Saule Marceau.

S. Caprea L.

- Feuilles velues sur les deux faces. . . . . . . 7

7. Feuilles lancéolées, larges, terminées par une petite pointe droite. - Arbre ou arbrisseau à jeunes rameaux et à bourgeons velus et blanchàtres. - Bords des eaux. Saule noir.

S. cinerea L.

- Feuilles arrondies, petites, obtuses ou terminées par une petite pointe oblique. - Arbrisseau très rameux, à rameaux grêles et dirigés en tous sens. S. aurita L.

\section{G. Populus Tourn. - Peupliers.}

Rameaux très anguleux. - Arbre à feuilles triangulaires ou orales.-Cult. - Peuplier de Caroline.P.angulata Ait.

- Rameaux arrondis ou à angles peu marqués. . . 1

1. Jeunes pousses velues; écailles des chatons ciliées. . 2

- Jeunes pousses glabres; écailles des chatons non ciliées. . . . . . . . ... 4

2. Toutes les feuilles d'un blanc brillant en dessous; écailles des chatons à peine crénelées. - Cultivé. Peuplier de Hollande.

P. alba L.

- Feuilles n'étant pas toutes d'un blanc brillant en dessous; écailles des chatons déchiquetées. . . . . 3

3. Arbre élevé; feuilles adultes fermes et d'un vert assez foncé en dessus. - Auvergne. P. canescens Sm.

- Petit arbre, à feuilles adultes minces et d'un vert clair, et $\dot{a}$ jeunes feuilles velues; style d̀ quatre lobes au sommet. - Tremble.

P. tremula L.

Varie à jeunes feuilles laineuses et à style découpé au sommet (P. villosa Rchb.)

4. Rameaux dressés contre la tige principale. - Cultivé. - Peuplier d'Italie.

P. fastigiata Poir.

- Rameaux étalés. . . . . . . . . . . 5

5. Feuilles triangulaires ou ovales et aiguës, plus longues que larges.

P. nigra L.

- Feuilles plus larges que longues. - Cultivé. - Peuplier de Virginie.

P. virginiana Desf.

Varie à rameaux ailés et à feuilles munies de deux glandes à la base ( $P$. canadensis Michx.) 


\section{G. Betula L.}

Plus de dix étamines; fleurs se développant après les feuilles. - S. G. Betula Tourn.

Quatre à dix étamines; fleurs se déreloppant avant ou avec les feuilles. - S. G. Alnus Tourn.

S. G. Betula Tourn. - Bouleaux.

Arbre à écorce blanche; rameaux grêles, lisses ou verruqueux; feuilles triangulaires et aiguës. - Bouleau. B. alba L. Varie à jeunes rameaux velus (B. pubescens Ehrh.)

$$
\text { S. G. Alnus Tourn. - Aulnes. }
$$

Arbre élevé, à feuilles ovales, arrondies, dentées; jeunes pousses visqueuses. (A. glutinosa Gœrtn.)

B. Alnus L.

Varie à jeunes pousses grises, velues, non visqueuses (A. incana Willd.)

\section{G. Garpinus L. - Charmes.}

Arbre assez élevé; feuilles ovales, aiguës, velues par places, dentées en scie; bractées des fruits à trois lobes. - Gultivé. - Charme.

G. Betulus L.

- Arbre moyen; feuilles ovales, lancéolées, aiguës, doublement dentées; bractées du fruit ovales, poilues. - Cultivé.

C. Ostrya L.

$$
\text { G. Conylus Tourn. - Coudriers. }
$$

Arbrisseau à feuilles ovales, en cœur, aiguës; styles rouges. Noisetier.

G. Avellana L.

\section{G. Fagus L.}

Chatons mâles globuleux. - S. G. Fagus T.

Chatons mâles allongés et cylindriques. - S. G. Castanea.

$$
\text { S. G. Fagus L. - Hètres. }
$$

Arbre éleré, lisse et blanchàtre; feuilles ovales, ciliées, lisses; fleurs verdâtres. F. sylvatica $L$.

S. G. Castanea T. - Châtaigniers.

Arlore élevé, grisâtre, ả branches étalées; feuilles lancéolées et dentées. - Lieux sablonneux de toute la région. - (Gastanea vulgaris T.)

F. Castanea L. 


\title{
G. Quercus L. - Chênes.
}

Feuilles persistantes, entières ou d̀ dents pointues. . . 1

- Feuilles non persistantes et plus ou moins découpées. 2

1. Ecailles de la cupule aiguës et étalées. - Arbre à écorce subéreuse, produisant le liège. - Cultivé de Bayonne à Agen et à Coutras. Q. Suber L. Ecailles de la cupule appliquées. - Arbre peu élevé, à écorce brune et lisse. - Ghêne-vert, Yeuse. Q. Ilex L.

2. Ecailles de la cupule hérissées, linéaires et recourbées.

- Ecailles appliquées les unes sur les autres. . . . 3

3. Feuilles velues et écailles de la cupule liches au sommet. - Arbre à feuilles adultes velues en dessous et parsemées en dessus de poils étoilés, ne poussant qu'en juin. - Les landes. - Chêne tauzin. Q. Tozza DC.

- Feuilles glabres ou feuilles velues avec les écailles de la cupule serrées. - Arbre élevé, à feuilles variables. Chêne rouvre.

Q. Robur L.

Varie : 10 à feuilles velues ( $Q$. pubescens Willd.); $2^{\circ}$ à fruits à longue queue (Q. pedunculata Ehrh.); $3^{\circ}$ à fruits presque sans queue (Q. sessiliflora $\mathrm{Sm}$.)

\section{Fam. des CONIFĖRES Juss.}

\author{
G. Pinus L.
}

Feuilles solitaires. . . . . . . . . . . 1 - Feuilles groupées par deux, par cinq, ou réunies en plus grand nombre dans une petite gaine. . . . . . 2

1. Feuilles persistantes; écailles des fructifications ou cônes obtuses. - S. G. Abies T.

- Feuilles caduques; écailles des fructifications prolongées en s pointe. - S. G. Larix T.

2. Deux à cinq feuilles par faisceau; écailles des cônes ligneuses et épaissies au sommet. - S. G. Pinus.

- Quinze à vingt feuilles par faisceau; écailles des cônes minces, non épaissies. - S. G. Larix.

$$
\text { S. G. Abies T. - Sapins. }
$$

Cônes pendants, à écailles persistantes. . . • • . . 1

- Cônes toujour's dressés, à écailles larges ét cadiuques. 3 
1. Cônes allongés, cylindriques. - Arbre élevé et droit; feuilles presque quadrangulaires, pointues, d'un vert gai. - Cultivé. - (A. excelsa DC.) P. Abies L. Varie à feuilles glauques, d'un blanc argenté. - Cultivé - (A. alba Poir.)

- Cônes ovoïdes ou elliptiques. . . . . . . . 2

2. Feuilles très courtes, presque quadrangulaires. - Arbre à écorce unie et noirâtre; feuillage d'un vert sombre; cònes petits, elliptiques. - Gult. - (A.nigra Poir.) P. nigra.

- Feuilles planes et linéaires. - Arbre à branches pendantes; cônes petits, de la grosseur d'un œuf de pigeon. Cultivé. - (A. canadensis Mich.) P. canadensis.

3. Feuilles marquées en dessous de deux lignes blanches.Arbre en pyramide; feuilles échancrées ou obtuses au sommet. (A. pectinata DC.)

P. Picea L.

Varie à feuilles plus petites, odorantes par le froissement (A. balsamea Mill.)

- Feuilles sans lignes blanches en dessous. . . . . . 4

4. Feuilles à deux dents au sommet, argentées en dessous. (A. Pindrow Royle.)

P. Pindrow.

- Feuilles hérissées, terminées en pointe sèche. (A. Pinsapo Bois.)

P. Pinsapo.

S. G. Larix T. - Mélèzes et Cèdres.

Feuilles caduques; cônes à écailles lâches, persistantes. 1 - Feuilles persistantes; cônes à écailles serrées, caduques. . . . . . . . . .. 2 1. Arbre pyramidal; feuilles molles, en alène. (L. europoea L.)

P. Larix L.

Varie à feuilles très menues et plus courtes $(L$. americana Mich.)

2. Arbre à gros tronc noueux et à large cime; feuilles sombres; cônes gros. (Cedrus Libani Barr.) P. Cedrus L.

Varie: 10 à feuilles glauques et à cônes petits (Cedrus atlantica Monett.); $2^{\circ}$ à feuilles blanchâtres et à rameaux flexibles et inclinés (Cedrus Deodora Roxb.)

S. G. Pinus Tourn. - Pins.

Feuilles réunies par deux. . . . . . . . 1

- Feuilles réunies par trois. . . . . . . . . 2

- Feuilles réunies par cinq. . . . . . . . . 3

1. Ecusson des écailles en pyramide losangique et tronquée au sommet.

P. sylvestris L.

Varie à pyramide de l'écusson aux arêtes aiguës; tronc et rameaux rouges (P. rubra Mill.)

- Ecusson des écailles très épais, irrégulier et non anguleux. P. Laricio L. 
- Ecusson des écailles renflé, terminé par un mamelon en losange pointu. (P. pinaster Lamb.) P. maritima DC.

Varie à feuilles longues et fines, dépassant le sommet des rameaux ( $P$. pyrenaïca Lap.)

- Ecusson des écailles à peine pointu. - Arbre en parasol et à cònes gros.

P. Pinea L.

- Ecusson des écailles en pointe forte et crochue. - Arbre à cime large.

P. pungens Mich.

- Ecusson des écailles obtus et élargi. - Arbre à cônes persistants sur les vieilles branches. P. Halepe zsis Ait.

2. Ecusson des écailles en pyramide très allongée, losangique et terminée par une pointe droite. - Arbre à trone nu, couronné par une cime élargie. P. Tæeda L.

- Ecusson des écailles en pyramide surbaissée, aussi large que longue, et portant une épine droite au sommet. Arbre à cime arrondie.

P. rigida Nich.

- Ecusson des écailles en crochet, qui est, en outre, recourbé en arrière.

P. australis Mich:

3. Ecusson des écailles plan et arrondi. - Arbre pyramidal, à feuillage tendre et glauque. - Pin Weimouth ou Pin du Lord.

P. Strobus L.

Varie 10 à feuilles pendantes ( $P$. excelsa Wall.); $2^{\circ}$ a feuillage d'un vert luisant ( $P$. Lambertiana Doug.)

- Ecailles sans écusson.

P. Cembra L.

\section{G. Thuia Tourn.}

Arbuste à rameaux dressés, d'un rert gai. - Cultivé dans les bosquets.

Th. orientalis $\mathrm{L}$.

- Arbuste à rameaux étalés, d'un vert sombre. - Cultivé dans les bosquets.

Th. occidentalis L.

\section{G. Cupressus T. - Cyprès.}

Feuilles menues et imbriquées. . . . . . . . . . 1 - Feuilles assez longues, d'un vert pâle, sur deux rangées, simulant par leur ensemble une feuille pennée. Cyprès chauve.

G. distichum L.

1. Feuilles obtuses. - Arbre en pyramide étroite. - Cultivé un peu partout. G. sempervirens L.

Varie à rameaux étalés (C. horizontalis Mill.)

- Feuilles aiguës. - Arbuste à rameaux pendants. - Cultivé.

G. pendula Lhér.

\section{G. Juniperus L.}

Feuilles étalées, verticillées par trois ou opposées. . . . 1 - Feuilles imbriquées sur plusieurs rangées. . . . . 3 
1. Fructifications roussâtres. - Arbriss. J. Oxycedrus L.

- Fructifications bleuâtres ou noirâtres. . . . . . 2

2. Arbre à écorce rouge.

- Arbrisseau très rameux, grisâtre. J. communis L.

3. Feuilles imbriquées sur quatre rangs; fructifications bleuâtres.

J. Sabina L.

- Feuilles imbriquées sur cinq ou six rangs; fructifications rougeâtres.

J. phœnicea L.

\section{G. Taxus L.}

Arbre rameux, à feuilles linéaires, d'un vert foncé; fruits d'un beau rouge, à la maturité. - Cult. - If. T. baccata L.

\section{G. Ginkgo L.}

Arbre élevé; feuilles fasciculées au sommet des rameaux, à limbe en éventail bilobé; fruits charnus. - Cultivé çà et là dans le S.-O. G. biloba L.

\section{G. Ephedra L.}

Sous-arbrisseau sans feuilles, à rameaux couchés; fleurs jaunes ; fruits rouges. - Sables maritimes. E. distachya L.

\section{Fam. des ALISMACÉES.}

\section{G. Sagittaria L. - Sagittaires.}

Plante à feuilles toutes radicales, en fer de flèche; fleurs blanches, par trois. - Fossés. S. sagittæfolia L.

\section{G. Alisma L. - Fluteaux.}

Six fruits étoilés. - Plante à feuilles toutes radicales, en cœur à l2. base; fleurs blanches, en ombelle. - Se trouve dans les marais.

A. Damasonium L.

- Plus de six fruits non vayonnants. . . . . . . 1

1. Fleur's petites; fruits à trois angles; feuilles asse: grandes. - Plante à rameaux verticillés et en panicule; feuilles en cour à la base; fleurs rosées. - Se trouve dans les fossés.

A. Plantago L.

Varie a feuilles lancéolées (A. lanceolatum. With.) 
Fleurs grandes; fruits en tête ou en cercle; feuilles étroites.................. 2

2. Fruits en têle arrondie. - Plante dressée; fleurs rosées. - Bords des eaux. A. ranunculoides $\mathrm{L}$. Varie à tige couchée et enracinée aux nœuds (A.repens DC.)

- Fruits en cercle. - Plante grêle, flottante; fleurs blanches.

A. natans L.

\section{G. Butomus L.}

Plante à feuilles toutes radicales, très longues; fleurs rosées, en ombelle terminale. - Marais. B. umbellatus L.

\section{G. Triglochin L. - Troscarts.}

Fruits ovales, au nombre de six. - Plante à feuilles linéaires et à fleurs verdâtres, en épi allongé. T. maritimum L.

- Fruits linéaires, au nombre de trois. - Plante à racine stolonifëre; fruits dressés.

T. palustre L. Lois.)

Varie à racine bulbeuse et à fruits étalés ( $\stackrel{T}{T}$ Barrelieri

\section{G. Hydrocharis L.}

Plante submergée; feuilles flottantes, arrondies; fleurs blanches, à fond jaune. - Eaux tranquilles. H. Morsus ranæ L.

\section{G. Vallisneria Michx. - Vallisnéries.}

Plante à feuilles toutes radicales, linéaires, denticulées au sommet; fleurs rougeâtres. - Se trouve dans le canal du Midi.

V. spiralis L.

\section{G. ELODEA Rich.}

Plante submergée, très rameuse; feuilles allongées, obtuses, nombreuses et par trois; fleur's femelles rosées, à tube très long, axillaires. - Les lacs de la côte et les eaux dormantes.

E. canadensis L.

\section{G. Potanogeton L.}

Feuilles ovales ou lancéolées, larges d'un centimètre au moins. ............... 1

- Feuilles linéaires et longues, n'ayant pas un centimètre de large. . . . . . . . . . . . 99

1. Feuilles pédiculées. . . . . . . . . . . . 2

- Fevilles sans queue. . . . . . . . . 5 
2. Queue de la fleur épaissie au sommet. - Plante très rameuse et très variable. $\quad P$. heterophyllus Schr. Varie : 10 à feuilles submergées linéaires et sans queue; 20 à feuilles submergées arrondies à la base et embrassantes ( $P$. nitens Web.); $3^{\circ}$ à feuilles flottantes nulles (P. gramineus L.); $4^{\circ}$ à feuilles flottantes sans queue (P. rufescens Sch.)

- Queue de la fleur non renflée au sommet. . . . . . 3 3. Feuilles membraneuses et transparentes. - Les eaux claires des terrains calcaires. P. plantagineus Duc. - Feuilles flottantes coriaces et opaques. . . . . . 4

4. Fleur's et fruits en épis serrés; ovaires à bec court ou nul.

P. polygonifolius Pour.

- Fleurs et fruils en épis laches ou interrompus; ovaires à bec recourbé.

P. natans $\mathrm{L}$.

Varie à feuilles rétrécies a la base et non en cour ( $P$. fluitans Roth.)

5. Feuilles ayant plus d'un centimètre de large. . . 6

- Fevilles n'ayant pas plus d'un centimétre. . . . 8

6. Fevilles échancrées et embrassantes. P. perfoliatus L.

- Feuilles ni échancrées ni embiassantes. . . . . . 7

7. Feuilles ovales ou allongées, transparentes. P. Iucens L.

- Fenilles d'un vert foncé, lancíolées ou linéaires. . . 2

8. Tige comprimée; feuilles infres alternes. P. crispus L.

- Tige cylindrique; feuilles infres opposées. P. densus L.

9. Feuilles embrassant la tige par une gaine allongée. Les eaux saumâtres.

P. pectinatus L.

- Fevilles peu ou point engainantes a la base. . . . 10

10. Tige comprimée, anguleuse ou ailée. - Plante variable. - Les eaux.

P. compressus $L$.

Varie : 10 à feuilles aiguës ( $P$. acutifolius Link.); $2^{\circ}$ à feuilles obtuses et it queue des fleurs de la longueur de l'épi ( $P$. obtusifolius Koch.); $3^{\circ}$ à feuilles obtuses et à queue des fleurs plus longue que l'épi (P. EEderi Mey.)

- Tige peu ou point comprimée ni ailée. . . . . . 11

11. Queue des fleurs renflée au sommet. . . . . . . 2

- Queue des fleurs filiforme. - Plante à feuilles linéaires, d'un vert clair et à fruits presque lisses. P. pusillus L.

Varie : 10 à feuilles plus larges, obtuses $(P$. Berchtoldi Bor.); 20 à plante d'un vert foncé et à un seul fruit tuberculeux (P. trichoïdes Scham.)

\section{G. Piuppia L.}

Plante nageante, rameuse et filiforme; anthères allongées; fruits ovales, aigus.

R. maritima L.

Varie à plante plus grêle, à anthères arrondies et à fruits en croissant ( $R$. rostellata Koch.) 


\section{G. Zannichellia L.}

Plante nageante, rameuse et filiforme; anthères à quatre loges.

Z. palustris L. Varie à anthères à deux loges ( $Z$. dentata Willd.)

\section{G. Althenia Pet.}

Petite plante filiforme, rameuse; feuilles capillaires. - Marais de-l'île d'Oléron.

A. filiformis Petit.

\section{Fam. des LILIAGÉES.}

\section{G. Colchicum L. - Colchiques.}

Plante à bulbe plein, revêtu d'une tunique noire; fleurs lilas rosé ; feuilles lancéolées, aiguës, poussant au printemps. - Les prairies. $\quad$ G. autumnale L. Varie à fleurs marquées de petits carreaux pourpres Cultivée - (G.variegatum L.)

\section{G. TulipA Tourn. - Tulipes.}

Etamines à filets glabres. . . . . . . . . . 1 - Etamines à filets barbus à la base. . . . . . . . 2 1. Pièces de l'enveloppe florale obtuses. - Plante à enveloppe du bulbe laineuse en dedans; feuilles ovales lancéolées; fleurs écarlates, à fond noir bordé de blanc. - Cult. et natural. dans la vallée de la Garne. T.Oculus Solis St-Am.

- Pièces de l'enveloppe florale aiguës. . . . . . . . 3

2. Fleurs panachées de rouge et de jaune, odorantes. Cultivée.

T. suaveolens Roth.

- Fleurs écarlates en dehors, blanches en decians, à fond noir.

T. clusiana DG.

3. Pièces de l'enveloppe florale aiguës et velues. - Fleurs jaunes, presque penchées. - Cà et là. T. sylvestris L.

- Pièces de l'enveloppe florale ob́tuses et glabres. - Fleurs dressées, variant de couleur à l'infini. - Gultivée et échappée çà et là.

T. Gesneriana L.

G. Fritillaria L. - Fritillaires.

Fleurs axillaires dans un verticille de feuilles. - Plante élevée, raide; feuilles en verticilles; fleurs orangées, jaunes ou panachées. - Cultivée.

F. imperialis L. 
- Fleurs terminales, pourpres, panachées de carreaux blancs et violets.

F. Meleagris L.

\section{G. Asphodelus L. - Asphodèles.}

Fleurs jaunes. - Plante à feuilles triangulaires, striées, et à tige florale feuillée. - Cultivée. A. luteus L.

- Fleurs blanches. - Plante à feuilles linéaires, en gouttière et raides; tige florale nue.

A. ramosus L.

\section{G. ANTHERicum L.}

Fleurs jaunâtres. - Plante rampante à la base; tige florale dressée; feuilles linéaires, en glaive; fleurs jaunes, en épi terminal. (Narthecium ossifragum Huds.; Abama ossifraga DC.)

A. ossifragum L.

- Fleurs blanches ou rouges.

1. Etamines à filets velus. - Plante à feuilles linéaires, en gouttière, tortillées; fleurs blanches, roses ou violacées en dehors. (Phalangium bicolor DC.) A. planifolium L.

- Etamines à filets glabres. . . . . . . . . . 2

2. Tige rameuse au sommet. - Plante à feuilles linéaires, en gouttière; fleurs blanches, à style droit. (Phalangium ramosum Lam.) $\quad$ A. ramosum $L$.

- Tige simple. - Plante à feuilles linéaires; fleurs blanches, a style arqué. (Phalangium Liliago Sch.) A. Liliago L.

\section{G. Allium L. - Ails.}

Tige creuse et très renflée vers la base. - Plante à bulbe aplati, tuniqué et rougeàtre; fleurs blanches. - Cultivée comme Oignon.

A. Gepa L.

- Tige non renflée. . . . . . . . . . . . 1

1. Tige anguleuse, surtout au sommet. . . . . . 2

- Tige cylindrique. . . . . . . . 3

2. Feuilles linéaires, étroites; fleurs roses. - Plante i rhizome portant des petits bulbes allongés. - Auvergne, Cérennes, Pyrénées; çà et lá dans le S.-O. A. fallax Don.

- Feuilles élargies; fleurs blanches ou blanchâtres. Plante à buibe allongé et it 2-3 feuilles radicales, ovales. - Lieux frais. 3. Feuilles planes, de un centimètre au moins de largeur. . . . . . ...... 4

- Feuilles linéaires, cylindriques ou a peu près. . . .9

4. Fleurs blanchâtres. . . . . . . . . . . 5

- Fleurs roses ou purpurines. . . . . . . . . 6

5. Bulbe composé; feuilles lisses. - Plante à fleurs en ombelle bulbifère. - Gultivée comme Ail. A. sativum L. 
- Bulbe simple; feuilles striées. - Plante à fleurs en tète. Cultivée comme Poireau.

6. Ombelle bulbifère. - Plante à bulbe composé. - Cultivée comme Rocambole.

A. Scorodoprasum L.

- Ombelle non bulbifère. . . . . . . . . . . 7

7. Trois des étamines très saillantes. - Plante a bulbe arrondi, produisant de nombreux bourgeons ou caïeux. Cultivée comme Poireau d'été. A. Ampeloprasum L.

- Etamines peu ou point saillantes. . . . . . . 8

8. Plante robuste; étamines à peu près égales à l'enveloppe florale. - Toulouse.

A. polyanthum Ræm. Plante grêle; étamines plus courtes que l'enveloppe florale.

A. rotundum $\mathrm{L}$.

9. Feuilles florales plus courtes ou égales à l'ombelle, à la

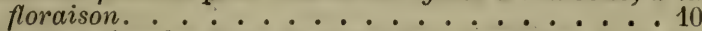

- Feuilles florales plus longues que l'ombelle, a ia flo-

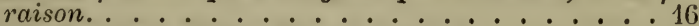

10. Trois étamines trifides et trois simples. . . . . . . 11

- Toutes les étamines simples. . . . . . . . 14

11. Feuilles planes. . . . . . . . . . . . 8

- Feuilles demi-cylindriques et creuses. . . . . . . 12

12. Fleurs d'un rose pâle, entremêlées de bulbilles. - Plante à odeur d'ail très forte et à bulbe composé. $\mathbf{A}$. vineale $\mathrm{L}$.

- Fleurs d'un beau rouge pourpre. . . . . . . . 13

13. Pièces de l'enveloppe florale à carène noire. - Plante à bulbes agrégés. - Echalotte. A. Ascalonicum L.

- Pièces de l'enveloppe florale à carène lisse ou rugueuse. - Plante à feuilles rondes. A. sphærocephalum L.

Varie à feuilles canaliculées (A. Deseglisei Bor.)

14. Etamines saillantes. - Plante à fleurs blanches ou rosées, odorantes, en tête serrée.

A. ericetorum Thore.

- Etamines non saillantes. . . . . . . . . 15

15. Fleurs d'un beau rose. - Plante à feuilles un peu en gouttière et ciliées.

A. roseum L.

- Fleurs d'un beau rouge. - Plante à feuilles cylindriques et creuses. - Givette.

16. Fleur's d'un beau jaune. - Plante à feuilles charnues, très lisses et à bulbe simple. - Vient en Auvergne, dans les Cévennes et les Pyrénées. $\quad$ A. flavum L.

Varie à feuilles trés longues - Gultivée comme Oignon d'hiver - (A. fistulosum L.)

- Fleurs jamais jaunes. . . . . . . . . . . 17

17. Fleurs d'un rose violet, à étamines saillantes. - Plante à bulbe simple et à feuilles charnues, rudes aux bords. Les lieux arides.

A. carinatum $\mathrm{L}$.

- Fleurs de couleur sale, ḋ élamines non saillantes. Plante à bulbe simple, fétide; feuilles demi-cylindriques, creuses.

A. oleraceum L. 
Varie: 10 à fleurs très nombreuses non entremêlées de bulbilles (A. paniculatum L.); $2^{\circ}$ à feuilles presque planes (A. complanatum L.)

\section{G. Ornithogalum L. - Ornithogales.}

Filets des étamines, tous ou plusieurs, sensiblement élargis à la base. - S. G. Ornithogalum L.

Filets des étamines peu ou point élargis à la base. - S. G. Gagea Sal.

\section{S. G. Ornithogalum L.}

Fleurs en bouquet.-Plante variable, à bulbe composé; fleurs blanches, à bandes vertes. - Les champs cultivés. - Belled'onze-heures.

O. umbellatum L.

Varie à queue des fleurs dirigée en bas $(O$. divergens Bor.)

- Fleurs en longues grappes. . . . • • . . . . . 1

1. Fleurs jaune pâle. - Plante élevée. O. pyrenaïcum L.

- Fleurs d'un blane pur, en grappe p!yramidale. - Cultivée.

O. pyramidale L.

S. G. Gagea Sal.

Queue des feurs glabre. . . . . . . . . 1

- Queve des fleurs velue. . . . . . . . . . . . . 2

1. Plante à trois bulbes, horizontaux et nus. - Fleurs jaunes et glabres. (G. stenopelata Fr.) O. stenopetalum Fr.

- Plante à un seul bulbe, enveloppé d'une membrane. Fleurs jaunes, en ombelle. (G. lutea Sch.) O. Iuteum L.

2. Divisions de l'enveloppe florale aiguës. - Plante ì. deux bulbes inégaux. (G. arvensis Sch.) O. arvense Pers.

- Divisions de l'enveloppe florale obtuses. - Plante à tubercules nombreux, enveloppés dans une membrane commune. (G. bohemica Sch.)

G. bohemicum L.

Varie à pièces de l'enveloppe florale plus allongées $(G$. saxatilis $\mathrm{K}$.)

\section{G. Scilla L. - Scilles.}

Enveloppe florale en cloche. (G. Agraphis Link.). . . . 1

- Enveloppe florale étalée. . . . . . . . 2

1. Etamines inégales. - Plante à feuilles linéaires, en gouttière; fleurs bleues ou blanches, penchées, en épi unilatéral. - Cultivée et çà et là.

S. nutans Sm.

- Etamines égales. - Plante à feuilles lancéolées; fleurs d'un bleu pâle ou violettes. - Cultivée. S. campanulata Ait.

2. Fleur's sans petites feuilles à la base. . . . . . 3

- Fleurs accompagnées de folioles membraneuses. . . 4 
3. Feuilles filiformes, poussant après ou en même temps que les fleurs, qui sont d'un bleu violet, en grappe terminale.

S. autumnalis $\mathrm{L}$.

- Feuilles lancéolées, en gouttière, au nombre de 2-3. Plante à fleurs violettes ou blanches. S. bifolia L.

4. Fleur's accompagnées de deux folioles chacune.-Plante à fleurs d'un bleu pâle, en bouquet. - Cultivée comme Jacinthe.

S. italica L.

- Fleurs accompagnées d'une seule foliole. . . . . 5

5. Feuilles linéaires. - Plante à bulbe tuniqué; fleurs d'un bleu violet, en bouquet.

- Feuilles lancéolées. - Plante à bulbe écailleux; fleurs violacées, en grappe ovale. S. Lilio Hyacinthus L.

\section{G. Muscari Tourn.}

Feuilles demi-cylindriques, étalées et jonciformes. - Plante à fleurs d'un bleu foncé, petites et rétrécies aux deux extrémités, en grappe courte et très dense. - Dans les champs cultivés.

M. racemosum DC.

Varie à grosses fleurs non rétrécies au sommet $(M$. neglectum Guss.)

- Feuilles plus larges, canaliculées et plus ou moins

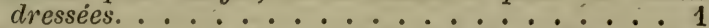

1. Grappe surmontée d'une touffe d'un beau bleu. - Les lieux cultivés.

M. comosum Mil.

- Grappe sans touffe terminale distincte. - Plante à fleurs en épi aigu d'abord, en grappe cylindrique ensuite. - Cà et là dans le S.-O.

M. botryoides $\mathrm{DC}$.

\section{G. Aphyllanthes Tourn.}

Plante à souche rampante; tige florale jonciforme; fleurs bleues, entourées d'écailles rougeâtres. - Vient aux environs d'Auch.

A. monspeliensis L.

\section{G. Convallaria L.}

Enveloppe florale à six dents recourbeies en dehors. Plante à rhizome rampant, long, grêle et cylindrique; deux feuilles radicales ovales; fleurs blanches, en grappe. - Les bois. - Muguet.

C. maialis L.

- Enveloppe florale à six dents dressées. (G. Polygonatum Tourn.). . . . . . . . . 1

- Enveloppe florale à quatre divisions réfléchies. - Petite plante at rhizome articulé; deux feuilles alternes; fleurs petites, blanches, en grappe.

G. bifolia L. 
1. Tige cylindrique. - Plante à gros rhizome; fleurs blanches, à étamines poilues; fruit charnu, noir bleuâtre. - Les bois frais.

C. multiflora I.

- Tige anguleuse. - Plante à gros rhizome; fleurs blanches, à étamines glabres. - Mêmes lieux. C. Polygonatum L.

\section{G. Paris L. - Parisettes.}

Plante à rhizome charnu, mince et allongé; tige à une seule fleur verdàtre, placée au milieu d'un verticille de quatre feuilles. - Les bois.

P. quadrifolia I.

\section{G. Asparagus L. - Asperges.}

Plante buissonnante, ligneuse et piquante; fleurs jaunâtres. Cà et là dans le Lot et le Tarn. $\quad$ A. acutifolius L. - Plante herbacée et molle, dressée, très rameuse au sommet; fleurs jaune verdâtre. - Cultivée comme Asperge et échappée.

A. officinalis L.

Varie à plante couchée $-\Lambda$ ux bords de la mer $-(A$. maritimus Lloyd.)

\section{G. Ruscus L. - Petit Houx.}

Sous-arbrisseau à rameaux terminaux, aplatis en forme de feuilles, épineux; fleurs verdatres; fruits rouges. - Petit Houx.

R. aculeatus $\mathrm{L}$.

G. Smilax L. - Salsepareilles.

Plante ligneuse, flexueuse,et grimpante, munie d'épines sur la tige; feuilles en cour, aiguês; fleurs verdàtres. - Ile de Ré et Bayonne. $\quad$ S. aspera $L$.

\section{Fam. des AMARYLLIDÉES R.B.}

\section{G. Galanthus L.}

Plante à deux feuilles radicales et à une fleur pendante, blanche, verte au sommet. - Perce-Neige. G. nivalis L.

\section{G. Levcorum L.}

Plante à trois feuilles basilaires; tige florale triangulaire, portant une seule fleur blanche.

L. vernum $L$.

Varie à tige florale à deux angles, portant plusieurs fleurs ( $L$. cestivum L.) 


\section{G. Amaryllis L.}

Plante à feuilles linéaires et à fleur jaune, campanulée, solitaire, accompagnée d'une foliole membraneuse et indivise. Natural. çà et lả et cult. dans les jardins. A. lutea L.

\section{G. Pancratium L.}

Plante à feuilles linéaires, glauques; tige florale longue, à fleurs blanches, en ombelle. - Se trouve dans les sables maritimes.

P. maritimum L.

\section{G. Narcissus L. - Narcisses.}

Les Narcisses sont des plantes de prairies, qu'on peut considérer comme indirectement cultivées pour la plupart. Elles forment aussi entre elles de nombreux hybrides. Ces deux causes rendent la détermination des espèces difficile et douteuse.

Enveloppe florale en entonnoir ou en cloche. . . . . 1 - Enveloppe florale étoilée. . . . . . . . . 2

1. Fleurs à couronne très grande, dépassant l'enveloppe florale. - Plante à feuilles demi-cylindriques et à tige uniflore.

N. Bulbocodium L.

- Fleurs à couronne égalant l'enveloppe florale ou plus courte qu'elle. - Plante à feuilles linéaires, planes; fleur jaune, solitaire et terminale. N. Pseudo Narcissus L.

2. Style mince au sommet. . . . . . . . . . . . 3

- Style élargi et trilobé au sommet. . . . . . 4

3. Une seule fleur, à couronne bordée de rouge vif. Plante à feuilles planes, linéaires, et à fleurs d'un beau blanc.

N. poeticus L.

- Plusieurs fleurs à couronne non bordée de rouge. Plante à tige comprimée en glaive et à fleurs jaunâtres. Les prairies.

N. biflorus Curt.

4. Feuilles en alène ou demi-cylindriques. . . . . . 5

- Feuilles planes ou presque planes. . . . . . . . 6

5. Feuilles filiformes. - Plante à fleur d'un beau jaune, au nombre de 2-5.

Varie à fleur solitaire ( $N$. juncifolius Req.)

N. Jonquilla L.

- Fevilles linéaires, élargies. - Plante à fleurs d'un beau jaune, à couronne lobée, odorante. $\quad \mathbf{N}$. odorus L. Varie à fleurs plus petites et à couronne en coupe ( $N$. intermedius Lois.)

6. Fleurs tout à fait blanches. N. niveus Lois.

- Fleurs à enveloppe florale blanche et à couronne jaune.

N. Tazetta L. 


\title{
Fam. des IRIDÉES Juss.
}

\author{
G. IRIS L. - Iris.
}

Enveloppe florale à pièces externes barbues en dedans. Plante à feuilles en large glaive; tige florale élevée; fleurs grandes, odorantes, d'un beau violet. - Gultivée et naturalisée çà et là.

Varie à fleurs blanches (I. florentina L.)

- Enveloppe florale à pièces non barbues. . . . . . 1

1. Feuilles larges, en glaive. . . . . . . . . . 2

- Feuilles linéaires. . . . . . . . . . . . . . 3

2. Fleurs jaunes. - Plante élevée, à plusieurs fleurs. - Bords des eaux.

I. Pseudo Acorus L.

- Fleurs bleuâtres. - Plante fétide quand on la froisse; fleurs de couleur sale, à style jaune livide au sommet. Dans les haies. I. fœtidissima L.

3. Plante à rhizome horizontal. . . . . . . . . . 4

- Plante bulberse. - Tige à une seule fleur violette, tachée de jaunâtre. - Tarn-et-Garonne.

I. tuberosa L.

4. Tige cylindrique. - Plante ì fleurs d'un blanc jaunâtre rayé de bleu.

- Tige comprimée, à bords tranchants. - Plante à petite fleur odorante, blanchattre en dehors, violette en dedans. - Lieux secs. I. graminea L.

\section{G. IxiA L.}

Petite plante bulbeuse, a feuilles linéaires et à 1-2 fleurs lilas, $\dot{a}$ fond jaune. - Les landes, au premier printemps. (Romulea Bulbocodium S.) $\quad$ I. Bulbocodium L.

Varie à fleurs blanc blenattre et à style bilobé an lieu d'être découpé en six parties - A chercher - (1. Column $\left.\alpha^{\prime}\right)$

\section{G. Gladiolus L. - Glaïeuls.}

Fleurs sur un seul rang. - Plante à feuilles linéaires ou lancéolées, aiguës; fleurs purpurines. - Pyrénées et S. - O.

G. communis $\mathrm{L}$.

Tarie it fleurs moins nombreuses (G. illyricus $\mathrm{K}$.)

- Fleurs sur deux rangs. ............ 1

1. Fleurs rosées, rayées de blanc. - Plante à tige élevée et à feuilles en glaive.

G. segetum Gaw.

- Fleurs roses, rayées de violet. - Plante élevée, à feuilles glabres. - Cultivee.

G. blandus Ait. 


\title{
Fam. des DIOSCORÉES R.B.
}

\author{
G. TAMus L.
}

Plante à rhizome épais, tuberculeux; tige florale élevée, grèle et grimpante; feuilles en cœur; fleurs d'un vert jaunatre, en grappes. .

T, communis L.

\section{Fam. des ORGHIDÉES Juss.}

\section{G. Orchis L. - Pentecôtes.}

Plante sans feuilles vertes. - Tige d'un beau violet. - Bois secs. - (Limodorum abortivum T.) O. abortiva L.

- Plante munie de feuilles vertes. . . . . . . . i

1. Tablier très entier. . . . . . . . . . . . 2

- Tablier denté, découpé ou lobé. . . . . . . . 3

2. Fleurs d'un pourpre écarlate. -- Plante à feuilles lancéolées et à fleurs peu nombreuses, en épi ovoìde, lâche. Toulouse. $\quad$ o. papilionacea $\mathrm{L}$.

- Fleurs blanchátres. - Plante à deux feuilles radicales, ovales, lancéolées; fleurs blanches, odorantes, à éperon grêle et aigu.

O. bifolia L.

Varie à plante plus robuste; $3-4$ fenilles radicales; fleurs verdâtres, à éperon renflé en massue au sommet (O.montana Schm.)

3. Pièces externes et supérieures de l'enveloppe florale réunies en forme de casque . . . . . . . . 4

- Pièces externes, supérieures ou latérales de l'enveloppe florale réfléchies ou étalées.......... 99

4. Eperon très court, renflé en bosse ou en sac. . . 5

- Eperon cylindr. ou conique, plus ou moins allongé. 6

5. Fleurs verdâtres; lobe moyen du tablier très petit. Plante à feuilles inférieures ovales, les supérieures lancéolées.

O. viridis $\mathrm{Cr}$.

- Fleurs blanchâtres; lobe moyen du tablier plus grand que ies autres. - Plante à feuilles inférieures allongées, obtuses, les supérieures très aiguës. $\quad \mathbf{O}$. albida Scop.

- Fleurs blanches, ponctuées de rouge. - Plante fétide, a feuilles ovales ou lancéolées; tablier très allongé, linéaire et tordu.

o. hircina Sw.

6. Tablier à bords denticulés. . . . . . . . . . . 2

- Tablier à 4 divisions, avec une petite pointe au milieu. 
- Plante à feuilles allongées, les supérieures engainantes; fleurs d'un rose cendré en dessus, purpurines en dedans; en épi gros, ovale; tablier piqueté de pourpre. - Les bois calcaires.

0 . militaris $\mathrm{L}$.

Varie : $1^{\circ}$ à fleurs d'un rouge brun, avec tablier blanc taché de pourpre (O. purpurea Huds.); $2^{\circ}$ à fleurs d'un blanc rosé, avec tablier piqueté de rose ( $O$. simia Lam,

Tablier à 3-4 lobes, sans pointe intermédiaire. . . 7 7

7. Tablier à 3 lobes, l'intermédiaire entier. - Plante à feuilles d'un beau vert et en gouttière; fleurs rouge terne, à tablier taché de rouge et à odeur de punaise. - Se trouve dans les prairies. $\quad$ O. coriophora L.

Varie à fleurs d'un rouge vineux, à odeur nulle ou agréable ( $O$. fragrans Poll.)

- Tablier à 3 ou 4 lobes, l'intermédiaire échancré. . . 8

8. Fleur's en épi noirâtre au sommet et à éperon beaucoup plus court que l'ovaire. - Plante à feuilles allongées et à fleurs rouge brun, avec tablier blanc taché de rouge. Les prairies.

O. ustulata L.

- Fleurs en épi jamais noirâtre et à éperon presque aussi long que l'ovaire. - Plante à feuilles lancéolées; fleurs rougeâtres ou blanches, à pièces externes de l'enveloppe florale rayées de vert.

9. Fleur's jaunâtres. - Plante à tige crense; feuilles d'uu vert clair. - Auvergne et cà et là. O. sambucina L.

- Fleurs d'un rose vif. - Plante à feuilles lancéolées; fleurs en épi ovale et serré; tablier muni à la base de lames verticales. - Régions calcaires. $\quad$ o. pyramidalis L.

- Fleurs rouges, blanches ou panachées. . . . . 10

10. Fleurs rayées ou piquetées de couleurs différentes ou plus foncées. . . . . . . . . . 11

- Fleurs uniformes, ni rayées ni piquetées. . . . . . 12

11. Fleurs d'un blanc lilas; tablier presque plane. - Plante à feuilles lancéolées, tachées de noir. O. maculata L.

- Fleurs purpurines, à tablier rabattu sur les cótés. Plante à tige creuse; feuilles lancéolées, étalées, tachées. - Prairies marécageuses.

o. latifolia L.

Varie à fleurs plus foncées et à feuilles dressées, non tachées (O. incarnata L.)

12. Fleur's plus courtes que les feuilles qui les accompagnent. . . . . . . . . . . .99

- Fleurs plus longues que les feuilles qui les accompa-

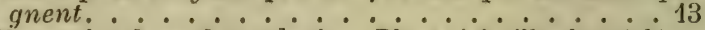

13. Plante à tubercules palmés. - Plante à feuilles lancéolées; fleurs rosées, non tachées, très odorantes, en épi aign; éperon plus long que l'ovaire.

O. conopsea L.

Varie à feuilles plus étroites et à éperon ne dépassant pas l'ovaire (O. odoratissima L.) 
- Plante à tubercules entiers et arrondis. - Plante variable, à feuilles lancéolées, planes, souvent tachées; fleurs rouge pourpre, en épi lâche; feuilles florales à une seule nervure.

O. mascula L.

Varie : 10 à feuilles en gouttière, non tachées, celles qui accompagnent les fleurs à 3-5 nervures (O. laxiflora Lam.); $2^{\circ}$ a plante plus grêle, avec tablier à lobe moyen grand et très échancré ( $O$. palustris Jacq.); $3^{\circ}$ à pièces externes de l'enveloppe florale étalées sur un même plan (O. alata Fl.)

\section{G. OPHRYs L.}

Toutes les pièces de l'enveloppe florale dressées en cloche, même le tablier. - Plante à 2-3 tubercules globuleux; feuilles ovales ou lancéolées; fleurs petites, d'un vert jaunâtre.

O. monorchis L.

- Pièces supérieures de l'enveloppe florale réunies en casque. - Plante à feuilles allongées; fleurs d'un vert jaunâtre, en épi serré; tablier à trois lobes linéaires. Les lieux calcaires arides.

O. anthropophora L.

- Pièces de l'enveloppe florale toutes étalées. . . . . 1

1. Tablier entier, denté ou obscurément lobé au sommet. 2

- Tablier trilobé à la base ou vers le milieu. . . . . . 3

- Tablier trilobé au sommet. . . . . . . . . . . 5

2. Pièces externes de l'enveloppe florale verdâtres. - Petite plante à feuilles inférieures ovales. O. aranifera Huds.

- Pièces externes blanches ou rosées. O. arachnites Hoff.

3. Pièces externes de l'enveloppe florale verdâtres. - Les bois calcaires. $\quad$ O. muscifera Huds.

- Pièces externes rosées. . . . . . . . . . 4

4. Pièces internes et supérieures de l'enveloppe florale triangulaires. $\quad$ O. apifera Huds.

- Pièces internes et supérieures linéaires et velues. Vallée de la Garonne. $\quad$ O. scolopax Cav. 5. Tablier brusquement rétréci à la base. O. Iutea Cav. - Tablier insensiblement atténué à la base. O. fusca Link.

\section{G. Serapias L.}

Fleurs beaucoup plus courtes que les feuilles qui les accompagnent. - Plante à feuilles lancéolées ou linéaires; tablier d'un pourpre noir, lancéolé. S. longipetala Poll. Fleurs égalant à peu près les feuilles qui les accompagnent. - Plante à gaîne des feuilles tachée de rouge; tablier rouge vineux, poilu.

S. cordigera L.

- Fleurs de moitié plus longues que les feuilles qui les accompagnent. - Plante à fevilles en gouttière; tablier d'un brun pourpre, glabre.

S. lingua $L$. 


\section{G. Epipactis L.}

Ovaire sans queue, un peu contourné lui-même (G. Cephalanthera Rich.). ............. 1

- Ovaire à queue contournée. . . . . . 3

1. Fleurs rouges, à ovaire velu. - Plante velue dans le haut, à feuilles pliées.

E. rubra All.

- Fleurs blanches ou jaunâtres, à ovaire glabre. . . 2

2. Feuilles florales plus longues que l'ovaire; fleur's d'un blanc jaunâtre. - Plante à feuilles ovales, embrassantes. $\quad$ E. grandiflora L.

- Feuilles florales supérieures plus courles que l'ovaire; fleurs d'un beau blanc. - Plante à feuilles linéaires ou lancéolées, aiguës.

E. ensifolia Sw.

3. Fleurs pendantes, en grappe très lâche. - Plante des marais, à feuilles lancéolées, embrassantes; fleurs blanc rosé, striées de rose. $\quad$ E. palustris Gr.

- Fleurs étalées or penchées, en grappe fournie; plante des lieux secs. . . . . . . . . . . . 4 4

4. Feuilles inférieures largement ovales, - Plante à fleurs blanc verdatre en dehors, rougeâtres en dedans; ovaire velu.

E. latifolia All.

Varie à fleurs d'un rouge foncé (E. atrorubens Reich.)

- Ferilles allongées ou lancéolées. - Plante d'un vert jaunâtre, à ovaire glabre.

E. viridiflora Reich.

\section{G. NeOtTiA L.}

Plante jaunatre et sans ferilles, ayant l'aspect d'une Orobanche; racines entrelacées en gros paquet; fleur's en épi servé.

- Plante feuillée et verte. . . . . . . . . . . . 1

1. Feuilles ovales, à nervures anastomosées, pourpres. Plante à rhizome grêle; fleurs blanchâtres, en épi unilatéral.

- Fenilles ovales, à nervures parallètes, au nombre de deux. .............. 2

2. Tablier à deux lobes allongés. - Plante à fleurs d'un vert jaunâtre.

N. ovata Rich.

- Tablier à trois lobes, l'intermédiaire bifide. - Plante à fleurs d'un vert jaunàtre.

N. cordata Rich.

\section{G. Spiranthes Rich.}

Feuilles linéaires, lancéolées, portées sur la lige. - Plante à fleurs blanches, odorantes le soir. S. æostivalis Rich.

- Feuilles allongées, ovales, en rosette latérale. - Plante à fleurs blanches, à odeur de ranille. S. autumnalis Rich. 


\section{G. Malaxis Sw.}

Tige à trois angles; anthère caduque. - Plante à rhizome épais; feuilles d'un vert jaunâtre, pliées en long..- Vient aux environs de La Teste.

- Tige à cing angles; anthère persistante. - Plante sans rhizome; feuilles en spatule; fleurs petites, en épi grêle. Bords du lac de Léon (Landes). M. paludosa Sw.

\section{Fam. des AROÏDÉES Juss.}

\section{G. ARUM L. - Gouets.}

Feuilles découpées en pédales. - Plante élevée, marbrée; feuilles florales pourpres en dedans. - Cultivée et échappée dans les sables maritimes.

A. Dracunculus L.

Varie à feuilles florales munies en dedans de soies violettes (A. muscivorum L.).

- Feuilles entières. - Plante à souche tuberculeuse; feuilles toutes radicales, en large fer de flèche, paraissant après l'hiver, souvent tachées de noir.

A. maculatum L.

Varie à feuilles paraissant avant l'hiver et souvent tachées de blanc (A. italicum Mil.)

\section{G. Acorus L.}

Plante à odeur forte, agréable; feuilles allongées en glaive; ne fructifie pas chez nous. - Cultivée, ou descendue des Pyrénées et çà et là dans les marais. A. Calamus L.

\section{Fam. des TYPHACÉES DC.}

\section{G. Sparganium L.}

Style linéaire au sommet. - Plante dressée, rameuse; feuilles triangulaires; fleurs en têtes, qui sont réunies en grappe composée. (S. ramosum Huds.) S. erectum L.

Varie à tige simple et à têtes en grappe simple ( $S$. simplex Huds.)

- Style ovale au sommet. - Plante flottante, à tige simple et à feuilles planes, d'un beau vert.

S. natans L.

Varie à feuilles d'un vert pâle et à fruits sans queue Descendue des Pyrénées - (S. minimum Fr.) 


\title{
G. Trpha L.
}

'Tige élevée, robuste; feuilles linéaires, en glaive; fleurs en épi rond et continu.

T. latifolia L.

Varie à tige moins robuste et à épi interrompu au milieu (T. angustifotia L.)

\section{Fam. des NAÏADÉES.}

\author{
G. NAïAS L.
}

Feuilles droites, linéaires, à gaine entière; fleurs verdàtres. Les eaux.

N. fluviatilis Lam.

Varie à feuilles recourbées et à gâne denticulée (N. minor All.)

\section{G. Zostera L. - Zostères.}

Plante à rhizome rampant et noueux; feuilles linéaires, comme celles des Graminées; fleurs sur deux rangées et d'un seul côté. - Les eaux salées.

Z. marina $L$.

Tarie à plante plus petite et à feuilles étroites ( $Z$. nana Roth.)

\section{G. Lemna L. - Lentilles d'eau.}

Feuilles ramifiées en trois lobes pointus. L. trisulca L. - Feuilles ovales ou arrondies, sans lobes pointus. . . 1

1. Plusieur's racines en faisceau. L. polyrrhiza L.

- Une racine solitaire. . . . . . . . . . . 2

- Point de racine.

2. Feuilles planes.

- Feuilles convexes, gonflées en dessous.

\section{Fam. des JONGÉES DC.}

\section{G. Luzula DC. - Luzules.}

Fleurs solitaires et en grappe. . . . . . . . . 1

- Fleurs groupées en petites têtes ou en petits épis dispo-

sés eux-mêmes en grappe. . . . . . . . 3

1. Plante à longs stolons et à feuilles très étroites. - Les Pyrénées. 
2. Rameaux de la panicule droits; fruit aigu. - Plante à feuilles linéaires, velues.

L. Forsteri DC.

- Rameaux de la panicule étalés et divergents; fruit obtus. - Feuilles lancéolées, velues. I. pilosa Willd.

3. Fleurs en petites têtes. ...........4

- Fleurs en petits épis. . . . . . . . . . 6

4. Fleurs brunes. - Plante à feuilles larges et fermes, les supérieures plus courtes que les fleurs. L. maxima DC.

- Fleurs blanches, blanchâtres ou jaunes; feuilles molles et étroites. . . . . . . . . . . . 5

5. Fleurs d'un blanc jauncitre, en grappe diffuse. - Plante à feuilles velues. - Pyrénées. $\quad$ L. albida DC.

- Fleur's d'un blanc brillant, en panicule serrée et droite. - Plante à feuilles velues. - Auvergne, Cévennes, Pyrénées.

L. nivea DC. Fleurs d'un jaune pâle et doré. - Plante à feuilles glabres. - Pyrénées.

L. lutea DG.

6. Un seul épi allongé, lobé et penché. - Plante à feuilles canaliculées, velues à la base. - Auvergne, Cévennes, Pyrénées. $\quad$ L. spicata DG.

Varie à feuilles velues sur les bords (L. pedeformis DC.) Plusieurs épis ovales et comme en ombelle. : . . 7

7. Tiges courtes, presque solitaires. - Plante à rhizome rampant.

L. campestris DC.

- Tiges élevées, croissant en touffe; plantes à racines fibreuses. ............. 8

8. Fleur's blanchatres ou brunes; fruit ovale et arrondi. Les landes.

L. multiflora Lej.

- Fleurs d'un noir luisant; fruit triangulaire. - Dans l'Auvergne.

L. sudetica DC.

\section{G. Juncus L. - Jones.}

Tiges florales nues. . . . . . . . . . . 1

- Tiges florales feuillées. . . . . . . 8

1. Des feuilles radicales; fleurs terminales. . . . . . 2

- Pas de feuilles; fleurs latérales. . . . . 5

2. Trois feuilles florales proeminentes. J. triphyllus L.

- Feuilles forales non proéminentes. . . . . . 3

3. Fleurs en tête. - Plante à tige très basse et à feuilles molles et très fines.

J. capitatus Weig.

- Fleurs en panicule; feuilles dures et raides. . . . . 4

4. Feuilles cylindriques. - Plante robuste, à feuilles florales dépassant les fleurs.

J. acutus L.

Varie, au bord de la mer, à feuilles florales plus courtes que les fleurs ( $J$. maritimus Lam.)

- Feuilles canaliculées. - Plante à tige florale comme - anguleuse.

J. squarrosus L. 
5. Tige filiforme, penchée au sommet. - Plante basse, à peu de fleurs.

J. filiformis L.

- Tige non filiforme et non penchée au sommet. . . 6

6. Tige glauque, fortement striée, souple et difficile d rompre, couverte à la base de gaînes d'un noir luisant.

J. glaucus Ehrh.

- Tige peu ou point striée, fragile. . . . . . 7

7. Fleurs en panicule arrondie, sans queue, à gaîne renflée.

- Fleurs en panicule lâche ou compacte, à gaîne non renflée. $\quad J$. effusus L.

8. Feuilles noueuses entre les dorgts. . . . . . 12

- Feuilles jamais noueuses. . . . . . . . . . 9

9. Pièces de l'enveloppe florale aiguïs, plus longues que le fruit. ............. 10

- Pièces de l'enveloppe florale obtuses, plus courtes que le fruit. . . . . . . . . . . 11

10. Feuilles florales membraneuses et très courtes. - Plante à feuilles en gouttière et à fleurs unilatérales. - Les lieux sablonneux. $\quad J$. bufonius L.

- Fúlles florales herbacées, dépassant la panicule. Plante a feuilles linéaires, en gouttière. J. tenuis Willd. 11. Tige comprimée; panicule étroite et serrée. - Plante à feuilles linéaires, en gouttière; enveloppe florale plus courte que le fruit. $\quad J$. compressus Jacq. Varie a enveloppe florale aussi longue que le fruit (J. Gerardi Lois.)

- Tige cylindrique; panicule lâche et étalée. - Plante à feuilles sétacées, en gouttière.

J. Tenageia Ehrh.

12. Enveloppe florale dépassant beaucoup le fruit. . . . 13

- Enveloppe florale ne dépassant pas le fruit. . . . 14 13. Enveloppe florale à pièces égales; fruit triangulaire et aigu. - Petite plante à tige filiforme, souvent rougeâtre; feuilles sétacées, en gouttière. J. pygmæus Lam.

- Enveloppe florale a pièces inégales; fruit obtus. Plante à feuilles linéaires, canaliculées à la base. - Dans la région maritime.

14. Feuilles étroitement canaliculées; fruits obtus. - Plante comme bulbeuse à la base; feuilles sétacées, en gouttière. - Bords des marais.

J. supinus Mœnch.

- Feuilles cylindriques, comprimées; capsule aiguë. . 15 15. Fleurs blanchatres; enveloppe florale a pièces obtuses. - Tige florale dressée.

J. obtusiflorus Ehrh.

- Fleurs brunes et luisantes; enveloppe florale à pièces aiguës. ................. 16

16. Feuilles de deux sortes, les unes grosses, très noueuses, les autres menues. - Plante à tige flottante, enracinée et épaisse. 
- Feuilles semblables entre elles. . . . . . . . . . 17

17. Enveloppe florale à pièces inégales. - Plante à tige dressée; fruit à bec aigu. J. acutiflorus Ehrh.

- Enveloppe florale à pièces égales. . . . . . 18

18. Fleurs assez grandes, en panicule étalée. - Plante à tige couchée à la base et à feuilles un peu comprimées. Marais des dunes. J. lampocarpus Ehrh. - Fleurs très petites, en panicule droite. - Plante à tige droite et à feuilles très comprimées. J. anceps Mutel.

\section{Fam. des GYPÉRACÉES DG.}

\section{G. Cyperus L. - Souchets.}

Fruit comprimé, surmonté de 2 styles. . . . . . 1

- Fruit triangulaire ou linéaire, surmonté de 3 styles. 2

1. Petite plante, à racine fibreuse et à fleurs d'un jaune pâle. - Bord des eaux. $\quad$ G. flavescens L. Grande plante, à fleurs brunes. $\quad$ G. Monti L. fils.

2. Petite plante, à racine fibreuse et à fleurs d'un noir brun.

- Grande plante, à rhizome rampant et à fleur's rougeâtres. - Bords des eaux et lieux humides. C. longus L.

Varie à rameaux floraux étalés au lieu d'ètre dressés (G. badius Desf.)

- Plante moyenne, à fleurs vert jaunâtre. - Plante des Etats-Unis naturalisée à l'embouchure de l'Adour et à Bordeaux. (G. vegetus Torr.) G. virens Michx.

\section{G. Schoenus L.}

Feuilles roides, piquantes, à trois faces. - S. G. Schœnus L.

Feuilles linéaires étroites, non piquantes. - S. G. Rhynchospora Vahl.

$$
\text { S. G. Schonus L. }
$$

Fleurs en tête ovale et noire. - Plante touffue, à tige florale nue.

Sch. nigricans L.

- Fleurs en bouquet jaunâtre. - Plante élevee, à feuilles coupantes. (Gladium Mariscus R.B.) Sch. Mariscus L.

S. G. Rhynchospora Vahl.

Plante élevée, grêle, à feuilles filiformes, en gouttière; fleurs blanchâtres. (Rhynchospora alba Vahl.) Sch. albus L. Varie à plante plus petite et à fleurs rousses (Sch. fuscus L.) 


\section{G. Scirpus L.}

Fruits entouris de longues soies brillantes, - S. G. Eriophorum L.

Base du style renflée et persistante. - S. G. Eleocharis R.B. Base du style non renflée ni persistante. - S. G. Scirpus L.

S. G. Eleocharis R.B.

Tige anguleuse et capillaire. - Plante gazonnante, à fruits allongés, finement sillonnés. $\quad S$. acicularis L.

- Tige cylindrique ou comprimée, non capillaire. . . 1

1. Epi ovale et renflé. - Plante i racine grèle et fibreuse, en touffes; fruits lisses et jaunàtres. $\quad$ S. ovatus Roth.

- Epi allongé; rhizome épais ou rampant. ...... 2

2. Fruits $\dot{a}$ trois styles. - Plante touffue; fruits bruns ou verts, à trois angles aigus. $\quad$ S. multicaulis Sm.

- Fruits à deux styles. - Plante à tige florale nue et à fruits jaunâtres.

S. palustris $\mathrm{L}$.

Varie à épis embrassés à la base par une seule glume (S. uniglumis Link.)

$$
\text { S. G. Scirpus L. }
$$

Un seul épi solitaire.

- Plusieurs épis sur deux rangs, terminaux et comprimés. - Les marais.

- Plusieurs épis autrement groupés. . ...... 4

1. Tige filiforme, couchée ou flottante. .......

- Tige non filiforme et droite. . . . . . ... 3

2. Tige rameuse et feuillée. - Plante à queue des fleurs longue et axillaire; deux styles; fruits comprimés. - Les eaux douces. $\quad$ S. fluitans L.

- Tige simple, non feuillée. - Petite plante gazonnante; trois styles; fruits triangulaires. S. parvulus Rœm.

3. Une feuille très courte $\ddot{a}$ la base de la tige. - Plante à racine fibreuse, très tenace; tiges florales en touffes serrées. $\quad$ S. cæspitosus L.

- Pas de feuille à la base de la tige. - Plante ì racine fibreuse et a stolons. $\quad$ S. pauciflorus Lig.

4. Tige cylindrique ou comprimée. ........ 5

- Tige triangulaire, au moins au sommet. . . . 8

5. Epis en panicule sur une tige plus ou moins élevée. 6

- Epis en tête latérale sur une très petite tige. . . 7

6. Tige dure et ferme. - Plante à gros épis globuleux. - Les lieux sablomneux.

S. Holoschœnus L.

- Tige molle et spongieuse. - Plante variable, à gros épis ovoïdes; 3 styles. - Jonc des chaisiers. S. lacustris L. Varie : 10 à tige glauque et à 2 styles (S. glaucus Sm.); 
$2^{\circ}$ à tige verte, comme triangulaire dans le haut et à 2 styles également ( $S$. carinatus Sm.)

7. Tige non filiforme portant les fleur's vers son milieu. Petite plante à racine fibreuse; fruits régulièrement. ridés en travers.

S. supinus $L$.

- Tige filiforme, portant les fleurs près du sommet.Petite plante gazonnante, à fruits striés en long. - Bords des eaux.

Varie à fruits lisses (S. Savii Seb.)

S. setaceus L.

8. Tige nue ou peu feuillée; fleurs latérales, surmontées d'une corne triangulaire. . . . . . . . 9

- Tige feuillée; fl. accompagnées de longues féuilles. 10

9. Ecailles florales plissées en long. - Plante touffue; trois styles; fruits chagrinés en travers. S. mucronatus L.

- Ecailles florales non plissées en long. - Plante à rhizome rampant; deux styles; fruits lisses. S. triqueter L.

Varie à épis tous sessiles (S. Rothii Hoppe.)

10. Fleur's en tête arrondie; tige basse. S. michelianus L.

- Fleurs en ombelle ou en grappe; tige droite et élevée. 11

11. Fleurs en ombelle simple, à glumes aiguës. - Région maritime et dans l'intérieur.

S. maritimus L.

- Fleurs en panicule très ramifiée, à glumes obtuses.Bords des eaux courantes.

S. sylvaticus $\mathrm{L}$.

S. G. Eriophorum L.

Plante variable; tige triangulaire; feuilles courtes, planes; queue des fleurs rudes; plusieurs tètes de fleurs au sommet de la tige. ( $E$. polystachion L.)

S. polystachion.

Varie : $1^{\circ}$ a tige cylindrique, a longues feuilles en gouttière et à queue des fleurs lisses ( $E$. angustifolium Roth.); $2^{\circ}$ à tige grêle, à feuilles en gouttière à la base et à queue des fleurs velues ( $E$. gracile K.)

\section{G. Carex L. - Laîches.}

Ovaire surmonté par deux styles. . . . . . . . 1 - Ovaire surmonté par trois styles. . . ...... 22 1. Panicule ou épi composé de plusieurs parties ou épillets à plusieurs fleurs. ........... 4

- Un ou plusieurs épis simples et nullement composés. 2

2. Un seul épi unique et terminal. . . . . . . 3

- Plusieur's épis distincts, unisexués, les supérieur's máles, les inférieurs femelles. . . . . . . . . . 20

3. Epi portant des étamines en haut et des ovaires en bas.

- Epi uniquement composé de fleurs mâles ou de fleurs femelles.

4. Epi composéd'épillets tous unisexués. G. disticha Huds. 
- Epi composé d'épillets lous munis d'étamines et d'ovaires. . . . . . . . . . . 5

5. Etamines au sommet de l'épillet et ovaires à la base. 6

- Ovaires au sommet de l'épillet et étamines à la base. 13

6. Tige lisse.

C. chordorrhiza Ehr.

- Tige rude, surtaut au sommet. . . . . . . . 7

7. Ecailles des épillets bordées d'une large membrane sèche. . . . . . . . . . . 11

- Ecailles des épillets sans bordure bien apparente. . 8

8. Tige robuste, toujours droite; feuilles larges de cing à sept millimètres.

C. vulpina L.

- Tige grêle, se courbant avec l'âge; feuilles n'ayant pas cinq millimètres de large. . . . . . . . . . 9

9. Racine fibreuse; fruit sans nervures et dépassant les écailles.

Varie à épillets écartés ( $G$. divulsa Good.)

C. muricata L.

- Rhizomes rampants; fruits couverts de nervures, ne dépassant pas les écailles. . . . . . . . . 1C

10. Epillets 3-6, rapprochés; fruits non ailés. - Les lierx humides; la région maritime.

G. divisa Hu/s.

- Epillets nombreux, espacés; fruits largement ailés xu sommet. - Sables maritimes. G. arenaria L.

11. Tige robuste, $\dot{a}$ angles rudes, accrochants; feuillas linéaires élargies.

C. paniculata L.

- Tige grêle, rule au sommet seulement; feuilles très étroites. ................ 12

12. Epis courts et fournis; fruits sans côtes saillantes.-Les lieux humides des dunes. $\quad$ C. teriuscula Good.

- Epis ramifiés en panicule; fruits chargés de côtes.- Les lieux tourbeux.

C. paradoxa Will.

13. Epillets agglomérés en tête arrondie et entourés de longues ferilles.

- Epillets alternes et distincts dans l'épi ou la panicule générale. . . . . . . . . . . . . 14

14. Epillets arrondis; fruits divergents en étoile, à la maturité.

C. stellutata Good.

- Epillets ovoïdes ou allongés ; fruits peu ou point divergents. . . . . . . . . . . 15

15. Fruits bordés d'une membrane denticulée. . . . . 16

- Fruits dépourvus de rebord membraneux. . . . . . 17

16. Epillets brunatres, écartés. C. leporina L.

- Epillets blanchaties, rapprochés. G. brizoïdes L.

17. Rhizome rampant; écailles rousses, de la longueur des fruits.

- Racine fibreuse; écailles pâles, plus courtes que les

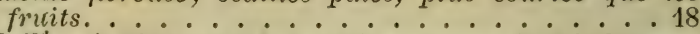

18. Epillets inférieurs très écartés et munis de très longues feuilles.

C. remota L. 
- Epillets tous peu écartés, à feuilles florales nulles ou très courtes. . . . . . . . . . . 19 19. Quatre à sept épillets ovoüdes, dressés; fruits imbriqués. $\quad$ C. canescens L.

- Sept ì douze épillets cylindriques, ouverts; fruits étalés. $\quad \mathbf{C}$. elongata L.

20. Deux à quatre épillets mâles; écailles et fruits allongés, de même dimension. $\quad$ G. acuta L.

- Un ou deux épillets mâles; fruits ovoüdes, comprimés, plus grands que les écailles. . . . . . . . 21

21. Fruits très caducs, sur huit rangs; gaine des feuilles inférieures se déchirant en réseau. C. Stricta Good.

- Fruits persistants, sur six rangs; gaine de feuilles entières.

22. Fruits velus. . . . . . . . . . . . . 23

-Fruits glabres. . . . . . . . . . . 31

23. Epi mâle solitaire et terminal. . . . . . . 24

- Deux ou plusieurs épis mâles. . . . . . . . . . 29

24. Epis inférieur's munis d'une feuille engainante. . . 27

- Epis inférieurs munis d'une feuille sans gaîne.. . 25

25. Ecailles des épis femelles aiguës. . . . . . . 26

- Ecailles des épis femelles obtuses. C. montana L.

26. Rhizome rampant; tige droite; épillets allongés; fruits plus grands que les écailles. C. tomentosa L.

- Racine fibreuse; tige penchée sous le poids des épillets arrondis; fruits égaux aux écailles. C. pilulifera L. 27. Feuilles florales des épillets inférieurs prolongées en pointe. . . . . . . . . . . 28

- Feuilles florales de tous les épillets tronquées et membraneuses au sommet.

C. humilis Leys. 28. Epillet mâle allongé, à écailles bórdées de blanc; feuilles très étroites, canaliculées. $\quad$ C. gynobasis Will.

- Epillet malle renflé en massue, à écailles brunes ou jaunatres; feuilles presque planes. C. præcox Jacq.

Varie à racines fibreuses et non à rhizome rampant (C. polyrrhiza Wall.)

29. Feuilles canaliculées, très étroites ou enroulées; épis femelles presque sans queue. $\quad \mathbf{C}$. filiformis L.

- Feuilles presque planes, un peu élargies; épis femelles à queue plus ou moins longue. . . . . . . 30 30. Fenilles glabres, glauques; fruits courts. C. glauca Sc. - Feuilles velues, non glauques; fruits aigus. C. hirta L. 31. Epi mâle solilaire et terminal. . . . . . . 32 - Deux ou plusieurs épis mâles. . . . . . . . 46 32. Feuilles velues, surtout sur les gaines. C.pallescens L. - Feuilles et gaînes glabres. . . . . - . . . 33 33. Epis femelles lâches et formés de trois à six fleurs. Les bois secs. $\quad$ C. depauperata Good. 
- Epis femelles serrés et formés de plus de six fleurs. $3 t$ 31. Fruits à bec tronqué et presque nul; épi femelle très court, n'ayant pas trois centimetres. . . . . . . 35

- Fruit ì long bec; épi femelle de plus de cinq centim. 39 35. Epi terminal allongé, mâle à la base, mixte ou femelle au sommet.

G. Buxbaumii Wahl.

- Epi terminal gréle et n'offrant que des étamines . . 36

36. Fevilles florales filiformes, non engainantes; épis femelles ovales, élargis et pendants. G. limosa L.

- Feuilles florales engainantes à leur base; épis femelles cyllindriques ou allongés, droits ou un peu penchès. . . . . . . . . . . . 37

37. Tige à angles aigus, mudes; fruits luisants. C. nitida $\mathrm{H}$.

- Tige à angles obtus et lisses; fruits ternes. . . . . 38

38. Epis rapprochés, presque sans queue; feuilles florales d'un décimètre et plus.

G. extensa Good.

- Epis distanls, munis d'une queue; feuilles florales n'ayant pas un décimètre. $\quad$ C. panicea L.

39. Epis femelles droits, sans queue ou ì très petite queue. 40

- Epis femelles penchés à la maturité, munis d'une longue

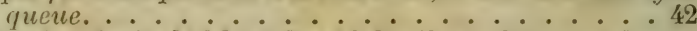

40. Bec des fruits bifide et bordé de cils roides assez longs. - Les marais. Var. Mairii du G. distans L.

- Bec des fruits sans cils. ........... 41

41. Epis femelles presque arrondis; feuilles florales étalées ou renversées.

G. flava $L$.

Virie it plante plus petite et à bee des fruits droit au lieu d'ètre recourbé (G. EEderi Ehrh.)

- Epis femelles plus longs que larges; feuilles florales droites.

C. distans L.

Varie beaucoup: 10 a ceailles munies d'une arète: $(G$. fulve Good) si lépi est jaunàtre, ou (Garex Hornschuschiana Iop.) si le fruit est rerditre; 20 à écailles sans arète: (G. punctala Gand.) si le fruit n'est que sillonné, ou (C. binervis Sin.) si le fruit a des nerrures ou des côtes saillimtes; 30 it épis femelles à longue queue (C. lavigata Sin.); ' to at fruits bordés de cils roides (G. Mairii Coss. et Germ.)

42. Bec des fruits très court; épis femelles longs de plus de un décimètre.

G. pendula Huds.

- Bec des fruits allongé; épis femelles alteignant rarement un décimètre. . . . . . . . . .43 43. Tige très rude sur les angles; épis rapprochés au sommel de la tige. $\quad$ C. Pseudo Gyperus L.

- Tige lisse ou rude seulement au sommet; épis écartés le long de la tige. . . . . . . . . . 4 4t 41. Epis supérieurs droils et ì feurs serrées; fruils à bec rude et à deux pointes. Tar. laevijala du G.distans L. 
- Tous les épis lâches et penchés.

45. Fruits très lisses.

- Fruits relevés de fortes nervures.

C. sylvatica Huds.

46. Fruits obtus, à bec très court et tronqué. C. glauca Scop.

- Fruits allongés en bec bifide. . . . . . . . 47

47. Ecailles des épis males de couleur claire, grisâtres ou membraneuses au bord.

C. vesicaria $L$.

Varie a tige lisse, a angles obtus et à feuilles glauques (C. ampullacea Good.)

- Ecailles des épis mâles d'un brun noirâtre et non mem-

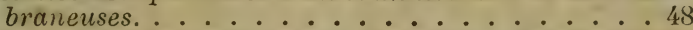

48. Ecailles des épis mâles toutes lancéolées et munies d'une arête; fruits renflés.

C. riparia L.

- Ecailles inférieures des épis mâles obtuses; fruils comprimés et finement striés.

C. paludosa Grood.

\section{Fam. des GRAMINÉES Juss.}

\section{G. ANDROPOGON L.}

Tige simple, à nœuds violacés; feuilles en gouttière, velues. Lieux arides.

A. Ischæmum L.

\section{G. Tragus Hall.}

Tiges couchées; feuilles courtes, ciliées, à gaines ventrues. Lieux sablonneux.

T. racemosus Desf.

\section{G. Spartina Sch.}

Tige élevée, raide; feuilles enroulées au sommet; fleurs alternes, sur deux rangs, velues, en deux épis unilatéraux collés l'un contre l'autre. - Se trouve dans les rases maritimes. S. stricta Roth.

Varie à épis au nombre de trois à sept - Bayonne (S. alterniflora Lois.)

\section{G. Leersia L.}

Tiges assez longues, velues sur les nœuds, genouillées; feuilles très rudes, d'un vert jaunàtre. - Vient aux bords des rivières.

L. orizoïdes L.

\section{G. Panicum L.}

Epis linéaires, digités: . . . . . . . . . . 1

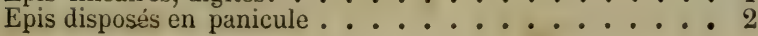


1. Fleurs sur un rang; rhizome rampant. - S. G. Cynodon Pers.

- Fleurs sur deux rangs; racine fibreuse. - S. G. Digitaria Hall.

2. Panicule resserrée en épi cylindrique.-S. G. Setaria P.B.

- Panicule étalée. - S. G. Panicum.

$$
\text { S. G. Cynodon Pers. }
$$

Plante courte, conchce; feuilles sur deux rangs, velues en dessous. - Se trouve dans les lieux sablonneux. (G. Dactylon Perș.).

P. Dactylon L.

\section{S. G. Digitaria Hall.}

Trois à cinq épis linéaires, assez longs. - Plante couchée; feuilles et gaines poilues. - Lieux sablomneux. - (D. sanguinalis $H$.)

P. sanguinale L.

Tarie : $1^{\circ}$ it fleurs munies de longs cils ( $P$. ciliare Retz.); $2^{\circ}$ ì feuilles et à gaînes glabres et à plante grèle $(P$. filiforme K.)

- Deux épis, dont l'un courtement pédiculé. - Plante couchée; feuilles presque glabres; étamines et styles violets ou noiritres. - Plante d'Amérique naturalisée le long des grandes rivieres du S.-O. - (Dig. vaginata Poir.)

P. vaginatum Sw.

$$
\text { S. G. Panicum. }
$$

Epis dressés. - Plante dressée; feuilles rudes, ondulées, sans ligule. - Bords des eaux.

P. Crus galli L.

- Epis penchés. - Plante poilue, dressée. - Cultivée comme Millet.

P. miliaceum L.

S. G. Setaria P. B.

Epis gros et penches au sommet. - Millet des oiseaux. Cultivée et échappée. - (S. italica P.B.) P. italicum L.

- Epis médiocres et non penchés. . . . . . . 1

1. Epis entremêlés de soies raides et accrochantes. - Tigẹ rule au sommet. - Lieux cultivés. - (S. verticillata P.B.) P. verticillatum $\mathrm{L}$.

- Epis entremêlés de soies non accrochantes. . . . . 2

2. Soies rertes ou rougecitres; feuilles it peu près glabres. - Lienx cultivés. - (S. viridis P.B.) P. viride L. - Soies d'un jaune fauve; feuilles parsemées de longs poils. - Lieux cult. - (S. glauca P.B.) P. glaucum L.

\section{G. Phalaris L.}

Epillets resserrés en épi cylindripue. - Glume portant au milieu dı dos une membrane lancéolée. - Les champs sablonneux. ........ Ph. paradoxa L. 
- Epillets en panicule étalée, très ramense. - Plante élevée, rhizomateuse. - Bords des eaux. - (Calamagrostis colorata DC.)

$\mathrm{Ph}$. arundinacea $\mathrm{L}$. - Epillets resserrés en épi ovale._Glume ailće au sommet; aile entière. - Gult. et échappée. Ph. cazariensis L.

Varie à aile de la glume dentelée au sommet et à épi plus long que large (Ph. minor Retz.)

\section{G. Anthoxanthum L.}

Plante odorante, une fois sèche; feuilles et gainnes poilues. Les bois.

A. odoratum L.

Varie : $1^{\circ}$ à plante annuelle et à arète plus grande (A. Ruelli Lecoq); $2^{\circ}$ à plante naine - Sur les rochers maritimes - (A. nanum LI.)

\section{G. Alopecurus L.}

Arête naissant au sommet de ğlumes.- S. G. Polypogon Desf. Arète naissant à la base ou sur le dos des glumes. - S. G. Alopecurus L.

\section{S. G. Alopecurus L.}

Tige droite et renflée à la base en forme de bulbe. - Les prairies.

- Racine fibreuse, non renflée en bulbe, ou tige étalée. i

1. Epi glabre ou à peu près. - Panicule d'un gris plombé. Les champs.

A. agrestis $\mathrm{L}$.

- Epi velu ou soyeux. . . . . . . . . . . 2

2. Tige droite, ayant plus de quatre décimètres. - Panicule obtuse. - Prairies.

A. pratensis L.

- Tige genouillée à la base et n'ayant pas quatre décimètres. - Anthères blanchâtres. A. geniculatus L.

Varie à anthères orangées (A. fulvus $\mathrm{Sm}$.)

S. G. Polypogon Desf.

Arête plus longue que la glume. - Panicule resserrée en épi soyeux, vert jamâtre. - Région maritime. - $(P$. monspeliensis Desf.) A. monspeliensis L.

Varie à panicule d'un vert roussàtre (P.maritimus Wild. ou $A l$. paniceus L.)

- Arête ne dépassant pas la glume. - Panicule lâche et grisâtre; arête égalant la glume. - Lieux maritimes. (P. littoralis Sm.)

A. littoralis.

\section{G. GRYPSIS Ait.}

Epi cylindrique, non enveloppé de feuilles. - Vient sur les bords des rivières. 
- Epi ovale ou arrondi, entouré par deux feuilles plus longues que lui. . . . . . . . . . . 1

1. Fleurs en épi orale, à trois étamines chacune. - Région maritime.

- Fleurs en épi globuleux, à deux étamines chacune. Région maritime.

C. aculeata Ait.

\section{G. Phleum L.}

Racine grêle, annuelle; ligule des feuilles plus longue que large. - Sables maritimes. Ph. arenarium L.

- Racine vivace; ligule tronquée. . . . . . . . . i

1. Glume en arête et ciliée. - Prairies. Fh. pratense L.

Varie à tige bullieuse à la base $(P h$. nodosum I.)

- Glume seulement pointue et non ciliée. - Lieux sees et calcaires.

Ph. Bœhmeri Wib.

\section{G. Mibora Ad.}

Très petite plante gazonnante, à feuilles linéaires; fleurs en épi linéaire, unilatéral. - Lieux cultivés. $\quad$ Tró. verna $\mathrm{Ad}$.

\section{G. Lagurus L.}

Petite plante velue; feuilles larges, la supérieure ì gaine renflée. - Sables maritimes.

L. ovatus L.

\section{G. Arundo L.}

Epillets à plusieurs fleurs; feuilles larges de trois a quatre centimètres. - S. G. Phragmites Trin.

Epillets à une fleur; feuilles n'ayant pas deux centimètres de largeur. - S. G. Galamagrostis Roth.

S. G. Phragmites Trin. - Roseaux.

Tige dure et droite; feuilles coupantes. - Bords des eaux. (Ph. communis Trin.)

A. Phragmites L.

\section{S. G. Galamagrostis Roth.}

Feuilles lisses et roulées en forme de jonc. - Plante rhizomateuse; panicule jaunàtre, resserrée en épi cylindrique. - Se troure dans les sables maritimes. - Ciourbet. (G. arenaria Roth.) A. arenaria L.

- Feuilles rudes au toucher et planes. . . . . . . 1

1. Arête naissant sur le dos de la glume. . . . . . 2

- Arête terminale ou nulle. . . . . . . . . . . 3

2. Ligule courte, tronquée, arête nulle ou triès courte. Feuilles étroites; panicule rougeâtre. - Marais. - (G. lanceolata Roth.) 
- Ligule longue, aiguë; arête très saillante. - Bois frais.(G. littorea DG.)

3. Poils de l'épillet aussi longs que la glume. - Feuilles larges. - Se trouve dans les lieux boisés. - (C. Epigeios Roth.)

- Poils beaucoup plus courts que la glume. - Feuilles étroites, rudes. (G. sylvatica DC.) A. sylvatica L.

\section{G. Agrostis L.}

Fleur' munies d'arêtes trois ou quatre fois plus longues que les glumes. - Moissons. A. spica venti L.

Varie à anthères arrondies et non linćaires (1. interrupta L.)

- Arêtes nuilles ou n'étant pas deux fois plus longues que les glumes. . . . . . . 1

1. Fleurs munies d'une arête fine; feuilles raticales filiformes et enroulées. . . . . . . . 3

- Fleur's souvent sans arête; toutes les feuilles plunes. 2

2. Ligule courte et tronqué; fleur's souvent rougeâtres. Les prairies.

A. vulgaris With.

- Ligule plus longue que large, saillante; fleurs blanchátres ou grisâtres. - Plante variable.

3. Glumes ovales, souvent rougeâtres. - Vient dans les prairies.

A. canina L.

- Glumes lancéolées, aiguës, souvent blanchatres. - Les landes.

A. setacea Curt.

\section{G. MrLium L.}

Epillets resservés en épi.

- Epillets écartés en panicule. - Tige élevée, lisse, ainsi que les gaines. - Bois frais.

IM. effusum L.

1. Tige élevée; épi lancéolé, vert blanchâtre, très luisant. - Vient dans les moissons. - (Gastridium lendigerum Gaud.)

M. lendigerum L.

- Tige bossue, rude de bas en haut; épi violacé. - Lieux sablonneux.

M. scabrum Rich.

\section{G. STipa L.}

Plante élevée; feuilles en touffe; épillets à poils soyeux, serrés. - Gả et là jusque dans la Charente-Infre. S. pennata L.

\section{G. Echinaria Desf.}

'Plante à racine fibreuse; tige lisse, striée; fleurs en tête. - Les lieux́ pierreux.

E. capitata Desf, 


\section{G. Sesleria Scop.}

Petite plante grèle, en épi presque unilatéral. - Vient dans les lieux secs.

S. cærulea Ard.

\section{G. Koeleria Pers.}

Fleur's munies d'arêtes molles. - Plante sans pousses stériles. - Lieux sablonneux.

K. phleoïdes Pers.

- Fleurs obtuses ou à très courte pointe. . . . . . . 1

1. Fenilles radicales glabres, enroulées, et dont les gaînes desséchées sont déchirées en un rés'au formé de filets. entrecroisés. - Coteaux calcaires. K. setacea Pers. - Feuilles planes, velues; gaines desséchées non déchirées en réseau. - Coteaux calcaires. K. cristata Pers.

\section{G. Aira L.}

Fleurs munies d'arêtes. - S. G. Aira L.

Fleurs sanis arêtes. - S. G. Airopsis Desv.

$$
\text { S. G. Aira L. }
$$

Feuilles planes, linéaires, élargies. - Plante sazonnante, à panicule ample, très làche. - Se trouve dians les lieux frais.

A. crspitosa L.

- Feuilles très étroites, pliẻes, ou filiformes enroulées. 1

1. Arête saillante et dépassant beaucoup les fleurs. . . 2

- Arête courte et clépassant à peine les fleur's. . . . 3

2. Panicule étroite et resserrée, à rameaux très courts. -

Arète noire jusqu'au milieu, où elle est articulée et barbue, puis épaissie en massue au sommet. - Vient dans les sables maritimes.

A. canescens $L$.

- Panicule étalée, à rameaux allongés. - Plante gazonnante, à fleurs roussîtres et violicées. - Se trouve dans les landes.

3. Epillets longs de deux millimètres environ. . . . . 4

- Epillets de plus de deux millimètres. - Plante a seconde fleur de lépillet très pédiculée. - Se trouve dans les landes.

A. flexuosa L.

Tarie ì ligule tronquée au lieu d'être aignë (A. uliginosa Weih.)

4. Panicule très serrée, en épi. - Petite plante, à racine fibreuse. - Les landes.

A. præcox L.

- Panicule lâche ou étalèe én tous sens. - Plante ì ramification trifurquée. - Se trouve dans les lienx sablonneux et arides. 
S. G. Airopsis Desv.

Plante à rhizome rampant et à fleurs riolacées; panicule étalée. - Les marais.

A. agrostidea DC.

- Plante à racine fibreuse et à épillets globuleux; panicule resserrée. - Les landes.

A. globosa Th.

\section{G. Holcus L.}

Plante à arête peu visible, dépassant à peine les glumes; gaine des feuilles velues. - Prairies.

H. lanatus L.

- Plante à arète dépassant beaucoup les fleurs; gaine des feuilles glabre ou à peu près. - Les bois. XI. mollis L.

\section{G. Avena L.}

Fleurs groupées en épi serré. - S. G. Gaudinia P.B.

Fleur's disposées en panicule large. ......... 1

1. Epillets à fleurs dissemblables, l'inférieure seule munie d'une arête. - S. G. Arrhenatherum P.B.

- Epillets à plusieurs fleurs semblables, toutes munies d'arête.

- S. G. Avena.

S. G. Gaudinia P.B.

Plante grêle, à feuilles poilues. - Lieux cultivés. - ( $G$. fragilis P.B.)

A. fragilis $L$.

S. G. Arrhenatherum P.B.

Plante à racine fibreuse, et à fleurs d'un vert pâle. - Bois. (Arr. elatius Gaud.)

A. elatior L.

Varie à racine bulbeuse et à nœuds de la tige velus (Arr. precatoria Thuil.)

$$
\text { S. G. Avena. - Avoines. }
$$

Epillets 'dressés, jamais pendants. . . . . . 1

Epillets penchés ou pendants, surtout à la matrité. 6

1. Epillets sillonnés de sept à neuf nervures prononcées.Lieux sablonneux.

A. tenuis Mænch.

- Epillets non sillonnés ou à trois nervures seulement. 2

2. Epillets composés de deux fleur's, dont une seule a une arête. - Plante à longues leuilles. - Se trouve dims les landes.

A. longifolia Th.

- Epillets composés de fleurs toutes munies d'arêtes. . 3

3. Panicule lache; épillets jaunatres, n'ayant pas un centimètre. - Les lieux secs.

A. flavescens $L$.

- Panicule resserrée; épillets longs de pius d'un centimètre. ............. 4 
4. Feuilles inférieures planes, velues, ainsi que les gaînes. - Plante à épillets panachés de blanc luisant et de violacé. - Les bois.

A. pubescens $\mathrm{l}$.

- Feuilles enroulees ou pliées, glabres, ainsi que les gaines. . . . . . . . . . . 5

5. Feuilles inférieures enroulées, tres rudes. - Les lieux secs.

A. pratensis L.

- Feuilles inférieures pliées. - Plantes à fleurs luisantes et violacées. - Les landes.

6. Fleurs glabres. - Cultivée et échappée.

A. sulcata Gay.

Varie beaucoup : $1^{\circ}$ à panicule presque unilatérale $(A$. strigosa L. ou orientalis L.); 20 a flenrs munies en dedans de membranes it fortes nervures (A. muda L.)

- Fleurs velnes. . . . . . . . . . . 7

7. Fleur's hérissées de poils roux. - Moissons. A. fatua L.

Varie à fleur supérieure portée par un pédicule particulier, non articulé (A. ludoviciana Dur.)

- Fleurs hérissées de poils blancs. - Vient dans les lieux cultivés. A. barbata Brot.

\section{G. Melica L.}

Tige florale à un seul nœud, situé vers la base. - Plante élevée, à fleurs panachées de vert et de violet. - Les landes. - (Festuca corula DC.) M. cærulea L.

- Tige florale à plusieurs nouds. . . . . . . 1

1. Feuilles rertes; fleurs dépourvues de poils soyeux. Panicule liche, penchée. - Les bois. M. uniflora Retz.

- Feuilles glauques; /leurs bordées de longs poils soyeux.Panicule resserrée en épi allongé. - Lieux secs. - ( $\boldsymbol{M}$. nebrodinsis Parl. et M. Magnolii God.) M. ciliata God.

\section{G. Briza L.}

Plante a feuilles courtes, à épillets ovales, panachés de vert et de violet. - Les prairies.

B. media L.

Varie à feuilles plus longues, à ligule aiguë au lieu d'être tronquée et à épillets triangulaires (B. minor L.)

$$
\text { G. PoA L. - Paturins. }
$$

Dos des fleurs comprimé en carène. - S. G. Poa L.

Dos des fleurs arrondi. - S. G. Glyceria R.B.

$$
\text { S. G. Poa L. }
$$

Fleurs en épi unilatéral très raide. - Petite plante des bords de la mer. $\quad$ P. loliacea Huds.

- Fleurs en panicule. ............. 1 
1. Tige sensiblement comprimée et aplatie. . . . . . . 2

1. Tige cylindrique ou à angles obscur's. $\ldots \ldots \ldots 4$

2. Fleurs sans poils laineux à la base. - Plante sans rejets rampants. - Auvergne.

P. sudetica Willd.

Fleurs laineuses à la base.

3. Tige fortement comprimée jusqu'au sommet. - Plante stolonifère.

P. compressa L.

- Tige cylindrique au sommet. . . . . . . . 6

4. Fleur's laineuses à la base; gaîne des feuilles non poilue............. 5

- Fleurs glabres à la base; gaîne des feuilles poilue au sommet. . . . . . . . . . 10

5. Tige renflée à la base en forme de bulbe. - Petite plante gazonnante.

P. bulbosa L.

- Tige non bulbeuse è la base. . . . . . . . . 6

6. Ligule des feuilles supérieures plus longue que lairge. 7

- Ligule des feuilles supérieures courte, tronquée et presque nulle. . . . . . . . . . . 9

7. Rameaux de la panicule solitaires ou deux par deux. - Partout.

P. annua $\mathrm{L}$.

- Ramears de la panicule nombreux, en demi-verticilles. ................ 8

8. Tige et gaine des ferilles rudes. - Vient dans les lienx humides. $\quad$ P.trivialis L.

- Tige et gaîne des feuilles à peu près lisses. - Plante variable.

P. palustris $\mathrm{L}$.

9. Gaine des feuilles n'allant pas d'un noud à l'autre; la supérieure plus courte que la feuille. - Les lienx secs.

P. nemoralis $\mathrm{L}$.

- Gaine des feuilles allant d'un noud à l'autre; la supévieure plus longue que la feuille. - Plante variable, it queue des fleurs rudes. - Se trouve dans les lienx sablonneux. $\quad P$. pratensis L.

Varie: 10 à queue des fleurs lisse ( $P$. anceps (iaul.); 20 à feuilles trés étroites et enroulées ( $P$. angustifolia $K$.) 10. Epillets lancéolés, ayant de quinze à vingt fleur's. - Lès lieux sablonneux.

P. megastachya liol.

- Epillets linéaires, étroits, ayant de cinq à douze fleurs. Plante à feuilles munies d'un collier de poils à l'entrée de la gaine, glabres du reste.

P. pilosa L.

S. G. Glyceria R.B.

Feuilles obtuses. - Plante couchèe à la base, puis redresscie, i épillets à deux fleurs. - Lieux aquatiques. - (Gr. airoüdes Reich; Aira aquatica L.)

P. airoïdes.

- Feuilles aiguës; épillets à plus de trois fleurs. . . . i

1. Glumes chargées de nervures très proéminentes. . . 2

- Glumes à cinq nervures peu marquées. . . . . . It 
2. Panicule très serrée, d̀ rameaux chargés de fleurs presque jusqu'à la base. - Petite plante glauque et gazonnante. - Se troure dans les lieux maritimes. (G. procumbens Sm.)

P. procumbens Curt.

- Panicule lache, à rameaux unis à la base. . . . . . 3

3. Plante élevée, raide; panicule très rameuse en tous sens. - Marais. - (G. spectabilis K.) P. aquatica L.

- Plante flasque; panicule unilatérale. - Fossés. - (G. fluitans R.B.)

Varie à panicule prramidale (G. plicata Fr.)

4. Planle stolonifère, ¿̀ feuilles étroites et enroulécs. Lieux maritimes. - (G. distans Wahl.) P. distans L.

\section{G. DACTYLIS L.}

Plante élevée, a feuilles rudes; ligule déchirée. - Vient dans les prairies.

D. glomerata L.

Varie a forme naine - Bords de la mer- (D. lispanica DC.)

\section{G. Festuca L.}

Epillets munis $i$ la base diune feuille florale dentée en peigne. - S. G. Cynosurus L.

Epillets a fleurs bordées de cils raides. - S. c. Brachypodium P.B.

Epillets à trois ou cinc fleurs enveloppées de glumes ventrues. - S. G. Danthonia DC.

Epillets a plusieurs fleurs et à glumes convexes. - S. G. Festuca L.

S. G. Danthonia DC.

Plante à feuilles poilues, surtout sur les gaînes. - Les landes. - (D. decumbens DC.)

F. decumbens L.

S: G. Cynosurus L.

Epillets resserrés en épi linéaire, unilatéral. - Plante à feuilles rudes, - Se trouve dans les lieux secs. - (C. cristatus L.)

F. cristata.

- Epillets resserrés en épi ovale, aussi unilatéral. - Plante a feuilles rudes. - Se trouve dans les landes. - (G. echinatus L.)

F. echinata.

S. G. Festuca L.

Epillets sans pédicule, disposés en épi grêle et allongé. 1 - Epillets plus ou moins pédiculés, disposés en pani-

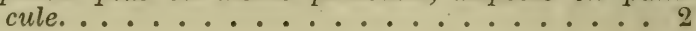


1. Epillets sur deux rangs. - Epi filiforme, à épillets alternes. - Lieux sablonneux. F. Poa Kunth. Varie à épillets munis d'arêtes ( $F$. tenuicula Kunth.)

- Epillets sur un seul rang. - Plante à feuilles en gouttière. - Lieux sablomeux.

F. tenuiflora Sch.

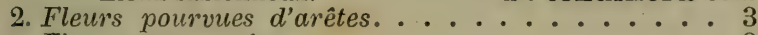

- Fleurs sans arêtes. . . . . . . . . . . 8

3. Arêtes plus longues que les fleurs. . . . . . . . . 4

- Arêtes égalant à peine les fleur's ou plus courtes. . . 6

4. Fleurs bordées de cils blancs soyeux, à une étamine.Lieux sablonneux. F. ciliata DG. ou F. myuros L.

- Fleurs non ciliées. . . . . . . . . . . 5

5. Trois étamines. - Plante à pièce inférieure de la glume nulle ou très courte, et à pièce supérieure avec arête. - Sables maritimes.

F. uniglumis Ait.

- Une étamine. - Plante à tige florale engaînée jusque sous la panicule. - Se trouve dans les lieux secs et arides. F.pseudo myuros S.W.

Varie à panicule dressée, éloignée de la feuille supérieure ( $F$. sciuroides Roth.)

5. Feuilles inférieures enroulées et en forme de soie; arête souvent assez longue. ........... 6

- Toutes les feuilles planes et linéaires; arête très courte. . . . . . . . . . 10

6. Plante à rhizome et à stolons. - Variable; feuilles supérieures planes. - Prairies.

F. rubra L.

Varie a feuilles toutes enroulées et en forme de soie ( $F$. arenaria Osb., $F$. sabulicola Desf., $F$. dumetorum L., etc.)

Plante à racine fibreuse. . . . . . . . . . . 7

7. Fuilles supérieures planes et linéaires. - Vient dans les bois.

F. heterophylla Lam.

- Toutes les feuilles enroulées, en forme de soie. - Lieux arides. F. duriuscula L.

8. Tige et feuilles comme des cheveux. - Vient dans les lieux arides.

F. ovina L.

Varie à feuilles moins rudes au toucher $(F$. tenuifolia Sibth.)

- Tige et feuilles qui ne sont pas fines comme des cheveux. .............. . 9

9. Plante de deux decimètres au plus, $\dot{a}$ panicule unilatérale. - Lieux secs.

F. rigida Kunth.

- Plante de plus de deux décimètres, à panicule ordinaire. - Plante élevée; panicule à rameaux par deux; deuxiépillets par branche, l'un plus court. - Vient dans les prairies.

F. pratensis Huds.

Varie à cinq épillets et plus par branche $(F$. arundinacea Schr.) 


\section{S. G. Brachypodium P.B.}

Plante souvent velue, d'un vert foncé; arêtes supérieures plus longues que les fleurs. - Vitunt dins les bois. (B. sylvaticum P.B.)

F. sylvatica Kœl.

- Plante sourent glabre, d'un vert clair; arêtes supérieures plus courles que les fleurs. - Tient dans les landes. - (B. pinnatum P.B.) F. pinnata Kiœl.

\section{G. Bromus L.}

Epillets rétrécis au sommet, ou arêtes ne dépassant pas la longueur des fleurs.

- Epillets élargis au sommet, ou arêtes bien plus longues que les fleurs. . . . . . . . . . . . 8

1. Epillets élargis, noüdes, ou plus longs que larges. . 2

- Epillets étroits, linéaires ou lancéolés aigne. . . . . 7

2. Gaines des feruilles presque toutes glabres; ipillets composés de fleurs ćcartées et comme cylindriqués, à la maturité. - Les moissons. B. scalinus L.

- Gaines des fenilles miesque loutes velues; épillets composés de fleurs contiguës et.non cylindriques. . . 3

3. Epillets mollement velus. - Arète toujours droite. - Les lienx cultivés.

B. mollis L.

Varie a arrestes tortillées, it la maturité, et dirigrées en tous sens (B. molliformis Ll.)

- Epillets glabres ou à peu près. . . . . . . . . . . 4

4. Arite droite, non divergente, ou tris légèrment arquée. . . . . . . . . . . 5

- Arite divergente et presque horizontale à la maturilé.

B. squarrosus L.

5. Panieule itroile et dont les rameaux inférieurs ont ì peine trois centimetres de long. - Se troure dans les prairies.

B. racemosus $L$.

- Panicule élaryic et don les rameau.c inférieurs ont plus de trois centimètres de lon\% . . . . . . . 6

6. Plusieurs rameana de la panicule portant lrois à quatre épillets, souvent colorés et étroits. - Se trouve dims les moissons.

B. arvensis $L$.

- Plusieurs rameaux de la panicule ne portant qu'un à deuc épillets, verdailres et larges le presque un centimèlre. - Les prairies.

B. commutatus $\mathrm{L}$.

7. Panicule droite. - Plante a feuilles infíricures cilices et it ipillets pourvis d'une arite tres risible. - Les prairies sèches.

B. erectus L.

- Panicule penchée et pendante. . . . . . . . 8

8. Epillets élargis au sommet. . . . . . . . . . 10

- Epillets linéaires, aigus. . . . . . . . . . 9 
9. Feuilles et gaines des feuilles velues. - Vient dans les bois frais.

- Feuilles et gaînes des feuilles glabres. - Vient dans les lieux boisés.

B. giganteus L.

10. Panicule serrée et pençée d'un seul côté. - Les lieux sablonneux.

B. tectorum L.

- Panicule diffuse ou droite. . . . . . . . . . 11

11. Tige glabre. - Epillets à long pédicule. - Se trouve dans les lieux secs.

B. sterilis L.

- Tige velue, surtout au sommet. - Plante à panicule serrée. - Se trouve dans les lieux sablonneux. - (B. rigidus Roth.)

B. madritensis DC.

Varie à panicule lâche et penchée au sommet (B. maximus Desf.)

\section{G. Triticum L.}

Epillets très serrés sur l'axe; glumes rentrues. - S. §. Triticum L.

Epillets espacés; glumes non ventrues, plus longues que larges. - S. G. Agropyrum P.B.

$$
\text { S. G. Triticum L. - Blés. }
$$

Epi très aplati; épillets sur deux rangs réguliers. - Cultivé.

T. monococcum L.

- Epi n'étant pas très aplati; épillets presque sur quatre rangs. . . . . . . . . . 1

1. Epi gros, un peu penché; glumes velues, à carène saillante. - Cultivée.

$\mathrm{T}$. turgidum $\mathrm{L}$.

Varie: 10 à épi ramifié ( $T$. compositum L. - Blé de miracle); - 2o á épi glabre ( $T$. durum Desf.)

- Epi médiocre, droit; glumes glabres ou velues, à carène obtuse. - Cultivée.

T. sativum Lam.

Varie à fleurs sans barbe (T. hybernum L.) ou avec barbe ( $T$. cestivum L.)

$$
\text { S. G. Agropyrum P.B. - Chiendents. }
$$

Plante à longs rhizomes rampants. . ...... 1

- Plante à racine fibreuse et grêle. - Lieux humides. (A. caninum R. et S.)

1. Fenilles striées, plus ou moins rucles en clessus. - Plante très variable. (Ag. repens P.B.)

T. repens $\mathrm{L}$.

Varie : 10 a nervures des feuilles épaisses et toutes contiguës - Dans les sables - (A. pungens R. et S.); $2^{\circ}$ it glume très obtuse, comme tronguée (A.glaucum R.et S.); 30 a glume faiblement obtuse (A. acutum R. et S.), ete.

- Feuilles enroulées, trés firement poilues en dessus. Sables maritimes. - (A. junceum P.B.) T. junceum L. 


\section{G. Elymus L.}

Plante élevée, à poils serrés; feuilles planes et rudes. - Les bois.

E. europæus L.

\section{G. Hondeum L. - Orges.}

Toutes les fleurs à deux sexes et fertiles. . . . . . 1

- Fleurs latérales mâles et stériles. . . . . . . . . . 2

1. Fleurs et fruits sur six rangs réguliers. - Cultivée sous le nom d'Orge d'hiver.

H. hexastichon L.

- Fleurs et fruits sans ordre, sur six rangs, dont deux peu prononcés. - Cultivée.

H. vulgare $L$.

2. Fleurs latérales et stériles sans arêtes. . . . . 3

- Fleurs latérales et stériles munies d'arêtes. . . . . 4

3. Epi allongé, à arêtes vedressées et peu écartées. Cultivée.

H. distichon $\mathrm{L}$.

- Epi court, large, pyramidal; arêtes écartées en éventail. - Cultivée.

H. Zeocriton L.

4. Glumes des fleurs latérales ciliées. - Vient dans les lieux arides.

H. murinum L.

- Glumes glabres ou seulement rudes. . . . . . 5

5. Epi grêle, comprimé; glumes de toutes les peurs fines cornme des soies. - Se trouve dans les prairies. - (H. secalinum Schr.)

H. pratense Huds.

- Epi plus long que large; glumes des fleurs latérales lancéolées. - Région maritime. H. maritimum With.

\section{G. LoLIUM L. - Ivraies.}

Epi cylindrique et filiforme. - Lieux cultivés. L. tenue L. - Epi plus ou moins élargi et comprimé. . . . . 1

1. Plante pourvue de tiges et de touffes de feuilles stériles. .............. 2

- Plante dépourvue de tiges et de touffes de feuilles stériles. .................. 3

2. Jeunes fenilles pliées en lon! ; lleur's sans arêtes. - Cultivée sous le nom de Ray-grass. $\quad$ L. perenne L.

- Jeunes feuilles enroulées par les bords; fleurs munies d'arêtes. L. italicum Braun.

3. Glumes trois fois plus courtes que l'épillet. - Se trouve dans les moissons. $\quad$ L. multiflorum Gaud.

- Glumes dépassant la moitié de l'épillet. ..... 4

4. Epillets lancéolés. $\quad$ L. rigidum Gaud.

- Epillets gros, elliptiques. . . . . . . 5 5

5. Epi court; fleurs courtes, d'abord plus longues que larges, ensuite ovales et élargies. L. linicola Sond. 
- Epi allongé; fleurs toutes plus longues que larges. Fleurs munies dirêtes longues. $\quad$ L. temulentum $L$. Varie à fleurs sans arètes ou à soies molles et blanches (L. arvense With.)

\section{G. Egrlops L.}

Epi ovale; arêtes de tous les épillets presque égales. - Les champs.

I\$. ovata L.

- Epi cylindrique, allongé; arêtes des épillets supérieurs deux fois plus longues.

सE. triuncialis $\mathrm{L}$.

\section{G. Lepturus R.B.}

Epi arqué; glume dépassant les fleurs. - Plante gazonnante. - Région maritime. $\quad$ L. incurvatus Trin. Varie à épi droit et à glumes égales aux fleur's (L. filiformis.)

- Epi en alène; une seule pièce à la glume. - Bois sees ct bords des chemins.

\section{G. Nardus L.}

Plante à tiges et à feuilles filiformes, en touffe; épi grèle, unilatéral. - Les landes.

N. stricta L. 


\section{ADDITIONS}

\section{Fam. des TAMARISGINÉES A. St-Hil.}

(A placer à la page 38, à la suite des GaryophylléEs.)

G. TAMarix L. - Tamaris.

Trois styles. - Arbuste de 1-3 mètres; fenilles menues, imbriquées; fleurs rosées, en grappe làche. - Bords de la mer. $\quad T$. anglica Webb.

- Pas de styles. - Arbuste très rameux; feuilles linéaires, ponctuées; fleurs blanchâtres, en épis terminaux, à dix étamines. - Aux pieds des Pyrénées. - (Myricaria germanica Desv.) T. germanica $L$.

Fam. des URTICÉES Juss. (p. 151.)

G. Celtis T.

Arbre ou arbrisseau à écorce presque noire; fenilles ovales, velues en dessous; fleurs blanchâtres; fruit noir, de la grosseur d'un pois, à longue queue. - Cà et là dans les haies.

G. australis L.

Fam. des SANTALACÉES R.B. (p. 147.)

G. Viscum L. - Guis.

Plante ligneuse, fourchue, à feuilles coriaces et opposeies; fleurs jaunâtres. - Se trouve surtout sur les peupliers et les pommiers. - Gui.

V. album L. 


\section{APPENDICE ORGANOGRAPHIQUE}

ALLÉE. - Se dit surtout des feuilles qui présentent de chaque côté une série de parties distinctes, séparées les unes des autres comme les plumes d'une aile étendue. Ex.: les feuilles de sainfoin, les feuilles de vesce, les feuilles de l'acacia ou robinier. - Se dit quelquefois aussi des fleurs dont l'enveloppe florale présente, sur les còtés, des pièces élargies, plus développées ou plus écartées que les autres. $E x .:$ les fleurs de haricot ou de pois.

ALTERNES. - Les feuilles et les fleurs sont alternes, quand elles sont éparses sur la tige et non placées deux par deux, trois par trois ou plus, vis-à-vis les unes des autres.

AigreTtE. - Faisceau ou couronne de soies, de poils, d'appendices fins qui terminent les fruits, comme dans les chardons.

AiguilloNs. - Appendices piquants, qui se trouvent disséminés sans ordre, comme des poils endurcis, sur les tiges et les feuilles. Ex.: dans les églantiers, les rosiers et les ronces.

AISSELLE. - C'est l'angle ouvert vers le sommet de la tige que forme la feuille avec cette dernière. Les bourgeons et les branches, les fleurs aussí, naissent à l'aisselle des feuilles. ANTHÈre. - Voy. Fleur.

APÉTALE. - Voy. Fleur.

ARbuste et Arbrisseau. - Plante ligneuse d'une hauteur relative, ne dépassant pas, en général, deux fois la taille d'un homme.

ARÊTE. - Appendice droit et raide, comme dans les fleurs d'avoine ou les épis de blè barbu.

Axmlatre. - Se dit des organes, fleurs ou autres, placés à l'aisselle d'une feuille.

BractéEs. - On appelle quelquefois bractées les feuilles, modifiées dans leur forme et leur couleur, qui sont les plus rapprochées des fleurs. On dit généralement, dans ce cas, feuilles florales. 
BulbE. - Corps de plante sonterrain plus on moins globuleux, comme dans le lis, l'ail, et qui domne à la belle saison des tiges florales.

Bulbilles. - Bourgeons charnus et globuleux, placés à l'aisselle des feuilles ou à la place des fleurs, qui se détachent et tombent tout seuls. Ex.: lis bulbifère, ail des vignes.

Calice. - Voy. Fleur.

Calicule. - Second calice, doublant le premier, ou ensemble de petites feuilles situées sous le calice et simulant par leur insertion à un mème niveau un calice inférieur. Voir la guimauve et le fraisier.

C.Apillaire. - Divisions, découpures ou organes fins comme des cheveux.

Capsule. - Fruit sec, s'ouvrant de lui-mêrne à la maturité et contenant un certain nombre de graines, qui y sont comme dans une boîte.

Carpelle. - Voy. Fleur.

C.InÈxE. - Partie antérieure ou inférieure de la corolle, qui est courbée en quille de navire, comme dans les pois.

Crnuve. - Tige analogue à celles de lavoine on du blé.

Chatox. - Fleurs males ou femelles disposées en queue ou épi serrés, comme dans le noisetier et le noyer.

Collerette. - Petit collier de feuilles vertes situé au-dessous des fleurs.

Corolle. - Voy. Fleur.

Corrube. - Disposition des fleurs en houquet serré, avec piel commun et surface large et uniforme au sommet.

Décunrentes. - Se dit des feuilles sans queue dont les deux còtés se prolongent sur la tige, au-dessous du point d'insertion.

DÉnISCExт. - Fruit sec qui s'ourre naturellement à la maturité.

Digrtée. - Feuille dont les parties sont disposées en éventail, ou comme les doigts écartés de la main.

Drö̈Qtes. - Se disait autrefois des plantes, quand, les fleurs étant toutes à un seul sexe, les mìles et les femelles étaient portés sur des pieds différents.

Ec.IILLE. - Lame généralement sìche, plus ou moins arrondie, de couleur variable, représentant une fenille ordinaire, une feuille florale, des pièces de l'enveloppe florale ou d'autres parties de la fleur.

Embrassinte. - Se dit d'une feuille dont la base élargie entoure presque la tige au point d'insertion.

Exgaisaxte. - Se dit d'une feuille tont la base en comet enveloppe la tige sur une certaine étendue au-rlessus du point d'insertion. 
Entonnorr (en). - Se dit d'un calice ou d'une corolle à pièces soudées qui se renfle au milieu et qui s'évase au sommet. $E x$.: le tabac.

EPERon. - C'est un prolongement creux de la base de quelques fleurs. $E x$.: les pieds-d'alouette.

EPI. - Fleurs sans queue, groupées le long du sommet d'une tige florale. Ex.: le plantain, le blé. Dans le premier cas, les fleurs sont insérées une à une, et l'épi est dit simple; dans le second cas, les fleurs s'insèrent par petits groupes et l'épi est dit composé.

EpIllet. - Petits groupes de fleurs disposées en épi, groupés eux-mêmes de diverses façons, comme dans l'avoine, etc.

EPIGyNe. - Se dit des étamines, de la corolle et des autres parties de la fleur insérées et placées sur l'ovaire.

Etamine. - Voy. Fleur.

Etendard. - Pièce supérieure ou postérieure de la corolle, comme dans les pois.

Fleur. - La fleur est l'ensemble des organes, qui, groupés d'abord en bouton, puis en petite tête épanouie, concourent à la fécondation et à la formation du fruit. Il est rare que la fleur s'implante directement sur les rameaux. Le plus souvent, elle est munie d'une queue, d'un petit pied, et c'est autour de l'extrémité libre de cette queue que les organes floraux se disposent en cercles ou en verticilles emboîtés les uns dans les autres et aussi rapprochés que possible.

La queue de la fleur reçoit quelquefois le nom de pédicule, de pédicelle ou de pédoncule. Elle nait souvent à l'aisselle d'une petite feuille modifiée, d'une foliole, ou en porte elle-mème. Ces folioles recoivent le nom de feuilles florales ou de bractées. L'extrémité de la queue, qui s'est plus ou moins épaissie pour donner insertion aux organes floraux, constitue le réceptacle de cette fleur, et ce réceptacle peut être allongé, arrondi, aplati ou même excavé au sommet.

Les organes floraux les plus externes ont la forme de lamelles ou de folioles et constituent l'enveloppe ou les enveloppes de la fleur. Si ces folioles sont toutes a peu près semblables entre elles, ou s'il y a une transition marquée entre les premières et les dernières, l'enveloppe florale est unique, et la fleur est dite apétale; si, au contraire, ces folioles forment deux verticilles distincts, un premier, vert et herbacé, et un second, coloré et brillant, l'enveloppe florale est double: le premier verticille reçoit le nom de calice, et le second, celui de corolle; les parties composantes de l'un sont les sépales, et les parties composantes de l'autre, des pétales. 
En dedans de l'enveloppe ou des enveloppes florales, vionnent des filaments plus ou moins allongés, terminés par une tête jaume et disposés, eux aussi, en verticille. Ce sont les étamines ou organes màles. Le filament porte le nom de filet et la tête jaune le nom d'anthère.

Tout a fait au centre de la fleur, se trouvent l'organe ou les organes femelles. $\mathrm{S}$ 'il y en a plusieurs, distincts et séparés, chacun d'eux est un carpelle, qui se compose, it la Jase, d'une cavité fermée où s'élaborent une ou plusieurs graines: c'est l'ovaire, et d'un appendice qui surmonte cette cavité : c'est le style. S'il n'y en a qu'un, c'est qu'il y a eu arortement de tous les autres carpelles, excepté celui-lit, ou, ce qui est le cas de beaucoup le plus fréquent, c'est que tous les carpelles de la fleur se sont soudés entre eux et plus ou moins intimement en une seule masse. Cette soudure peut porter sur l'ovaire seulement, en liaissant les styles distincts, ou envahir ceux-ci jusque près du sommet, qui reste presque toujours divisé.

Glabre. - Totalement dépourvu de poils.

GLAUQue. - De couleur vert de mer.

Glumes et Grumelles. - Ce sont les enveloppes extérieures, im peu sèches, des fleurs de Graminées. Les glumes sont les piices, an nombre de deux, qui sont i la base des épillets; les glumelles sont les deux pièces qui recourrent inmédiatement les étamines et l'ovaire. Ex.: les balles du blé et de l'avoine.

Goncic. - On appelle ainsi l'ouverture du tube de la corolle ou du calice, quand ce tube existe.

Grappe. - Fleu's munies de queue, sroupées le long d'une tige florale. Ex.: le groseillier rouge, le choux, la vigne, le lilas. Dans les deux premiers cas, les fleurs sont insérées me a me et la grappe est dite simple; dans les deux derniers cas, les fleurs s'insèrent par petits groupes ramifiés, et la grappe est dite composée.

Henmapirodite. - Se dit d'une fleur réunissant les deux sexes.

Hapogrie. - Se dit des étamines, de la corolle et des autres parties de la fleur insérées et placées au-dessous de l'ovaire ou à còté de lui.

IxDÉnIsCeNT. - Fruit qui ne s'ourre pas naturellement it la maturité.

IxFÉRE. - Inséré et placé an-dessous de quelque chose. Eir.: l'ovaire est infère lorsqu il est placé sous les autres parties de la fleur, comme dans le poirier ou le melon et toutes les plantes analogues. 
Irvolucre et INvoltcelle. - Collerette ou couronne de petites feuilles florales qui accompagnent souvent les fleurs en ombelle, comme dans la carotte.

L.ABEL. - Pièce de l'envelope florale, plus développée et plus bizarrement découpée ou colorée que les autres, dans les pentecòtes. On dit aussi Tablier.

LABIÉ. - Se dit de la corolle et du calice à deux lèvres.

Ligule. - Petite membrane sèche et blanchâtre, saillante au sommet de la gaine des feuilles, dans les Graminées.

Moxoï@ue. - Se disait autrefois des plantes, quand les fleurs étant toutes à un seul sexe, les mâles et les femelles se trouvaient sur le même pied.

Orbelle. - Disposition des fleurs en bouruet serré, de telle facon que les queues de celles-ci partent toutes du sommet de la tige florale, comme les branches d'un parapluie ouvert. Ex.: la carotte, le persil, la primevère. Dans ce dernier cas, les branches divergentes ne portent qu'une fleur, et l'ombelle est dite simple; dans les deux premiers cas, les branches premières en présentent d'autres plus petites à leur sommet, semblablement disposées, et ce sont celles-ci qui se terminent chacune par une fleur; l'ombelle alors est dite composée.

Oxglet. - Pièce de la corolle, ou pétale, munie d'un pédicule.

Ovarre. - Voy. Fleur.

Pallletres. - Appendices courts, aplatis et assez résistants, qui se trouvent entre les fleurs, dans la camomille, par exemple, et dans les fleurs analogues.

P.ıLıí: - Se dit des organes disposés comme les doights écartés de la main.

PANicule. - Synonyme de grappe composée. Voy. Grappe.

Papilionacée. - Fleur qui ressemble à celle des pois, par exemple.

PÉnoncule. - Mot synonyme de queue de la fleur.

Pédrcelle. - Diminutif du pédoncule, et parties ramifiées de ce dernier.

PínnéE. - Synonyme de feuille ailée.

PÉriaxthe. - Mot qui signifie l'enveloppe de la fleur, c'est-à-dire les petites pièces aplaties, le calice et la corolle qui recouvrent les organes sexuels.

Péricarpe. - Signifie la peau des fruits.

P'ERSONÉE. - Se dit des corolles en masque, comme dans le muflier.

Pétales. - Pièces et parties composantes de la corolle. Ex.: pièces des roses. 
PÉTIOLE. - Mot synonyme de quẹe de la feuille.

Polygane. - Se dit d une plante qui a sur le mème pied des fleurs màles, des fleurs femelles et des fleurs à sexes réunis.

RÉceptacle. - Sommet, élargi ou non, du rameau floral ou de la queue de la fleur, c'est-à-dire la surface sur laquelle s'inserent les direrses parties de la fleur, ou les fleurs ellesmèmes lorsqu'elles sont groupées en tètes, comme dans l'artichaut.

Rinzose. - Synonyme de tige souterraine ou de souche bourgeonnante.

SÉPales. - Pièces et parties composantes du calice.

Sessile. - Se dit des feuilles et des fleurs sans queue.

Stiginte. - C'est le sommet glanduleux de l'ovaire ou de la tige qui le termine.

Stipules. - Appendices foliacés ou membraneux, qui sont de chaque cóté de la base de la feuille. Ex.: dans les rosiers.

Strue. - Ciest la tige qui surmonte et termine en général l'ovaire.

SupL̀Re. - Contraire d'infère.

TABlier. - Synonyme de label. Voy. Label.

Vrille, - Organe accrochant et fin. E.c.: dans les pois. 


\section{TABLE DES NOMS DE PLANTES}

$\mathbf{A}$

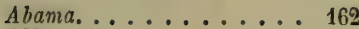

Abies .............. 155

Abricotier..........

Absintlies .........

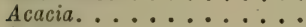

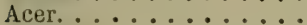

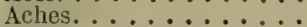

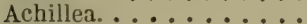

Acorus ..........

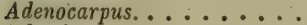

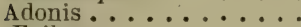

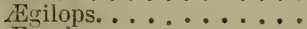

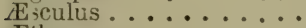

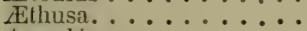

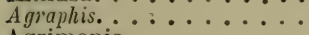

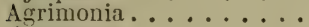

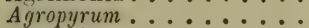

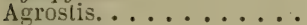

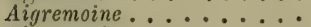

Aigremoines.......

Ailanthus. ........

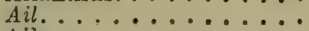

Ails $\ldots \ldots \ldots \ldots$

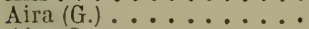

Aira (S. G.) ..........

Airopsis.

Ajones.

Ajuga.

Alchemilla ...............

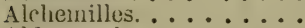

Alchrovanda. ........

Alisicr..........

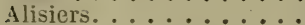

Alisma $\ldots \ldots \ldots$

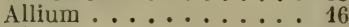

Alnus .......... 154

Alupecurus (G.) ....... 185

Alopecurus (S. G.). . . . . 185
Alsine.......... 33

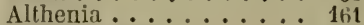

Althoca en arbre. . ...... 25

Althac ......... 25

Alyssum ........... 18

Alyssons ............... 18

Amandier......... 60

AMARANTHICÉES. . . . 141

Amaranthes ........ 141

Amaranthus ........... 141

Amaryllis ........ 167

AMARYllidÉEs. . . . . . 166

A mberboa......... 100

A mbrette jaune....... 100

Ambroisie.......... 142

Amelanchier......... 65

AMEnTacíEs ......... 152

Anmi.............. 76

Ampelonsis. .......... 42

Amygdalus. ......... 60

Anarrhinum......... 127

Anagallis......... 113

Anclisa ........ 120

Ancolies ......... 6

Andropogon .......... 183

Androsamum ........ 40

Andryala.............. 108

Anemone......... 2

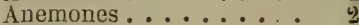

Aneth.............. 78

Anethum......... 78

Angelica ......... 79

Antréliques............. 79

Anis........... 76

Ansérine......... 63

Anthemis................ 92

Anthericum .......... 162

Anthoxanthum....... 185

Anthriscus......... 81

Anthyllis......... 46

Antirrhinum....... 127

Aphanes.......... 64 
Aphyllanthes ....... 165 Apium (G.). . . . . . . 75 $\operatorname{Apium}(\mathrm{S} . \mathrm{G}.) \ldots \ldots \ldots .75$ APOCYNÉES. . . . . Aquilegia........... Arabettes. . . . . . . . . Arabis. . . . . . . . . Arbousier. Arbre de Judée............ Arbutus. Arenaria (G.). Arenaria (S. G.) . . . . . . Argyrolobium.

Aristolochia ARISTOLOCHIÉS. . . . . . Aristoloches . . . . . . . . Armeria. . . . . . . . . Armoise. . . . . . . . . Arnica............ Arnoseris . . . . . . . . AROIDÉES. . . . . . . Arrhenatherum ........ Arroches .......... Artemisia. . . . . . . . Artichauts . . . . . . . . Artichaut. . . . . . . . . Arum . . . . . . . . . Arundo. . . . . . . . . . Asclepias. . . . . . . . Asparagus . . . . . . . . Asperges. ........... Asperge ........... Asperugo. . . . . . . . . Asperula . . . . . . . . Aspérules. . . . . . . . . Asphodèles. . . . . ${ }_{\text {Asphodelus. }}, \ldots \ldots$ : Aster . . . . . . . . . . Asterocarpus .......... Astragalcs . . . . . . . Astragalus . . . . . . . Atriplex. . . . . . . . . Atropa .......... Aubepine............ Aubergine . . . . . . . Aulnes . . . . Aunées . Avena (G.) ....... Avena (S. G.) . . . . . . Avoines. . . . . . . . . .

\section{B}

Baguenaudier. ....... Baguenaudiers. . . . . . . . .
Ballota . . . . . . . 136

Balsamines. . . . . . . . 28

Balsamine.......... 28

Barbarea .......... 13

Barbeau musqué ....... 100

Bardanes. . . . . . . 101

Bardane. . . . . . . . 101

Barlihausia . . . . . . 106

Bartsia.......... 129

Belladones. . . . . . . 124

Belle d'onze heures...... 164

Bellis ........... 91

Benoîtes. . . . . . . . . 62

BerbérIDEES. . . . . . 7

Berheris ........ 7

Berles......... 7

Beta........... 141

Betonica . . . . . . 136

Bétoines ......... 136

Betula (G.) . . . . . . . 154

Betula (S. G.) . . . . . 154

Bidens..........

Bifora........... 83

Biscutclla. ........ 20

Blé de miracles ........ 19

Blés ......... 19:3

Bleuet . . . . . . . . 100

Borragintes. . . . . 118

Borrago........ 120

Bouillon bianc . . . 122

Bouillons blanes. . . . . . 122

Bouleau. . ......... 154

Bunleaux........ 154

Boule de neige. $\ldots \ldots . .86$

Bourdaines. . . . . . . . 42

Bourrachs. . . . . . . 120

Bourse è pasteur. . . . . . 20

Boutons dor. . . . . . . 3

Brassica. . . . ..... 10

Braya. . . . . . . 12

Briza ......... 190

Bromus. . . . . 194

Brugnon. . . . . . . . 60

Brunella . . . . 137

Brunelles. . . . . . . 137

Bruyeres ......... 111

Bryones........ 108

189 Bryonia. . . . . . . . 108

189 Buffonia.......... 34

189 Buglosses. . . . . . . 1으

Buis. . . . . . . 150

Bunias. . . . . . . . 16

Buphthalmun. . . . . . 9 91

Buplevrum. . . . . . 77

53 Butomus ......... 159

53 Buxus. .......... 150 
C

Cactus............ Caille-lait. .......... Cakile. . . . . . . . . . Calamagrostis $\left(G_{0}\right) \ldots \ldots$. Calamagrostis (S. G.)...... Calamintha. ........ Galendula . . . . . . . . Galepina.......... Callitriche......... Callitrichinées . . . . . Calluna.......... Caltha. ........... Camomilles ......... Camomille romaine. ...... Camelina. .......... Camélines ......... Campanulacées. . . . . . Campanula (G.) . . . . . . Campanula (S.G.). . . . . . Capsella.......... Capsicum............ Caquillers ........... Cardamine........... Cardamines .......... Cardères ............ Cardon.............. Carduncellus .......... Carduus (G.). . . . . . . . Garduus (S. G.) . . . . . . Carex.............. Carlina............. Carlines............ Carottes............. Carpinus............ Carthamus........... Carthames............ Carum.............

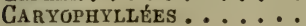
Gassis............... Gastanea.............. Catananche........... Catananches. ......... Gaucalis (G.)......... Caucalis (S. G.) ........

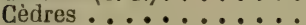

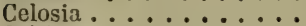
Celtis .............. Centaurea $(\mathrm{G}),. \ldots \ldots \ldots$. Centaurea (S. G.) . . . . . . Centaurées. .......... Centranthus. ........... Centunculus..........
Cephalanthera....... 172

Cerastium (G.) . . . . . . 34

Cerastium (S. G.). ...... 34

Cératophyllées . . . . 151

Ceratophyllum....... 151

Cercis..........6 60

Cerfenil. . . ...... 81

Cerfeuil musque. . . . . . 8. 82

Cerisiers......... 61

Cerisier.......... 61

Chærophyliuin ....... 82

Chaiturus ........ 136

Chardons. . . . ..... 101

Chardon-Marie ........ 101

Chardonnette....... 101

Ghardon bénit. ........ 100

Chardons bleus . . ..... 98

Chardon-Roland...... 74

Chardon à foulon ...... 87

Charmes......... 154

Charme.......... 154

Ghàtaigniers. . . . . . 154

Chataire. .......... 134

Chausse-trape ....... 99

Cheiranthus (G.). . . . . 14

Gheiranthus (S. G.) ...... 15

Gtiélidoines........ 8

Chelidonium. ....... 8

Chênes.......... 155

Chêne-vert.......... 155

Chêne-tauzin........ 15 .

Chêne-rouvre....... 155

Ghénopodées. . . . . . . 141

Ghenopodium (G.). .... 142

Ghenopodiun (S. G.). . . . . 142

Ghervi.......... 76

Chevvrefeuilles. . . $\ldots .87$

Ghèvrefeuille ........ 87

Chicoré des jardins. ...... 103

Chicorée sauvage ....... 103

Chicorées.......... 103

Chiendents. ....... 195

Ghlora.......... 116

Chondrilla ........ 105

Choux marins ........ 16

Choux. ......... 10

Chrysanthemes.......... 93

Chrysanthemum $\left(\mathrm{G}_{0}\right) \ldots \ldots 93$

Chrysanthemum (S. G.). . . 94

Chrysosplenium. ..... 73

Gicendia. ........ 117

Cichorium ......... 103

Cicuta.......... 74

Cicutaires........ 74

Cineraria ......... 98

Cinéraires........... 98 
Gircæa ..........

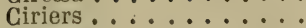

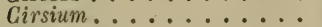

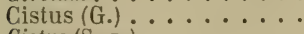

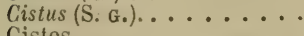

Cistes..........

Cistinées. ..............

Citronnelle........

Civette.

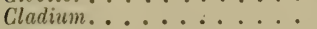

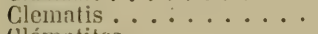

Glématites ........

Clinopodium............ 13

Cnicus........... 100

Cochlearia ....... 17

Cognassiers........ 66

Colchicum ............ 161

Colchiques. ....... 161

Colutea.......... \$3

Comarum.......... 64

Compostes........... 89

Concombres ......... 109

Conitm.......... $\$ 2$

Conifines ................

Conopodium........

Consoudes .........

Convallaria. . . . . . . .

Convolvulus. . . . . $11 \mathrm{~T}$

Convorvulackes ..... 11 J

Comyza. .......... 90

Corpuelicots........... 7

Coquerets............. 123

Coriandres....... 83

Coriandrum (G.)..... 83

Goriandrum (S. G.)...... $\$ 3$

Coriaria. .......... 41

Cormier.......... 66

Cornouilliers........ 74

Cornus ......... 74

Coronilla........... 5.

Coronilles ....... $\$ 4$

Corrigiola ....... 37

Corydalis .......... 8

Corylus. ............ 154

Cotoneaster............. 67

Goudriers. . ......... 1 it

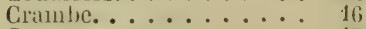

Cransons............ 17

Crassulachis ...... 71

Cratiegus (G.) ...... 69

Cratagus (S. G.)...... 67

Crepis $\left(G_{.}\right) \ldots \ldots \ldots \ldots$

Crepis (S. G.) . ....... 107

Gresson de fontaine...... 13

Cressons .......... 13

Criste marine ....... 79
Grithmum ....... 79

Crucianella......... 86

Cructfìres. . . . . . . . 9

Crupina............ 100

Crypsis............ 185

Gucubalus.......... 30

Cucumis .......... 109

Cucurbitacées. . . . . 108

Cupressus ............. 1 137

Cuscula.................... 118

Cuscutes........ 118

Cyclamen........ 113

Cydonia . . . . . . . (if

Cynanchum............. 116

Cynara........... 1111

Cynodon............... 181

Cynoglosse.......... 121

Cynorlossum (G.). .... 12)

Cynoglossum (S. G.)..... 121

Cynoglosses ......... 190

Cynosurus. ......... 199

GiYpéracées ....... 177

Cyperus.......... 17i

Cyprès chauve. . . . . . 1957

Cyprès .......... 157

Cylinets........... 147

Cytimus. ......... 147

Cytises.............. 40

Cylisus (G.)........ 44

Cytisus (S.G.). . ..... 45

\section{D}

Dabacia............ 111

Dactylis. .......... 192

Danthonia......... 192

Daphne. . . . . . . 146

DAPHNAGÉES....... 146

Datura.......... 122

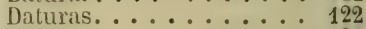

Daucus.......... 81

Delphinium ......... 6

Dentaria ............ 16

Dianthus........ 29

Digitaria............ 184

Digitales ........ 126

Digilalis ........... 126

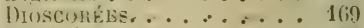

Diotis............. 93

Diplotaxis. ....... 11

J)IPSACIES. . . ... $\$ 7$

Dipsacus ......... 87

1) jronicum. ........ . . 97

Dorycnium........

Douco-amère........ 123 
Draba............ 18

Drosera. . . . . . . . . 23

Droséracées........ 23

\section{E}

Ebénier (faux) ...... 45

Ecarlate. . . . . . 78

Ecballium ......... 109

Echinaria. ........ 187

Echalotte......... 163

Echinops......... 98

Echinospermum....... 121

Echium.......... 118

Eglantines......... 65

Elatine........... 37

Eleocharis. ....... 178

Elodea. . . . . . .... 159

Elodes........... 40

Elymus. . . . . . . . 196

Epervières........ 107

Ephedra.......... 158

Epilobes . .......... 68

Epilobium ......... 68

Epine blancho (Aubépine). . . 67

Epine noire (Prunier épineux)

Epines-vinettes .......

Epipactis...........

Epurge..............

Erables. . . . . . . .

Erica ...........

Értatáés.........

Erigeron (G.). . . . . . .

Erigeron (S. G) . . . . . .

Eriophomum.........

Eruca ...........

Erucastrum. ........

Erodium. . . ........

Ervum. . . . . . . .

Eryngium .........

Erysimum (G.) . . . . . .

Erysimum (S. G.). . ..... .

Erythraa......... 116

Estragon ......... 95

Eufragia.......... 129

Eupatoire........ 89

Eupatoire.......... 64

Eupatorium . . . . . . . . . . 89

Euphorbes ............... 147

EUPHORBIACÉES ........ 147

Euphorbia........ 147

Euphrasia (G.) . . . . . . 128

Euphrasia (S. G.). . . . . . 128

Euphraises. . . . . . . . 128

Evonymus.........

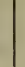

F

Fagus (G.) . . . . . . 154

Fagus (S. G.) ......... 154

Falcaria.......... 75

Farouche ......... 49

Faux-ébénier ....... 45

Fenouil ............ 78

Fenugrecs.......... 48

Fessecul. ........... 143

Festuca (G.) ......... 192

Festuca (S. G.) ........ 192

Fève.......... 57

Ficaria........... 6

Ficoidées.......... 71

Fieus ........... 152

Figuiers .......... 152

Filago.......... 96

Filipendule .......... 62

Fleur de veuve....... 87

Fluteaux......... 1:8

Foniculum ........ 78

Fragaria .......... 64

Fraisier des bois......... 64

Fraisiers .......... 64

Framboisier. . . . . . . 62

Frangulacées........ 42

Frankenia ......... 29

Fraxinus . ......... 115

Frènes.......... 115

Frêne fleuri. ....... 115

Fritillaires. . . . . .... 161

Fritillaria. ........ 161

Fumana. ........... ${ }_{23}$

Fumaria (G.). ........ 8

Fumaria (S. G.) ........ 9

FuMARIAGÉES. . . . . . 7

Fumeterres........ 8

Fusains. . . ....... 42

\section{G}

Gagen........... 164

Gaillets. . . . . . . . . 83

Galactites..........

Galanthus ......... 166

Galega ........... 53

Galcobdolon. ......... 134

Galeopsis............ 13ă

Galium........... 84

Garances........... 83

Garance tinctoriale, ..... 83

Gastridium......... 187 
Gaudinia............ 189

Gazon blanc......... 121

Gazon de Mahon....... 14

Genèts................ 43

Genét a balais. ....... 43

Genêt d'Espagne....... 44

Genévriers........ 157

Genista............. 43

Gentiana (G.)........ 116

Gentiana. (S.G.)...... 116

Gentianées........ 116

Gentianes......... 116

Géraniacées. . ..... 26

Géranions ........... 26

Gerauium (G.)...... 26

Geranium (S.G.) ....... 26

Germandrées........ 137

Gesces................... 58

Geum. .......... 62

Ginkgo................ 158

Giroflies............. 14

Gladiolus............ 168

Glaïeuls.......... 168

Gluncium ......... 8

Glitux............. 113

Glechoma............ 134

Globularia....... 138

Globulariles. . . . . . 138

Glyceria............ 191

Glyeyrithiza ....... 53

Gnaphalium (G.) ..... 96

Gnaphalium (S. G.) . . . . . 96

Gouels .......... 173

Gouttes de sang......

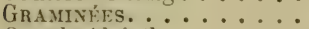

Grande Absinthe.......

Grande Aunée........

Grande liguë........

Grande Marguerite.....

Grand Muflier. . . . . . .

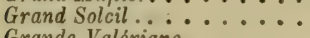

Grande Valériane......

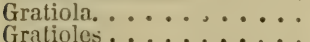

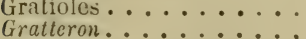

Grémils. . . . . . . . .

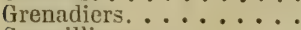

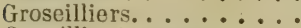

Groseillier à grappe......

Groseillier à gros fruits ....

Guignier..........

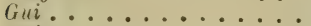

Guis...........

Guimauves........

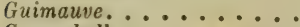

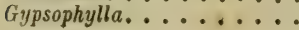

183

93

91

82

94

127

92

88

126

126

8.;

119

67

73

73

73

61

198

198

25

25

\section{H}

Hariculs......... 60

Hetlera.......... 74

Helianthemum....... 22

Helianthus........ 92

Helichrysum......... 97

Héliotrope d'hiver. ..... 89

Heliotropium....... 118

Hellébores........ 3

Helleborus (G.) ...... 3

Helleborus (S. G.)...... 3

Helminthia........ 104

Helosciadizt. . . . . . . 75

Heracleum....... 81

Herniaria. . . . . . . 37

Hesperis.......... 14

Hètres.......... 154

Hiliscus........ 25

Hieraciun ........ 107

Hippocrepis ........ 55

Hippophaë......... 146

Hippuris ......... 70

Holeus ......... 189

Holosteum ....... 34

forrleum....... 196

Hottonia ........ 112

Houblon.......... 151

Houx ......... 43

Humulus. ....... 191

IIutchinsia. .......... 19

Hydrocharis... .... 159

Hydrocotyle....... 74

Hyoscyamus. ....... 122

Hypochoris ........ 103

Hypecoum ........ 8

HYPÉRICINÍES . ..... 39

Hypericum (G.). ..... 39

Hypericum (S. G.). . . . . 39

Hyssopes. ....... 133

Hyssopus. ......... 133

\section{I}

Iberis............... 20

If . . . . . . . . . . 158

Ilex............... 43

Illicebrum ............. 37

Immortelles . . . ..... 97

Immortelle rouge ....... 98

Impatiens........ 28

Inula .............. 91

IRIDÉES ............ 168 
Iris. . . . . . . . . . . 168

Iris. . . . . . . . . . . . 168

Isatis ........... 17

Isnardia. . . . . . . . .

Isopyrum. . . . . .

Ivraies . . . . . . .

Ixia............

\section{$\boldsymbol{J}$}

Jacinthe........ 165

Jalousies. . . . . . . . . .

Jasione..........

JASMINÉES .........

Jasmills. . . . . . . . .

Jasminum . . . . . . .

Jerzeau..........

JoNGÉEs. . . . . . . . .

Jonc des chaisiers. . . . . .

Jones . . . . . . . . . .

Juubarbes . . . . . . .

Juliennes. . . . . . . . .

Juncus . . . . . . . .

Juniperus. . . . . . .

Jusiquiames . . . . . .

Jusquiame. . . . . . . .

Jussiøea. . . . . . . . . .

\section{K}

Kentrophyllum ...... 100

Ketmies. . . . . . . . . . 25

Knautia. ........ 87

Koleria. . . . . . 188

Koniga...........

$\mathbf{L}$

LABIÉES. . . . . . . . . 131

Lactuca. . . . . . . . . . 105

Lagurus . . . . . . . . . 186

Laiches, . . . . . . . . 179

Laiterons. . . . . . . . 106

Laitues. . . . . . . . . 105

Laitue vireuse. . . . . . . 105

Lamiurs .......... 134

Lamium ........ 134

Lappa. . . . . . . . . . 101

Lapsana. . . . . . . . . . 102

Larix ............ 156

Laserpitium . . . . . 81

Lathræa . . . . . . . . 131
Lathyrus (G.). . . . . . . 58

Lathyrus (S. G.). . . . . . 58

Laurette........... 150

Laurier d'Apollon. ...... 146

Laurier-cerise. . . . . . . 61

Laurier-rose. . . . . . 116

LAuRinśes. . . . . . 146

Laurus . . . . . . . . 146

Lavandes......... 131

Lavande............. 131

Lavandula........ 131

- Lavatera . . . . . . . . . 25

Leersia . . . . . . . . 183

LÉGUMINEL AES . . . . . 43

Lemna......... 174

Lentille.......... 5

Lentilles .......... 55

Lentilles d'euu. . . . . 17t

Leontondon......... 103

Lepidium (G.) . ....... 18

Lepidium (S. G.) . . . . . . 19

Lenturus. . . . . . . . 197

Leucanthemum . . . . . . 9. 94

Leucoium . . . . . . . 166

Leuzea. . . . . . . . 100

Levisticum. . . . . . . 79

Libanotis........... 78

Lierre........... 74

Lierres........... 74

Lierre-terrestre . . . . . 134

Ligularia . . . . . . . . 98

Ligustrum. . . . . . 115

Lilas. . . . . . . . . 115

Lilas. . . . . . . . 115

Lilas de Perse. . . . . . 115

LiLIACÉEs. . . . . . . . 161

Limnanthemum. . . . ... 117

Limodorum. . . . . . . 169

Limosella. . . . . . . . . 126

Linnires. . . ...... 127

Linaria. . . . . . . . 127

Lindernia. . . . . . . . 126

Linosyris. . . . . . . . . 90

Lin............ 28

Lins. ......... 28

Linum . . . . . . . 28

Lithospermum. . . . . . 119

Littorella. . . . . . . . 139

Lirêches. . . . . . . . 79

Lobélies. . . . . . . . 110

Lobelia. . . . . . . 110

Lolium . . . . . ..... 196

Lonicera........ 87

Lotiers ......... 52

Lotus (G.). . . . . .

Lotus (S. G.). . . . . . 52 
Lunaires .......... 18

Lunetières . . . . . . . . .

Lupins ... . . . . . .

Lupinus... . . . . . . . .

Lupuline. . . . . . . .

Luzerne. . . . . . . . . .

Luzula .

Luzules. . . . . . . . . .

Lychnis.

Lyciers.

Lycium. . . . . . . .

Lycopsis. . . . . . . . .

Lycopus. ........

Lysimachia. . . . . . . .

LYTHRARIÉES. . . . . . .

Lythrum . . . . . . .

\section{MI}

Mâches..........

Mâche de Hollande. . . . . .

Nlàcres...........

DIalachium .........

Malaxis. . . . . . . .

MIalcomia.........

Malva. . . . . .....

MaLvacées...........

Marguerite diutomne. . . . .

Marguerite dorée. . . . . .

Marjolaine .........

Maroute..........

Marronniers dinde.....

Narrubes...........

Marrube blanc. . . . . . . .

Marrube noir. . . . . . . . .

Marrubium. . . . .....

Matricaire. . . . .....

Matricaria.........

Matthiola . . . . . . . .

Mauves...........

Mledicago ..........

Melampyres . . . . . . . .

Melampyrum. . . . . . .

Mélèzes. . . . . . . . .

Melica. . . . . . . . . . 190

Melilots. . . . . . . . 48

Nelilotus. . . . . . . . 48

Mlelissa.......... 133

Mélisse............ 133

Mélisses. . . . . . . . . 133

Mellitis . . . . . . . 134

Melons. . . . . . . . . 109

Mentha. ......... 131

Menthes. . . . . . . . 131
Menthe-coq........ 95

Menyanthes . . . . . . . . 117

Mercuriales. . . . . . . . 150

Nercurialis. . . . . . . . 150

Mespilus.......... 67

Mibora . . . . . .... 186

Micropus.......... 91

Milium .......... 187

Millefeuilles. . . . . . . 93

Millepertuis . . . . . . . 39

Millet . . . . . . 184

Millet des oiscaux. . . . 184

Manchia. . . . . . 35

Monotropa. ......... 112

Montia.. . . . .... 38

Morelle............ 123

Morelles. . . . . . . . . 123

Moutardes ........ 11

Mufliers. . . . . . . . 127

Muguet. . . . . . . . 165

Muscari.......... 165

Myagrum (G.) ....... 16

Myagrum (S. G.) . . . . . 17

Myosotis ......... 119

Mlyosotis .......... 119

Myosurus. . . . . . . . 3

Myrica.......... 15ั2

Myricaria. . . . . . . 198

Myriophyllum...... 70

Myrrhis.......... 82

MÝRTACÉES....... 67

Myrtes........... 67

MIyrtilles ........ 111

Myrtus . . . . . . .

\section{$\mathbf{N}$}

NAÏADÉES. . . . . . . 174

Naìa . . . . . . . . 174

Narcisses......... 167

Nareissus. . . . . . . 167

Nardus . . . . . . . . . 197

Narthecium. . . . . . 162

Nasturtium. . . . . . . 13

Néflier.......... 67

Nénuphars. . . . . . 7

Neottia......... 172

Nepeta .......... 134

Nerium. . . . . . . . . 156

Nestia.......... 17

Nicandra. . . . . . . . 123

Nicotiana. . . . . . . . 121

Nielle........... 32

Nigella . . . . . . . . 6

Nigelles. . . . . . . . . 6 
Noisetier. ........ 154

Niphar..........

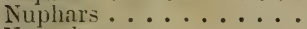

Nympha: $\ldots \ldots \ldots \ldots . .$.

NYMPHÉACÉlis ....... 7

\section{O}

Obione. . . . . . . . . .

Ocimuin ...........

Odontites. .........

OEgopodium........

OEillets...........

Eillets des poetes... . . . . .

OEnanthe. ........

OEnanthes .............

OEnothera ............

Oignon..............

Oignon d'hiver. .........

Olea..... . . . . . . . .

Oliviers. . . . . . . . . .

OMBELLIFÉREs........

Omphalodes..........

Onagrahiées. . . . . . . .

Onagres.............

Onobrychis ..........

Ononis .............

Onopordon. ..........

Onosma..........

Ophrys...........

Orcanettes............

Orcanette jaune........

ORCHIDÉES .........

Orchis. ............

Oreille de souris. . . . . . . . .

Orges ...........

Orge d'hiver. ...........

Urigans..........

Origanum .........

Orlaya .........

Ormes............

Ornithogales............

Ornithogalum.iG.).......

Ornithogalum (S. G.). . . .

Ornithopus............

Orobanches . . . . . . . .

Orobus. ...........

Orpin .............

Orties. . . . . . .

Ortie lianche $\ldots \ldots \ldots \ldots$

Oseilles. ...........

Osier jaune..........

Osyris.............

oxalis.............

\section{$\mathbf{P}$}

Paliurus ......... 42

Pallenis........... 91

Pancratium. . ...... 167

Panicauts......... 74

Panicum (G.) . . . . . 183

Panicum (S. G.) . . . ..... 181

Papaver.......... 7

Papaveraclíg. . . . . 7

Pâquerettes.......... 91

Parietaria. . . . . . . 151

Pariétaires. . . . . . . 151

Paris ........... 166

Pariseltes. . . . . . . 166

Parnassia. . . . . ...... 21

Pas d'ane......... 89

Passerage......... 18

Passerina. . . . . . 146

Passerines . . . . . . 146

Pastels ........... 17

Pastinaca.......... so

Patience. . . . . . . . 145

Paliences. . . . . . . 143

Paturins. . . . . . . . 190

Pavot........... 7

Pavots cormus........ 8

Pêcher.......... 60

Pedicularis. . . . . 129

Pensées.......... 23

Pensées sauvages . . . . . . 23

Pentecôtes........... 169

Peplis.......... 70

Perce-Neige. ........ 16

Persils............... is

Personées. . ......... 121

Pervenches. . . . . . 115

Pesses.......... 70

Petite Absinthe . . . . . 96

Petite-Centaurée........ 117

Petit-Chène......... 137

Petite-Ciguë........ 78

Petit-Houx. . . ..... 166

Petit-Houx.......... 1ti6

Petite-Marguerite........ 91

Petroselinum ........ $7:$

Petunia........... 121

Petunias. . . . . . . . 121

Peucedanum $(\dot{G}.) \ldots \ldots$. 79

Peucedanum (S. G.). . . . 80

Peupliers......... 153

Peuplier de Caroline...... 153

Peuplier de Hollande. . . . 153

Peuplier d'Italie. ........ 153 
Peuplier de Virginie.

$1: 3$

Phalangium

...............

Phaseolus. . . . . . . .

Phelipoa..........

Phillyrea. ........

Phleum...........

Phragmites.........

Physalis . . . . . . . .

Phyteuına .........

Phytulactit. .......

Phitulaciées........

Picris. . ..........

Pieds-dialouette......

Pigamons. . . . . . . . .

Piment. . . . . . . .

Pintints..........

Pimpinella.........

Pimprenelles.........

Pimprenelle.........

Pinfuiculi..........

Pin du Lord. . . . . . . . .

Pin Weimouth. ........

Pins. . . . . . . . . . .

Pinus (G.). . . . . . . . .

Pinus (S. G.). . . . . . . .

Pisseulits..........

Pistiteia. . . . . . ....

Pistachiers. . .......

Pisum............

Plantaginées. . . . .

Plantago...........

Plantains. . . . . . . . .

Plombaginées. . . . . . .

Plumbago. . . . . . . .

Poa (G.). . . . . . . . .

Poa (S. G.).........

Podospermum........

Poireau ............

Poireau d'été . . . . . . . 163

Puiriers......... 65

Poiriers......... 66

Puis. .......... 58

lois........... 58

L'vis curré....... 58

Pois de senteur . . . . . .

Polyearpon. . . . . . . .

Polycnemun. ........

Polygala ..........

Polygalées. . . . . . .

Polygonatum .........

Polygonées . . . . . . .

Polygonmun. . . . . . .

Polypogon..........

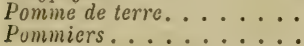

162

184

130

114

186

186

123

140

110

104
Populages.......... 3

Populus. . . . ...... 153

Porcesles. . . . ...... 103

Portulaca......... 38

Potumogeton. . ..... 159

Potentilla (G.). . . . . 63

Potentilla (S. G.) . . . . . 63

Potentilles........ 63

Pouliot. . . . ...... 131

Puurpier doré. . ..... 38

Primeveres. . ...... 112

Primula.......... 112

Primulacées. . . . . 112

Pruniers......... 60

Pruniers. ........ 61

Prumus. . ....... 60

Psorilea. ....... 53

Pterotheca. . . . . . 106

Ptychotis. . . . . . . : 79

Pulmonaires........ 119

Pulmonaria ....... 119

Pulsatille.........

Punica..........6 67

Pyrèthre. ........ 93

Pyrethrum....... 94

Pyrus.......... 65

Q

Quercus. ......... 155

Quintefeuille........ 63

\section{$\mathbf{R}$}

Radiola.......... 28

hadis........... 10

Ranuneulus (G.). . . . 3

Ranunculus (S. G.). . . . . . 3

Raphanus. . ....... 10

Rapistrum. . ....... 17

Katoncules........... 3

Ray-grass. . . . . . . 196

Reduils. ........ 41

Réglisses.......... 53

Réglisses......... 53

Reine-Marguerite...... 89

Reine des prés........ 6.

Renonculacées...... 3

Renoneules........... 3

Renouées. . . . . . . 143

RÉSÉDACÉES. . . . . 21

Résédas........... 21

Reseda (G.). ......... 21

Reseda (S. G.)......... 21 
Rhagadiolus....... 103

Rhamnus.

Rhinanthus.

Rhus

Rhynchospora.

Ribes

177

Robinia.

Robiniers.

Robinier.

Rocambole.

Rcemeria.

Romarins.

Romulea.

Ronces.

Roquettes.

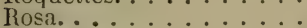

Rosacées.

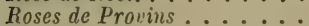

Rose-trémière.

Rosmarinus.

Rossolis.

Rubia.

Rubiacées

Rubus.

Rues.

Ruppia.

Ruscus

Ruta.

Rutacées.

133

168

62

12

65

60

1

2⿺辶

133

23

83

83

62

46

144

160

166
Rose de Noel. . . . . . . .

Rumex

SANTALACÉES. : : : : : . Santolina.

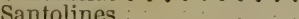

SapINDACÉES $\cdots \cdots \cdots \cdot \cdot$

Sapins.

Saponaires $\cdots \cdots \cdots$

Saponaria. . .......

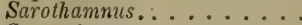

Sarrazin.

Sarriettes.

Satureia. .

\section{S}

Sablines. : : : . : ... 32

Safran bâtard. ...... 100

Sagina.......... 34

Sagittaria.......... 158

Sagittaires ....... 158

Sainfoins.............. 55

Salicaires............ 70

Salicornia........ 143

Salicors......... 143

Salix............. 152

Salsepareilles ...... 166

Salsitis ......... 104

Salsifis.......... 104

Salsola ........... 143

Salvia.......... 133

Sambucus ........ 86

Samolus. $\therefore \therefore \quad 113$

Sanyuenite. .............. 93

Sanguisorba ........ 64

Sanicles......... 74

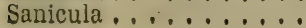

Sauge :........

Sauges. ..........

Saules............

Saule Marceau. . . . . ...

Saule noir. . . . . . . . 153

Saxifraga........... 73

SAXIFRAGEES........ 73

Saxifrages . : . . . : 73

Scabieuses........... 87

Scabiosa ........... 87

Scandix (G.) ........ 81

Scandix (S. G.) ....... 81

Schœenus (G.)...... 17i

Schænus (S. G.): ...... 177

Scilles......... 164

Scilla . : . . . . ... 164

Scirpus (G.). $\quad \ldots \ldots \ldots 178$

Scirpus (S. G)........ 178

Scleranthus......... 37

Scolymes......... 102

Scolymus. . . . . . . 102

Scorpiurus. : . . ... 54

Scorzonères ........... 104

Scorzonera. : . . : ... 104

Scrophulaires....... 126

Scrophularia. . . . . . 126

Scutellaria........ 136

Sedum.......... 71

Selinum. ........ 79

Sempervirum ....... 72

Senebiera. ......... 20

Senecio (G.) . . . . . . 97

Senecio (S. G.). ....... 97

Senecons............. 97

Senecion............. 97

Serapias ......... 171

Serpolet......... 132

Serratula......... 102

Seseli (G.). . . . . . 78

Seseli (S. G.). ........ 78

Sesleria................ 188

Setaria ........... 184

Sherardia........ 86

Sibthorpia........ 126

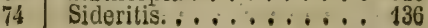


Silaus

Silene $\left(\dot{G}_{.}\right) \ldots \ldots \ldots$

Silene (S. G.) ........

Siliquiers........

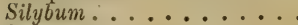

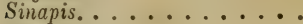

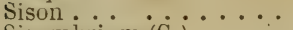

Sisymbrium (G.). . . . .

Sisymbrium (S. G.) .....

$\operatorname{Sium}($ G.). . . . . . . .

Sium (S. G.). ........

Smilax .........

Smyrnium ........

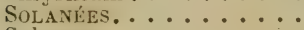

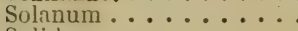

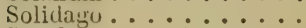

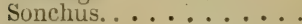

Sorbier.

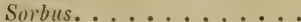

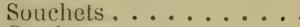

Souci sauvage.......

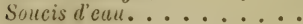

Soudes

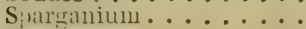

Spargoutes.........

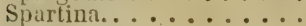

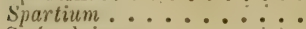

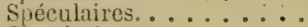

Specularia.........

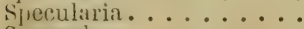

Spergula.........

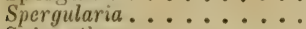

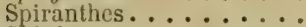

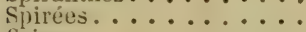

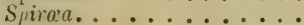

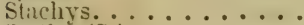

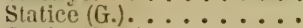

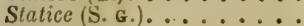

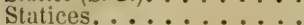

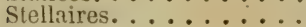

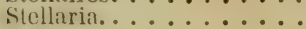

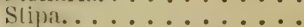

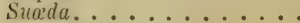

Sumar's.........

Surcau.

Sureaux. . . . . . . .

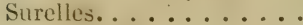

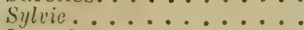

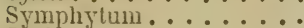

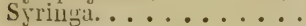

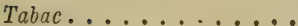
Tabacs ............
80

30

31

101

11

76

12

12

75

7

166

82

121

123

90

106

66

$6: 3$

177

98

1.43

173

33

183

4.4

110

110

110

35

33

172

62

$6 z$

135

139

139

139

36

36

187

142

43

86

S6

29

12

115

121
Tabourets......... 19

Tamaris. . . . . . . . . 198

TAMARISCINÉES. . . . 198

Tamarix......... 198

Timus ......... 169

Tanacetum........ 95

Tanaisie.......... 9

Tautisies......... 9:

Taraxacum....... 10:

Taxus........... 1 \%

Teesdalea......... 20

Telephium........ 37

Térébinthacées. . . . . 43

Tetragonolobus....... 52

Teucrium......... 137

Thalietrum. ........ 1

Thesium........ 147

Thé vert. . . . . . . 142

Thlaspi (G.) . . . . . . 19

Thlaspi (S. G)........ 19

Thrincia. ......... 103

Thuia. . . . . . . 1:i7

Thrmus.. ...... 132

Tilia........... 38

TILIAGÉES. ........ 38

Tilliea......

Tilleuls. . . . . . 38

Tolpis. . . . ... 1117

Tomate......... 123

Topinambour....... 92

Tordslium ........ 81

Torilis. . . . ..... 83

Tormentilla. ....... 6

Tournesol ............. 92

Tragopogon ........ 1114

Tragus ......... 183

Trapla.......... 69

Trètle.......... 50

Trefle d'eau. ........ 117

Trèfle inearnat. . . . . 49

Trelles......... 48

Tremble. . . . . . . 153

Tribulus ....... 40

Trifolium........ 45

Trifolium........ 45

Trirluchiu. . . . . . 159

Trigonella........ 48

Trinia..........

Triticum (G.). . . . . $19 \%$

Triticum (S. G.). . . . . . 195

Trixago......... 129

Troëiles. . . . . .... 115

Troscarts. . . . . . 159

Tulipa........... 161

Tulipes. . . . . ..... 161

Turgenia . . . . . . . . (9) 


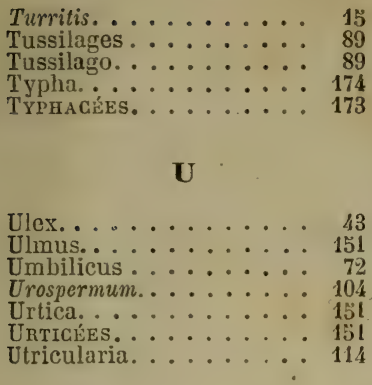

\section{V}

Vaccinium......... 111

Valériane rouge. . . . . . 88

Valeriana (G.). . ...... 88

Valeriana (S. G.) ...... 88

Valérianes. ....... 88

Valerianella........ 88

Vallisneria. . . . . . . . 159

Vallisuéries ........ 159

Vélars ........... 13

Verbascum. ......... 122

Verbena......... 138

VERBENACÉES. . . . . . 138

Verges d'or. . . . . . . 90

Vergerettes. . . . .... 90

Verniers......... 41

Vernier du Japoí . . . . . . 41

Veronica.......... 124

Véroniques. . . . . .... 124

Verveine. . . . . . . 138

Vesces .......... 55

Viburmum....... 86
Vicia (G.). ....... 55

Vicia (S. G.). . . . . .

Vignes......... 42

Vigne vierge. . . . ..... 42

Vignes vierges. . . . . . 42

Villarsia........... 117

Vinca. . . . . . . . 115

Vioche........... 1

Viola........... 23

Violariées. . . . . . . 23

Violette.......... 23

Viornes. . . . . . . 86

Vipérines. . . . . . . 118

Vipérine, . . . . . 118

Viscum. . . . . . . . 198

Vitis. .......... 41

Vittadinia. . . . . . 90

Volubilis.......... 117

Vrillée. ......... 117

Vulnéraires . . . . . . . 46

Vulvaire.......... 142

Wahlenbergia........ 109

\section{$\mathbf{X}$}

Xanthium ........ 108

Xeranthemum. . . . . . . 98

\section{Y}

Yèbte.......... 86

Yeuse ......... 155

\section{$\mathbf{Z}$}

Zannichellia. ........ 161

Zostera........... 174

Zosteres. .......... 174 


\section{TABLE DES MATIÈRES}

Introduction . . . . . . . . . . vII

Bibliographie et ouvrages consultés pour la rédaction du premier volume . . . . . . . . . xxviII Analyse des familles et des genres d'après le système dichotomique de.Lamarck. . . . . . . . . xxxi Analyse des familles et des genres d'après le système sexuel de Linné . . . . . . . . . . . . . . Lxxxxix Analyse et description somınaire des espèces. . . . . . 1 Additions. . . . . . . . . . . . . . 198 Appendice organographique. . . . . . . . . 199 Table des noms de plantes. . . . . . . . . . 205 


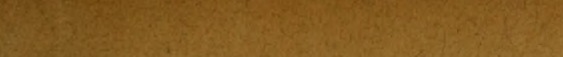

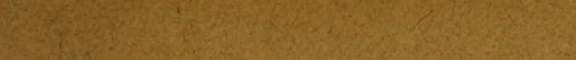

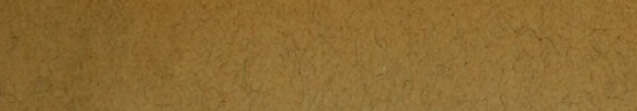
sen (a)

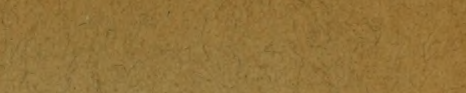
$\sin 2 x=0$

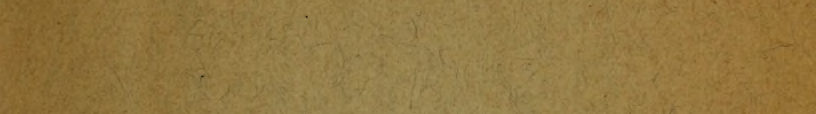
$\operatorname{cin}=3$

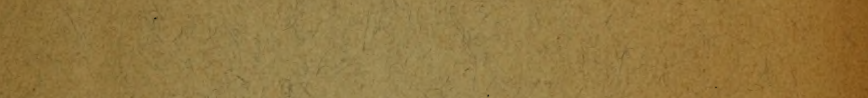
s)

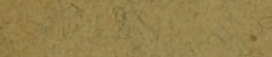
(15. $x+2 x=0$ (20.0. 20. $(x+3)$

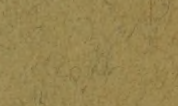
$-$

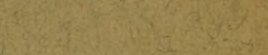
*

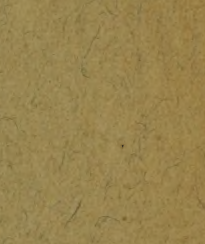
कx

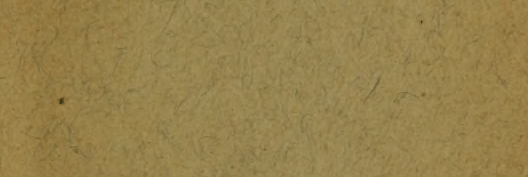

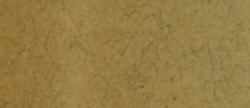

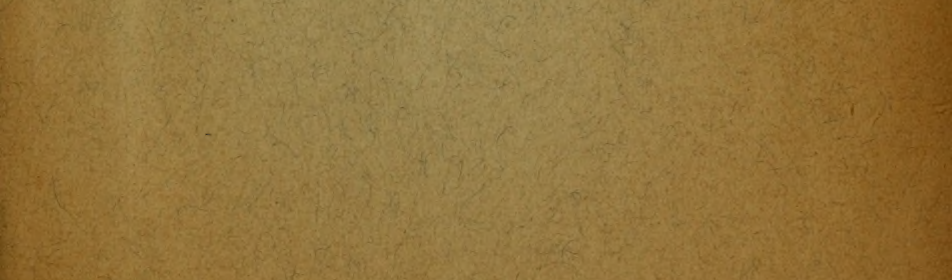<smiles>[AsH2][AsH2][AsH2]</smiles>

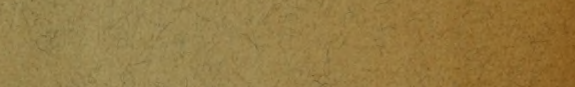




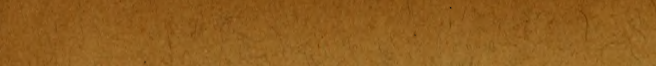
2.

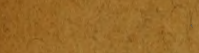

$\frac{1}{2}+\frac{2}{2}$

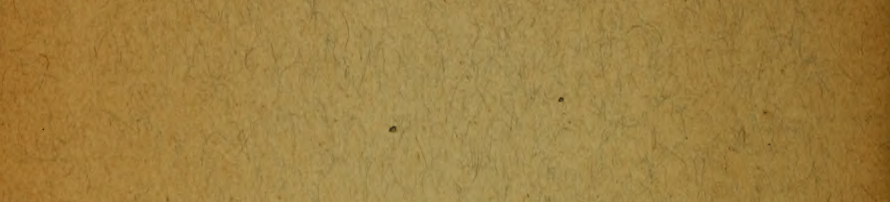
80

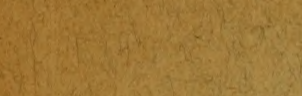

19.2.

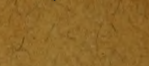
-

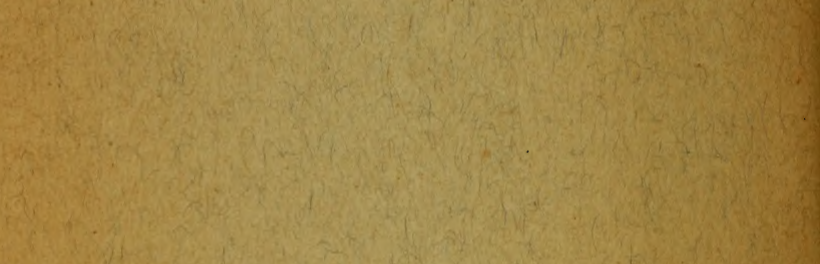

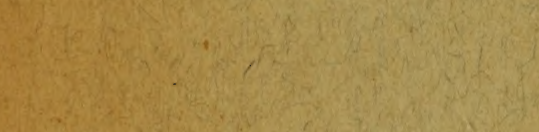

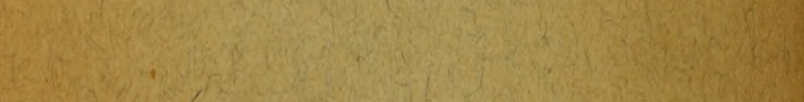

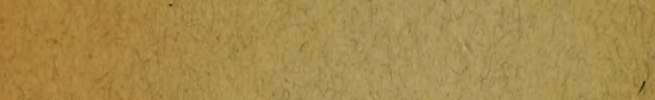

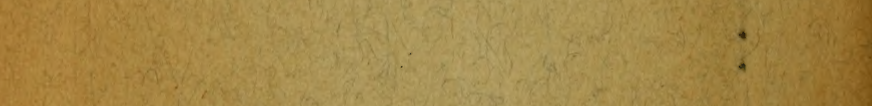

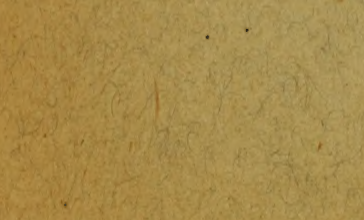

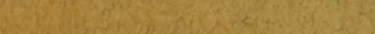
(n) 
QK313.G835

Guillaud, J. A./Flore de Bordeaux et du

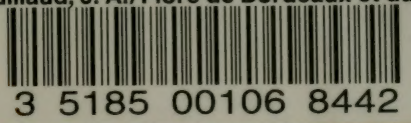

35185001068442 


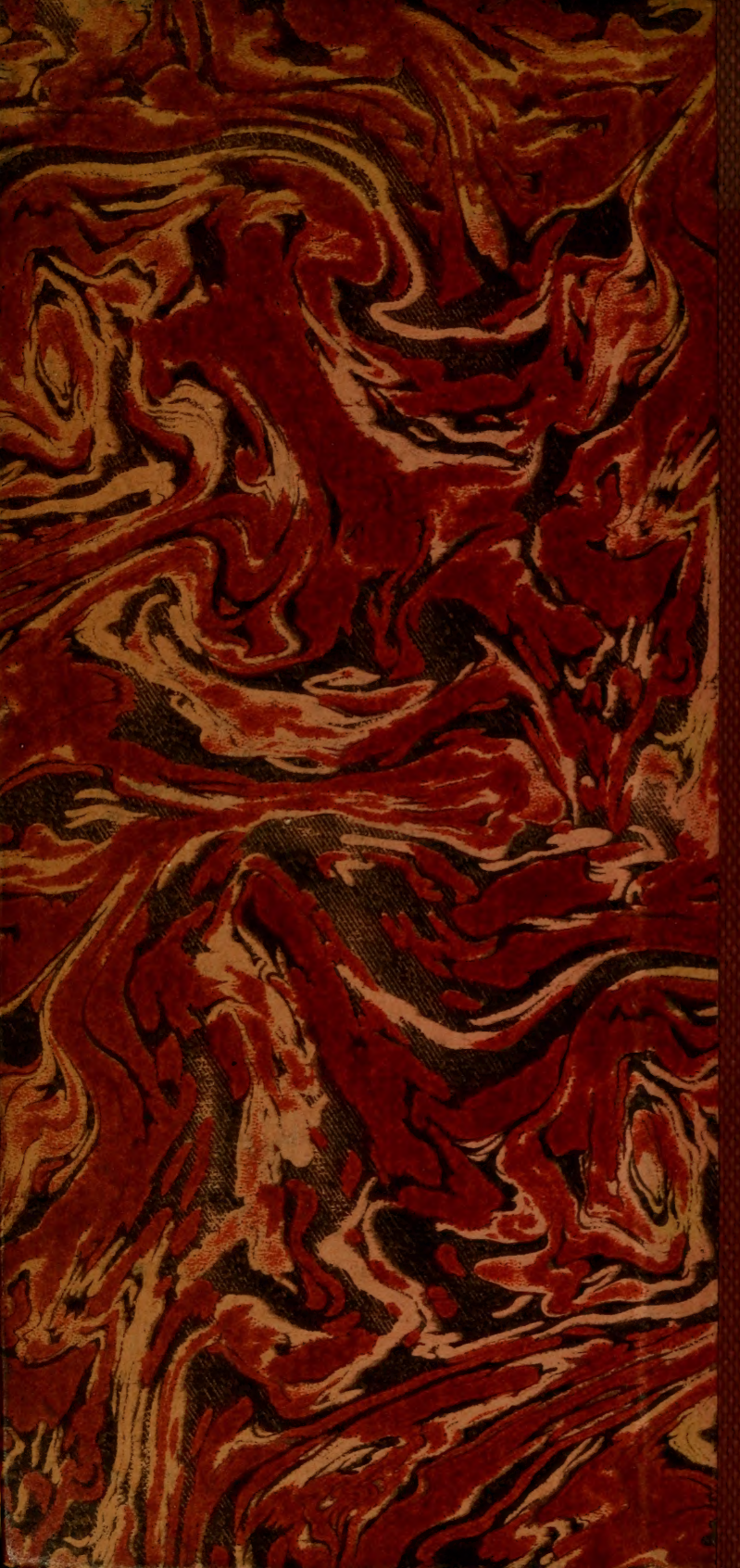

